\title{
Northeast Migrants in Delhi
}

Race, Refuge and Retail

DUNCAN MCDUIE-RA

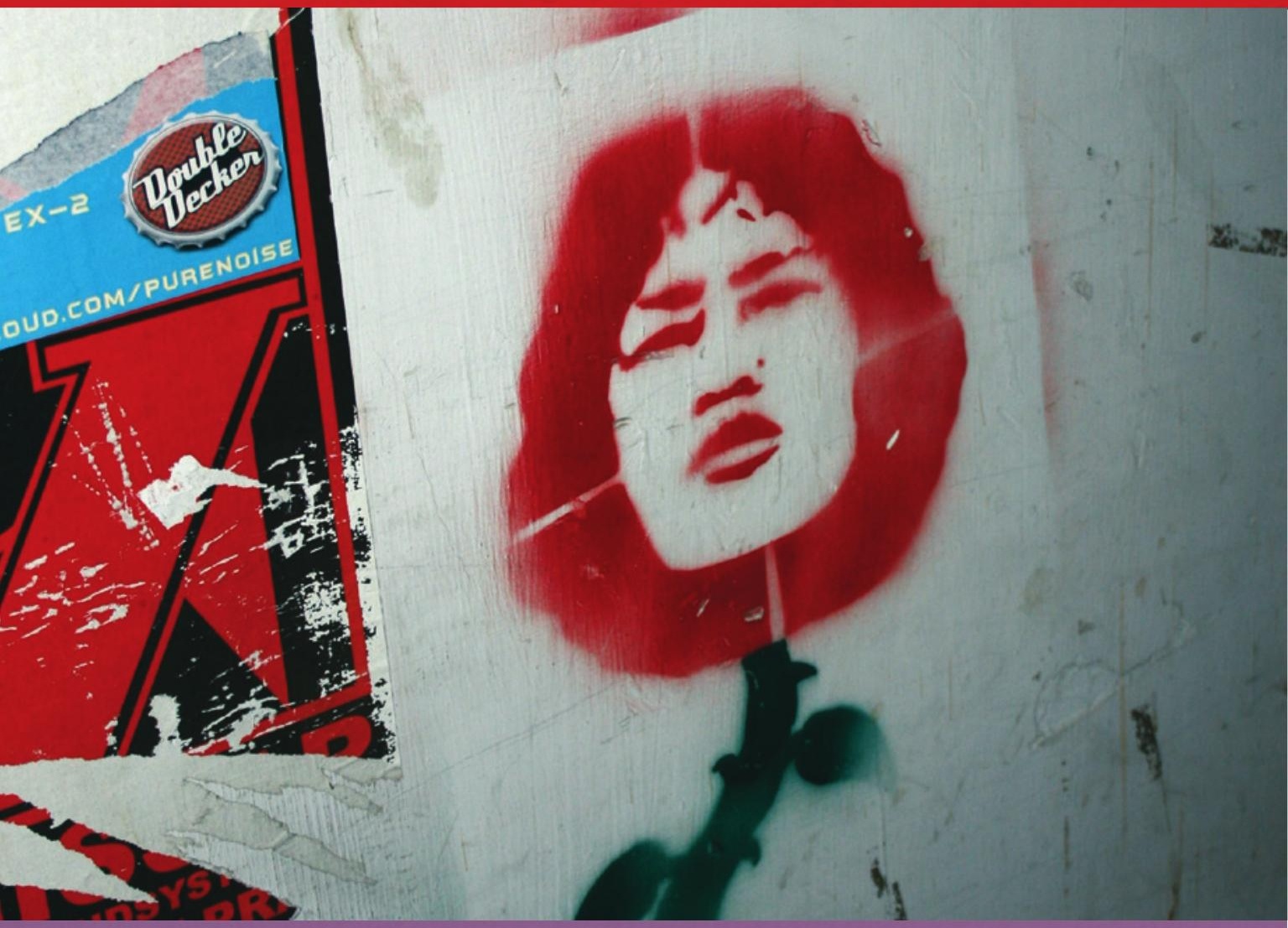


Northeast Migrants in Delhi 


\section{IIAS Publications Series}

International Institute

for Asian Studies

\section{General Editor}

Paul van der Velde

\section{Publications Officer}

Martina van den Haak

\section{Editorial Board}

Prasenjit Duara (Asia Research Institute, National University of Singapore) / Carol Gluck (Columbia University) / Christophe Jaffrelot (Centre d'Études et de Recherches Internationales-Sciences-po) / Victor T. King (University of Leeds) / Yuri Sadoi (Meijo University) / A.B. Shamsul (Institute of Occidental Studies / Universiti Kebangsaan Malaysia) / Henk Schulte Nordholt (Royal Netherlands Institute of Southeast Asian and Caribbean Studies) / Wim Boot (Leiden University)

The IIAS Publications Series consists of Monographs and Edited Volumes. The Series publishes results of research projects conducted at the International Institute for Asian Studies. Furthermore, the aim of the Series is to promote interdisciplinary studies on Asia and comparative research on Asia and Europe.

The International Institute for Asian Studies (IIAS) is a postdoctoral research centre based in Leiden and Amsterdam, the Netherlands. Its objective is to encourage the interdisciplinary and comparative study of Asia and to promote national and international cooperation. The institute focuses on the humanities and social sciences and, where relevant, on their interaction with other sciences. It stimulates scholarship on Asia and is instrumental in forging research networks among Asia scholars worldwide.

IIAS acts as an international mediator, bringing various parties together, working as a clearinghouse of knowledge and information. This entails activities such as providing information services, hosting academic organisations dealing with Asia, constructing international networks, and setting up international cooperative projects and research programmes. In this way, IIAS functions as a window on Europe for non-European scholars and contributes to the cultural rapprochement between Asia and Europe.

For further information, please visit www.iias.nl. 


\section{Northeast Migrants in Delhi}

Race, Refuge and Retail

Duncan McDuie-Ra 
IIAS Publications Series

International Institute

for Asian Studies

MONOGRAPHS 9

Cover illustration: Spray-painted stencil of Irom Sharmila, anti-AFSPA activist from Manipur (likely artist: Bass Foundation); Khan Market, Delhi

Cover design: Maedium, Utrecht

Layout: The DocWorkers, Almere

ISBN 9789089644220

e-ISBN 97890485 I $623 \circ$ (pdf)

e-ISBN 97890485 I 6247 (ePub)

NUR $74 \mathrm{I} / 76_{3}$

(C IIAS / Amsterdam University Press, Amsterdam 2012

All rights reserved. Without limiting the rights under copyright reserved above, no part of this book may be reproduced, stored in or introduced into a retrieval system, or transmitted, in any form or by any means (electronic, mechanical, photocopying, recording or otherwise) without the written permission of both the copyright owners and the author of the book. 


\section{Contents}

$\begin{array}{ll}\text { List of Maps and Images } & 7\end{array}$

Acknowledgements 9

I Introduction 13

Looking for an everyday Northeast $\quad 15$

Finding a Starting Point $\quad 20$

$\begin{array}{ll}\text { Terminology } & 27\end{array}$

Structure of the book $\quad 32$

2 Leaving the Northeast $\quad 35$

The Making of the Frontier $\quad 35$

Tribe $\quad 36$

Colonial encounters $\quad 38$

$\begin{array}{ll}\text { Insurgency } & 40\end{array}$

$\begin{array}{ll}\text { The State of Exception } & 40\end{array}$

The Migration Moment $\quad 44$

Refuge $\quad 49$

Livelihoods $\quad 50$

Aspirations $\quad 52$

Attitudes towards India $\quad 55$

$\begin{array}{ll}\text { Labour recruitment } & 57\end{array}$

Connectivity $\quad 59$

3 Coming to Delhi $\quad 61$

Explaining Delhi's Popularity $\quad 62$

Delhi meri jaan $\quad 65$

Inclusion in the Exclusionary City $\quad 71$

$\begin{array}{ll}\text { New consumer spaces } & 71\end{array}$

The Services Sector $\quad 75$

$\begin{array}{ll}\text { Education City } & 77\end{array}$

$\begin{array}{ll}\text { Job prospects } & 78\end{array}$

Education back home $\quad 80$

Prestige $\quad 82$

Brain Drain $\quad 83$

4 Backward, Head-hunter, Sexy, Chinky 87

The Racialised Frontier $\quad 89$

$\begin{array}{ll}\text { Backward and exotic } & 92\end{array}$ 
$\begin{array}{ll}\text { Anti-national } & 93\end{array}$

Anti-assimilation $\quad 95$

Loose and immoral 96

$\begin{array}{lr}\text { Discrimination } & 98\end{array}$

Harassment and violence $\quad 103$

Responding to Racism $\quad 108$

$\begin{array}{ll}\text { Tolerance } & 109\end{array}$

Retaliation $\quad 110$

Safety 112

Race in Contemporary India $\quad 115$

5 Provincial Men, Worldly Women 119

Gendered mythmaking $\quad 120$

Urbane Women, Provincial Men 125

City Love, Frontier Politics $\quad 130$

Stuck in Delhi 134

Fluidity and Adaption $\quad 138$

Subaltern masculinity $\quad 138$

$\begin{array}{ll}\text { Cosmopolitan masculinity } & 141\end{array}$

6 Place-making in the City 145

$\begin{array}{ll}\text { The Northeast Map of Delhi } & 147\end{array}$

Neighbourhoods 149

Food 153

Religion $\quad 157$

Protesting in Delhi: New places, new identities? 160

Solidarity 164

$\begin{array}{ll}\text { Cosmopolitanism } & 166\end{array}$

Fashion and music $\quad 167$

$\begin{array}{ll}\text { The Korean Wave } & 170\end{array}$

$\begin{array}{ll}\text { Global Christian Culture } & 173\end{array}$

7 Conclusion $\quad 177$

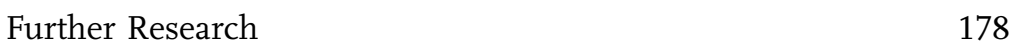

Borderlands and citizenship $\quad 178$

Ethnic Minorities and Asian Cities $\quad 182$

$\begin{array}{ll}\text { Cosmopolitanism } & 185\end{array}$

$\begin{array}{ll}\text { Short Biographical Note on the Author } & \text { I87 }\end{array}$

$\begin{array}{ll}\text { Bibliography } & \text { I89 }\end{array}$

$\begin{array}{ll}\text { Index } & 201\end{array}$ 


\section{List of Maps and Images}

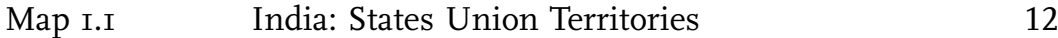

Image I.I Northeast Neighbourhood. Humayanpur, Delhi 23

Image 2.I Advertisement for airline training. Guwahati, Assam 52

Image 2.2 Labour recruitment advertisement. Aizawl, Mizoram

Image 3.I Ambience Mall. Vasant Kunj, Delhi 68

Image 3.2 Northeast wait staff. South Extension, Delhi 73

Image 4.I Northeast Housing. GTB Nagar, Delhi 102

Image 5.I Northeast wait staff. Hauz Khas, Delhi 128

Image 5.2 Shopping for Beef. Nizamuddin, Delhi 140

Image 6.I $\quad$ Northeast restaurant. Humayanpur, Delhi 150

Image 6.2 Naga migrants practicing dance. Deer Park, 



\section{Acknowledgements}

This book has its origins in conversations, friendships, and an interlude. After almost a decade of researching and travelling in Northeast India and Burma, I have formed many close friendships in the region and with scholars of the region located in other parts of the world. The idea to study Northeast migrants came from conversations over akhuni, kaeng hang-le, and herring in the Northeast borderlands, Chiang Mai, Delhi, and Amsterdam. Thank you to Willem van Schendel, Yenkhom Jilangamba, Parismita Singh, Jason Cons, Tina Harris, Anjulika Samom, Thung-shang Ningreichon and family, Martin Pachuau and family, Grace Jajo, Achan Munglung, Joy Pachuau, Makiko Kimura, David Zou, Sarat Phukan, and Evanshania Syiem for inspiring and encouraging this study. I especially want to thank Dolly Kikon and Xonzoi Barbora for encouragement and feedback throughout the fieldwork and writing. It simply would not have happened without you two! In Delhi I am forever indebted to Mhademo and Adeno for going to great lengths to help me with my fieldwork and for being great cooking and eating companions. I could not have done the fieldwork without you both. In particular, I wish to thank Selina and Mona for listening to and commenting on my ideas as they took shape. So many migrants shared their stories with me in Delhi and back in the Northeast in Aizawl, Gangtok, Guwahati, Imphal, Kohima, Shillong, and Ukhrul - I am sorry I can't thank you by name but I hope I get the chance to share the finished book with you when the time comes.

While the idea for this book has been floating around on scraps of paper for a very long time, the interlude provided by a semester sabbatical from my job at the University of New South Wales gave me the time to conduct the research and write the first draft of the manuscript. I wish to acknowledge the Faculty of Arts and Social Sciences for the financial contribution to my travel and semester away from Sydney. For four months of this time I was a visiting fellow at the International Institute for Asian Studies in Leiden, the Netherlands. The IIAS provided the perfect environment to write the manuscript and engage in discussions with other fellows and IIAS staff. I am very grateful to everyone who was at IIAS during the first half of 20II for their comments on this material and their encouragement. I also wish to thank 
Paul van der Velde and Martina van den Haak of the IIAS Publications Series for their encouragement and support throughout.

Back home in Sydney, vital assistance in preparing the manuscript was provided by Ananya Srivastava and Simon O'Connor. John Rees provided advice and friendship throughout the writing process, for which I am ever grateful. Marc Williams has been ever patient while I finished writing the manuscript at the cost of our joint research endeavours.

Finally, thank you to Yoo-Kyong once again for your support and for accompanying me on yet another journey. I think this one was the most memorable yet.

Duncan McDuie-Ra

June 2012 

Map 1.1 India: States and Union Territories

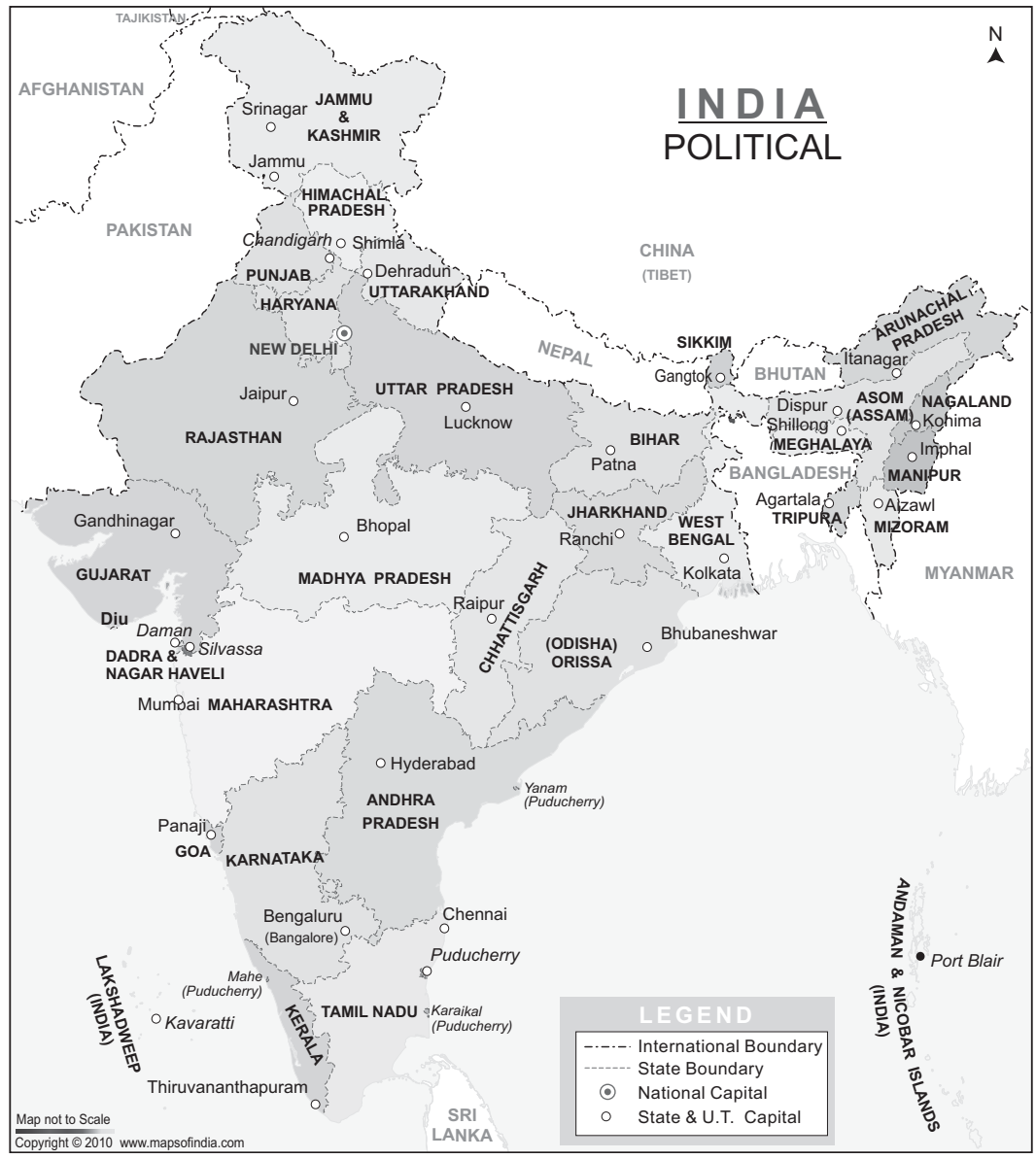




\section{Introduction}

On a January evening in Humayanpur, a neighbourhood in south Delhi, three young men from Nagaland in baggy jeans, coloured sneakers and spiky hair - one with dyed highlights - inspect vegetables from a mobile vendor in the narrow alleyway outside the entrance to their stairwell. From a window five floors up, another Naga calls out for them to hurry up because he has already started cooking. The vegetable vendor begins negotiations in English, touting the quality of his eggplants. One of the Nagas starts speaking to the vendor in Hindi, telling him not to bother trying to overcharge them. They live upstairs and will be buying vegetables every day. The vendor chuckles, and jokes that he has never heard such bad Hindi but is happy to know he has new customers. The next morning a dozen young men and women wait at the main gate of the same neighbourhood in the Delhi fog. The men wear the jeans and sneaker combination while the women wear ensembles of leggings, cardigans, and skirts. They chat to each other in Mizo, Nagamese, and English while waiting to be picked up by a minibus that will drive them to their shift at a call centre in a corporate park in the satellite city of Gurgaon. Later that day in the brand new shopping mall in nearby Vasant Kunj, a trio of women from Manipur serve chicken burgers and fries in an Americana-styled restaurant. Dressed in a uniform of a black polo shirt and black pants with their hair tied up and generous applications of eyeliner, they move around the tables with oversized menus and answer frequent questions about the content of the meals. One of the customers, a foreign tourist, speculates with her companion as to whether they are migrant workers from China.

All over Delhi, Bangalore, and Mumbai, similar scenes are being played out with increasing regularity. Contemporary Indian metropolises are experiencing a rapid increase in migration from frontier areas, including large numbers of migrants from the Northeast region. This is significant given that migration involves engagement with the people and places of the Indian heartland, which clashes with the anti-India underpinnings of social and political life in the Northeast.

This book is an ethnographic study of migrants from the Northeast frontier of India to one of these cities, Delhi. Attention to migrants from the Northeast to Delhi offers insights into three interlinked 
processes taking place in contemporary India. First, migration provides insights into the changes taking place in the Northeast itself. These changes are profound but rarely visible, as academic and policy research on the Northeast remains fixated on separatist insurgency and outdated inquiries into the compatibility of ethnic minority societies with modernity and/or the modern Indian state. Focusing on migrants leaving the region helps to re-situate research on the Northeast and reveal some of the dynamics of change taking place. While many migrants leave the region to escape conflict, many more leave to find work, to pursue education, and to fulfil changing aspirations. Engaging with India reveals shifts in the way the Indian heartland is perceived among communities in the Northeast. The mistrust of the past and present lingers but is assuaged by a mixture of necessity and opportunity. Second, migration from the Northeast reveals the ways in which Indian cities are changing. The liberalisation of the Indian economy over the past two decades and the (partial) embrace of consumerism among the burgeoning middle classes have created new spaces for consumption and investment, often critiqued for creating an exclusionary city. Yet Northeast migrants covert the employment opportunities in these spaces and employers in these spaces desire Northeast labour, particularly in shopping malls and call centres. Third, the stories and experiences of Northeast migrants give insights into what it means to belong to distinct ethnic minority communities in $2 \mathrm{I}^{\text {st }}$ century India. The experiences of Northeast migrants invite one to consider the ways in which tribal and other ethnic minority communities perceive their own identity, 'Indian' identity and society, and the degree to which they feel like they belong and don't belong to India. The spaces, places, networks, and politics of Northeast life in Delhi demonstrate a complexity to contemporary life that is worthy of detailed analysis and has implications for studying ethnic minorities throughout globalising Asia. Northeast migrants experience high levels of racism in Delhi, which in turn reveal a great deal about how race functions within India: crucial at a time when the majority of public debate and academic scholarship remains fixated on how Indians experience racism in other parts of the world. Migration places new strains on gender relations among Northeasterners, increasing tensions between men and women. Yet Northeasterners are far from passive victims in a hostile city. Northeast migrants engage in place-making practices by building neighbourhoods and religious communities. They protest the ways they are treated in the city and take the opportunity of being in the national capital to protest injustices back home. The 'Northeast map' of Delhi is a collage of urban spaces where migrants have established a presence in order to navigate, negotiate, and survive the city. In doing so, Northeasterners enact complex and multi-layered identities. Parochialism and ethnic tensions from the frontier travel to 
Delhi, but a pan-Northeast solidarity that is virtually extinct back home characterises the migrant community in Delhi. At times the boundaries of this community extend to include migrants from across the Himalayas, mostly Ladakhis, Nepalis and Tibetans, and Burmese, especially members of ethnic minority groups sharing lineage and often faith with Northeast communities. Furthermore, there is a dramatic discord between the ways many Northeasterners see themselves (as largely cosmopolitan) and the ways they are perceived by the Indian mainstream (as largely backward). Enacting cosmopolitanism in Delhi challenges these stereotypes while affirming a sense of solidarity and difference among Northeasterners.

\section{Looking for an everyday Northeast}

There are a number of incidents that, drawn together, explain how this research came about. I have been visiting Northeast India since 2003 and my research began at the local level in the state of Meghalaya. Northeast India refers to the area of land located on India's far eastern periphery. The Northeast is a quintessential borderland. The region shares over 90 per cent of its borders with other countries: Bangladesh, Bhutan, Burma, China, and Nepal. Barely connected by land to the rest of India, the Northeast is home to a diverse population ethnically distinct from the rest of India, even when accounting for India's ethnic and cultural diversity. There are eight federal states in the region: Assam, Arunachal Pradesh, Manipur, Meghalaya, Mizoram, Nagaland, Sikkim, and Tripura, as well as a number of autonomous territories within other states (mostly within Assam). The region is populated by three main categories of people. First are 'Scheduled Tribes' which make up the majority of the population in four out of eight of the federal states in the region (Arunachal Pradesh, Meghalaya, Mizoram, and Nagaland). They also make up the majority of the population in different autonomous districts in the other states. Scheduled Tribes refer to communities listed under the Sixth Schedule of the Indian constitution. The Sixth Schedule provides safeguards for tribal lands, recognises traditional institutions of governance at the local level, and provides reservations in the bureaucracy and legislative assembly for members of Scheduled Tribes. Scheduled Tribes are also entitled to reservations outside the Northeast in national level institutions including colleges and universities. In a very general sense, Scheduled Tribes in Northeast India are hill-dwelling communities (often called 'hill tribes' in other parts of Asia) and speak Tibeto-Burman and Mon-Khmer languages. Many have strong ties to communities across international borders, particularly in Burma and China, and also farther afield in Southeast Asia. 
Christianity is the dominant religion among tribals, with smaller communities of Buddhists and animists. I will refer to members of these communities as tribals throughout the book when there is a need to distinguish them from other Northeast communities. It is very important to point out that these communities are ethnically distinct from other Scheduled Tribes in India. I will discuss this difference further below but for the moment it is important to starkly differentiate between Northeast tribals as hill-dwelling communities with roots in Southeast Asia and central Indian adivasis, a set of communities possibly better described as indigenous, though this in itself opens up a raft of other debates best left to other studies (see Shah 2010).

The second are ethnic groups that share lineage with East and Southeast Asia but are not classified as tribals. These communities include valley-dwellers, principally the Ahom of Assam who trace their lineage to Tai-speaking peoples of Southeast Asia, and Meiteis of Manipur who speak a Tibeto-Burman tongue and trace their lineage to Yunnan in China and perhaps further east (Parratt and Parratt I997, xii). The majority of the Ahom and Meitei communities practice Vaishnavite Hinduism, though with startling degrees of variation and incorporation of older faiths and rituals (Gogoi 2006; Parratt I980). As members of fairly consolidated polities at the time of British expansion, neither groups were designated as 'backward tribes' and later as Scheduled Tribes. In the colonial era it was not simply ethnicity that determined whether a community was tribal but a conflation of British perceptions of political order, production methods, and degree of 'civilisation' (see Guha I999; Robb 1997). Since the small Himalayan state of Sikkim became administered as part of the Northeast in 2002, this second group also includes the Sikkimese population, itself a complex mix of ethnicities including Bhutia (Tibetan), Nepali, and Lepcha under various different local reservation policies (Shniederman \& Turin 2006).

The third are migrant communities from other parts of India and surrounding countries. In the Brahmaputra and Barak valleys, waves of migrants have arrived through the expansion of the colonial economy, from the violence of the Partition in 1947, and from the Bangladesh Liberation War in 1971. Migrants continue to be drawn by construction work, the expansion of the agrarian frontier, and the lucrative illicit trade across international borders. Thus in some parts of the region such as western Assam, Assamese speakers coexist with speakers of Bengali, Bihari, Nepali, and tribal languages like Boro, Garo, and Santhali. By contrast, in the Mizo hills a long armed struggle against the Indian state in the I96os and i970s led to the creation of the federal state of Mizoram in I986. Bordered by Burma, Bangladesh, and parts of Assam, Mizoram has maintained strict entry controls for non-Mizos. 
As a result the Mizos, a Tibeto-Burman people, dominate most areas of the economy, government, and police. Thus while internal diversity in Mizoram is limited, the distinctness of Mizo people from the rest of India is stark.

Academic and policy interest in the Northeast has remained preoccupied with ethnicity and/or conflict primarily explained through greed and grievance debates (Grossman I99I). Greed and grievance debates posit that armed conflicts are caused by either the desire for profits or are caused when 'grievances are sufficiently acute that people want to engage in violent protest' (Collier \& Hoeffler 2004: 564). While the greed and grievance debates have proven fruitful for understanding the origins of insurgency in Northeast India (Bhaumik 2009; Cline 2006; Hazarika I995; Nag 2002; Vadlamannati 20II), they are limited when applied to the social order that has emerged after almost 60 years of insurgency and counterinsurgency. Academic and policy literature on the Northeast is still dominated by attempts to explain the causes of violence rather than analysing the ways this violence is experienced, normalised, and contested. In the majority of the literature, the causes of violence are viewed as unchanging factors: poverty on the one hand and ethnic differences on the other (Hazarika 2004; Madhab I999). While these are important factors, such analysis reveals very little about the enormous changes taking place in the region, particularly over the last 20 years.

Scholars and policymakers continually discuss the ways India has changed, but analysis of these dynamics is rarely extended to the Northeast region. The communities of the Northeast are viewed in much the same way as they were viewed at the time of Indian Independence in I947. Scholars remain preoccupied with the incompatibility of ethnic-minority aspirations with the institutions of the modern nation-state, especially among tribal communities, obscuring an analysis of everyday life. Studying Northeast migrants in Delhi opens up scholarship on the region by focusing on those who leave it. More people are leaving the Northeast than ever before, and the heightened scale of migration is relatively new. This study asks what this tells us about the place they are from, the place they are going, and how migration challenges and affirms ethnic minority identities and belonging in contemporary India.

Since my first visit in 2003 , I have returned to the Northeast several times a year. I have conducted fieldwork in different parts of the region for various research projects and have developed strong friendships throughout the Northeast, especially in the hill areas where my research has been based. It is through these friendships that the ideas behind this book gradually emerged. When I return to visit friends, enquiries after different family members are often met with replies like, 'Oh, she 
is in Kolkata studying literature' or 'He has gone to Delhi for a hotel job' or 'She is in Bangalore in a call centre'. Sometimes such remarks are followed by admissions of anxiety about the welfare of said family member, but at other times it is followed by pride. One comment has stuck in my mind for a long time. When visiting a family I knew in the rural West Khasi Hills district of Meghalaya, they informed me that their son was now working in a hotel kitchen in Delhi. His mother beamed as she said proudly, 'He is just a boy from the hills and now he is serving food to foreigners in Delhi!' I can remember thinking that it must be odd being a Khasi, a Mon-Khmer tribal community, in one of the Indian cities. Who would you hang out with? Who would you talk to and in which language? What would people make of you? Where would you find jadoh ${ }^{\mathrm{I}}$ to eat? A first I didn't take much notice of these stories. I took them as examples of isolated paths that Northeasterners were taking to get through life. At the time I was far more interested in things that were happening in the frontier itself; the activities of the army, land disputes, hydropower projects, and anti-foreigner protests.

From 2007 I began to travel to Delhi more and more to attend conferences and workshops and to conduct research. I would spend long periods of time on university campuses where I would get a chance to talk to Northeast students about where they were from and what they were doing. During these trips I would meet with friends from the Northeast living in Delhi. On one occasion a friend asked me to meet her in Green Park, a suburb in south Delhi which - unbeknownst to me at the time - has a sizeable population from the Northeast. My friend and I met at a Southeast Asian themed restaurant staffed almost entirely by Northeasterners. I asked a few of them where they were from, and two were from Manipur and one from Nagaland. The young Naga waitress remarked that there were several other Nagas working in the kitchen. Over dinner my friend discussed her life in Delhi. She couldn't wait to leave. She was tired of her boss and his sexist comments, she was tired of not being able to move around the city without having to endure harassment and unscrupulous auto rickshaw drivers, and she was tired of being away from home. As we were leaving she commented that at least she had a decent job (she worked in an NGO at the time) and didn't have to work in a restaurant where the pay was scarcely enough to survive Delhi. I must have looked very confused. I paused to think. Delhi is over two thousand kilometres from the Northeast. Among Northeasterners I knew in the frontier it has a reputation for violence, racism, discrimination, and sexism. Delhi was in the heart of north India, seen by many Northeasterners as the antithesis of their social world (or how they imagined their social world):

I A Khasi dish made from rice cooked in pork lard. 
predatory and caste-ridden as opposed to collective and egalitarian. Besides, it was the capital of India, a state that granted citizenship to Northeasterners but that was also viewed variously as an illegitimate occupier, resource extractor, and/or source of corrupt and dysfunctional governance. My friend asked me what was wrong. Out came the question at the heart of this book: 'Then what are all these Northeasterners doing here?', I asked.

The final episode occurred in Assam in late 20I0. Along with some other researchers originally from the Northeast, I was involved in organising a two-day seminar to take our research to the region and invite the public to listen and comment and also try to encourage scholars in the region to share their research. We had invited a number of scholars from the Northeast. Almost everyone we invited was based in heartland cities: Bangalore, Delhi, Kolkata, and Mumbai. It was quickly apparent how dispersed the Northeast population has become. During one of the lunch breaks I was talking to a fellow academic and friend from Manipur. I commented that the critical mass of Northeast scholars had now shifted to other parts of India. A resident of Delhi for ten years, he told me that it wasn't just scholars but also ordinary people from the Northeast workers, students, city people, rural people. He started telling me about the neighbourhood where he lived in Delhi, where a Hmar from Manipur cooked roti in a Punjabi dhaba, where two young women from Nagaland sold clothes they had sent from the Burma border markets from an illegal shop in their apartment, and where an Afghani butcher peddled beef to Khasis and Mizos late at night in a designated alleyway next to the Karbi church housed in a one-room shop front. I responded with question after question. Why do they go? What do they do? Where do they live? What is it like? Even his infinite patience was wearing thin after a while. 'Come to Delhi when you get a chance,' he said, 'I will show you.' A little over a month later I was there and started fieldwork that felt as if it had been eight years in the making.

Once attuned to the phenomenon, I became quickly obsessed with the topic of Northeast migration. As someone who had studied identity politics, the environment, gender, rights and the law in the Northeast, the idea of following those who had left the region for a few months quickly opened up new angles. For me, Northeast migration converged with two issues I had started to follow in my research. The first emerged from research into pro-development, specifically pro-dam groups, representing ethnic minorities in the state of Sikkim (Deo \& McDuie-Ra 20II; McDuie-Ra 20II). Pro-dam groups among the Lepcha minority posed complex dilemmas for environmentalists and anti-dam activists seeking to equate ethnic minority status, especially a small and 'vulnerable' minority, to a deeper ecological sensibility and anti-development ontology. Research into pro-dam Lepcha groups, while uncomfortable to 
my own sensibilities, fragmented the homogenised view of ethnic minorities and highlighted the existence of differentiated political positions and agency among a numerically small tribal population. What stuck with me from this research was my growing fascination with ethnic minority communities behaving in ways no one expected of them. By this I include both the expectations of hegemonic communities who patronise and discriminate against ethnic minority communities and the expectations of the advocates and supporters of minorities who cast them in largely homogenous and often romantic ways.

Northeast migrants also behave in ways that no one expects. According to common portrayals, Northeasterners - and tribals in particular - are meant to be fighting for their land, opposing mines, and in the case of the Northeast, engaging in armed struggles against India. When they are not doing these things, they are supposed to be dancing in traditional outfits, weaving colourful shawls, and curing sicknesses with forest produce. These portrayals are reproduced through numerous outlets, from museums to government policy documents, from tourism advertising to environmental campaigns, and even among activists and ethno-nationalist groups from these communities (see chapter 4). Few expect, or indeed show much interest in, Northeasterners who are working as shop assistants in global chain stores, singing in karaoke lounges, or trading Korean movie DVDs. Migrants from the Northeast complicate the common view of frontier ethnic minorities as homogenous wholes, or as Xiaolin Guo terms it, the 'unified front' view of ethnic minorities (2009: 3I4).

The second issue had come up during research into extraordinary laws in the Northeast (McDuie-Ra 2009a, 20I2a). I had been writing about the frontier culture of violence and had begun to explore, albeit briefly, the psychological impact of militarism on everyday life in the frontier. I became very interested in the ways 'routine violence', to use Gyan Pandey's term (2006), had become woven into the fabric of everyday life in the Northeast and the ways this affected men and women in different ways. When I began to learn that migration was in part a way for young people to seek refuge from the frontier culture of violence, I saw a deeper link between frontier and city that needed much further investigation.

\section{Finding a Starting Point}

It is perhaps telling that I began my fieldwork into Northeast migrants in Jorhat, a busy town in upper Assam established through the tea industry, some 2,200 kilometres from Delhi. Winters in the Northeast are a time when those living outside the region return home for 
Christmas and New Year. I was fortunate enough to be staying with a number of scholars of the Northeast who had converged on Jorhat. Over several days I sought counsel on how best to undertake this project. My initial plan was to conduct ethnographic research in four cities: Bangalore, Delhi, Hyderabad, and Kolkata to get a comprehensive picture of Northeast migrants in all the cities where they live in significant numbers. Thankfully I was dissuaded from this undertaking and chose instead to focus on Delhi. All four cities are immense in terms of size and population and thus choosing one city would allow me to live there and get a much richer sense of the migrant community in one location.

I chose Delhi for a number of reasons. First, it has the largest community of Northeast migrants. The difficulties of obtaining reliable data on Northeast migrants are discussed in chapter 2, but irrespective of this Delhi is generally agreed to have the highest number of migrants. Second, the Northeast community in Delhi is more diverse. As discussed at length in chapter 2, Northeast migrants in Delhi are there to work, study, and do both. The other cities are usually known as destinations for work (Bangalore, Hyderabad) or study (Kolkata), but not both. Third, Delhi is an intriguing destination for Northeasterners. It is known as an unpleasant city in the Northeast. It is seen as unfriendly, expensive, and violent. This makes migration to the city so interesting. Furthermore, the symbolism of migration to Delhi is captivating. Delhi is the capital of India, and many ethnic groups in the Northeast predicate their identity on rejecting India. Six decades of insurgency and counterinsurgency in the Northeast has created a sense of living in an occupied territory. Anger at state neglect of development in the region underpins many of the grievances that have led to armed conflict. Successive Indian governments have responded through increased militarisation, the maintenance of extraordinary laws, and a paternalistic approach to the region's development and governance. Delhi is the site where these policies are formulated. From the point of view of the frontier, it is the central node where the occupation of the Northeast is conceived, executed, and justified. What does migrating from the frontier to the capital mean for Northeasterners? What does it mean for their families and peers? Does it debunk the oft-repeated grievances against India? Focussing on Delhi provokes questions that go beyond the material aspects of migration and draws upon questions of identity, citizenship, and nationalism.

As word travelled among friends that I would be researching Northeast migrants, I was put in touch with their relatives living in different parts of Delhi. Through these contacts I was eventually able to secure a place to stay in Humayanpur, one of the larger Northeast neighbourhoods in south Delhi. Humayanpur became an integral site for my fieldwork as I experienced daily life through its inhabitants. My 
contacts in Humayanpur introduced me to friends and neighbours and they took me into their lives. We cooked and ate together, washed our clothes together, and travelled around the city to where they worked and studied. They in turn introduced me to other migrants they knew in other parts of the city. I was usually introduced as a friend 'studying Northeast people in Delhi' or 'tribals in Delhi', and this was usually met with enthusiasm among new acquaintances who would take me to places they thought would interest me: parties, churches, shopping malls, student meetings, neighbourhoods. After a while I had my own bearings and was able to navigate the migrant 'map' of Delhi myself. If I was ever at a loose end, I could to go to different places - alleyways, parks, restaurants, shops - and find people I knew. I would wait and soon meet someone who I recognised or, more often than not, someone who recognised me - a foreigner they had seen around the Northeast places or had heard about from their friends.

I also travelled to parts of Delhi where Northeast migrants were working. I spent a great deal of time visiting shopping malls. For most of the time I concentrated on three interlinked malls in Vasant Kunj, a suburb in south Delhi: the Ambience Mall, the DLF Promenade, and the DLF Emporio, marketed as Delhi's 'most exclusive' malls with almost 300 stores between them. In these malls there were Northeast migrants working in large numbers. I was able to meet migrants while they were at work and often we made arrangements to meet outside work. This extended the neighbourhoods I visited and expanded my contacts in the city. I also spent a long time in these malls observing the rhythms of Northeast labour and their interactions with customers and supervisors. No one seemed to mind me - a foreigner - loitering in the malls for hours on end. Call centres were more difficult to visit as a non-employee. Friends offered to take me to where they worked but I was wary of getting respondents in trouble. I was able to visit the corporate parks where the offices are located and observe the beginning and end of the shifts as workers pile into mini-buses dropping them to different parts of the city.

Researching in this way forced me to adapt my research methods. In Delhi I tried arranging formal interviews but this did not go very well. Northeast migrants were often confused and also bemused when I tried to interview them formally. Often they would feel they didn't have anything important to say or that what they would say wouldn't be sufficient enough for an academic study. I realised that some of their hesitation came at least in part because their friends or relatives introduced me into their life. In this way I was accepted as a friend. Asking friends to consent to hour-long interviews, especially when we saw each other every day for several months in some cases, was simply strange. As fieldwork 
went on, I had to be content with conversations rather than interviews. Conversations were invariably rich, insightful, and often very humorous.

Image 1.1 Northeast Neighbourhood. Humayanpur, Delhi

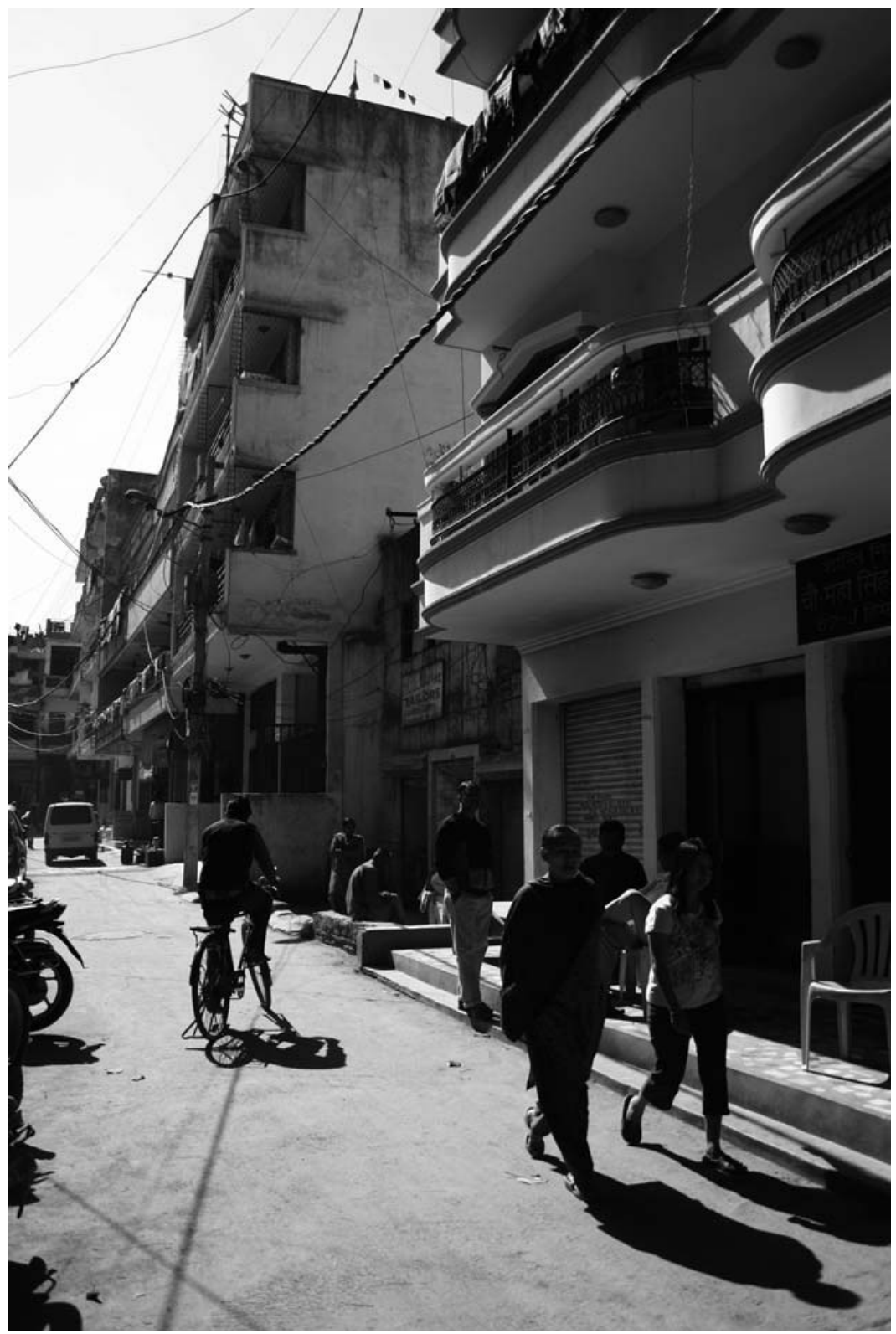


During my fieldwork I had conversations with Northeast migrants every day for almost three months. I also returned for a follow-up visit in December 20II. Some of these conversations were brief. On a university campus I would meet a Northeast migrant and ask where they were from, what they were up to in Delhi, and how they found it. That would take a few minutes and we might never meet again. Other migrants I saw almost every day. If they lived in my neighbourhood we would talk while passing in the street, while cooking, or when I went to their flat in the evenings. There were all manners of interactions in between these extremes. There were people I met three or four times and with whom I had very unstructured conversations. There were others I met once but spoke for an hour around very specific topics. As the research progressed, there were certain people I really wanted to speak to church leaders, student activists, and migrant community leaders. Aside from these specific respondents, everyone I met during my fieldwork - whether by intent or accident - contributed to the research in some way with a comment, an anecdote, or an action.

In conducting fieldwork I benefitted from my race and nationality. While this can be a disadvantage in many other South Asian contexts, in the case of research with Northeast migrants it worked to my advantage. As an Australian, I was seen as a distant outsider, removed from the tensions between Northeastern people and Indians, enabling respondents to speak openly and frankly to me about their experiences with India and Indians. Furthermore, I was not associated with any particular ethnic or tribal group from the Northeast, and this was an advantage when discussing intra-migrant issues and ethnic tensions from home. However, escaping such associations occasionally depended on how I came to meet particular respondents or how I was introduced. Some respondents were more forthcoming when around members of their own ethnic group and more cautious around acquaintances from other groups, especially in cases of already existing tensions. During fieldwork in 20II, this played out from time to time between Naga and Meitei respondents. Respondents from one group often wanted to air grievances about the other and would ask me to meet them another time if they felt they were unable to speak freely. This happened only a few times during my research. More often than not I benefitted by knowing a relative of a respondent back home, or their flatmate, or having visited their hometown. Respondents would often express surprise to meet a foreigner who knew of their home place, and this helped friendships form quickly.

My gender played an interesting role in the research. Gendered norms vary significantly between what I refer to as the Indian mainstream and among Northeasterners. This is discussed at length in chapter 5 . The crucial point to note is that as a Western male it may have 
been strange for me to meet with an Indian woman on her own in public, and very strange to meet with her alone in private, but for most Northeastern communities this is not strange at all. I often met with female respondents one to one in public and where they lived. Often we would go out to eat or wander around shops and markets. This did not mean, however, that other people didn't find it strange or scandalous; often people would stare at us, sometimes passing crude comments in Hindi and sometimes in English. It was not only men who indulged in this. Once I was sitting in a café with a female friend from Manipur and a table of young women sitting near us began to pontificate over whether my friend was a sex-worker. The stereotype of the loose and immoral tribal women loomed over many of these encounters and will be discussed throughout the rest of the book.

Race and gender intersected in different ways for many Northeasterners, especially from tribal communities. Spending time one on one with women was a non-issue because I was a foreigner and not an Indian, the latter suspected of having primarily dishonest intentions. Had I been conducting research in Southeast Asia, especially in locations where Western men are the ones identified as having dishonest intentions, the situation would likely have been very different. I also spent a great deal of time with tribal men. We spent more time hanging out on the street and in parks, though most often we spent time inside flats, playing cards, or listening to music. It was difficult to determine whether men and women spoke more or less openly with me when we were in mixed gender groups. The presence of men in a flat or in a group sitting at a restaurant did not result in women respondents falling silent or obviously altering their answers, though no doubt this happened. In fact, the reverse seemed more common. Men would be a little less forthcoming when their female friends were around, especially on topics like relationships and employment. As can be expected when respondents were among friends with whom they were comfortable, they talked more openly - this was not obviously determined by gender but did seem to rest on ethnicity.

Audio recordings made people uncomfortable and I soon jettisoned it in favour of a notepad. Respondents were generally good-humoured when I would stop them and write something down, even when I asked them to repeat it. With migrants I met regularly, this became a bit of a joke. Someone would pause mid-sentence and say, 'You should write this down', after which they might pause theatrically and say something banal like 'I am going to cook rice now.'

I have used the general term 'respondent' throughout to refer to subjects of this research. I have changed all the names of respondents in this book in keeping with standard ethical practice. Many Northeast names are complicated. Names are particular to different ethnic groups 
and often to smaller clan and tribal groups within. Thus in selecting pseudonyms, it is important to select an appropriate one matching the ethnicity of the respondent. Any mistakes made in doing this are wholly mine. Furthermore, it is common for many Northeasterners, especially tribals, to have Western names as a product of Christian conversions. In these cases I have used Western pseudonyms. Some respondents were known by their nicknames, often shortened versions of their first or family name. Others were known by their last names, often the name of their tribe. In selecting pseudonyms for respondents, I have remained faithful to their preferences.

In adopting a standard ethnographical approach using participant observation and interviews/conversations, I make no claims to absolute objectivity. In fact I am clearly telling this story from the perspective of Northeast migrants. I have not interviewed those who employ Northeast migrants, landlords who rent to them, academics/teachers who teach them, their classmates, city authorities, or the police. This is deliberate. Northeast voices are seldom heard outside the frontier, and telling the migration story from the perspective of Northeast migrants - in so much as this is possible as an outsider - gives precedence to the ways they see their own encounters with the city and mainstream Indian society. Gaining insights into how the mainstream population in India views Northeast people is not difficult to gauge from other sources, and chapter 3 discusses this in both the national context and specifically in Delhi. As such I am a kind of 'engaged observer' (Sanford 2006), though my aim is to direct a critical lens in all directions rather than typecast a vaudeville scenario of valiant Northeast victims on one side and a devious conglomerate villain made of non-tribal urban dwellers, the Indian state, the Delhi government, and the authorities on the other. In my previous work in the region I have endeavoured to avoid this kind of trap, and I continue to do so here.

In framing the ethnographic material, I deploy a number of useful concepts where necessary in the relevant chapters but avoid the temptation to mute the rich experiences of Northeast migrants by relating them to the latest trends in academic thinking. While certainly a proven method for temporary popularity, when fascination with such trends subsides the material faces abandonment as readers move on to the next bright spark. In addition, such framing often leads to diverse and interesting empirical material being framed in predictable ways, leaving the intricacies of context in the background, especially the contradictory or messy elements. 


\section{Terminology}

Finding an accurate collective term for Northeast migrants is difficult. Initially I used the term 'tribal migrants' because tribal is the commonly used word by the communities designated as such in the Indian Constitution, and used by the state and central governments in India to describe the same communities. This term is also useful as it enables a separation to be made between tribals from the Northeast and nontribal 'Indians'. This is attractive in explaining racism and discrimination experienced by Northeast migrants in Delhi, which draws upon distinct differences in physical appearance. However, the term poses a number of problems. First, not all people in the Northeast are tribals. The general and much abused rule in the Northeast is that tribals live in the hills and other communities in the valleys. This holds in many parts of the region but it is not only people from the hills who migrate to Delhi or who face racism and discrimination based on their ethnicity. Tribal communities form the overwhelming majority of the population in Arunachal Pradesh, Meghalaya, Nagaland, and Mizoram. They are the majority communities in the hill districts of Assam, Manipur, and Tripura, although migrants from the hills also live in towns and cities in the valleys, and many have done so for generations. In other parts of these states, the scenario is more complicated.

In Assam, not all tribals live in hill areas. Furthermore, within the non-tribal category are Tai-Ahoms who are descendants of Tai-speaking migrants and considered to be the true 'sons of the soil' in Assam. The grievances of the Tai-Ahom community have been at the heart of the insurgency in Assam since the I970s, much of it directed at unfettered migration into Assam from other parts of India and Bangladesh. Although they are distinct from the Indian mainstream, have pursued separatist politics, and trace their lineage to Southeast Asia (with a few centuries of acculturation in between), Tai-Ahoms are not considered tribals legally, nor would they self-identify as such. The adoption of Hinduism and a version of the caste system, historical animosity (and cooperation) between the hills and the valleys, and a civilisation core to ethno-nationalist discourse vis-à-vis uncivilised hill dwellers ensure that this separation continues.

In Manipur, the Meiteis of the Imphal valley are the majority population and also the decedents of an independent kingdom with strong ties to Ava and other polities in what is now Burma. The Meitei are a Tibeto-Burman people, like most tribes in the hills surrounding the valley. Their politics has been unequivocally anti-India and the state has been torn apart by separatism, though they too are not tribals legally nor do they identify themselves as such. A dichotomy between the civilised valley and the primitive hills also operates in Manipur. Tensions 
between Meiteis and the tribal communities in the hills have led to violence in recent decades, though this exists alongside intermarriage between Meities and tribals and other instances of everyday cooperation and harmony. Nonetheless, many Meiteis would be very uncomfortable about being cast as tribals. This matters a great deal, as migrants from Manipur make up such a significant proportion of those leaving the Northeast and settling in Delhi. A term that excludes Meiteis cannot adequately describe the Northeast community in Delhi.

In Sikkim, the population consists of two scheduled communities, the Bhutia and the Lepcha, administered under the conglomerate Bhutia-Lepcha category, and the majority Nepali population. Sikkim is an interesting case because it is undergoing a process of tribal category creation, mostly led by the state government to facilitate patronage (Shniederman \& Turin 2006). Thus among the Nepali population, ethnic groups with Tibeto-Burma lineage such as the Limbu, Rai, and Tamang are discovering their 'tribal roots' and celebrating them in return for reservations in employment and educational institutions, while the Lepcha community has been designated Most Primitive Tribe status since 2006 (McDuie-Ra 20II). The only communities left without tribal status in Sikkim are Nepalis from the upper castes, migrants from elsewhere, and recently arrived Tibetan migrants (as opposed to older Tibetan migrants). In the Darjeeling Hills, the territory immediately south of Sikkim and not included as part of the Northeast, a movement for an independent Gorkhaland state has revived in the last decade. Part of the demands includes giving Scheduled Tribe status to communities living in these hills, most of whom are from the same ethnic groups as in Sikkim.

The challenge I face in this research is where to draw the boundaries of the category I use to discuss migrants from the Northeast. Using 'tribal migrants' excludes some migrants from Manipur, some from Sikkim, and some from Assam. In Delhi, migrants from these states are very much part of migrant communities and are subject to much of the same harassment, discrimination, and violence. Ignoring these communities makes no sense, especially Meiteis who make up such a large contingent of migrants. Furthermore, for scholars familiar with India but not so familiar with the Northeast, the term 'tribal' creates confusion with tribal communities from central India, often referred to as adivasis. Adivasis are not related to Northeast tribals ethnically nor have they had a great deal of historical contact, and they fall under a different constitutional provision (the Fifth Schedule). Most importantly, the term 'tribal' is often considered pejorative when referring to these communities, whereas for Northeast tribals the term is internalised and used in identity discourses as a source of pride, akin to being identified as indigenous and being able to make claims on ethnically defined 
territory (Van Schendel 20II; Xaxa I999). Despite this clear difference, the term evokes suspicions from those familiar with tribals in other parts of India, and this is a confusion I am loath to perpetuate if it can be avoided.

The second option, and the one I have chosen, is to just use 'Northeast migrants' and 'Northeasterners' instead. The problem with this is that the Northeast just refers to a chunk of land. It is a recently created administrative territory that has limited meaning and significance to its inhabitants. Northeast denotes an area to the north and the east of the Indian heartland, firmly placing it within the cartographic bounds of the modern Indian nation-state; an inclusion that many communities in the Northeast have struggled against. There is a further problem in that while tribal may have been a limiting term, the term Northeast is not limited enough. It is a geographic rather than an ethnic term. There are people born in the Northeast whose parents or grandparents came to the region from Bihar, or Rajasthan, or Bengal to trade, farm, and serve in the civil service or the armed forces. Yet when these people migrate to Delhi they blend in rather than stand out. Therefore in using the terms 'Northeast migrants' and 'Northeasterners', I am referring to those people from the Northeast who trace their lineage to East and Southeast Asia and as such are members of ethnic minorities racially distinct from communities in the rest of India, even when accounting for the diversity of India's population. As I will argue frequently, there is a distance between the peoples of the Northeast frontier and the rest of India that is qualitatively different to other regional differences within the country. From time to time I discuss specific groups using the name of their tribe or ethnic group, Khasi or Mizo for instance. At other times I discuss the federal state where they originate, a migrant from Meghalaya for example. I usually refer to both ethnic and tribal groups when talking about identities and allegiances. This is simply because some groups in the Northeast describe themselves as tribes, usually when they fall under the Sixth Schedule, and other groups consider themselves ethnic groups (or nations). In some cases there is a hierarchy generated through decades of anthropological classification and ethno-nationalist politics. Thus an individual may belong to a tribe (Lotha) and an ethnicity (Naga). Add to this a sense of regional identity (Northeasterner) and citizenship (Indian), and it becomes clear why it is important to keep the specificities of identity as open as possible.

The terms 'Northeast migrants' and 'Northeasterners' are far from perfect. However, in the interests of being inclusive to all the ethnic groups, it will have to suffice. The practical difficulties of discussing 'tribals, Ahoms, Meiteis, and non-scheduled Sikkimese' throughout the book can no doubt be appreciated. Further, as the only other collective 
name for this group of people is the derogatory term 'chinky', a term used in racial abuse and not claimed by Northeasterners, there is no other satisfactory collective term. It is also interesting to note that despite my initial opposition to use the geographic term, other people in Delhi use the term 'Northeast' to describe migrants from the frontier. ${ }^{2}$ Thus a homemade sign spotted in Munirka advertising positions for 'I50 telli-callers' for work calling 'UK and US' requests applicants from 'Nort-East Peopel' [sic]. Small shops selling vegetables from the frontier advertise 'Northeast Herbs' on signs pasted to their entranceways. A restaurant in Humayanpur advertises 'North-East Food' and lists a menu of primarily Naga specialities. While the question 'northeast of where?' is important for critically deconstructing episodes of colonial and postcolonial state-making on the frontier, in Delhi the question 'northeast of where' is answered simply 'northeast of here'; namely northeast of Delhi, of India. Finally, during this research it became clear that although a common Northeast identity is elusive in the frontier itself, among the different ethnic minority groups a nascent panNortheast identity exists among migrants, forged through shared experiences of life in an Indian city and a reconsideration of the ties that bind communities from the frontier. This is discussed in detail in chapter 6 and reiterates the point that although the idea of the Northeast may be deeply contested in the frontier, in Delhi it gives migrants from the region an identity that is inclusive but also distinct from the Indian mainstream.

Throughout the book I use 'frontier' to describe the Northeast and 'heartland' to describe the rest of India. Occasionally I use periphery instead of frontier when suitable. Frontier is an inherently colonial concept when applied to the Northeast. Indeed, the word frontier was used often in colonial laws, regulations, and geographical descriptions including the North East Frontier Agency, now Arunachal Pradesh, and the North East Frontier Railway, still in use today. The hills in particular were seen as a physical and civilisational frontier between the valley polities and the so-called 'backward tracts'. A similar view is evident from the Burmese and Chinese side of these hill ranges (Giersch 200I; Sakhong 2003). I continue to use the term frontier, as it best surmises the way the Northeast and its inhabitants are viewed by the rest of India. Relegating frontier to a purely colonial context overlooks the way the frontier mentality has been reproduced in post-colonial India. Furthermore, 'frontier' suits the perspective of many communities in the Northeast who see themselves as external to the rest of India or on the edge, margins, or periphery of the Indian state. The concept of the frontier has become more common among Northeast migrants as a

2 I am grateful to Dr. Joy Pachuau for pointing this out to me. 
self-conscious reference to the distance of home from the rest of India. 'We live way out on the frontier' is a common refrain uttered by a migrant to explain why she or he is mistaken for a Chinese by a classmate or why she or he attended boarding school in another state. Yet this is usually only when reference to home is being made from far away. At home, place is not usually considered as part of the frontier but the centre of social and political life. Viewing home as a part of the frontier only really happens when home is considered separate from the heartland.

In contrast, I refer to other parts of India as the heartlands. Heartlands are the antithesis of frontiers. While India has other frontiers aside from the Northeast, making the idea of a unified or even identifiable heartland problematic, the concept of a unitary 'India' that is 'out there' away from the Northeast is an important part of the local spatial imaginary. Thus, for Northeasterners, travelling to Delhi or Mumbai is referred to as 'going to India'. People who live in the heartlands and not in the frontier are considered Indians whether they are Punjabi, Tamil, or Goan. This is not to suggest that Northeasterners are incapable of differentiating between the different peoples of India - far from it. But from the viewpoint of the frontier, these communities fit into India in ways they themselves do not, and in many cases do not wish to. Heartlands suggest a typical landscape peopled by typical Indians. Of course no such landscape exists, nor do typical Indians, but for ethnic minorities on the very edge of the Indian national imaginary, there needs to be some way to conceive of 'the rest of India'. Thus I use heartland as the antithesis of frontier, acknowledging its severe limitations, but also I use the comparison to try to privilege the Northeast worldview and emphasise the ways they locate themselves in India.

I refer to the culture of the heartland as 'mainstream Indian society'. Again this is an empirically weak generalisation but one that is common among Northeast migrants. National media, national history, national public sphere, national symbolism, national sporting teams contribute to the idea of a mainstream India from which Northeast communities are either excluded or from which they exclude themselves. To cite a brief example, one evening I was with a friend from Manipur and we were buying beer from a rather seedy liquor store in Delhi. When I got to the front of the iron cage that separated customers from store attendants, I saw that they had two kinds of beer: Fosters, an Australian beer, and Kingfisher, an Indian beer. I turned to my friend and asked, 'Your country's beer or my country's beer?' He looked at me strangely and said, 'Manipur doesn't make bottled beer. And India is not my country. So let's have your beer.' I was very embarrassed. After so many years being involved with the Northeast, I should have known better. The point to note is that the dichotomy between heartland and 
frontier, between mainstream society and different ethnic minority societies, is very real. There are varying degrees of ambiguity on the edges of this dichotomy, as will be seen throughout this book. And while the boundaries of where mainstream Indian society begins and ends are virtually impossible to define, I use Indian mainstream in much the same way as one might use 'white America' when discussing Hmongs in Minnesota, or 'Han China' when discussing Uyghurs in Beijing. The Indian mainstream is a fuzzy idea but something that Northeasterners feel. It is the hegemonic society that they don't belong to but that characterises the space they live in when they migrate to heartlands. Whatever the flaws of the generalisation, it is one that ethnic minorities from the frontier make to distance themselves from the mainstream and reproduce their minority identities. It is also worth briefly noting that during fieldwork I began to suspect that when Northeasterners referred to 'Indian society', 'Indian culture' and 'the mainstream', they were really referring to typified north Indian society, itself stereotyped and caricatured in their worldview. Often when discussing Indian society, respondents would add the caveat that what they were saying did not apply to south Indians, nor sometimes to Kashmiris.

\section{Structure of the book}

This book contains six substantive chapters, including this introductory chapter, and a shorter concluding chapter. Chapter 2, Leaving the Northeast, identifies push factors behind the rapid increase in outmigration from the Northeast migration over the last decade, what I refer to as the migration moment. The chapter sets out six main factors spurring migration from the frontier: refuge, livelihoods, aspirations, attitudes towards India, labour recruitment, and connectivity.

Chapter 3, Coming to Delhi, examines the pull factors leading migrants to Delhi. Migrants choose Delhi for two main reasons. The first is the demand for Northeast labour. The desire for Northeast faces and bodies in the de-Indianised spaces of globalising Delhi is fuelling a rapid increase in migration. The second reason is that Delhi is seen as the best destination for higher and tertiary education. Delhi has India's best universities and colleges, all of which have reserved places for Northeasterners. Delhi is the site where the tools of the Indian state can be learned; tools that can be used to acquire the highly valued Indian Administrative Services (IAS) posts back in the Northeast.

The remaining chapters concentrate on the ways Northeasterners experience the city. Chapter 4, Backward, Head-hunter, Sexp, Chinky, is about racism. Northeasterners are judged first and foremost by their 
appearance. Physical features denoting Tai, Tibeto-Burman, and MonKhmer lineages mark migrants as separate from the India mainstream, even when accounting for the diversity of that mainstream. I analyse racism through discussions of racial epithets and stereotypes, discrimination experienced by migrants, harassment and violence, and the different ways migrants respond to racism. The final section questions what this reveals about race within India. While the discourse on race has been dominated by the colonial experience and the experience of racism among the Indian diaspora, racism towards ethnic minorities in India is largely overlooked.

Chapter 5, Provincial Men, Worldly Women, is about gender. I concentrate on two phenomena: the divergent experiences of migration for Northeastern men and women and the unravelling of masculine norms among migrants. After a discussion of the ways gender is constructed in the frontier, I analyse what happens to notions of gender among migrants focussing specifically on men's desire to protect and police women from their ethnic group. I also explore the sense of guilt expressed by men who have left militarised environments for the (relative) safety of the faraway city, while in the final section I explore new gendered identities emerging among migrants.

Chapter 6, Place-making in the City, is about the tactics, practices, politics, and objects that are imperative to migrant life in Delhi. In contrast to the chapters on race and gender, I try to move beyond the notion of Northeasterners as victims of the city and instead focus on what migrants actually do in Delhi and how this helps them to create their own places in the city. I share what I refer to as the Northeastern map of Delhi: the collection of places where migrants live, pray, socialise, celebrate, and establish everyday patterns and rituals. After discussing politics and protest in Delhi as a place-making practice, I explore cosmopolitanism among migrants. Cosmopolitanism is an important part of ethnic identity in the frontier, especially in urban areas. Yet in Delhi, away from the frontier, cosmopolitanism takes on additional significance as a way of differentiating from the Indian mainstream and contesting archaic stereotypes. Respondents demonstrated a number of cosmopolitan influences in what they consume, what they reproduce, and what they relate to.

In the concluding chapter I explore three themes raised by this book. The first is what I refer to as the 'inward pull' of citizenship that complicates some of the analysis of frontier areas in the burgeoning field of borderlands studies. The case of migrants from the Northeast shows us the circumstances under which citizenship of a state, even if realised through hostile perceptions of the heartland, matters for frontier dwellers. The second is the experience of ethnic minorities in urban areas throughout Asia. Is the urban experience of ethnic minorities 
particular? If so, will it always be different from the experiences of other urban migrants? As Asian cities continue to grow and frontier areas are becoming linked more closely, even if forcefully, to heartland cities, these questions become pertinent. Finally, the theme of alternative cosmopolitanisms has been discussed by a number of authors from various disciplines. The case of migrants from the Northeast shows the ways in which cosmopolitanism helps to differentiate between ethnic minorities and the mainstream rather than seeking commonality through universalism. It is the commonalities felt with peoples outside India that draw Northeasterners together and give them a more complex notion of who they are and who they are not. 


\section{Leaving the Northeast}

Northeast India is on the far eastern frontier of India. It is the ultimate borderland, barely connected to the rest of India and sharing international boundaries with five other nation-states. The frontier is located in the Indian national imaginary as distant, violent, and backward. Its people, especially in the hill areas, are racially distinct from the Indian mainstream, even when accounting for India's diversity. Different tribal and ethnic groups in the Northeast have pursued secessionist and autonomy struggles in the six decades since Indian independence. The region's government, development, and everyday life are militarised, and policy is orchestrated through national security priorities. In the second half of the 2000s, more people had begun to leave the frontier for other parts of India than ever before. This is not simply a steady increase; migration out of the frontier has multiplied many times over in a dramatically short period. This chapter examines the catalysts for migration out of the frontier. I make a two-fold argument. First, decades of insurgency and counter-insurgency have resulted in a militarised society in much of the Northeast region, which is a major catalyst for migration to other parts of India. Second, while very valid, the overwhelming focus on militarisation ignores the ways the dynamics of migration and the demographic profile of migrants have shifted in the last decade. These dynamics reveal a far more complex everyday social, economic, and political reality among the people leaving the region.

\section{The Making of the Frontier}

Conceptualising the Northeast as a singular territory is problematic and something many scholars from the region seek to actively avoid. However, in this chapter it is necessary to utilise the concept of the Northeast as a singular region because this construction determines the way the region is governed by the Indian state and underpins a shared identity among peoples from the various parts of the region, especially when they migrate to cities like Delhi.

A region this diverse, geographically varied, and historically contested can be discussed using a raft of different focal points. However, I will 
limit my discussion to three main components of the region's past and present: the category tribe, colonial encounters, and insurgency.

\section{Tribe}

The term 'tribe' is a colonial category and was used to denote a lack of civilisation, backwardness, and primitiveness (Robb I997: 270-7I). In the Northeast frontier, the concept of tribe is tied up in the practice of territorial demarcation in the late $19^{\text {th }}$ and early $20^{\text {th }}$ centuries. As colonial economic interests expanded in the Brahmaputra Valley in what is now Assam, primarily in coal, oil, timber, and tea (Saikia 2004), it became necessary for authorities to demarcate the extent of their territory and to devise mechanisms to control movement in and out. During this period the colonial authorities devised the Inner Line intended to provide uniform administration to territories falling inside the line and leaving the areas outside the line only partially administered, with entry restricted (Baruah 200I). Writing in I930 about an expedition into what is today Arunachal Pradesh, the British botanist F. Kingdon Ward remarked, "An imaginary "inner line" is drawn between administered and independent territory, and no European is allowed to cross the line without special permission. Naturally such permission is rarely, and for the Abor country never granted' (I930: 424). The history of the Inner Line is complex: it continually shifted; restricted entry to the lands beyond was inconsistently enforced; and it did not stop the machinations of colonial agents in the restricted areas (Luthra I97I). The Inner Line created an administrative distinction but also a civilisational one. The classification 'tribal' was applied to communities who lived beyond the line, mostly in the hills. As Bodhisattva Kar notes, the Inner Line 'was not only a line in territory; it was also a line in time. The advance of the Line on the map was read as progress from pre-capital to capital, from the time of "no law" to the time of "law" (2009: 60). The Inner Line still exists in parts of the Northeast, and visitors must obtain an Inner Line Permit in order to enter certain areas. The Inner Line separated hills from plains and valleys and tribals from other Northeast communities such as Ahoms and Meiteis. Separation was not absolute and the frontier was characterised by fluidity. However, the lineage of contemporary distinctions between tribal and non-tribal people of the frontier can be seen.

The concept of tribe was not only about civilisation but also about justifying the violent subjugation of frontier areas by the colonial authorities for economic gain and military and labour conscription; it also later underpinned the paternalism of European and North American missionaries (Downs 2003). The category denotes several characteristics. First, tribals were outside the caste system (Béteille I99I: 7I). 
Second, tribes were portrayed as practicing 'primitive' forms of subsistence agriculture, predominantly shifting cultivation, known as jhumming in the eastern parts of India and Bangladesh (Van Schendel I992). Thirdly, tribes were seen as pre-modern, or anti-modern, preferring isolation (Pels I999). Fourthly, this isolation was perceived to be a result of their primitiveness, leading to ideas that tribes lived in harmony with nature, especially forests (Prasad 2003; Shah 2010). Lastly, tribes were portrayed as having primitive religious beliefs and unrestrained sexuality (Van Schendel 2002b). These associations have persisted in postcolonial India.

It is also important to point out once again that in India, 'tribal' applies to two broad categories: Fifth Schedule tribes and Sixth Schedule tribes, referring to the section of the Indian Constitution where these tribes are 'scheduled' or listed. Sixth Schedule tribes are primarily of Tibeto-Burman, Mon-Khmer, and Tai lineage and thus trace their roots to Southeast Asia and southern China. Fifth Schedule tribes are mostly located in eastern and central India and are also referred to as adivasis. Adivasis are considered a separate population from Sixth Schedule tribes from Northeast India. Indeed, up until the colonial era they inhabited different and unconnected territories. Their respective places in contemporary India are geographically, economically, politically, and socially separate.

During the colonial era, many adivasis were transported to an area of what is now Assam to work on tea plantations (Chatterjee 200I; Saikia 2004). Many remain to this day, and some advocate for recognition of their tribal status (Baruah 2010: 28-29). Confusion arises when 'tribal' is used interchangeably to refer to the different communities. In this book I discuss only tribals from the Northeast - that is, people identified as tribals by the Sixth Schedule of the Indian Constitution, who identify themselves as tribals in the Northeast, and who trace their lineage to Tai, Tibeto-Burman and Mon-Khmer peoples.

The Sixth Schedule is a stronger protective legislation than the Fifth Schedule. The Sixth Schedule protects tribal land from being owned by non-tribals, provides reservations in government employment at the federal, state and local levels, and gives authority to traditional institutions to oversee land use and resolve customary disputes (though this varies in different parts of the region). As a result, tribals dominate the bureaucracy and politics in the tribal majority states and in autonomous districts in tribal minority states. In non-tribal majority states and areas, the picture is more complex. In Meitei areas of Manipur, the Meitei ethnic group controls the bureaucracy and government; though within the Meitei ethnic group there are different reservations for different castes and sub-groups. In Sikkim, reservations for Sikkimese ensure a similar scenario, and new reservations are continually being created for 
different ethnic and tribal groups in the state. In Assam the situation is quite different. Non-Ahom migration and the capture of political constituencies and much of the bureaucracy fuelled the Assamese liberation movements that grew in the I970s and have continued through to the present (Baruah I999).

\section{Colonial encounters}

Colonisation has had a profound impact on what is now the Northeast. The details of the encounters between colonisers, missionaries, anthropologists, and frontier peoples have been discussed at great length by historians, theologians, and in ethno-nationalist narratives. Given the breadth and quality of this material I will not repeat the details here; rather I will briefly discuss the major changes to the region during the colonial period that began in 1826 until Indian independence in 1947 . The British rapidly expanded into the relatively sparsely populated and forested Brahmaputra Valley (Assam) by logging timber, planting tea, and extracting oil (Saikia 2005). The economic expansion connected the frontier to colonial India and later colonial Burma through roads and railways. Adivasis were brought as plantation labour from central India (Saikia 2004: I07). Clerks and administrators were brought from other parts of India, mostly Bengal, making Bengali the language of the bureaucracy and government (Weiner I978: 9I-95). Marwaris, traders from Rajasthan, dominated the trade in goods (Saikia 2004: Io8). This demographic shift sowed the seeds for armed struggle in later decades.

Many of the hill people were bypassed by this economic expansion, though some were conscripted into forced labour while others migrated voluntarily to work in the expanding economy (Robb I997). In I935 there were major changes in the frontier. British Burma was split from British India through the Government of Burma Act I935 (operational from I937), and an imaginary line was drawn through the hill areas - a line that would later become the international border between India and Burma. In the same year the Government of India Act was passed which formally categorised many of the hill areas as 'excluded areas' or 'partially excluded areas', thereby formalising the Inner Line of earlier decades. Persons from outside these areas were not permitted to enter or settle in the so-called 'backward tracts'. Yet this was far from splendid isolation. Drawing on Stanley Tambiah's notion of 'galactic polities', David Zou shows how 'open border zones' soon became 'frozen into fixed boundary lines' (2009: 218). The galactic politics of pre-colonial hill areas became subjugated to colonial administrative structures, provoking resistance. At the same time, subjugation allowed for new identities and solidarity but also fragmentation among and between communities (2009: 232). 
Exclusion from the rapidly expanding extractive economy in the valleys did not prevent missionaries, anthropologists, and military units from making forays into the hill areas. Many tribal communities were converted to Christianity, though not always without resistance, and many tribal languages were written for the first time using the Roman alphabet (Downs 2003). Missionaries from different denominations concentrated on different tribes, leaving a complex legacy of inter-tribal tensions for the present era, and also giving Christianity a highly localised character (see Lasetso \& Hümtsoe eds. 2009). Baptists, Calvinists, Catholics, Pentecostals, and Presbyterians from England, Ireland, Italy, Scotland, Wales, the United States, and even Australia and Canada came to the region throughout the late $19^{\text {th }}$ and early $20^{\text {th }}$ century (see De Maaker 2007; Joshi 2007; Pachuau 2003; Syiemlieh 2005; Zou 2009). Missionaries established and ran schools which continue to supply education in much of the region today, though the staff and clergy have become largely indigenised (Dubey \& Pala 2003). In recent decades the Northeast has seen an increased uptake of spirit-empowered Christianity. This has led to a steady stream of missionaries from different Northeast ethnic groups undertaking church planting and other mission work in the region itself, the emergence of local churches or 'new churches', and to a surge in Korean missionary activity throughout the region. Thus during the colonial era an educated elite emerged and began to supplant traditional elites (for examples from different ethnic groups, see Singh ed. I982b, I983). The elite had varied levels of influence in the different communities. However, a clear sense of difference from the rest of India and a vision for a separate political path had emerged leading up to Indian independence.

Anthropologists were particularly influential in the Northeast in the late $\mathrm{I}^{\text {th }}$ and early $20^{\text {th }}$ centuries. Fascination with the 'untouched' and 'isolated' frontier tribes produced voluminous material on their language, habits, and folklore. The sheer quantity of material makes it difficult to acknowledge it in its entirety, however the works of Elwin (I959), Gurdon (I907), MacGregor (I887), Mackenzie (I884), Shakespear (I9I4), von Fürer-Haimendorf (I939), and Watt (I887) have been particularly influential in shaping colonial and, in the case of Verrier Elwin, postcolonial policies towards the region (Guha I999). Importantly, this fascination has not abated in the period following Indian independence, and many postcolonial Indian scholars have taken up the task begun by colonial anthropologists. Of particular note are the edited and encyclopaedic works authored and collated by Kumar Suresh Singh (I972, I982a, I982b, I983, I992), who served as Director General of the Anthropological Survey of India. This fascination has further embedded identities constructed during the colonial era and reinforced the distinction between the Northeast and the Indian mainstream. 


\section{Insurgency}

In the aftermath of the Partition that divided India and Pakistan in I947, frontier communities found themselves part of the new nationstates of Burma, East Pakistan (now Bangladesh) or India. In the Indian parts of the frontier, disquiet was building in the decades leading up to the Partition. Many communities did not consider themselves Indian. They had never been part of India and even during the colonial era they were part of a frontier polity between Bengal and central Burma rather than linked to the abstract concept of Indian nationhood. Armed struggles in the Naga Hills (Nagaland), Lushai Hills (Mizoram), and Manipur broke out immediately following the Partition. In the decades since, armed insurgency has affected every part of the Northeast to different degrees. These struggles were a response to forced integration into the Indian Union, uneven local political and economic autonomy, and the neglect of basic needs. In response, the Indian government has created new states and territorial units normalising the notion of 'ethnically exclusive homelands' (Baruah 2003a). Groups without homelands sought new territorial units leading to local struggles between ethnic groups, with the Indian state acting as arbitrator (Baruah 2003c). Furthermore the inability of successive Indian governments and local governments to control migration into the region has furthered grievances and violence. As a result, conflicts exist between different ethnic groups (and the territorial units representing them), between particular ethnic groups and the Indian state, and between communities indigenous to the region and migrants (Baruah 2005; Bhaumik 2009). Willem van Schendel (2OII) refers to this as an 'exclusive politics of belonging'.

Six decades of insurgency and counterinsurgency have militarised the region. Militarisation comes from the Indian Army, paramilitary groups (referred to as armed forces hereafter) and local militant groups primarily organised along ethnic lines. Armed personnel are encountered on the roads, in towns, in villages, and in markets. Military cantonments and bases occupy town centres, strategic hills, bridges, and border crossings. Members of the armed forces frequently stop vehicles to search passengers and cargo. Checkpoints are numerous, heavily curtailing movement. The Indian armed forces have come to symbolise an occupying force for the peoples of the region.

\section{The State of Exception}

Despite its very recent construction during the colonial and postcolonial eras, the Northeast exists in a permanent state of exception that 
separates it from the rest of India and makes the rapid rise in migration by frontier dwellers to other parts of India so intriguing. Giorgio Agamben's concept of a 'state of exception' (2005) is apt in understanding the position of the Northeast within India. Drawing on Carl Schmidt, Agamben argues that in contemporary states, certain peoples and regions can remain outside the boundaries of the law and are subject to extraordinary provisions, and in time these provisions come to be the norm, creating a permanent state of exception. While critics argue that Agamben's thesis cannot be applied as widely as many would like (Humphreys 2006: 684; Huysmans 2008: I77-78; Ong 2006: 23), it is relevant for understanding the ways the Northeast is located within the 'world's largest democracy' and the ways exception plays out when migrants leave the region and live in other parts of India - something that will become clear throughout this book.

While people in different regions throughout India consider themselves different from each other and these differences are pronounced and often articulated forcefully at the local level, they still fit into the larger nation, although rarely seamlessly, in ways that the Northeast does not. There is a strong belief in both the Indian mainland and in most of the Northeast itself that the different states, autonomous units, and peoples grouped together as 'the Northeast' do not share. They will never be able to be part of India in the same ways that other diverse groups of peoples have been accommodated. There is a binary between the peoples of the Northeast and peoples in other parts of India. Rarely explicitly articulated in mainstream politics, this binary is constant in any interaction between the states of the Northeast and the central government, between the armed forces and local communities (Kikon 2009a), and, crucially, between Northeast migrants and other communities in Indian cities. The Northeast is exceptional and the rest of India is normal. This binary is bridged in certain ways, as will be seen in the remainder of this book, yet in the majority of interactions this binary is constant. This also means that the narratives of Northeastern lives do not fit neatly into the standard canon of literature on India.

Exceptionalism manifests acutely in two realms: race and the law. Ethnic minority groups from the Northeast consider themselves to be different peoples from the rest of the diverse communities that make up contemporary India. They believe they have a different history, though not a unitary history, and are culturally, linguistically, and racially separate from the Indian mainstream. This distinction becomes blurred in places, especially in western Assam and among certain classes that have benefitted greatly from loyalty to the Indian state, but it holds socially and politically for most of the people in the region. Similarly, the peoples of the frontier are considered racially different by the Indian mainstream. The depths of racial exception remain slightly 
opaque when analysing the frontier from within the frontier itself. To be clear, within the frontier the politics of race and ethnicity are paramount. However, they take the form of inter-ethnic tensions and antimigrant politics. Being a racial minority within India has certain dimensions when viewed from within the frontier. Here, the Indian state and mainstream Indian society are distant, though not without a presence, but within ethnic homelands local communities can articulate their identity forcefully and draw the boundaries of inclusion and exclusion vis-à-vis other communities. For migrants from the Northeast, India is no longer distant, Indians are not migrants or tourists, and narrower ethnic identities from home give way to a shared experience of marginalisation. Migration reveals the depths of racial exceptionalism far more lucidly. Contending with Indian citizenship and the issue of territorial integration into the Indian Union takes on a different dynamic for migrants leaving the frontier.

Racial exception is mutually constituted by legal exception, chiefly through the Armed Forces Special Powers Act of 1958 (AFPSA). The AFSPA allows 'any commissioned officer, warrant officer, non-commissioned officer or any other person of equivalent rank in the armed forces' to fire upon - 'even to the causing of death' - any person acting in contravention of any law or order, any person carrying weapons or anything capable of being used as a weapon, and to prohibit the assembly of more than five people (MHA I958/1998: S4a). It allows armed forces personnel to arrest without warrant and with any necessary force 'any person who has committed a cognizable offence or against whom a reasonable suspicion exists that he [sic] has committed or is about to commit a cognizable offence' (MHA I958/1998: S4c). It allows armed forces personnel to enter and search any premises without a warrant to 'make any such arrest' (MHA I958/1998: S4d). The most significant part is Section 6, which states: 'No prosecution, suit or other legal proceeding shall be instituted, except with the previous sanction of the Central Government, against any person in respect of anything done or purported to be done in exercise of the powers conferred by this Act' (MHA 1958/1998: S6).

Over the last 50 years, the AFSPA has been applied to any area of the Northeast declared 'disturbed' by the Indian government. Designating an area as 'disturbed' must be reviewed every sixth months, yet there is no limit on the number of times this designation can be renewed, effectively meaning that some areas can, and have been, classified as 'disturbed' for decades. As of 20II, the only states with no 'disturbed' classification are Sikkim, only recently included and administered as part of Northeast India, and Mizoram, which experienced two decades of civil war until peace in the I980s. 
Murder, rape, beatings, and sexual harassment by the armed forces in the Northeast has been well documented in a number of international and national human rights reports (ACHR 2008a, 2008b; HRW 2008), and by women's organisations, activists, and human rights groups in the region itself. Crucial to all of these incidents is that the perpetrators are protected under the AFSPA. The AFSPA provides de jure impunity in that members of the armed forces are not prosecuted in civilian courts. As Human Rights Watch reports, the AFSPA also provides a form of de facto impunity as military courts responsible for prosecuting soldiers have often failed to investigate violations or been 'simply unwilling' to bring charges against military personnel (HRW 2008: I8). Despite a I997 amendment to the AFSPA that any person arrested under the act must be handed over to civilian authorities within 24 hours, this is frequently ignored (ACHR 2008b). Persons arrested have been detained for periods ranging from one week to several months. These periods of detention have facilitated torture, rape, and murder by the armed forces, including the rape and torture of children (ACHR $2008 \mathrm{~b}$ ). The persistence of the AFSPA epitomises the tacit acceptance of systematic violence as a necessary by-product of securing an unruly border region and policing a suspect population (Kikon 2009a). The region is constructed externally and internally as an exception to norms and laws upheld in other parts of India (McDuie-Ra 2009a).

Violence is not only perpetrated by the 'occupying' armed forces but by the local law enforcement agencies as well. While this also takes place in other parts of India and the world, in the frontier, violence by law enforcement agencies is more feasible and less extraordinary when it occurs. Compared to a national average of ${ }_{13} 60$ police per one million people, all states in the Northeast have much higher ratios. In some Northeast states, the ratios are multiple times higher: Nagaland has 9,500 police per one million people, Mizoram 7,250, Sikkim 6,230, and Manipur 5,930 (Government of India 2002: 279). The proximity to international borders means additional security personnel are constantly on the move throughout the region. Despite being bound by different laws to the AFSPA, law enforcement agencies operate in a culture of impunity (Kikon 2009a). As Anuradha Chenoy argues, in this environment 'the very sight of men in uniform is traumatizing' (2002: I33).

Violence is not simply a product of the armed forces and the AFSPA; it is enhanced and reproduced by ethno-nationalist militant groups. Ethno-nationalism does not always manifest itself in insurgency and violence. It has also underpinned powerful social movements that have made vital gains for ethnic minority cultural rights, land rights, and social justice. Similarly, armed violence has not always been carried out in the pursuit of ethno-nationalist ends: extortion, smuggling, trafficking, control of natural resources, and political power have all taken on 
armed dimensions in the region (Dai 2007; Lacina 2007). In some parts of the region, militant groups enjoy deep community support and legitimacy, in others they are viewed as an antisocial element involved in organised crime and extortion. Regardless of their motivations and support, the number of armed militant groups has increased dramatically over the last 50 years to 'between IOO and I20' (Baruah 2005: 5).

Exceptionalism enhances the 'frontier' mentality towards the Northeast by the Indian state and by mainstream Indian society. The frontier is distant, violent, and populated by peoples who are simultaneously backward, exotic, and anti-national. Yet the frontier provides a useful heuristic device for understanding two phenomena crucial to this study. First, the notion of the frontier affirms the geographic location of Northeasterners outside the Indian mainstream and within a dynamic borderland. As such, it is adopted by many people in the region and reproduced as part of their identity. There is comfort being on the periphery. The frontier is home. Second, the frontier denotes a set of assumptions about this same region and its peoples. Many Northeasterners actively set about challenging these assumptions by refashioning their identity as cosmopolitans, connected to the rest of the world through the frontier rather than being isolated. Thus I will use the term frontier from time to time in this book, recognising the ways the frontier has been constructed through colonial and postcolonial state-making but also recognising its centrality for people from the region at home and as migrants.

\section{The Migration Moment}

There are more migrants from the Northeast leaving the region for Indian cities than ever before. Migration from the Northeast to Delhi has taken place since Indian independence, yet those travelling to Delhi were mostly the wealthy and educated. While this group of migrants continues to come to Delhi, there has been dramatic growth in migrants from other backgrounds. As migration is internal and few Northeasterners own property or capital in the cities where they settle though this is changing in neighbourhoods like Humayanpur and Munirka - accurate migration figures are very difficult to produce. Census and human development data for either the Northeast states or Delhi does not reveal migration numbers. Most Northeast migrants in Delhi are renters and thus don't 'show up' in the Delhi stats. If they do, they are under a larger category of 'Scheduled tribes'. In data from Northeast states, absent persons are either not counted or included in the surveys by other members of their household, as it is uncommon 
for entire families to relocate. Electoral rolls are also used in compiling data, and migrants are registered to vote in their home states.

As discussed in the introduction, the search for such figures was a frustrating and mostly fruitless exercise during and after fieldwork for this book. State governments in the region do not keep statistics, and residents are not required to report leaving their home states for other parts of India. Virtually all those consulted from state government departments during this research made estimates on the spot or treated the issue as a cherished state secret. A survey released by a small non-profit organisation, the North East Support Centre and Helpline (NESCH), in early 2OII provides limited migration statistics (NESCH 20IIa). The report puts the number of Northeast migrants outside the region at 4I4,850 (NESCH 20IIa: IO), alhough this figure comes from a newspaper report that doesn't disclose how it reached the figure. The same report cites a twelve-fold increase in migration out of the Northeast from 2005 to 20II. Of migrants leaving the Northeast, 48 per cent migrate to Delhi. Articles written since the release of the NESCH usually quote its figures, and as such they have gained a certain truth from being repeated so often. While the accuracy of the figures may be disputable, it is clear from qualitative research in Delhi and throughout the Northeast that more people are leaving the region than ever before and that the majority travel to Delhi. Survey figures are likely to be underestimates, as movement back and forth between the Northeast and Delhi is constant and periods of stay vary dramatically from a few months to several years.

Throughout the Northeast, especially in cities and towns, return migrants, migrants visiting home, and locals seeking to migrate are seemingly everywhere. Inquiring after an old friend brings the news that he has gone to visit his niece working in Bangalore. Students at local colleges talk about going to study in Delhi. Younger brothers of activists talk about looking for call centre work in Hyderabad. Shops in towns from Ukhrul in the hills of Manipur to Tura in Meghalaya advertise courier services to Delhi or Mumbai with higher rates for food needing speedy delivery. Posters for political meetings in the region advertise guest speakers of the relevant student union's Delhi branch. While I was in Imphal, the capital of Manipur, in February 2011 a local newspaper ran an editorial about the disrespect faced in Delhi by the sons and daughters of the state. In short, any quantitative estimate of migration will fail to capture its significance back home, the experience of migration among those leaving the Northeast, and the sense that the peoples of the frontier are living in a 'migration moment'. The norm that migration is necessary and desirable is spreading throughout the region, impacting on notions of belonging, notions of otherness, notions of exclusivity, and notions of place - all of which will be explored throughout the remaining chapters. 
Academic research into migration from the frontier is virtually nonexistent. Research into migration and India is voluminous. Scholars from a number of disciplines have analysed the contemporary and historical dynamics of migration into, out of, and within India (Bates 1985; De Haan \& Rogaly I994; Jeffrey 20I0; Kapur 20I0; Yang, I979). However, migration from the Northeast to cities like Delhi is absent from migration research. There are a number of reasons for this. First, as noted earlier, communities in the Northeast have long been analysed by ethnographers and anthropologists who were interested in customs, folklore, and the 'confrontation' with modernity (Das I989; Jones I978; Singh 1982a). As such, colonial and postcolonial scholars had little interest in analysing mobility. In fact, scholars have been far more concerned with migration into the Northeast during the colonial and postcolonial eras, seen as permanently rupturing the demographics of the region and launching the grievances that have sustained armed struggle (Bandyopadhyay \& Chakraborty I999; Baruah I999; Dutt I98I; Hazarika 2000; Singh 2009). Second, studies of urbanisation in India have not taken much notice of Northeast migrants, reinforcing their status as isolated people from hills and forests. The heyday for urbanisation studies in the period after independence and up to the early i980s tended to focus on class characteristics of migrants, and those that focussed on regional differences rarely considered urban migrants from the Northeast, as migration from the Northeast was at much lower levels when scholarly interest in urbanisation was highest. Thirdly, studies of migration and India in recent decades have become dominated by transnational migration - be it professional migrants, labour migrants, or educational migrants - and this has also fuelled an immense examination of Indian diasporas in different parts of the world (Bhatia 2007; Brown 2006; Clarke et al. 20I0). Migration from the Northeast out of India is on a much smaller scale, and Northeast migrants living outside India tend to steer clear of established Indian diaspora communities. Yet lack of scholarly attention should not be equated with lack of significance. Migration out of the frontier areas of India is taking place at a scale and intensity never before seen. Most significantly, the profile of migrants is also changing. Where once migration was reserved for the elite and was primarily for the purposes of education, migrants now come from a much broader set of circumstances and migrate for education, work, and refuge.

From fieldwork it is apparent that most Northeast migrants come to Delhi after secondary school without their parents, though some migrate with siblings. Both men and women migrate to Delhi in more or less equal proportions. Respondents migrate to Delhi from urban areas and from rural areas, though most of those from rural areas spent at least some of their secondary school years in urban areas prior to migrating 
to Delhi. In other words, there were few migrants who came directly from the remote hill areas to Delhi without time spent elsewhere. Most migrants in Delhi are in their 2os. Among older respondents, most of those in their 30 s had come to Delhi in their 2os and stayed, or had come to Delhi from another city such as Bangalore or Kolkata. Respondents in their 4 os were usually professionals or academics, with a small number of central government employees and church clergy. Some have partners and children in Delhi with them, while others come alone and leave their families back home. There are increasingly numbers of families coming to Delhi, especially from Manipur. During follow-up fieldwork in December 20II, I was able to meet a number of these families and their stories have shaped the content of later chapters. Respondents ranged from migrants who have come to Delhi to work, those who have come to work and study, those who have come only to study, and those that began doing one but have now started doing the other. There is also a smaller group doing neither.

Northeast migration offers insights into changes taking place in the frontier. These changes are profound but rarely visible, as academic and policy research on the Northeast remains fixated on the separatist insurgency on the one hand and an outdated inquiry into the compatibility of ethnic minority societies with modernity on the other. Focusing on migration and the lives of migrants in urban India offers new perspectives on the region by turning our attention to those leaving the Northeast behind, whether permanently or temporarily. This acknowledges that far-reaching social and economic changes have altered social relations, aspirations, and the ways many people in the Northeast view their place in India. This is difficult to 'see' within the region itself, where more fundamental questions about identity, conflict, and development occupy public and academic attention. These questions are also conceived in a smaller spatial scale. They are questions revolving around distinct localities, often removed from national considerations. Life for the parents of the present wave of migrants was more geographically contained. Insurgency and counterinsurgency, poor transport links, and suspicion and mistrust of neighbouring communities meant mobility entailed high risks. This is still true in many parts of the region, but the region has also become more connected to the rest of India, and across international borders the horizons of mobility are being redefined in a very short period of time. It is here that the immense changes that have taken place in the region in the last few decades are so apparent, yet so readily bypassed by literature on the region.

For older generations the parameters of mobility were from the village to the nearest town, or perhaps to the state capital or even one of the larger cities in the valley like Dibrugarh, Guwahati, or Silchar. Most societies were agrarian. In the hills, shifting cultivation was the primary 
means of livelihood, supplementary income, and supplementary nutrition. Rice and other sedentary crops were the staples of the valleys. As towns grew and the creation of new federal states required larger bureaucracies, urbanisation within the Northeast increased (Bahadur 2009; Deka 1986; Ganguly 1995). As small border states at the heart of India's territorial anxiety, particularly with relation to China, funds poured into the region to cultivate loyalty among secessionist ethnic groups. Party politics, public contracting, and land privatisation proved to be attractive arenas for money making. In other words, new opportunities were within the rapidly transforming frontier. The brave new world for many locals was Dimapur, Imphal, or Shillong rather than the distant mainland cities. As federal states were created in different phases (Dasgupta 1997), what Sanjib Baruah refers to as 'cosmetic federalism' (2003b), new jobs opened in towns and cities, especially in the civil service where reservations increased local employment in white collar jobs. Furthermore, as ethno-nationalism took hold in many Northeast polities, migrants from the merchant and working classes were chased out of towns and cities, opening space in the labour market for rural folk. Nepalis in particular have been targeted throughout the region since the I970s (Dutt I98I; Nath 2006a, 2006b; Subba 2003). This process is ongoing in some parts of the region, though the reverse is also taking place where new migrants have taken advantage of economic expansion and ceasefires in cities like Dimapur in Nagaland and the mining areas of Meghalaya (McDuie-Ra 2007).

In the past, those with financial means or connections migrated to study in mainland India, and a small number received scholarships to travel to Delhi or Kolkata for study or civil service training. An even smaller number went abroad to the United States or the United Kingdom on various scholarships. Others travelled for theological study and ministry training; what respondents would refer to as being 'on mission' to other parts of India and occasionally abroad. A friend from Meghalaya spoke of being invited to Kolkata in the early I980s as a young student leader to learn about Marxism and take the message back home. Others crossed borders to towns and cities in neighbouring countries to work and trade. Members of armed groups lived across borders for years at a time in camps in Burma and Bangladesh.

For older generations, migration was instrumental rather than aspirational. Skills gained were to be applied back to the local society. For peoples that had been classified as 'backward', the notion of improvement (Li 2007) - both of one's self and of one's society - was crucial in decisions to migrate. Rural livelihoods are hard to generate in steep hill country, and during insurgency and counterinsurgency campaigns safety is an issue in rural areas. Yet for those leaving rural areas beset by conflicts between insurgents and the armed forces and between rival 
insurgent factions, urban areas contained large army barracks and a heavy military presence that did not always alleviate the sense of insecurity. This contrasts with the rationale for migration among those leaving the region in the current era. Not only are Northeasterners moving further away but they are going for different reasons, though continuity with the past is evident to some degree, and migrants come from different backgrounds.

From my fieldwork, six clear themes emerged that explain why migrants leave the Northeast for Delhi: refuge, livelihoods, aspirations, attitudes towards India, labour recruitment, and increased connectivity.

\section{Refuge}

Northeasterners migrate to seek refuge from violence, insecurity, and dysfunction at home. Respondents often mentioned that it was not specific outbreaks of violent conflict that spurred their choice to migrate but the undercurrent of violence in the region. The number of ceasefires currently in place in the Northeast means that, at least theoretically, conflict is more subdued now than in the past (Rajagopalan 2008). Sudden outbreaks of violence have usually led to internal displacement and temporary migration within the Northeast itself. The number of internally displaced persons, their vulnerabilities, and the violence that produces them have been analysed in detail in a number of excellent studies (Baruah 2003a; Das ed. 2008; Goswami 2006; Hussain 2008; Lama 2000). As Monirul Hussain notes, displacement in the Northeast is not simply a product of insurgency but also of environmental degradation, poorly planned development policies, and insecure land tenure (2008: I6-I7). Evidence of links between internally displaced persons and migration to Delhi and other cities in India is scant. Migration to Delhi, which is over 2,000 kilometres away from parts of the Northeast, requires planning, resources, and a commitment of at least a few months and usually a few years. Displacement comes suddenly from violence, floods, or landslides, and those affected have little time to orchestrate a move to the mainland cities. Instead, their migration is into camps or to other towns and cities in the region. That is not to say that many will not end up in mainland cities eventually, but refuge from outbreaks of violence and natural or development-induced disasters is found closer to home.

Understanding migration to the mainland for refuge requires consideration of the ways violence is normalised in everyday life in the region. Violence, to draw on Pandey (2006), has become 'routine' and unspectacular. By this I do not wish to suggest that the Northeast is constantly violent - rather that the prospect of violence is constant. Those who can leave this environment do. Violence has bred dysfunctional state 
structures in many parts of the region, furthering insecurity for locals and enhancing the desire to leave.

In an antique shop in the trendy Hauz Khas area of south Delhi I met Wortip, a Thangkhul Naga from the hills of Manipur. Wortip's parents sent her to Delhi five years ago and she lived with her aunt until she found her own place a year later. Once she was established in Delhi her parents sent two of her brothers and one sister to live with her. She works so that they can study. She has three other siblings living in Dehradun, in the Himalayas north of Delhi. I asked her if she liked Delhi. She chose her words carefully. 'I like it a little.' When she expanded she mentioned she would rather be at home but she had to support her siblings because it was too dangerous back in Manipur and there was no education for them. She reminisced about when she was young and she would spy on Japanese tourists visiting war graves. 'No foreigners come now because the government won't give them permits. It is too dangerous.' She gestured to the small boutique shops in the neighbourhood and told me I could find many migrants from the hills of Manipur in these shops. She was right. In a clothes shop, a bookshop, a café and a restaurant I met more migrants from the hill districts of Manipur. They had similar stories. They came to Delhi to work and get away from the uncertainties of life in Manipur. These are migrants who would not have come to Delhi a decade ago. It was too far, there were no jobs, and it was deemed too dangerous. In recent years, the population who can leave has broadened and the distance they are prepared to go has increased.

\section{Livelihoods}

People leave the region to pursue livelihoods. Unemployment in the Northeast is high ${ }^{3}$ and civil service jobs are difficult to access for those without connections. Six decades of conflict have created a corrupt

3 Measuring unemployment in Northeast India is not straightforward. Data exists in state and national human development reports and census figures; however, given the large number of persons employed in the informal sector and the difficulties of gaining accurate information in parts of the Northeast where conflicts are taking place, the figures are incomplete. Sample statistics from the 200 I census give some indication: Arunachal Pradesh 10.78\%, Assam 23.00\%, Manipur 22.20\%, Meghalaya, I2.57\%, Mizoram 7.05\%, Nagaland I6.31\%, Sikkim 8.83\%, Tripura 30.15\%, India's national average I5.86\%. State-level reports give more specific detail around gender, rural and urban employment and sector but are too vast to list here and some of the more recent reports use different methodologies than the census, making comparisons difficult. More instructive for understanding migration is the perception that there are no jobs or poorly paid jobs-perceptions that are virtually universal in the Northeast and among migrants. 
patronage system throughout the region. In a sensitive border region, the Indian government requires loyalty from local governments in the region, and insurgency and instability is used as leverage to demand more funds from Delhi. These funds are in turn distributed to local contractors with connections to the local elite. In some of the most corrupt and dysfunctional states, such as Manipur, civil service jobs are even bought and sold by those with connections. Those buying them do not always end up working in them but instead pay someone else to do the job at a lower portion of the salary while they take up other work. Private sector jobs are few. Conflict and central government anxiety has reduced private sector investment, and any investment that does exist is in extractive industries with minimal local employment (Hussain 2008; McDuie-Ra 2008). With a well-educated and highly literate population, especially in the tribal majority states, the lack of livelihood options contributes to an environment of frustration, militancy, narcotic drug use, and migration out of the region to find jobs elsewhere (Baruah 2002; Kermode et al. 2009).

Stephen was one of the first migrants I was introduced to in Humayanpur. We met many times during fieldwork and in many ways he captures the changing profile of migrants from the Northeast. In his mid-2os when I met him, Stephen lived on one of the upper floors of a 'tribal tower', the popular name for the bland high-rise apartments built in the lal dora (village) areas of Delhi where there is little control over building height or construction quality. Stephen shared a flat with another friend from Nagaland but over the Delhi winter of 20I0-II he was hosting another friend who had left his accommodation after having trouble with his landlord. The three friends shared a small bedroom with two beds and a desk, a narrow kitchen, and a bathroom. Stephen liked this place because the bathroom was inside, unlike his last few flats. The walls were painted pink and posters of Swiss mountain scenery and Dutch tulip fields were stuck on the walls. Stephen rolled his eyes at the posters; they were obviously not his idea. He showed me his contribution to interior decorating, a photomontage of a most recent church picnic. I recognised a few of the people in the photo from the neighbourhood, and he pointed out people he thought I knew. On the desk was his computer that he had bought recently. Stephen was clear that he had saved for the computer and wasn't given it like some of the rich migrants that come to Delhi from back home. He was trying to get an Internet connection so he could use Facebook. Stephen had a reputation among other Nagas in the neighbourhood for being addicted to Facebook, and they used to tease him good-naturedly about it, saying he was looking for a wife online.

Stephen left Nagaland to study hospitality. He ended up studying in Chandigarh, the capital of Punjab and Haryana. He got a job in an 
Image 2.1 Advertisement for airline training. Guwahati, Assam

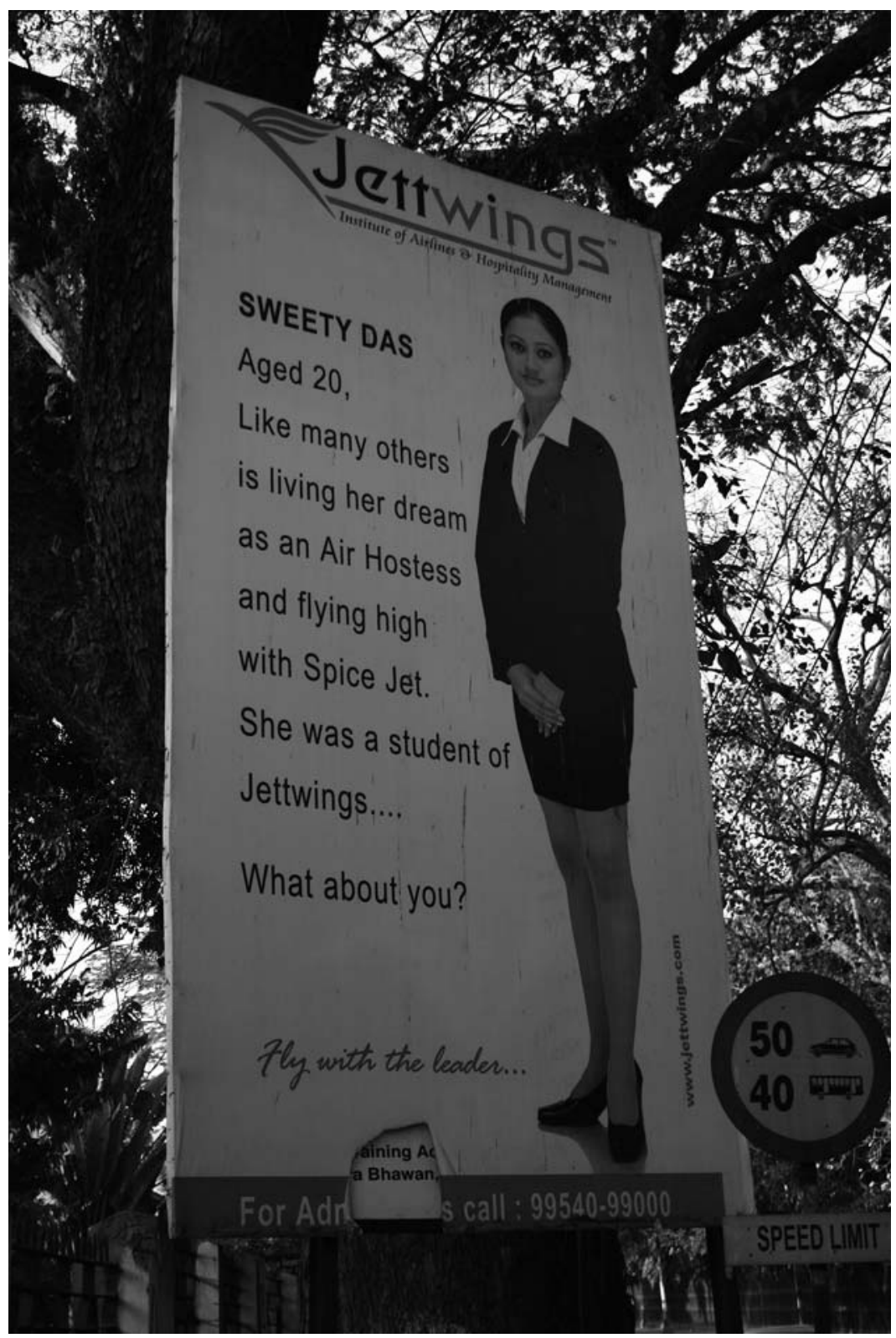


Indian café chain and was placed in different cities working as a barista. For a while he worked in Srinagar in Jammu and Kashmir, where he was constantly asked if he was from China. He was tired of moving around so he decided to come to Delhi so he could live with other Naga people but still earn a living. He thought about going back to Nagaland, to Wokha, the administrative town where he was from, but he added 'What would I do there?' Through friends he got a job in a call centre. Stephen worked his way up quickly and switched companies a few times until he got a job in the finance department. He put his rise down to working harder than Indians and knowing the tricks of speaking to the Indian management in the call centres; tricks he has passed on to his friends.

Despite his success in Delhi, Stephen wants to go home. On his computer he has a picture of his family rice paddy field in Wokha. We talked about all the things he misses about home: hunting, fishing, food, and small town life. Hunting came up often and he was sad that few Nagas his age know how to hunt like their ancestors. He didn't want to work in call centres much longer and was eager to go back to Nagaland, though he felt there were no jobs of equivalent stature there. He missed home and didn't like Delhi much, but it wasn't conflict that kept him away but the sense that there were few ways to earn a living at home. Stephen admitted he had no connections back home. He didn't come from a family with any 'big men' or any MLAs (members of the legislative assembly). He pointed out that even if he could find a job, he wouldn't earn enough. He would have to pay money to the different armed groups and extortionists. Unless he was prepared to be corrupt, he would not be able to survive in the Nagaland economy, a sentiment other respondents expressed again and again. Work in Delhi did not have these same intricacies. You found a job and if you worked hard you were paid. Of course, Northeast migrants do get exploited in the workplace; they get summarily dismissed, they have pay withheld, they are refused leave, etc. Yet compared to some of the challenges of making a living at home, these can be minor concerns.

\section{Aspirations}

Migration out of the Northeast reflects changing aspirations. Middle class desires, analysed with fervour in the rest of India, are also present in the Northeast. As Baviskar and Ray argue, the Indian middle class is heterogeneous and internally differentiated, but also has distinct regional characteristics (20II: I6). This is certainly true in the Northeast where the middle class rests on configurations of traditional power, kin and clan networks, relations with armed groups, and connections to and within the bureaucracy. The foundations of the middle classes in the 
Northeast are much more closely aligned to state connections than the middle classes in many other parts of India, especially urban areas, where middle class identity is closely associated with liberalisation and the shift from Nehruvian ideals to individualism (Fernandes 2006). The Sixth Schedule of the Indian Constitution, in place since I947, has provided reserved places in the bureaucracy and in educational institutions, increasing the size of the middle class, especially among tribals and Sikkimese. It also gives traditional institutions power over land. As the value of land has increased through the shift from subsistence to commercial agriculture, this has empowered a class of rural land brokers and absentee landlords (Barbora 2002). Better connectivity to other parts of India and to neighbouring countries has increased the availability of consumer goods, especially those coming across international borders from China. The rapid growth of cities and towns in the region, linked in part to changes in land ownership and use and the displacement from conflict, has urbanised lifestyles for many but also increased the cost of housing. Careerism, something limited among previous generations, is far more common among youths in the Northeast, and this was expressed again and again by respondents during fieldwork. In this case, parallels can be drawn to the evolution of 'new' middle classes in other parts of India. In his study of youths in Uttar Pradesh, Craig Jeffrey (2010) reveals the steady growth of the rural middle class through the pursuit of education in urban areas. As increased education failed to reap expected employment, members of the middle class moved farther afield to pursue further education, thereby increasing their cultural capital and ensuring that the rural middle class developed a resiliency. A similar phenomenon can be witnessed in the Northeast as the continual pursuit of better quality education to get a better job and 'stay ahead' takes hold.

Evidence of these growing aspirations can be seen in the rapid development of malls and brand-name stores in the Northeast itself; especially in Guwahati, the largest city in Assam, Gangtok, the capital of Sikkim, and Shillong, the capital of Meghalaya. Especially eye-catching are billboards and notices advertising vocational training colleges, career fairs, and employment agencies, such as in Guwahati outside Handique Girl's College and the enormous billboard bolted to a tree in the Botany Department of Guwahati University. The billboard features a young Assamese woman in a flight attendant's uniform, complete with high heels and an above-the-knee skirt. The billboard introduces passers-by to Sweety Das, a 20 year old who, as the text notes, 'Like many others is living her dream as an Air Hostess and flying high with Spice Jet. She was a student of Jettwings ...' Similar posters advertising flight attendant schools are found throughout the region. Northeasterners are coveted in the airline industry and are visible throughout India working 
for the private sector airlines like Spice Jet, Jet Airways, and Indi Go. As with retail and hospitality discussed in the following chapter, the airline industry desires the 'exotic' appearance of Northeasterners, their appeal to a globalised aesthetic of the class of travellers using airlines, and their English language skills. The airline industry has an allure for Northeasterners offering travel, excitement, and the 'fulfilment of dreams' - dreams crafted very differently to those of their parents' generation who dreamed of simpler futures and often of independent homelands.

The difference between the aspirations of young people and their parents was a major theme in my fieldwork. Among respondents in the Northeast there was recognition, albeit reluctant much of the time, that the younger generation wanted more and were capable of more. How does all of this relate to migration? For parents, having their children working or studying in Delhi or another city is important for their status and standing in the community. For migrants, the desire to live a middle class lifestyle, to consume goods, to own property (usually always back home), and to secure employment in the civil service or private sector make migration necessary in order to begin earning money and/or to take up tertiary education. Delhi is the preferred destination, as it is home to the best universities in India - most of which have reserved places for people from the Northeast - and is where the tools of the Indian bureaucracy can be learned. It is also home to an expanding private education sector of coaching schools to help migrants pass their civil service exams.

\section{Attitudes towards India}

The increase in migration reflects changing attitudes towards India. Ethnic minority communities in the Northeast have generally viewed India with hostility, yet this is gradually giving way to (tacit) tolerance. Indian citizenship, viewed ambiguously among many in the Northeast, is also an opportunity for education and livelihoods in Delhi and other cities. Equating contemporary ethnic identity with a simple rejection of all things Indian is thus complicated by migration. Changing attitudes are very uneven. For some respondents it is generational. This was very much apparent among respondents from Mizoram. Mizoram experienced some of the worst excesses of Indian state violence from the I96os to the mid-I980s including grouping villages in fortified camps by the roadside, food eradication, and sexual violence (Nunthara I98I; Rangasami I978; Sundar 20II). Respondents from Mizoram too young to have lived through this period still referred to the dangers of everyday life during this period, which suggests that the memory of struggles against the Indian state are integral to the identity narratives among 
Mizos. Yet as more and more Mizos leave the hills for other parts of India, these narratives do not always preclude a sense of belonging in the heartland. Vankhuma, a Mizo living in Delhi in his 4os, noted that young Mizos do not have the same depths of 'mistrust and hatred' for the Indian state as people of his generation, even if they appreciate the struggle. Migrants from areas that have experienced the worst excesses of counterinsurgency such as Manipur and Nagaland find this tolerance difficult to foster, whereas those from locations where violence has been minimal such as Arunachal Pradesh may not automatically trust mainland society but the association with violence is less severe. Of course, this varies among individuals. However, the overall feeling among migrants and back in the Northeast is that engagement with India may be necessary in contemporary life and trust or at least suspending mistrust is part of this change.

For others, changes are a by-product of their experiences of migration and the experiences of returning friends and relatives. People survive the cities and return home. To be clear, violence against Northeasterners in Indian cities is publicised and protested back home. Parents and relatives warn against migrating to the heartland. Violence by members of the armed forces and the paramilitary are a constant part of everyday life in much of the region. However, migrants manage to make a life in the heartland cities and return home for holidays or to settle with savings and stories of braving the inhospitable Indian cities. These stories and experiences are essential in giving friends and

\section{Image 2.2 Labour recruitment advertisement. Aizawl, Mizoram}

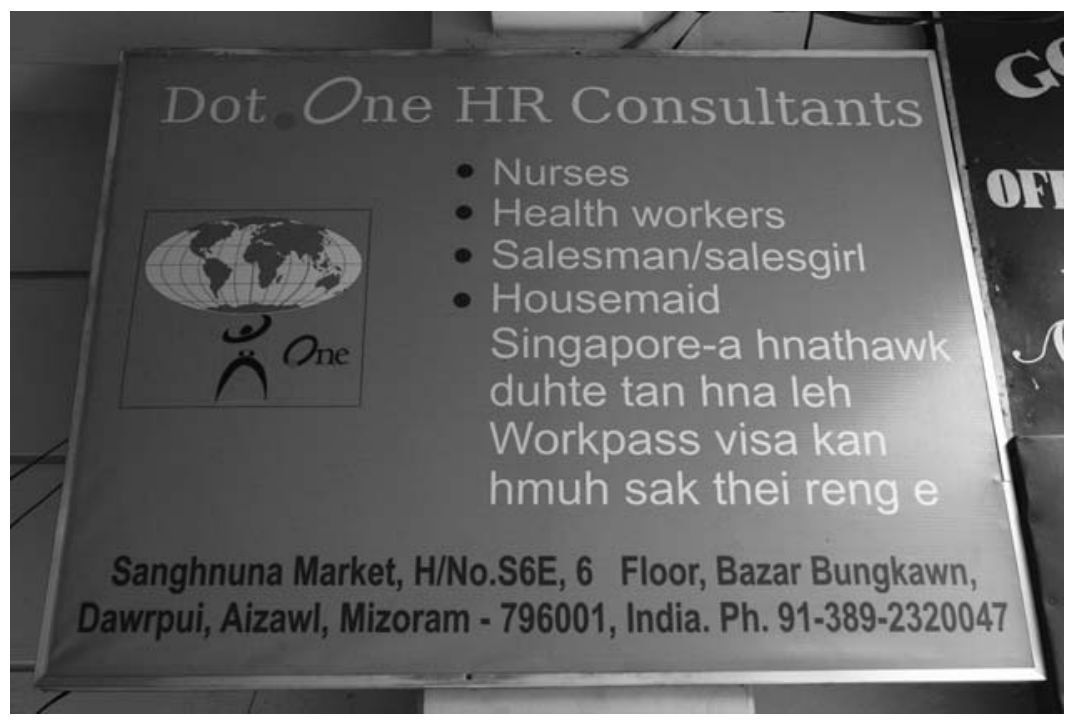


relatives the confidence to migrate. During a visit to the Naga areas of Manipur, one of the most fragmented parts of the Northeast, I stayed with the family of a Naga friend living in Delhi. One of her cousins had just returned home for a brief visit. She had been working in an upmarket hotel in Mumbai and had come back during her leave to bring her sister back with her. Listening to her experiences of the city in the small village on a high ridge facing the town of Ukhrul, where the streets are empty at dusk and electricity is sporadic, the lure of the city seemed inexorable. The younger sister was nervous but excited about following her elder sister to a place over 3,000 kilometres away. Her trust was invested in her sister.

As the number of migrants has increased, dense networks based on ethnicity, clan, and tribe have spread through Delhi. Migrants live together in certain neighbourhoods, eat and shop together, study together, and help each other get work. For many migrants there may be little need to come into contact with the Indian mainstream. Kho, a Naga in his late 20 s studying animation, explained this clearly as we sat in his flat one Sunday. Kho said he couldn't stand the aggressive and predatory culture of the Indian mainland. But he also has little to do with it. He spends all his time in the neighbourhood with other people from the Northeast, mostly all Nagas. He shared a flat with three friends. Some friends from home live in the same building and other friends in another building across the alleyway outside. He goes between these houses and rarely hangs out on the street. He has no money to eat out and his friends get together and cook Naga food most days. If they don't, he eats at the Tibetan restaurant in the same neighbourhood, though usually he just brings the food back home. Aside from rickshaw drivers, landlords, and a few students at his college, he has little contact with Indians. Kho inhabits a Northeast world in Delhi, something that did not and could not exist a decade ago. His attitude towards mainstream India hasn't changed. In other words, being in Delhi hasn't made him rethink how he feels about India or about Indian society. It is important to note that Kho's case is not universal for migrants, especially as he was not working. For others, confronting the city and society are an integral part of their time in Delhi, as discussed in later chapters.

\section{Labour recruitment}

As the demand for labour from the Northeast increases, labour recruitment in the Northeast is becoming more common. As will be discussed in the next chapter, Northeasterners have gained a reputation in certain labour markets in the Indian mainland. Their English language ability, work ethic, physical appearance, and limited predilection for 
organised labour have made Northeast migrants a desired labour force in the call centre, retail, hospitality, and airline industries. Labour recruitment comes from travelling agents who visit towns and cities for a short period. These recruiters are usually not from the Northeast. Those from more established businesses, call centres, airlines, and hotels hold interviews in towns and cities in the region. Others go to high schools and colleges to talk about the opportunities available in their business. As can be expected, many of those going to the Northeast to recruit labour are unscrupulous, offering jobs that don't exist or that exist for far lower pay, offering accommodation that is inflated on arrival, and also trafficking Northeasterners for sex work under the guise of hotel and restaurant work. This is a separate issue to migrants travelling with the intention to work in the sex industry, which takes place but was not discussed by respondents. In some recent examples cited by respondents, businesses from Indian cities are sending employees from the Northeast back to the region to recruit new staff. This seems intended to increase the level of trust after a few major cases of trafficking made the headlines, although even this tactic raises suspicion. In a recent case from 20II, two Naga men were arrested in Mizoram on suspicion of trafficking while recruiting women to work in a spa (Vanglaini Daily, 20II). Alongside travelling recruiters are labour agents based in towns and cities in the Northeast. These are a far more recent phenomenon, and agents work on behalf of several businesses in Indian cities to recruit and in some cases hire locals. In most cases I found that these local recruiters were working on behalf of airlines and call centres.

Many migrants leave the Northeast to join relatives and friends in Delhi. Yet for those who do not know anyone in the cities, labour recruiters are a crucial point of contact. However, the role of labour recruiters goes beyond employment provision - like labour recruiters everywhere, they peddle dreams and aspirations. Mina, a postgraduate student from Sikkim, remembered the visit of recruiting agencies to her high school in the mid-200os. Northeast labour is popular in call centres because of their English language proficiency and non-Indian accented speech. The recruiters were dressed in suits and were very professional. They were recruiting for call centres and they showed pictures of new office buildings in Delhi's satellite cities of Gurgaon and Noida. Mina said that the recruiters told them they could work for foreign companies and earn a big salary, which was very appealing given the limited livelihood prospects at home. She added that it just looked so different from home where offices were old government buildings with windows falling out of their frames. The idea of working for a foreign company was exciting to Mina and her friends, and she says they equated it with eventually going abroad. 
International labour recruitment appears to be taking hold, albeit in a limited manner, in the Northeast. In Aizawl, the capital of Mizoram, I saw an advertisement for a labour recruitment agency offering work for nurses, health workers, 'salesman/salesgirl', and housemaids. It also offered to arrange working visas for Singapore. Given that very few respondents in Delhi or the Northeast talked about labour migration abroad, though many discussed travelling abroad to study, this is an interesting sighting and one that perhaps reflects a newly emerging phenomenon of labour migration from the Northeast to other parts of Asia in a mirror image of migration patterns from elsewhere in South Asia and neighbouring Burma. This is an important area for further research.

The arrival of suit-wearing call centre managers in frontier towns to recruit the erstwhile backward savages to work in the futuristic glass and steel office blocks of Gurgaon epitomises the changing relationships between the frontier and the heartland. All irony aside, it also reflects the ways in which neo-liberal capital is orchestrating these relationships in ways that the Indian state has been unable to do. For older frontier dwellers and students of the history of the hill areas, it is also eerily reminiscent of labour recruitment in the era of colonial expansion and after the creation of international borders, though without the 'quasi-criminal' methods experienced in the early $20^{\text {th }}$ century (Kumar 2005: 2944; see also Robb i997; Van Schendel 2006).

\section{Connectivity}

Lastly, the costs and time of travel from the Northeast to Delhi and other cities have been reduced substantially. None of the hill states are connected to the Indian railway network aside from the town of Dimapur in Nagaland, and passengers must come from the hills to railheads in Assam to make the long journey west, through the narrow corridor at Siliguri into the Indian mainland. For passengers in Arunachal Pradesh, southern Mizoram, western Nagaland, or north Sikkim, this can be a journey of several days. Combined with the train journey, around two days to Delhi from Assam, this makes travel back and forth time-consuming and costly. It also reinforces the notion of distance between the frontier and the heartland cities. Safety is also a major concern, especially on trains travelling through western Assam through West Bengal to Bihar and Uttar Pradesh. Harassment on trains is frequent and Northeasterners often feel they are targeted. Due to this, many migrants travel in groups, are chaperoned by parents or other relatives, or they fly.

One of the biggest changes in recent years has been the growth of the private airline industry. Northeast airports were poorly serviced by 
Air India, the state-owned domestic airline, and fares were expensive. The region became far better connected when private airlines such as IndiGo, Spice Jet, Jet Airways, and Kingfisher started flying to and between Northeast capitals in the mid-200os. For migrants, travel between home and mainland cities has been reduced from five to six days to a few hours. Many travellers still have to travel considerable distances from airports to their hometowns and villages but bypassing train travel makes the journey much faster and trips back and forth can be more frequent. It also means that relatives from home can visit migrants in Delhi more frequently, though as will be discussed in later chapters, such visits are not always welcome! Air tickets can be expensive but can be cheaper than train fares, especially train fares in the safer classes of travel. Migrating to Delhi requires no passport, no visa, and usually no need to have employment organised in advance. Migrants can go for a while and return if it doesn't work out.

Another major change is mobile telecommunications and the Internet. Indian mobile phone companies, including a number of national subsidiaries of multinational firms, have expanded their business rapidly in the Northeast. The landscapes of towns and cities are branded with billboards for mobile phone companies. In some rural areas, such ads are the only reminders that one is indeed in the boundaries of the Indian state. Mobile phones are cheap and while call costs to mainland states can be quite expensive, the ease of contact has dramatically reduced the psychological distance between frontier and heartland for migrants and those remaining behind. The Internet plays a similar role, though connectivity is far more limited than mobile phones. Leaving the frontier no longer means being out of contact for months and perhaps years. Delhi and other cities are still distant, still dangerous, and still in the heartland of the nation-state that few in the frontier view sympathetically. Yet connectivity bridges the distance and means migrants and their families reassess the risks and costs of migration in new ways. 


\section{Coming to Delhi}

In this chapter I discuss why Northeast migrants choose to come to Delhi. I focus on two main reasons. The first is the demand for labour from the Northeast. This needs to be understood in the context of Delhi's transformation into a 'global city' through neo-liberal capitalism and the changing consumer and business landscape of the city. The drive to transform Delhi into a global city has been critiqued for reorganising, sanitising and enclosing urban spaces which has excluded the urban poor, labourers, and migrants. The end result is an uneven urban landscape with differentiated rights of access and participation. One of the neglected aspects of this focus on exclusion is the ways in which the new spaces created by Delhi's transformation enable inclusion for Northeast migrants in these very spaces. The desire for Northeast labour in the de-Indianised spaces of the global capital draws migrants from the frontier. It is precisely because these spaces are crafted as global that they are open to peoples outside the boundaries of the nation. Economic inclusion is possible in spaces that are stripped of distinct national signifiers: shopping malls, spas, restaurants, and call centres. Outside these spaces of economic inclusion, Northeasterners continue to live as exceptional citizens.

The second reason is that Delhi is seen as the best destination for higher and tertiary education. This has been the primary historical reason for migration from the Northeast to Delhi, and this continues today though on a much larger scale. Delhi has India's best universities and colleges; all of which have reserved places for Sixth Schedule tribals and members of other ethnic communities under different reservation schemes. Delhi is the site where the tools of the Indian state can be learned; tools that can be used to acquire the highly valued Indian Administrative Services (IAS) posts back in the Northeast. In response to this, the education sector in Delhi has expanded and specialist colleges and tuition schools have proliferated. 


\section{Explaining Delhi's Popularity}

The last chapter discussed the acceleration of migration out of the Northeast to other parts of India. The difficulties of obtaining reliable data aside, the largest share of these migrants head to Delhi. The North East Support Centre and Helpline report on Northeast migrants estimates that 48.2I per cent of migrants move to Delhi (201ra: Io). In the absence of more reliable data, this figure has been used by the Northeast media and by support groups in Delhi. Attempting to prove or disprove the accuracy of the figure is a largely futile exercise. The difficulties of obtaining more accurate data are discussed in chapter I. The figure is likely to be an underestimate. More importantly, it is doubtful that any quantitative measure can capture the back-and-forth nature of migration from the Northeast to other parts of India.

Respondents in Delhi, officials from the various state bhawans (houses), ${ }^{4}$ and respondents back in the Northeast were almost unanimous in their belief that Delhi receives the largest number of migrants. As will be discussed in this chapter, Delhi is preferred because it is a destination where education and work are possible. Other destinations tend to be favoured for either one or the other. For instance, according to respondents, migration to Bangalore, Hyderabad, and Mumbai is growing but mostly for work. In fact, many people migrating to these cities first complete their studies in Delhi before looking for jobs in these other cities, especially in hospitality and call centres. That is not to say that Northeasterners do not undertake education in these cities, but they are not considered as education destinations first and foremost. There are other cities where Northeasterners migrate solely for education, especially for pre-university college: Pune in Maharashtra, Dehra Dun in Uttaranchal, and Kalimpong in West Bengal, among others. Importantly, migration to Shillong, the capital of Meghalaya, one of the tribal majority states in the Northeast, is common for youths from all over the Northeast for education. Interestingly, Kolkata was once a very popular destination for education, though its popularity is waning due to the increased means to travel farther afield and the reputation of the city for parochialism when compared to Delhi, Bangalore, Hyderabad, and Mumbai.

Migrants are also travelling to more out-of-the-way places than before. During a break from fieldwork, I travelled to Gwalior in Uttar Pradesh.

4 Each state in India has a bhawan, or house, in Delhi. In some ways, these function almost like embassies. Here, officials work and in some cases reside. Residents of the state can avail certain services at these bhawans, but these vary. Some Northeast states also have bhawans in other cities, particularly Kolkata and in neighbouring states within the region. 
One evening at a local cafeteria I met two women, one from Nagaland and one from Mizoram, studying at the local medical college. They were astonished that someone knew about where they were from just as I was astonished to find them living and studying there. They said they rarely moved about the city, usually only going from their campus to the cafeteria and back again. Respondents in Delhi were full of stories of relatives, friends, former classmates, and acquaintances from home now living in obscure places in India. Some of the migrants discussed in these stories have achieved mythical status, particular those undertaking mundane work: a waiter in Gujarat, a shop assistant in Kashmir, a hotel worker in Pondicherry.

Delhi is also used as a pathway to other cities. Respondents often spoke of their plans to migrate to another city in the future. This was more common among Northeasterners who were planning to go into professions rather than government jobs. Remy, a woman from Nagaland, worked as a singer in an upmarket Delhi hotel. She had previously studied in Delhi and worked in a call centre before getting her singing job. She has plans to move to Bangalore or Goa, as they are more 'relaxed' than Delhi. Zana, a male also from Nagaland, was completing his studies in graphic design and computer animation. For Zana, Delhi held few options once his study was completed and he planned to migrate to Mumbai to try to get work in the television and film industry in post-production. Other respondents planned to move within the same industry. A number of respondents who worked in call centres planned to shift to call centres in Hyderabad or Mumbai. Others simply wanted to leave Delhi but knew they had limited prospects at home so they wanted to try another city. Bangalore was a favourite destination simply because of its reputation for tolerance and a fairly large community of Northeasterners there, especially from Manipur. Respondents would tell stories of friends or relatives living in Bangalore who experienced much less racism and harassment than in Delhi. However, if the topic ever came up among groups of migrants, those who had lived in Bangalore were often quick to dispel any fantasies. As one respondent from Manipur put it, 'Bangalore is not Delhi, but it is not home either'.

The reality is that Delhi provides the opportunities to work, to study, to learn the tools of the Indian bureaucracy, and to do all of these things at once. Among respondents there is a sense of inevitability steering them towards the city. Regardless of the reasons individuals have for migrating, they share the view that they had few alternatives but to migrate to Delhi given the circumstances back home (discussed in the previous chapter). Inherent in this view was anger at the role of the Indian state in perpetuating violence and dysfunction back home. This provokes complex and even contradictory feelings among many migrants, 
especially those from areas that have experienced the worst excesses of violence and militarisation. Adang, a Naga woman from Manipur, has lived in Delhi for thirteen years. She believes that the increase in migration to Delhi over the last five years can be attributed to the worsening ethnic relations among Nagas and Meiteis and Nagas and Kukis in Manipur. She said: 'life in Manipur is almost impossible because of the harassment by the army, the militarisation, the blockades, the strikes. So we take our chances in Delhi. But even if we stay here, we will never die here.' Stephen, a 24-year-old from Nagaland put it in a similar way. He doesn't want to be in Delhi but says India has failed to protect livelihoods in Nagaland from migrants. He said, 'I want to start a shop in Dimpaur (the commercial town of Nagaland) but the market is all controlled by Marwaris. So I have to be here.' Although the factors encouraging Northeast emigration create a sense of injustice, Delhi itself is changing rapidly and facilitating a shift in the demographic profile of migrants from the frontier.

As migration from the frontier has increased, Northeast neighbourhoods have also grown and become more distinctive. I will consider this in more detail in later chapters. However, it is worth briefly outlining the location of Northeast neighbourhoods in Delhi. Northeasterners live in north and south Delhi, but rarely in east or west Delhi. The north is mostly home to students, while the south is home to those working and studying, though this distinction is dissolving as the demographic profile of migrants shifts. In the north, migrants live in the neighbourhoods around Delhi University and close to GTB Nagar metro station. In the south there are a range of locations. Green Park, Munirka, Safdarjung Enclave, and Safdarjung Development Area are close to Jawaharlal Nehru University and the Indian Institute of Technology. Duala Kuan, Moti Bagh (south), and Shanti Niketan are popular areas close to Delhi University's south campus. Other areas in the south include Kotla Mubarak and South Extension I and II.

Some locations were more popular with certain tribal or ethnic groups. Moti Bagh and Shanti Niketan are known for having more Mizos; Munirka and Green Park have more Manipuris; and Safdarjung has more Nagas. In truth, however, the Northeast population in all these areas is very mixed. Migrants make a further distinction about the cost of housing in the different areas. Areas in the north, Munirka, and parts of South Extension are known to be cheaper. Again, views on this varied among respondents, and as virtually everyone consulted for this research felt Northeasterners paid far more than anyone else for housing, the differences are a moot point. Far more important were perceptions of danger and safety in the different areas. Most respondents felt the north of Delhi was more dangerous and more unpleasant than the south. Many respondents living in the north expressed the desire to 
move to the south as soon as they could. However, given the difficulties of transport across the city - made somewhat easier with the Delhi Metro - it is difficult to live in the south and study or work in the north and vice-versa. Within the south, perceptions varied, but Dhaula Kuan, Munirka, and Kotla Mubarak were considered riskier locations. Dhaula Kuan and Munirka were also the sites of two gruesome attacks on Northeast migrants in late 2010 and early 20II (see chapter 3), which perhaps explains why they were often mentioned as dangerous areas. Interestingly, Munirka has such a high number of Northeast migrants that perceptions of danger are offset by the attractions of a concentrated population of people from home. In fact, Munirka has become the main hub for Northeast migrants, especially new arrivals. Their growing presence can be tracked through the opening of shops selling food, clothes, and air tickets run by Northeast migrants.

An important final point is that most Northeast migrants are very rarely homeless or live in illegal dwellings. Kin, clan, familial, and ethnic ties ensure that migrants have a place to stay even if they have no money. Family members back in the Northeast will go to great pains to ensure that their relatives can afford accommodation, even if it is very modest. This forms part of Northeast identity narratives, as will be discussed in chapter 5 . Northeast migrants are rarely property and business owners, though they rent shops in some of the neighbourhoods. Their presence in the city is not formalised through ownership. This matters because Northeast migrants remain outside the city's hierarchical politics as potential clients to political and business patrons. Furthermore they are not on the radar of civil society activists focussing their attention on the urban poor. Indeed the strength of Northeast student unions and churches means that other civil society activists rarely engage with Northeast migrants. Northeasterners' race, rather than economics or party politics, is what defines their place in the city.

\section{Delhi meri jaan}

The liberalisation of India's economy from the late I980s (officially since I99I) has transformed urban areas through the privatisation and enclosure of urban spaces, the creation of investment-friendly infrastructure, and the partial privatisation of governance and welfare (Chaplin 20II). Neoliberalism is recurrently identified at the heart of this urban transformation, though in literature dealing with India neoliberalism it is often used interchangeably with liberalisation to describe the same phenomena. David Harvey defines neoliberalism as 'a theory of political-economic practices that proposes that human well-being can be best advanced by liberating individual entrepreneurial freedoms and 
skills within an institutional framework characterized by strong private property rights, free markets, and free trade' (2005: 2). The role of the state is to provide the institutional structures to support this and guarantee the functioning of markets. This process has led to what Harvey terms 'creative destruction' of previous institutional frameworks, divisions of labour, social relations, and welfare provisions, among other things (2005: 3). Neoliberalism takes on a variety of national and subnational forms. In the case of India, this has necessitated a dramatic shift from the role of the state as provider under Nehruvian socialism to the role of the state as a champion for private investment and market penetration, albeit with extreme variation at the federal and local levels and in different sectors of the economy and society (see Gupta \& Sivaramakrishnan 20II). It has also meant that the state has stepped back from welfare provision in some instances, leaving this to NGOs.

In urban India, transformation is constant, and as Nandini Gooptu (20II) warns, many of the processes attributed to neoliberalism are not necessarily unique to the past two decades but take on a distinctive character under neoliberalism. For Gooptu, distinctiveness can be seen in the creation of 'entrepreneurial cities' to trigger economic growth, with dramatic consequences for the reorganisation of urban space, and the capture of urban politics by the middle classes in response to the mobilisation of the poor. In Delhi, neoliberal transformation is partial and diverse spaces coexist and overlap; it is what Kudva refers to as a 'patchwork of deeply segregated localities' (2009: I6I5). In Delhi, attempts to transform the city are increasingly driven by the desire to fashion a 'global city', in line with Gooptu's entrepreneurial city but with a further drive to make a mark, to be on the global map. I am concerned with the ways the global city aspiration frames urban transformation in Delhi and helps to usher in neoliberal practices rather than questions of whether Delhi fits into the definition of a global city or how its relative 'globalness' compares to other cities (see Robinson 2002). Nor am I particularly concerned with detailing the historical evolution of the city; a task already executed superbly by other authors (Gupta I98I; Legg 2007; Pandey 200I; Tarlo 2003). Delhi's history is rich and fascinating, and accounting for its varied pasts is vital in understanding the city, its character, and its appeal. I do not wish to imply that Delhi's past is unimportant in understanding its present. Rather, from the perspective of migrants from the Northeast, Delhi is a city that has only entered their lives, narratives, and identity in a meaningful way in recent decades. The Delhi of the 2000 s is the city encountered by most Northeast migrants, not post-Partition Delhi or the Delhi of the Emergency years. For Northeast migrants, Delhi's historical evolution affects their lives in indirect ways: the layout of the city, laws, neighbourhoods, capital, governance, patronage. Before the 
2000s, Delhi was a distant place where the occasional relative went to study or protest or where Chief Ministers went to represent their state and come back with a deal. Certainly Delhi was known as the Indian capital and the place where government policies are created and laws are passed that directly affect life on the frontier. Sometimes Northeasterners even travelled to Delhi for holidays and sporting competitions. However, the city as a place to pursue aspirations and as a place to encounter mainstream India is recent. It does not shape their collective memory or their identity narratives as it does for other residents. As will be discussed in the following chapter, they are outsiders in a way that is qualitatively different to other migrants coming to the city for the first time. They are outsiders to all strata of the city, not simply elites and the middle classes but also other migrants and subaltern peoples. Thus I am interested in Delhi's recent past and its present. These implications are captured in the drive to make Delhi a 'global city', acknowledging of course that the global city vision itself is the result of historical processes in the city and the nation.

The ambition to make Delhi a 'global metropolis' and 'world class' city is set out explicitly in the Delhi Development Authority's (DDA) Master Plan for Delhi 2021, released in 2007 (DDA 2007). As Véronique Dupont notes, reaching that desire was officially proclaimed in a resolution passed by the Delhi Legislative assembly in 2007 (2011: 536). The Master Plan gives clear directives. Infrastructure is to be built rapidly to allow all 'people (and) resources' to 'conduct themselves in productive work with a better quality of life, living in a sustainable environment.' In order to achieve this productive and sustainable environment, the city's planners need to meet the challenges of population growth and immigration, housing, and environmental and heritage conservation. Part of this involves addressing the 'problem of small enterprises, particularly in the unorganized informal sector', 'dealing with the issue of slums', and 'up-gradation [sic] of old and dilapidated areas of the city'. The distinctly modern vision of the clean, orderly, and efficient city is to be pursued 'within a framework of sustainable development, publicprivate and community participation and a spirit of ownership and a sense of belonging among its citizens' (DDA 2007 online).

The global city aspiration has necessitated a shift in urban logic. Construction that is 'planned' is afforded almost incontestable legitimacy, whereas construction that is 'unplanned' can be deemed illegitimate. As D. Asher Ghertner (2OII) argues, the attribute of 'plannedness' also carries over to legal decision-making. He discusses the case around a proposed shopping mall in Vansant Kunj in south Delhi to be built on ridged forestland. A group of activists attempting to save the ridge land took the matter to the Supreme Court. The DDA defended the development on the grounds that it was 'planned'. Despite finding a 
Image 3.1 Ambience Mall. Vasant Kunj, Delhi

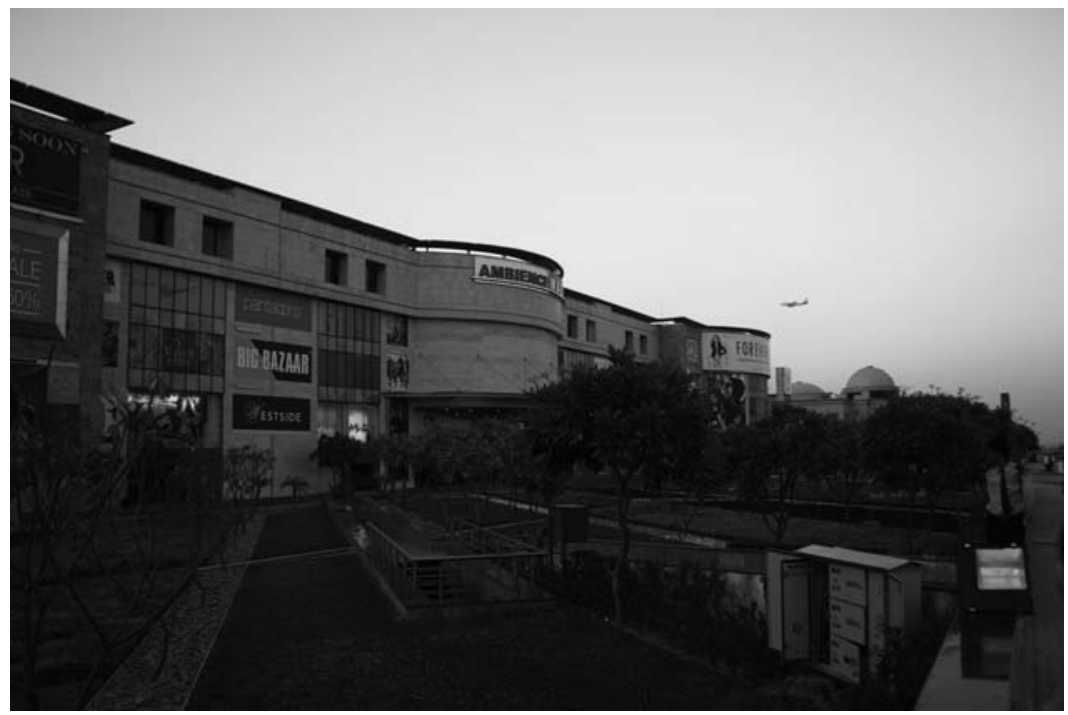

number of severe violations of planning law, the court ruled in favour of the DDA based on the mall's 'world-class' appearance. This is in marked contrast to unplanned dwellings that are cast as illegitimate and subject to demolition.

Gautam Bhan estimates that 45,000 homes in Delhi have been demolished between 2004 and 2007 (2009: I28), reflecting a shift in 'how the urban poor in India are represented, governed and judged' (2009: I3I). Bhan argues that the rights of Delhi's poor are eroded by the targeting of 'encroachers' or improper citizens of the city (2009: I39). The poor, including the working poor, are seen as threats to the sanitising spaces of the global city. Key to this rationale is the creation of exclusionary spaces: gated neighbourhoods, restricted-entry shopping malls, and restricted-entry parks and green spaces. Waldrop argues that such spaces reflect anxiety derived from the perceived crumbling of old caste and class boundaries and the need to 're-establish a sense of order' (2004: 99). Leela Fernandes calls this 'the spatial reconfiguration of class inequalities' which is part of a larger phenomenon of the 'politics of forgetting' wherein 'marginalised social groups are rendered invisible and forgotten within the dominant national political culture' (2004: 24I6). Even the commodification of space, however, has its limits in the city as Amita Baviskar (20II) shows in the case of the Yumuma River. 
Delhi has pursued the vision of the global city by staging major events. Perhaps no single event has galvanised scrutiny on the global city ambition like the XIX Commonwealth Games in 20I0. For India, the Games reflected the "propensity of "semi-peripheral" polities to pursue such events as a pivotal strategic response to the exigencies of globalisation' (Black \& Van der Westhuizen 2004: II96). Not only did the Games exemplify the global city aspiration, they were also credited with accelerating other crucial exemplars of the global city: the metro system (Siemiatycki 2006), a new airport, flyovers, stadiums, new roads, new buses, and sanitised spaces (Menon-Sen 2010: 678). Under the banner of the Games, extreme urban transformation was hastened and more difficult to oppose. Urban transformation requires an inflow of migrant workers from outside the city, and yet it also leads to the demolition of informal settlements containing the dwellings and shelter upon which many migrants depend. The costs are significant: the Games left behind a city with 3 million homeless people and as many as I००,००० relocated families (Menon-Sen 2010: 679-80).

The global city is given a cosmopolitan face through advertising campaigns celebrating the city's heritage and diversity. The Delhi meri jaan (Delhi my love) campaign seeks to celebrate Delhi's cosmopolitanism. After all, a global city cannot be a parochial city. Creating a cosmopolitan global city can be a very specific and even exclusionary process, but it is seen by city planners, governments, and officials as a vital way to attract the skills and resources of transnational capital (Yeoh \& Chang 20II). The reverse - a parochial, closed city - will scare away capital and skilled professionals. Thus in Delhi, the marketing of the city has involved ensuring that diversity and cosmopolitanism are enshrined in the global city discourse (see Cheah 2006), regardless of how removed they are from the urban realities. Billboards throughout the city in early $201 \mathrm{I}$ featured photographs of diverse scenes in Delhi, focussing on crafts manufacturing, street stalls, brightly coloured textiles and foods, and smiling inhabitants with the slogan Delhi meri jaan. The campaign includes a song and television advertisements launched in September 2010 prior to the Commonwealth Games. One of the billboards spotted around Delhi during January and February 20II as part of the meri jaan campaign featured four cartoon-style drawings of heads. Each head represented a different male member of a major religious group. There is a Hindu, a Muslim, a Sikh, and a Christian. All have the same round face, eyes, and mouth, and different religious signifiers (without an obvious signifier, the Christian simply has parted hair and a goatee beard). On the other side of the billboard are four photographs of corresponding places of worship: a temple, a mosque, a gurdwara, and a church. The slogan reads: 'Truly [sic] Cosmopolitan: Warm and Friendly'. This is a telling image of how those marketing the city see cosmopolitanism. There is 
diversity, but diversity clearly within the limits of the Indian national imaginary. As will be discussed in the following chapter, this national imaginary has limitations when it comes to migrants from the Northeast.

At the same time, citizens' participation in the city's governance is altering the locus of political power in Delhi. The most notable change is the Bhagidari initiative, begun in 2000 , which formalises the citizengovernment partnership and deliberation on local issues through Residents Welfare Associations (RWAs). Critics of Bhagidari argue that RWAs have become vehicles for narrow middle-class interests effectively hijacking the governance agenda and directly and indirectly affecting the urban poor (Chakrabarti 2008). RWAs promote an associational life that appeals to the middle classes, whereas the urban poor are much more likely to address problems through political mediation (Harriss 2005). The rising middle classes in India have been able to produce a politics of 'hegemonic aspiration' (Fernandes \& Heller 2006). This hegemony is created through political practices, uniting the disparate and fragmented middle classes and offsetting the divisive politics of religion and caste. Yet as Fernandes and Heller show, this hegemony is 'marked by middle-class illiberalism, and most notably a distancing from lower classes' (2006: 496). RWAs work in partnership with the DDA, the Delhi Police, and the Municipal Corporation of Delhi to 'sanitise their neighbourhood by trying to remove encroachments and petty commercial establishments' (Kundu 20II: 24). The end result is exclusion.

If Delhi is a 'patchwork', then many of these patches are becoming more and more exclusive. As many of the poor and working poor are migrants who have come to Delhi from other parts of India, and also from Bangladesh and Nepal, the city is fast becoming enclosed for new arrivals, with only selected spaces still open to improper citizens. Considering Harvey's paradigmatic ruminations (2003) on the 'right to city' as rights of access and rights to transform the urban environment, Delhi is failing the poor and migrants on both accounts. Urban space is sanitised, pushing the poor further into the margins, and participation in increasingly formalised local associations is captured by middle and upper class interests.

The creation of exclusionary spaces through the neoliberal transformation of cities like Delhi has received a great deal of attention. The consensus view is that this transformation is further excluding large parts of the population, especially already marginalised communities, and partitioning the city into segregated localities. In this view, marginal peoples share a common fate at the hands of this transformation and their rights to the city are trampled by the onslaught of neoliberal 
capital and accommodating authorities. The case of Northeast migrants in Delhi does not wholly refute this view, but it does destabilise it.

\section{Inclusion in the Exclusionary City}

The neoliberal transformation of Delhi is creating spaces of engagement between Northeasterners and the Indian mainstream. The desire for Northeast labour in the city's global spaces is fuelling a rapid increase in migration from the Northeast frontier, the very limit of India's geographic and territorial imaginary. It is precisely because these spaces are crafted as un-Indian that they are open to peoples outside the boundaries of the nation. Importantly, economic inclusion is not matched by social inclusion, and this will become clearer in later chapters. Here I focus on economic inclusion in two sectors: the rapid growth of new consumer spaces for the middle and upper classes, and the growth of the services sector serving global capital. I focus on these two because they were identified by respondents as the most common sectors for Northeast employment in Delhi. Both sectors are also popular in Bangalore, Hyderabad, and Mumbai. Two other sectors that draw Northeast labour are the airline industry and the hospitality industry, especially high-end hotels and resorts. These are not discussed here, as overall employment of Northeasterners is lower and they tend to be centred in other cities in India.

\section{New consumer spaces}

In Delhi, neoliberal transformation has produced consumer spaces that are physically within India but resemble other ubiquitous, though amorphous, global spaces. New consumer spaces are exemplified by the proliferation of upscale shopping malls. Unlike neighbourhood bazaars where shops are usually organised along adjoining lanes and may include 'dry market' goods like clothes and electronics alongside 'wet market' goods like fish and vegetables, shopping malls are contained spaces without 'wet market' goods, the climate is controlled, entry is restricted, customers are dropped at the door in vehicles - thereby minimising contact with the street - and restaurants and cinemas are included under one roof. As Christiane Brosius argues, the mall in India makes shopping an 'experience' (2010: 53), while Nita Mathur argues that the shopping mall in urban India helps to 'reframe status distinctions' (2010: 2I9). During fieldwork I concentrated on three interlinked malls in Vasant Kunj, a suburb in south Delhi: the Ambience Mall, the DLF Promenade, and the DLF Emporio, marketed as Delhi's 'most exclusive' malls with almost 300 stores across the three malls. These 
malls are the outcome of the 'planned' and 'world class' development described above. The malls are owned and operated by the Indian firm DLF Ltd., a real estate firm described as using construction projects in Delhi 'for expressions of numerous ideologies of modernity and community life' (Srivastava 2009: 338).

The malls are by any reckoning exclusive spaces. Right of admission is reserved, airport style security is performed, access is difficult without motorised transport, and the scale of the space itself seems designed to intimidate. As Brosius' study of consumerism in Delhi has shown, at the heart of consumer spaces like the DLF malls is the aim to satisfy the desire of the upper and aspiring middle classes to live abroad in India' (2010: 65). To truly experience this kind of statusdriven consumption, consumer spaces serving these classes have become de-Indianised. By this I mean that these spaces seek an aesthetic that transports consumers away from the city, and even the nation, outside and into the global world of fashion, food, and brand-name consumer goods. This has served the interests of Northeast migrants. Migrants from the Northeast have Tai, Tibeto-Burman or Mon-Khmer lineage, and thus their features are similar to those of East and Southeast Asian peoples. Their labour is in demand because they reproduce the de-Indianised aesthetic without the need to import foreign labour.

During fieldwork I visited these three malls over twenty times. I visited at different times of the day and on different days of the week to converse with Northeast migrants. I also met Northeasterners working in these malls at other sites including Northeast neighbourhoods and university campuses. Northeasterners are ubiquitous in clothing stores, sports stores, spas and beauty stores, restaurants and cafes (except Indian restaurants of which there are few), and home wares stores. They were especially well represented in stores that project a global brand image: Adidas, Benetton, Esprit, Levis, Nike, and Zara. There were very few Northeasterners working in ultra high-end retailers aimed at rich consumers making major purchases: jewellery, expensive watches, wedding dresses, and expensive suits. In restaurants, Northeast men and women worked as wait staff, maître d's in more expensive restaurants, and in the kitchens of cheaper eating-places. They also work as concierges at the mall entrances.

This suggests very defined roles for Northeast migrants in the new consumer spaces of Delhi. Aside from those working in the kitchens, Northeasterners are all in very visible roles. They are rarely in managerial positions and in some stores they do not handle cash transactions. Women are cast in highly sexualised roles, particularly in fashion stores, restaurants, and spas. The body is emphasised in tight clothes, heavy eye make-up, and lipstick. In some restaurants and spas, women 
were dressed in cheongsams, the tight fitting Chinese evening dress. Given the historical and contemporary anxieties over China in Indian political and popular culture, the sheer number of Chinese restaurants in malls and upscale south Delhi neighbourhoods is astounding. Most are simply more expensive versions of Indian-Chinese restaurants found throughout the country. For the extra cost, the interiors are full of hanging red lanterns, dark wood tables, dragon motifs, and Chineselooking staff from the Northeast. In other cases, emphasising body shape is less important than portraying exotica. In more expensive Korean restaurants I have met Naga women wait staff wearing hanbok, a flowing traditional dress that hides body shape. In an upscale Himalayan restaurant in Hauz Khas, the female wait staff wear bakhu, a Bhutia/Tibetan tunic with a long dress and a silk honju (blouse) underneath. The irony is that many of these women are not from Sikkim or other parts of the Himalayas but are from Manipur and Nagaland. They look the part, but likely work for low wages and speak good English to better communicate with the clientele - a mix of trendy Delhi youth, artists, foreigners, and visitors to the city from across the Himalayas. The contrast to the clothes worn by women out on the streets of Delhi could not be greater. The masculinity of Northeast men is less clearly defined, though in places their bodies are emphasised through dress projecting athleticism and street fashion sense.

\section{Image 3.2 Northeast wait staff. South Extension, Delhi}

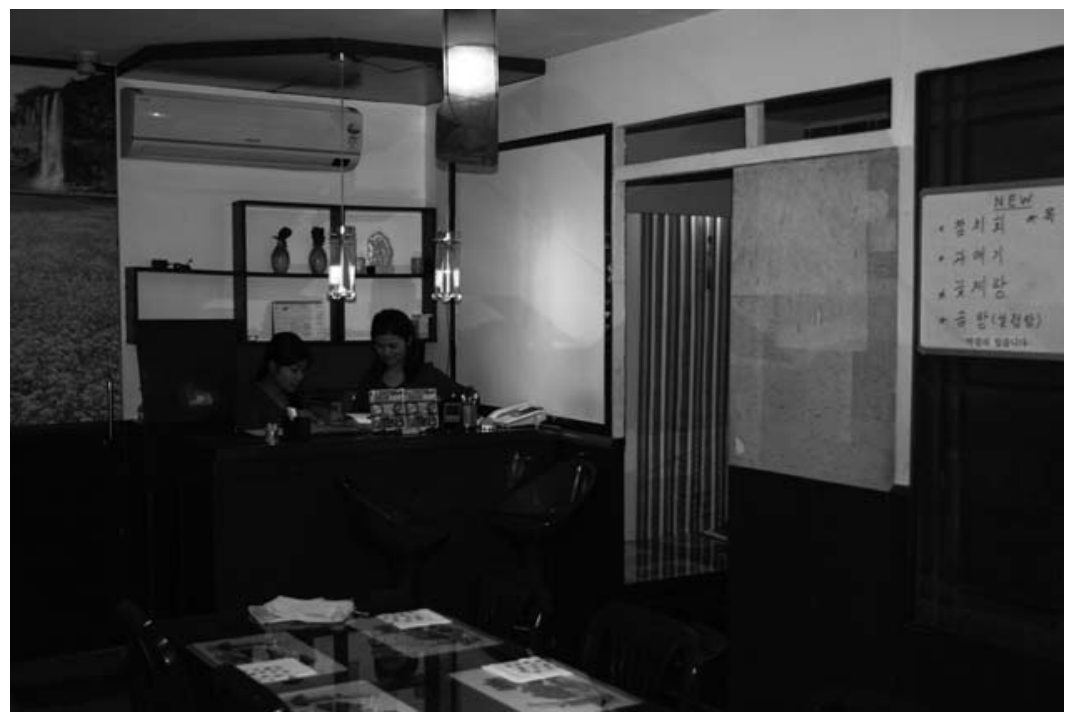


In these global spaces, Northeasterners perform these roles because they look, speak, and act 'un-Indian'. They are not associated with a particular caste, religious or regional group within the boundaries of mainstream India. They are simultaneously neutral and exotic. Their high visibility in Delhi is recent, owing to the surge in migration, and thus they act as a new labour force to complement the new consumer spaces of the global city. The labour force crafted through orientalised exotica, mixed at times with a sense of East Asian cool, constructs a space that is in India but not of India; perfect for 'world-class' aspirants of the middle classes. As Zana, a 23-year-old male from Nagaland put it, 'for Indians it is like going to Bangkok for shopping. We look the same but some of us can speak Hindi'. Many of the young people working in these jobs are very aware of the ways their race is desired and many are uncomfortable with this construction. Yet they also see it as a way they can take advantage in a highly competitive urban labour market. Thus tolerating and utilising this portrayal is an important part of staying afloat in Delhi.

Northeast migrants working in malls and restaurants expressed a number of reasons for pursuing this kind of employment. Some work in order to pay for their education, some for their siblings' education in Delhi, some send their earnings back home, some are working to stay in Delhi and seek refuge from conflict, and others to set themselves up to travel abroad. For example, Ben, a I9-year-old male from Haflong, a town in the Cachar Hills district of Assam, worked as a concierge in one of the malls. He came to Delhi at age i7 to find work. After two years in Delhi he had recently got his job at the mall after working in a restaurant kitchen. His main duty was to give directions to consumers and to tell people not to take photographs in the mall. He found the job boring but liked working inside the enclosed space away from the dust, the cold winter, and the hot summer. He wants to go back home but he is not sure what he would do there, so for now he stays in Delhi though he doesn't make enough money to send home. In a global chain restaurant in a new shopping mall I met Chon, a woman from the Naga areas of Manipur working as wait staff. She had come to Delhi at age I8 to work and send money back to her family. She had got the job through her flatmate, also from Manipur, and she had since secured jobs for other friends. She found the work good but as the restaurant closed after midnight she didn't like leaving alone late at night. She misses Manipur but feels she is better off than she would be at home.

Many respondents had experience working in other locations before getting their job at the malls. For some of these respondents working in these malls was better than their previous jobs; they were paid more, it was clean and quiet, they were shielded from harassment and violence, and several respondents were proud to work in such a fancy place. A 
few respondents mentioned that the clientele in the malls was easier to deal with than in other shops and restaurants they had worked in previously. Others seemed conscious of their disproportionate representation in malls as opposed to any other area of life in Delhi. However, the most critical views of mall labour came from Northeast migrants who were not working in malls but who witnessed the phenomenon through friends, relatives, and neighbours. Achi, a Naga woman from Manipur resident in Delhi for over ten years, said that Northeasterners have come to be servants of the 'wealthy and sophisticated'. She said this is creating aspirations among them that life back home can't fulfil. Zana argued that Northeasterners work in these malls but can't afford to shop there, so they are becoming viewed by the Indian mainstream as a race of shop assistants and waiters. This makes it easier for them to get work in these types of jobs but harder for them to be taken seriously in other professions or in their studies.

\section{The Services Sector}

A major part of Delhi's transformation has been the shift from manufacturing and heavy industry to the services sector. In response to pressure to 'clean up' the city in the I980s and I990s, coming from what Baviskar (2003) refers to as the diffusion of 'bourgeois environmentalism' among the middle and upper classes, the Supreme Court pushed for the relocation of polluting industries outside residential areas (Rosencranz \& Jackson 2003). This was followed by the pursuit of foreign investment in the services sector, and the powerful DDA has worked to appropriate land and make it available to developers courting foreign capital. As Dupont demonstrates, Delhi ranked first in cumulative foreign direct investment flows in India from 2000 to 2005 (2011: 540-I). Investment has benefitted the services sector, especially in the special economic zones. Delhi and the National Capital Territory area has had 72 such zones approved since 2005 and these are concentrated in Gurgaon and Noida, satellite cities that have stretched the reach of the Delhi government into neighbouring states (Dupont 20II: 54I). Call centres have been set up in these zones and in other redeveloped parts of the city. Gurgaon and Noida are home to Delhi's call centres mostly serving global corporations (Taylor \& Bain 2005). Call centres depend upon access to a relatively low-cost labour force and one that is welleducated and fluent in English. This has served the interests of urban upper-caste workers, but as yet there has been no analysis of the explosion of Northeast labour in call centres, especially in Delhi (Upadaya 2OII).

Northeast labour is in high demand in these call centres. Unlike shopping malls that desire a visual orientalism, call centre employers 
desire the non-Indian accented English spoken by most Northeasterners, especially those from the hill states. Literature on call centres in India has identified the various tactics adopted to hide the accents and personalities of the labour force (Taylor \& Bain 2005: 278). Research in Delhi call centres serving North American voice-to-voice clients shows that workers in call centres are trained to 'neutralise' their accents (Mirchandani 2004). Additionally, call monitoring, scripting, and 'locational masking', as in hiding the fact that the call centre worker is located in India, are all crucial components of call centre work.

Most Northeasterners from the hill states and hill areas attend English medium schooling, and literacy rates in hill areas are very high (Government of India 2002). English is also the lingua franca spoken between different ethnic groups. Some may speak Hindi but usually after English, as they attend school in the English medium and consume English language films and television. ${ }^{5}$ Hindi is banned in Manipur as a result of ethno-nationalist campaigns to restore the Meitei language and resist Indian domination. With limited engagement with the Indian mainstream, most Northeasterners do not have a typical Indian accent in English. In addition, most Northeast migrants in Delhi are unmarried and in their 2os. Most do not have children or have left their children with relatives back home. This makes them able to work shifts timed to serve Australian, European, and North American business hours. As such, Northeasterners have become desirable as a 'flexible' and well-qualified workforce for the burgeoning call centre industry.

As familiarity with the industry has grown, Northeasterners have begun migrating to Delhi solely to work in call centres. As mentioned in the previous chapter, call centre recruitment agencies travel to the Northeast recruiting high school and college graduates. Job advertisements are plastered all over Northeast neighbourhoods in Delhi. During conversations with Northeast call centre workers it became clear that migrants with experience of the industry act as conduits for new arrivals. There is no sense that there is any financial gain in this, rather this is a function of community support among migrants. Salaries in call centres are undisclosed, and if an employee discusses their salary with other employees they can be fired. Most salaries are determined at interviews with recruitment agencies in the Northeast and in Delhi. In a conversation with two respondents from Nagaland, Stephen and Zana, both of whom had worked for several years in call centres, discussed how they trained their friends for these interviews so they could have a larger starting salary. Call centres also try to poach workers from

5 The exceptions are Assam and Arunachal Pradesh, where Hindi proficiency is much higher than in the other hill states. 
one call centre to another by offering higher salaries. Wary of this, experienced migrants encouraged friends to overstate their salary slightly and baulk at offers to move until those targeting them increased their offer. Sometimes they would mention this offer to their current employers and ask for a pay rise to stay put. As Zana noted, 'it's survival of the fittest in the call centre.'

For many Northeast migrants the call centre industry offers livelihood opportunities that can't be found at home. Finding work is relatively easy, and migrants who come to Delhi for other reasons often find themselves working in call centres when their initial plans don't work out. I met respondents who had taken full-time work in call centres after dropping out of university. Others were trying to get a job after university to tide them over until they could break into their preferred field. Others had gone back home and found it difficult to adjust and had come back to Delhi with no real plan and eventually took up work in the call centres. Others stayed working in call centres to avoid having to go home, especially to areas of conflict.

Call centres have been particularly resistant to unions (Norohna \& D'Cruz 2006). Respondents rarely mentioned unions. Those that had problems in their workplace left and found work somewhere else or put up with the conditions. Most Northeasterners depend upon support networks with their own tribal and ethnic groups or the church, and labour organising means joining networks with Indians with whom there is limited trust. Similarly, workers' unions back in the Northeast are far less powerful than ethno-nationalist organisations, student organisations, and insurgent groups. In the context of high unemployment and low wages back home, introspection on working conditions is less pertinent. This plays into the hands of employers who have a growing stream of well-qualified 'flexible' employees who are well qualified, unorganised, and far from home.

\section{Education City}

For Northeast migrants, Delhi has been an education city for far longer than it has been a place to work. In the past, access to education in Delhi was restricted to a small number of migrants. In recent years the growing demand for Northeast labour has made it easier for migrants from different backgrounds to afford education in Delhi. The availability of work means many more can stay afloat in Delhi and undertake study, or as is increasingly common, undertake work so their siblings can study. Respondents gave a number of reasons for coming to Delhi to study. From these I have identified three main themes: job prospects, poor education options back home, and prestige. 
Job prospects

For most respondents, studying in Delhi gave them the best chance of a job. For many, this meant a good job back home. Nani, a postgraduate student from Arunachal Pradesh, completed her undergraduate degree in Delhi and had just completed a Masters of Sociology when we met in early 20II. She said her sole reason for coming to Delhi was that it had the best universities. Now that she had finished her Master's degree, she was ready to go back. She wants a government job because she feels a responsibility to give something back to society. She added, 'my state is still very undeveloped and very backward. So I feel a duty to go back.' She said that too many smart people from the Northeast don't go back or they go home and don't stay, so she is determined to stay in Arunachal. For others, Delhi was a springboard for jobs in Delhi itself or in other cities as discussed earlier in the chapter. Given the low amount of private investment in the region, the lure of the private sector is limited when compared to the lure of the IAS (see McDuie-Ra 2oogb).

Some respondents came to Delhi to study but dropped out and went home. Some came to study but dropped out and stayed in Delhi. Some dropped out of university but later enrolled in a private college or technical school. Others started working and stopped studying because either they could not balance the two or they preferred working. Alternatively, some began working until they could save enough money to keep them afloat while studying. Others completed their study and remained behind in Delhi to work or to avoid going home, while some started studying and working but switched to full-time work when circumstances back home changed.

Conversations with Northeast migrants about dropping out of their studies were reflective of the challenges of life back home. Mary, a woman in her 20 s from Manipur, had to stop studying because the army had detained her brother. He had been earning an income back home and sending money to pay for her college fees. When he was detained, the money stopped. She wanted to return home but her mother insisted she stay in Delhi, as she was afraid for Mary's safety. So she found a job in a restaurant and was able to stay. Other reasons were more reflective of the ways kin and clan networks take precedent in decision-making. For Bhoi, a Khasi from Meghalaya working in a call centre, the arrival of two siblings and a cousin from back home meant he had to stop studying and work full-time to support them until they could find work and support themselves. This was not an imposition for him because he knew when one or two of them found work he could go back to study. 
Delhi is the site where the tools of the Indian state can be learned; tools that can be used to acquire the highly valued IAS posts back in the Northeast. The Sixth Schedule of the Indian Constitution ensures reserved places in parliament, government employment, and educational institutions for tribals. In the tribal majority states (Arunachal Pradesh, Meghalaya, Mizoram, Nagaland) and the tribal majority autonomous regions within the other states, this has indigenised the bureaucracy at the state government level and below (though not at the central government level). While not under the Sixth Schedule, state laws in Manipur and in Sikkim ensure the bureaucracy is staffed by locals. In response to this, the education sector in Delhi has expanded and specialist colleges and tuition schools have proliferated in response to the growing numbers of migrants heading to the city. Private IAS coaching 'schools' have mushroomed all over the city but are concentrated in areas where students live; described by one respondent as 'IAS hotspots'. As the IAS has a number of exams, interview hopefuls undertake seemingly endless preparation classes. Among Northeasterners, tribals included in the Sixth Schedule of the Constitution have unlimited chances in the IAS exam until they are 38 years old. Non-tribals have only four chances until the age of 35 .

Some respondents came from the Northeast especially for these tuition schools, while others attended IAS tuition while studying at university for a few months after completion. In the Northeast migrant neighbourhood near G.T.B Nagar metro station, I met with two friends from Nagaland who had arrived in Delhi three months earlier. They had graduated from university in Nagaland and were in Delhi for the first time. Mhon was in Delhi to attend IAS coaching and Imchen to study his Masters in Political Science at Delhi University and then take IAS coaching.

We met on the main road and then walked through narrow alleyways of adjacent apartment buildings until we reached their building and made our way to the top floor. We passed the open doors of the apartments below and saw other Northeasterners sitting on the floor or on beds reading or chatting with friends. Mhon and Imchen's room was small. It had two beds, a desk, and a rope tied from one end to another where their clothes were hanging. There was a shared basin and toilet on the landing outside. They had a small portable electric stove-top that they used to cook. One section of their wall was missing and had been replaced with cardboard by the landlord, making the room freezing in the Delhi winter. On the wall there were some motivational messages hand-written on paper, printed copies of psalms, photos of family, a football poster, and a coaching timetable.

We sat on the bed and they started to talk about Delhi. Mhon said he was very worried about his safety on the streets. He doesn't speak 
Hindi well and the peddlers and shop owners are always trying to cheat him. He also knows Delhi is violent so he doesn't want to go too far at night. Imchen said they prefer to stay inside and cook Naga food. All their neighbours are Naga or Mizo so they hang out together. There is not much to do because they don't have a lot of money to spend going out. Sometimes they go to watch football in one of the apartments with a TV. Otherwise they just study.

Mhon didn't want to stay in Delhi but he had to pass the IAS exam. He is an only child and he needs to get a good job back home. His parents really want him to become an IAS officer and were paying a lot of money for him to come to Delhi. Mhon's tuition fees at the coaching school were above 80,000 rupees for the semester (I,800 USD), but they could be as high as I00,000 in other tuition schools. To put this in perspective, undergraduate tuition fees at Delhi University are around a quarter of this amount. Imchen added that government jobs are the best thing to have if you want to stay home in Nagaland. He said Indians wanted to study for an MBA (Masters of Business Administration), whereas Northeasterners want to do the IAS exams. There was no future in private sector jobs in Nagaland. There are usually two main reasons given by respondents for this. The first is lack of investment due to distance, instability, insurgency, and extortion. The second was that outsiders from the heartlands dominated the private sector jobs that did exist back home and they usually employed their own kind. From the landing outside their room, Mhon gestured towards the equally shabby apartment blocks surrounding their building on all sides and said 'all of these are full of tribals studying for the IAS.'

However, some respondents feared that the jobs they wanted back home might not materialise. Respondents who had been in Delhi for a few years or more had come to realise that study in Delhi might not be enough to prosper back home without connections. They had seen others return and not get the kinds of jobs they wanted. They had also seen less qualified people get jobs through personal connections, corruption, and all manner of shady relationships that exist in militarised societies. Some were preparing for this by taking courses that led them away from the IAS path.

\section{Education back home}

The poor standard of education back home was a compelling reason for migration. This was particularly common among respondents from Manipur, where ethnic conflict, anti-government insurgency, and a deeply corrupt and predatory bureaucracy have left the education system all but defunct. Schools and colleges can be closed for months at a 
time under pressure from insurgent groups, strikes by employees, and blockades. The Government of Manipur regularly blames insurgent groups for these disruptions, but respondents from Manipur pointed to large-scale corruption. During fieldwork I travelled back to the Northeast to meet with men and women who had returned from Delhi. In Imphal, the capital of Manipur, Ruth, a friend and social activist, described the ways that government jobs are allocated. She gave the example of schoolteachers. To get the job, the candidate would have to pay a large bribe to outbid other candidates, perhaps up to 3 lakh $(300,000$ rupees or $6,800 \mathrm{USD})$. Once they have secured the job, they have to find ways to make money to offset the bribe, especially if they borrowed money. To do so, they might directly appropriate funds from the school or the students in return for high grades. In other cases they will simply not turn up for their job but continue to draw their salary and earn money in another job at the same time, including working as a private tutor. Sometimes they will pay another person a portion of their salary to teach their classes while they work elsewhere, regardless of their qualifications. As a consequence, education is largely privatised to individual tutors - some of whom are teachers making money on the side and coaching schools. Thus parents do everything they can to send their children outside the state for schooling.

A further factor is the lack, or perceived lack, of tertiary education options in the Northeast. With changing aspirations and limited options, migration to Delhi is ever more attractive. The quality of primary education is renowned, though uneven especially in rural areas, and owes its success to the long-standing missionary education system. Most of the hill states have very high literacy levels and regularly rank at the top or near the top in all of India (Government of India 2002: I86). Christian colleges function throughout the region and provide a valuable source of tertiary education. The problem comes with a shortage of college, university, and technical institutions where students can get the qualifications they need to secure IAS positions.

The Indian Government has tried to address this in different ways. The first university specifically intended for ethnic minorities from the hill areas was set up in I973 in Shillong, Meghalaya. The North Eastern Hill University (NEHU) continues to draw students from all over the Northeast. Shillong also contains a number of theological, technical and private colleges that cater to students from all over the Northeast and especially from Meghalaya and Assam. However there is a growing sentiment that the popularity of Shillong as an education destination is declining as migration to Delhi and other cities has increased. This may be a response to changing socio-political circumstances in Shillong, particularly more aggressive ethno-nationalist politics (see Karlsson 20II; Malngiang 2002; McDuie-Ra 2009a), and it may also be a response to 
rising education and career aspirations among Northeast youth and their families and to increased competition for jobs. Through a series of acts passed in the 2000s the Indian Government has created new central government universities (often from former state universities), meaning they can access more funds and the faculty is professionalised. Thus there are now central government universities in all eight Northeast states: Assam and Manipur have two each, and more are being proposed. This may have some impact on arresting the brain drain, though this remains to be seen. At the very least, it increases tertiary education opportunities by opening up more places for those staying in the region and should, in theory, increase the quality of facilities and faculty at these universities. However, many of them are in bad shape and the boost provided by central government funds has yet to make any noticeable impact.

\section{Prestige}

Travelling within the Northeast for education, while considered safer and closer to home, is less prestigious than travelling to other parts of India. Shillong is still popular, the student body at NEHU remains diverse, and it still has gravitas as the hill university for the Northeast. But there is the growing feeling that those students who can bypass Shillong and head to other parts of India should do so. With the opportunity to work in Delhi to support study, this is becoming easier. However, as will be shown in the following chapter, racism, discrimination, and violence may cause some Northeasterners to re-consider education within the Northeast. This came up from time to time among respondents who posited that if the tertiary options were better, they would stay closer to home. Until this leads to an actual change, the brain drain from the region seems set to continue. Once only the very best students left the Northeast through scholarships to the top universities and colleges in Delhi. Now as the demographics of migrants are shifting, there is the perception that tertiary institutions back in the Northeast are being 'hollowed out'. This has a flow-on effect and reinforces the idea that migration out of the region is the best way to enhance career prospects. There is also a sense of intergenerational change. Many Northeasterners, especially those from upper middleclass and elite backgrounds, want to move beyond the experiences of their parents. Several respondents in Delhi noted that their parents and sometimes grandparents studied in Shillong and they wanted to make their own mark farther afield. 


\section{Brain Drain}

It is not just tertiary institutions that are experiencing a 'hollowing out' as migration out of the Northeast increases. There is a broader anxiety in the Northeast and among migrants over the brain drain from the frontier. As migration out of the Northeast increases, the region is losing its best and brightest people - impacting educational institutions, labour markets, and investment back home. Though some do return, there is a great deal of concern that the drain brain is seriously affecting the region's human and social capital.

A sense of this anxiety within the Northeast can be gleaned from MoDONER's flagship North East Vision 2020 policy document released in 2008 (MoDONER 2008a, 2008b, 2008c). The document provides the blueprint for addressing poverty and insurgency in the Northeast by attracting investment, creating employment, and opening the Northeast to surrounding countries. Elsewhere I have discussed the counterinsurgency mindset underpinning development planning in the region and Vision 2020 in particular (McDuie-Ra 2008; 2009c). However, the document is also instructive in revealing how policymakers view the region, what they consider to be the region's problems, what is prioritised, and what they ignore. The near 6oo-page document is replete with references to creating employment and building economic capacity in the region but contains virtually no mention of the impacts of out-migration on human capital. In fact, the only instances where the negative impacts of out-migration are mentioned are in comments on Vision 2020 from public consultations tabled in the appendix. During the planning process, community consultation sessions were held throughout the Northeast region and despite the limitations of these sessions emanating from the ways the public sphere is imagined and created in Northeast states (McDuie-Ra 2009c: 325), they do offer some insight into public debate at the local level. A telling comment was tabled from consultations in Guwahati, the largest city in the Northeast and the commercial centre of Assam. The comment (not attributed to an individual) reads:

... some 40,000 students from the Northeast go to universities outside the region every year and most do not return. This brain drain must be reversed. Applied learning is needed through new courses. But the sanctioning of new courses or curricula takes up to I 8 months. Good teachers are needed too, especially in the rural areas, but salaries are poor. More Central Universities are welcome but existing state universities should not be allowed to languish. They require more funding. Education must be linked to employment and industry but there are few industries in the Region. (MoDONER 2008c: 258) 
While ignored at the national level, state governments in the Northeast have recognised the impacts of the brain drain. In Meghalaya, the state government has released a new policy document entitled IT Vision 2020 (20I0), which plans to create infrastructure to make Shillong attractive to the call centre industry and keep local labour in the state and in the Northeast region. The document states:

Call centres all over India have a good percentage of employees who are from north east [sic]. Over the last few years Meghalaya has been loosing [sic] good educated youth to other Indian states. Due to lack of job opportunity [sic] in private or public sector in Meghalaya the youth of the state go out of Meghalaya for their livelihood. With more and more demand being created in other cities of India, more and more educated youths are leaving Meghalaya. (2010: 6)

The government of Nagaland commissioned a Music Taskforce in 2004 to investigate ways to establish a viable music industry in Nagaland that will capture the immense musical talent in the state. The task force has been successful and has been relocated into the Department of Youth Resources and Sports. Government money has been used for music training programmes and recording studios. Parts of the programme have been combined with anti-narcotics and peace initiates. For musicians in the region, success is still judged on recognition elsewhere both within and outside India, particularly in Delhi and Mumbai. However, recently the draw of the music industry has brought Nagas back to Nagaland to set up nightclubs, music cafes, and to teach music (Ekin 20II). The government of Sikkim has drawn the pharmaceutical industry to the state to boost skilled local employment, but opposition to the industry has developed because many feel that locals are not benefitting from the jobs on offer. The protests during 2010 and $201 \mathrm{I}$ are interesting because they are directed at the private sector for failing to protect local employment - something the state governments are constitutionally bound to do. This indicates other factors that shape trust between locals and the different employment providers. Trust in the private sector, which is often associated with outsiders, is low, while trust in the indigenised public sector is high.

For the state governments in the Northeast, development orthodoxy has shifted from dependence on central government funds to attracting investment (McDuie-Ra 2009c). Admitting that there is an outflow of skilled people jeopardises that agenda and perhaps explains the lack of overt recognition of the brain drain. Further, the continued outflow of migrants places little onus on state governments in the Northeast to provide employment, a situation that likely suits many beleaguered state 
governments coping with multiple challenges. Money earned in other parts of India and sent back to families as remittances also offsets the employment challenges to a degree. In this way, federal states in the Northeast are beginning to resemble other remittance-dependent political units, whether nation-states or subnational regions, and the onus to dramatically alter education and employment provision may be reduced as the dependency grows. For Northeast states there is a dual dependency, namely dependence on the central government for between 6o-85 per cent of state budgets (MoDONER 2008c: I69) and dependence on migration to provide employment and support families. While perhaps an unavoidable outcome of the realities of frontier existence, the longterm viability of this dual dependency is questionable. Few North-east migrants hold stable jobs in Delhi or elsewhere in India. Should a decline in investment in call centres, a downturn in mid- to high-end retail, or further problems in the private airline industry close the employment opportunities in Indian cities, it will be very difficult for Northeast states to absorb returning migrants back into local economies. Considering the relationships between unemployment, underemployment, and the continued presence of non-tribal /non-indigenous labour in the Northeast on the one hand and insurgency and ethnonationalism on the other, the impacts of such a downturn would aggravate the already unstable reality of life in the region.

Respondents in Delhi would refer to the brain drain when discussing their own situation. Many respondents regretted coming to Delhi and leaving home but saw few alternatives. Respondents more involved in political activism often mentioned that the labour exchange was uneven. The Northeast loses intelligent and skilled people indigenous to the region, only to be replaced by unskilled labour migrants, central government bureaucrats, and soldiers. As one respondent from Mizoram noted, 'we give them [India] our best and they give us their worst in return.'

Stephen, a call centre worker from Nagaland, was angry that many Nagas could not get work at home but that many non-tribals could. He made the point that Nagas earn all this money in Delhi but they also spend it in Delhi so nothing ever goes back home. Adi, a working student from Arunachal Pradesh felt that the Northeast was purposefully underdeveloped by the central government and this meant that tribals, the most well-educated people in the country, flowed into India's cities to do 'nothing work'. Monpa, a post-graduate student from Arunachal Pradesh, said that many people leave Arunachal Pradesh but many go back better qualified and more experienced, which ultimately benefits the community. She noted that this is uneven, as returning to largely peaceful Arunachal Pradesh is easier than returning to states where there is conflict. 
Respondents in the Northeast who had returned from Delhi and elsewhere tended to be more circumspect. From meeting the families of migrants in Assam, Manipur, Meghalaya, Mizoram, and Nagaland, it is clear that migration is neither celebrated nor maligned. Most see it as necessary given the circumstances at home. Many wished it wasn't the case, but families back home are nonetheless proud of their children and neighbours. Some even related it to their own family migration narratives from more distant villages or across international borders. As one respondent from Meghalaya put it, 'we tribals are always on the move. Now we just go further.' 


\section{Backward, Head-hunter, Sexy, Chinky}

Racism defines the Northeast migrant experience of Delhi. For those unfamiliar with the Northeast region, this may seem a moot point. India is made up of diverse peoples from different ethnic lineages, so what makes migrants from the Northeast unique? Different groups in India experience prejudice and discrimination when they migrate and, for more marginal groups, even in their home locations, so why are migrants from the Northeast any different? The answer is race. Northeast migrants are seen as racially different from the Indian mainstream. India contains many communities earmarked as 'others' based on religion, caste, and even ethnicity, yet the nationality and origin of these communities are not questioned at every turn. They can 'blend in' to the heartland in ways that Northeast migrants cannot. This is not to argue that these 'others' do not face discrimination and violence; rather, the experiences of Northeast migrants are distinct and reveal different elements of contemporary Indian society as the distance between frontier and heartlands shrink.

For Northeast migrants, physical appearance is central in interactions with members of other communities and with other Northeasterners. Physical features denoting Tai, Tibeto-Burman, and Mon-Khmer lineages mark Northeasterners as separate from the Indian mainstream, even when accounting for the diversity of that mainstream. In fact, these features routinely lead to questioning of nationality and citizenship. Race is not isolated from the social fields in which individuals and groups exist (Wimmer 2008). Through their physical appearance, Northeast migrants are not simply viewed as others, but their otherness is also associated with the ways the Northeast frontier is understood and misunderstood socially and politically in the Indian mainstream. Importantly, many Northeasterners do not contest their difference from the Indian mainstream. Yet firm ethnic and even separatist identities do not supplant the realities of racism experienced by migrants throughout their time in Delhi and other heartland cities. In the course of a single journey across Delhi in a bus, a Northeast migrant may be judged as immoral and sexually promiscuous, a backward subject from the misty jungle, an anti-national rebel, a Chinese national, and a privileged elite benefitting from government reservations. Appearances 
invoke stereotypes about Northeasterners. Stereotypes engender prejudices. These prejudices result in discrimination, harassment, and violence. In this chapter I focus on the experiences of racism for Northeast migrants in Delhi, how they respond, and what this says about race in contemporary India.

In this book I use the concept of race when discussing relations between Northeast migrants and the Indian mainstream. In contemporary scholarship, ethnicity is used far more commonly than race, especially in Asian Studies. Race is usually used when differentiating between distant groups of people - Europeans and Asians, for example - whereas ethnicity is used to make more localised distinctions such as Malays and Chinese. Michael Banton (forthcoming) argues that race has been used to denote both differences among humans (horizontal) and within these groups (vertical), but it is the horizontal usage that has come to dominate, especially since the $\mathrm{I}^{\text {th }}{ }^{\text {ch }}$ century. Many scholars are uncomfortable using a concept that evokes essentialist and determinist understandings of human societies. Even more troubling are the ways race have been used to classify peoples into categories that were then used to oppress and dominate these same peoples (Jahoda I999). Ethnicity focuses less on externally defined attributes of groups and more on attributes defined by the group itself. Thus ethnicity is seen as a far more empowering concept than race.

If this is the case why use race? The answer is twofold. First, 'race' captures the distinction made by Northeasterners themselves to denote their difference from other peoples in India and it captures the ways migrants from the Northeast are differentiated by the Indian mainstream. Racial differences denote peripheral peoples, and this is the primary way migrants are seen and the primary determinant of how they are treated. However, treatment of frontier peoples is not characterised solely by exclusion, as will be seen below. More complex ethnic identities that characterise life in the region become less salient in Delhi, primarily because Northeast migrants are lumped into a singular category because of their distinctive appearance. The production of this category also works in favour of building solidarity among Northeasterners, even across rifts considered irreparable back home. This in turn engenders a reverse racism towards the Indian mainstream, as will be discussed below. Second, a concept of race is needed to analyse pervasive racism. As Thomas Hylland Eriksen argues, one need not have to believe in the 'objective existence' of race to be able to study the social, political, and cultural relevance of 'the notion of race' (2002: 5). In other words, one can focus on the social construction of race without accepting the central tenets of that construction. For Northeast migrants, race defines their experiences of Delhi. No respondent ever qualified this. It was an unequivocal feeling. The characteristics of the Northeast category, most 
often expressed through the derogatory term 'chinky', are not defined by Northeasterners themselves. This is different to life in the Northeast itself, where groups have at least a modicum of control over articulating their own ethnic identities.

Northeast migrants have distinctive physical features, and these features separate them from the rest of the Indian ethnic and cultural milieu in a lasting and profound way. To put it simply, Northeasterners look different from the other peoples of India. They are not viewed as yet another ethnic group in the vast Indian milieu sharing legitimacy with Punjabis, Tamils, or Bengalis; they are an exceptional population. As such, they are subject to different perceptions and treatment than other groups. This makes it 'difficult for them to escape from their ethnic identity if they wish to' (Eriksen 2002: 6). Put simply, Northeast migrants are viewed as people of another race when in Delhi. They are not viewed as a complex and diverse set of ethnic and tribal communities. Even if this exception is not expressed by all other groups all of the time, the feeling of exception is experienced with such frequency and poignancy by migrants that it defines and orchestrates their interactions with the city and its inhabitants; even for those who have been in Delhi for a decade or more.

\section{The Racialised Frontier}

For the overwhelming majority of Northeast migrants, racism in Delhi is reflected in the epithet 'chinky'. Other groups are subject to this derogatory: Bhutanese nationals, Burmese refugees and migrants, Chinese nationals, Ladhakis, Nepalis from certain ethnic groups (Limbus, Magyars, and Rais), and Tibetans. All of these groups inhabit Delhi. They share some of the same places of work, education, and neighbourhoods as Northeast migrants, but for the most part they occupy different niches in the city. They can also be subject to different nuances in the stereotypes to which they are subject. As will be discussed further below, many Northeasterners object to being identified as members of some of these groups. In turn, some members of these groups see advantages in being mistaken for Northeasterners, especially those with a dubious status in India. In an interesting take on this issue, the Manipuri writer Sunita Akoijam (20II) talks about moving from Delhi to Kathmandu, the capital of Nepal. In Kathmandu, Sunita is continually mistaken for a Nepali owning to her features, and this engenders a sense of belonging she never felt in Delhi, where her citizenship was doubted and she was mistaken for 'Chinese, Nepali, Japanese ... I was offered a long list of citizenships from the Mongoloid-looking world' (20II: 57). She writes, 'Of Delhi, I remember my earlier years fighting a 
bitter battle against exclusion from India. Of Kathmandu, I recollect the sweet amusement of fighting off attempts at inclusion into Nepal' (2011: 57). This sense of belonging comes despite being born over a thousand kilometres away from Nepal in Manipur.

Returning to 'chinky', it is not simply the epithet itself but the stereotyping that accompanies the epithet that angers migrants. During fieldwork I spent months walking, commuting, eating, shopping, loitering, and living with Northeast migrants in Delhi. Virtually every time we were outside Northeast neighbourhoods, migrants would hear 'chinky'. Whether part of a sentence in English, Hindi, or a vernacular tongue, the word 'chinky' itself was usually always the same and always distinguishable for ears used to hearing it. As one respondent from Manipur put it, 'it is like they have spotted a rare animal in the national park.'

At first it seemed that the epithet was only spoken on the streets, usually by groups of young men egging each other on. For example, when walking with two friends from Arunachal Pradesh, a group of adolescents sitting at a bus stop called out: 'Chinky! Hey China!' This was followed by uproarious laughter. On another occasion I was walking with a female friend from Meghalaya on a residential street, and a middle-aged man whispered to my friend 'chinky' in passing, followed by an obscenity in Hindi. Perhaps this was because she was walking with a foreign male or perhaps not. Plenty of Northeast women (and men) hear the term without a foreigner around.

As my fieldwork continued and through conversations with Northeast migrants from different ages, backgrounds, and purposes in Delhi, the variety of contexts in which Northeast migrants hear the epithet became more clear. Respondents reported hearing the term in direct conversation from classmates, landlords, etc. For example, one respondent said her employer asked her: 'Listen chinky, can you work a shift on Sunday?' At other times it was spoken by customers patronising places where Northeasterners worked. On one occasion, in a restaurant at a high-end shopping mall, two women commented in English on the make-up being worn by the two 'chinky girls' waiting on their table. The term was also spoken in a paternalistic manner. This infuriated respondents. Mina, a postgraduate student from Sikkim was told by her supervisor to 'cheer up chinky' when she was upset about losing data.

Importantly, 'chinky' is not used by Northeasterners to refer to themselves or each other. In other words, they have not claimed ownership of the epithet. Most respondents found the term to be deeply racist and reflective of ignorance and hostility. Chen, a student from Arunachal Pradesh, said that the term made him angry every time he heard it. For Chen, virtually every group went by at least one colloquial name but 
they didn't face the same treatment as Northeasterners. He gave the example of Bengali speakers living in Delhi:

People say "Bong” to mean Bengalis. But the Bengalis also use it themselves. And no one runs across the street just to say it to their faces like they do to us. They don't say it and then start laughing. Even if someone wanted to say it to their face they can't tell if someone is a Bengali by looking. With us you can. So as soon as someone sees us, they say "chinky". And at least "Bong" refers to the right people. They call us "chinky" because they think we are Chinese.

If a Northeast migrant bumps into someone in a crowd, refuses to pay an inflated price for something in the market, makes too much noise in their flat, or complains about being cut off in a queue, then they will hear the epithet. As Adi, a student from Arunachal Pradesh put it:

If we do one thing wrong, we will hear "chinky", "stupid chinky", "go home ching-chong", like that. No one else gets treated like that. But what can I do? If there are lots of them and only one of me, I can't fight, I can't argue. So sometimes even when someone does the wrong thing by me, I just keep quiet.

Some respondents felt that non-Northeasterners didn't understand that it was offensive. Nani, a woman from Arunachal Pradesh who has been living in Delhi for seven years, related a story about an Indian friend from university who used 'chinky' all the time to refer to her and other Northeast friends. Eventually Nani told her friend that she shouldn't say 'chinky' and her friend stopped using it. Nani commented, 'if no one told her not to use it, she wouldn't have known and kept saying it forever'.

Epithets matter because they reflect deeply embedded stereotypes about Northeast women and men. These stereotypes have an impact on the ways Northeast migrants experience Delhi and heartland India more broadly. Stereotyping of Northeasterners is layered. By this I mean that the stereotypes Northeasterners are subject to have multiple layers, multiple effects, and multiple origins. Stereotypes are not always negative and have enabled the growth of the labour niche for Northeasterners, yet Northeast women and men have very little control over the ways they are perceived, whether the impacts of these perceptions are positive or negative. I will focus on four main stereotypes that recurred most commonly during fieldwork: backward and exotic, antinational, anti-assimilationist, and loose and immoral. 


\section{Backward and exotic}

In contemporary India, Northeasterners are represented as exotic peoples in tourism campaigns and travel media, museums, and in geographic and ethnographic depictions of 'peoples of India' in schoolbooks, parades, fairs, and other events. This is particularly true for tribal communities. With limited direct contact, most people outside the Northeast receive their knowledge of the region and its peoples through these mediums. Museums throughout India have sections on tribals and other Northeast peoples. Museums are places where children and adults come for outings with their families, on school fieldtrips, and to pass their spare time. At the National Museum in Kolkata, there is a separate section on human anthropology in a wing separated from the archaeological displays depicting great Indian civilisations. The long room has glass cabinets on either side with life-sized dioramas of tribal groups from the Northeast in their villages. Each of the major tribal groups has a cabinet. The backgrounds are painted with forest or mountain views, depending on the ethnic group being depicted, suggesting an intimate connection to nature. Dolly Kikon describes the exhibit in the following way: 'All the models, slightly yellowish in colour, look alike with the epicanthic fold of the eyes but are juxtaposed in a manner that would be typical of a child dressing a doll in a dollhouse' (2009b: 92). The displays are not historicised like other groups in India; for tribals, their past is the same as their present.

Images of tribals and other ethnic groups in tourism campaigns both construct and reflect dominant ways of seeing Northeast peoples. The portrayal of the Northeast for the tourism market reflects the three 'un' myths discussed by Etchner and Prasad (2003) in their analysis of the ways Third World destinations are represented to foreigners: 'unchanged', 'unrestrained', and 'uncivilised'. Interestingly, in the case of the Northeast, these 'un' myths not only cater to foreign tourists but to the enormous domestic tourism market. The recent Incredible India campaign run by the Ministry of Tourism in international and domestic markets is instructive. One of the Incredible India television advertisements aired in India from 2009 to $201 \mathrm{I}$ depicts a Western male travelling through India experiencing all of its diversity and richness. In Mizoram, he takes part in the Cheraw, a dance featuring bamboo poles that men hold and tap together while women step in between. He also pilots bamboo rafts down a river in Nagaland with a group of men in tribal costume, their half-naked bodies and headdresses prominent as they navigate a landscape devoid of buildings, electricity poles, and roads.

Similar representations of Northeast people are displayed at Republic Day parades, held each year on 26 January and telecast across the 
country. At the parade, each state has a float and the floats representing the Northeast states usually have members of the main ethnic group in traditional costume dancing on top of an agricultural product. In an interesting twist, at the opening ceremony of the Commonwealth Games held in Delhi in 2010, the woman holding the placard reading 'India' leading the Indian team around the stadium was wearing traditional Mizo dress, the puanchei. The costume designer remarked that the original idea was to have the placard holder wearing a saree but then decided that it would not be distinctive enough and thus opted for the Mizo outfit (Times of India, 6/10/2010). However, the woman wearing the outfit was not Mizo, she was north Indian. While some Mizos were proud to see their national dress at the forefront of India's big moment, during fieldwork a number of Mizos commented that the organisers were happy to have their clothes represent India but not their 'chinky' faces.

To be fair, many other states and peoples within India are represented by emphasising dances, traditions, and distinctive cultural traits. However, most other communities are also represented in other ways, whereas tribals are not. Museums, advertisements, and national parades illustrate the broader social field within which Northeast migrants interact with other communities. During fieldwork this was evident in a number of interactions between Northeasterners and other urban residents during which Northeasterners were studied as if they were in a glass case in the National Museum. One Sunday afternoon I was meeting two women from Arunachal Pradesh, Nani and Monpa. We met in the north of Delhi, close to the Delhi University campus in a workingclass housing area where they stayed. We decided to sit in a nearby park. Periodically during our conversation, groups of people would come and stand very close, staring at Nani and Monpa. After a few minutes they would move on and others would come and stand for a while. For a time I thought they were staring at me, but my friends assured me that this happened to them often. I asked if this bothered them. Monpa remarked that when she first arrived she found it very uncomfortable, but now she is used to it. She believes that most of the people who stare at her are from 'villages in UP (Uttar Pradesh) or Bihar or somewhere' and they have never seen anyone who looks like her in their lives. For Monpa and other migrants, this is a spectacle that must be endured, a regular reminder of life as an exotic specimen.

\section{Anti-national}

Reporting on violence and 'terrorism' in the Northeast is one of the only other times that the region and its people are mentioned in the media. Here, the backward and exotic 'chinky' meets the violent anti- 
national separatist bent on destroying India. Daisy Hasan has studied the ways that the Northeast and its peoples are presented in the Indian media and the ways Indian media and film are received in the Northeast (2004, 2009, 2010). She argues that the Northeast has received increased attention when the focus is on 'terror' but is otherwise barely represented, as it is seen as politically and culturally insignificant. Labelling the different armed groups fighting the Indian state as 'terrorists' helps to translate the politics of the frontier into an easy reference point in the national media landscape.

What does this have to do with stereotypes experienced by Northeast migrants in Delhi? Northeast migrants are viewed as suspect citizens. Of course, to be viewed in this way, migrants need to be recognised as Indian citizens from the Northeast and not as itinerant Chinese or Southeast Asians. Respondents related stories of their daily struggles to prove their Indian citizenship. Simple acts like signing a real estate lease, connecting a telephone, and gaining admission to a historical site requires proving citizenship - a performance that does not apply to other ethnic groups considered part of the mainstream. Bureaucratic suspicions are one thing, but it is the everyday suspicions that create the most frustration. For many respondents, this came down to trust. Respondents often remarked that they could coexist with neighbours, landlords, co-workers, employers, and classmates most of the time, but when there was a violent attack against an Indian settler or paramilitary battalion back in the Northeast, when Northeasterners are involved in fights, when a tenant was found to have extra people staying in their flat, or when an employee complained about unfair treatment at work, they were open to accusations of being untrustworthy, prone to violence, or linked to terrorist outfits. These accusations were even more pronounced when there was competition between Northeasterners and Indians for jobs, positions at educational institutions, and housing.

These suspicions provoke an unusual dilemma for Northeast migrants. Many migrants view Indian citizenship with a deep ambivalence. In the Northeast, ethnic identity is predicated on not being Indian. There are other elements to identity, and otherness is applied to other communities in the region as well as the Indian mainstream. However, the core binary between the Northeast and the rest of India discussed in chapter 2 is rarely destabilised by other axes of differentiation between ethnic groups within the region. In other words, while members of the Garo ethnic group, a Tibeto-Burman Scheduled Tribe from the state of Meghalaya and parts of Assam, may go to great pains to distinguish themselves from Khasis and Rabhas, this does not make them feel any more 'Indian' nor alter their grievances against the Indian state. In fact, the growing inter-ethnic hostilities throughout the Northeast can further grievances against the Indian state, rather than 
solely against a rival ethnic group. It is common for ethno-nationalist movements among a particular community to claim that the Indian government favours a neighbouring group, and vice-versa.

Insurgencies and ethno-nationalist politics affirm the sense of difference from India at all levels of public and private life in the Northeast. Indian citizenship is a reminder of the forced integration of many parts of the region into the modern Indian state. However, migration to Delhi and other cities is possible because of Indian citizenship. Employment and education opportunities are also dependent on citizenship status and in some cases on differentiated citizenship rights afforded by the Sixth Schedule. Many communities who are not included in the Sixth Schedule actively seek this status and the exceptional citizenship rights that come with it. This dilemma will be discussed in more detail in chapter 6 .

\section{Anti-assimilation}

Northeastern migrants are perceived to be living in isolation and refusing to mix with other communities in Delhi. This may appear a minor element to stereotyping but it helps to affirm the exceptional status of Northeast migrants and means migrants themselves are blamed for any troubles they face under the charge that they don't attempt to assimilate. Northeast migrants try to live in areas where there are other members of their ethnic group. When migrants arrive in Delhi they usually stay with someone they know, either a family member or someone from their home village. In the Northeast, members of the clan and tribe will almost always accommodate someone who has lost their job or has no place to live. This extends to Delhi, and most Northeast migrants don't think twice about sharing their living space with a friend or relative, even if that friend or relative can't contribute to the rent. In many flats I visited during fieldwork, there would be an extra mattress on the floor of the kitchen or the small hallway where an extra guest was sleeping. Sometimes they are accommodated for months while they look for a job and for a place to live. In this time they usually build up social networks in the same area. These networks include friends, fellow students, and/or co-workers, but can also include a church congregation, shopkeepers who know them and will give credit, and one or two older persons from their tribe or ethnic group who they can turn to for advice and help. When it comes time to find a place of their own, migrants usually want to keep these networks intact and will try to stay in the same neighbourhood. Even migrants who have graduated and secured jobs as professionals will often stay in the same areas, as they prefer to be among members of their own tribe and ethnic group. With the rapid rise in migrants coming to Delhi in recent years, these neighbourhoods 
have grown and multiplied. As these neighbourhoods have grown, so too have negative stereotypes about Northeast lifestyles and animosity at their presence in certain parts of the city.

\section{Loose and immoral}

Most significantly, Northeasterners are stereotyped as loose and immoral. This affects women and men in different ways. Women are cast as loose in morals and sexually promiscuous. Northeast women work in highly visible occupations where their sexuality is emphasised. They live in shared houses, most are not yet married, they move about the city for work without male chaperons, almost always use public transport, those who work have some financial independence (subjecting them to speculation that they achieved this independence through 'immoral' means), most Northeast women dress very differently from Indian women, and they socialise with friends of the same sex and those of the opposite sex. Their subjectivity is not coterminous with the subjectivity of Indian women more generally who are constructed as mothers and daughters through almost universal marriage and the ubiquitous portrayal of the housewife and mother in the media, public policy, and national symbolism.

Respondents also felt that intertwined with stereotypes about Northeast women are stereotypes about Southeast and East Asian women more generally. For example, scholars have analysed the ways the sexuality of Asian women are constructed in the West. For example, Sumi Cho argues that East Asian women are cast as 'ideal gratifiers of western neo-colonial libidinal formations' (I997: I9I). Celine Shimizu (2007) on the other hand refers to the 'hypersexual' Asian woman and her portrayal (and subversion) in film, tourism, the sex industry, and advertising. The experiences of many Northeast women in Delhi suggests that stereotypes of 'hypersexuality' have become globalised and shape relations between different cultures within Asia as much as they do between Western and Asian cultures. The expansion of media outlets in India brings more foreign content than ever before onto Indian television replete with the kinds of imagery that reproduce stereotypes of Asian women in the West (Rampal 200I). In addition, Indians living in the US, Australia, or the UK are not necessarily more immune to Western stereotypes of Asian women's sexuality than others in the same cultural setting. The growing connectivity between diaspora Indians and those back home means that stereotypes also travel back and forth. As more Indians travel to Southeast and East Asia for holidays and business, they are more directly exposed to stereotypes of Asian sexuality. 
There is also a spatial dimension to consider in the urban environment. Northeast women work in professions where they are 'on show'. They are visible in urban spaces where many men (and women) go to loiter and look at members of the opposite sex. In his study of middleclass masculinity in Delhi, Paulo Favero examines the male pastime of going to public and semi-public places to look at women, what he refers to as 'places of voyeurism' (2005: I67). Favero points out that these men have very little contact with women in these places. Contact mostly comes in private, through family friends or classmates. In these 'places of voyeurism', women are analysed and comments are passed between males, but that is the extent of the interactions. This raises two points. It is not only Northeast women who are subject to voyeurism in Delhi a fairly obvious point but one worth making. However, with few avenues for contact with Northeast women in private and with Northeast women being 'on show' in many of these places of voyeurism - malls, restaurants, campuses - the possibility of Northeast women being anything other than sexual bodies is limited.

Northeast men are also subject to some of the loose and immoral assumptions but are mostly cast as heavy drinkers, unpredictable, and potentially violent. This furthers the assumption that Northeast men and women are constantly partying and infers they are not serious students but children of rich politicians or insurgent leaders back in the Northeast, benefiting from government scholarships and reservations. Northeast migrants do indeed hold parties, and I attended several during visits to Delhi and while living in a Northeast neighbourhood. Northeast migrants hold parties for the same reason most other people do; they are in their 20 s and want to socialise with each other. Add to this the fact that most are living in Delhi without their parents and in neighbourhoods where there are a lot of friends and acquaintances and it becomes easy to gather people together. But there are other reasons for parties that are instructive. Many Northeast migrants do not feel safe going out at night. Male respondents felt that they are often provoked into fights when they go out and women respondents remarked that they feel unsafe, especially when returning home. Furthermore, going out in Delhi is very expensive. Admission to bars and clubs can have an expensive cover charge, alcohol incurs a 30 per cent tax, and Northeast men and women are often refused entry, including a highprofile case from 2008 when a female Naga journalist was refused entry into a nightclub in the Greater Kailash area of Delhi for not having the 'right profile' (Indian Express, 24/06/2008). Interestingly, the case only came to light because the Naga women took the club to court. As an instructive aside, she was repeatedly referred to as a 'Naga girl' in the press, despite being a professional living in Delhi for over Io years. While there is a subset of Northeast migrants who go out regularly and 
enjoy the high life in Delhi, this is limited to those with access to a lot of money - a small minority given the shifting profile of migrants as discussed in chapter 2 .

\section{Discrimination}

Stereotypes manifest themselves in discrimination against Northeast migrants in a number of aspects of their lives in Delhi. This includes both positive discrimination, particularly in labour markets as discussed in chapter 3, and negative discrimination, particularly in the housing market, in dealings with the police, and as subjects of harassment and violence. Harassment and violence will be discussed in the following section. The focus of this section is discrimination in the housing market. Regardless of age, gender, or time spent in Delhi, housing was the most common aspect of discrimination discussed by migrants. For many respondents, housing demonstrates their vulnerability and their dependence on non-Northeasterners for their basic needs. It is through housing that Northeast migrants feel their marginality most profoundly. Housing reinforces their temporary existence in the city and their disenfranchisement from its politics.

It is extremely rare for Northeasterners to own property in Delhi. Only members of the ultra-elite can afford to do so, and even then it is extremely rare. Although there are stories of migrants from some of the areas worst affected by conflict buying small plots of land on Delhi's fringe, I was unable to meet any of these migrants to find out more. Respondents would occasionally refer to someone they knew who owned property in Delhi, but they were usually unsure about whether they actually owned property or had just lived there for a long period of time. Central government employees can be given housing for the duration of their employment, but they do not own this property. Academics have access to housing on university and college campuses in a similar way. Given this scenario, virtually all Northeast migrants in Delhi are renters. Some sublet from other Northeast migrants, but even this is surprisingly rare.

Northeast migrants do not fit neatly into other categories of urban dwellers. As they are not property owners, they are not considered in research that identifies the rise of class interests in Delhi's urban governance (Fernandes \& Heller 2006; Mawdsley 2009). As they rarely vote in Delhi, they are not courted by politicians and are thus excluded from analyses of corruption and clientalism. As non-propertied persons, they are not involved in resident welfare associations, one of the main platforms for exclusionary urban practices (Chakrabarti 2008). In effect, Northeast migrants bypass the city's urban politics. Yet they are also 
different from other marginal urban dwellers who are also bypassed in the neoliberal city. They are not slum dwellers or informal settlers and thus they escape the purview of those advocating for the rights of those displaced by urban development or marginalised by changes to urban governance. Few if any Northeast migrants seek title to land or dwellings in Delhi, reflecting their view of the city as a place to work, study, and survive. They rarely take land issues to court. The city is never their place. They don't fight for a stake in it. They have little power to change the city they inhabit. Hence they are at the mercy of landlords and the ways landlords utilise conceptions of race in the housing market. This does not mean, however, that they don't contest the ways they experience the city or practice place-making (both of which will be discussed later).

As discussed above, most Northeasterners prefer to live in neighbourhoods with other Northeast migrants. In Delhi, the most popular areas are Shanti Niketan, Safdarjang Enclave, Green Park, South Extension I, and Munirka in south Delhi and the suburbs around G.T.B Nagar Metro station close to Delhi University campus in north Delhi. During fieldwork I spent time in all of these areas but mostly in Humayanpur in Safdarjung Enclave, where I lived during fieldwork, and Munirka, which was close to Jawaharlal Nehru University and the shopping malls where many migrants worked. In urban areas designated as lal dora, there is more freedom for construction without violating the central tenets of Delhi's building codes (Kundu 2004). In these areas, landlords have realised the economic returns of renting to Northeast tenants. Both Humayanpur and Munirka are lal dora areas. With limited restrictions on construction and guaranteed revenue from Northeast tenants, landlords continue to build additional floors on their houses, creating what respondents refer to as 'tribal towers'. Respondents referred to landlords as 'ground floor people', because they lived in their own house on the ground floor and continued to build seven or eight story towers above. Several respondents remarked that they feel like they are supporting entire families and that the children of landlords don't even have to work because there are so many Northeast tenants paying high rents. Whether or not this is true is difficult to ascertain, but it is a popular perception among Northeast migrants and a source of bitterness.

Housing for Northeast migrants is expensive. Respondents surveyed in January and February 20II were paying between 5,500 rupees (I22 USD) for a single room and 8,500 rupees (I90 USD) for what is called a I+I room (usually one big bedroom and a smaller room with a kitchenette) per month. For migrants working in malls and call centres, this is between $40-80$ per cent of their monthly income. For those not working, the cost of housing can be a major drain on their families back home. This has two main impacts. First, migrants share living space as 
much as possible. Second, more and more migrants have to work to stay in Delhi, whether during study or instead of studying, and thus the desire for Northeast labour plays an even more important role in the connections between the frontier and Delhi.

Virtually every respondent consulted during this research felt that Northeasterners pay far more for housing than other groups. Many Northeast migrants arrive in Delhi with limited Hindi language skills and are in a poor bargaining position with housing agents and landlords. Respondents felt landlords pretended to misunderstand them to then take advantage of confusion and charge them higher rent. One respondent complained of his landlord installing a separate electricity meter in his room and then demanding 2,000 rupees (45 USD) for electricity at the end of the month without ever presenting a bill. There were stories of landlords raising the rent with no warning, renting to other tenants when migrants returned to the Northeast for short visits and refusing to evict the new tenants unless the first renter agreed to pay more, keeping advances but renting rooms to others, keeping their own keys to the flat and in two cases giving copies of these keys to unknown persons, refusing to fix broken taps, pipes, lights, heaters, holes, and vermin problems.

The stereotype of the immoral Northeasterner is used by landlords and housing agents to justify higher rents. Often this is stated explicitly to tenants, and several respondents were told that because they want to live in mixed-sex flats they must pay more. As discussed above, it is common for Northeasterners to share housing and to stay with friends if they do not have anywhere else to stay. Many households have male and female tenants, sometimes in relationships with each other, but usually they are friends or members of the same tribe or clan back home. This fuels anxiety about the morality of Northeast tenants and clearly differentiates them from the Indian mainstream, where such a thing would not be tolerated (even though it can be common). This empowers housing agents, who negotiate with landlords on behalf of Northeast migrants for a fee. This leads to some farcical circumstances. One respondent from Manipur was shocked when the absentee owner of a flat he was renting with two friends showed up with the police. Neighbours had reported their comings and goings and were suspicious. When they contacted the owner, he was not aware that the flat was being rented to Northeasterners, as the agent had obscured their ethnicity to get a better rental price and a larger cut from the Manipuris.

Food is also used as leverage. Bamboo shoots, the staple of cuisine in the hill areas, akhuni, a fermented soy paste common in Naga cooking, and fermented fish are targeted for their unfamiliar odours. Some respondents reported that this is used to drive up rental prices; landlords 
argue that as Northeasterners will be cooking smelly food, landlords need to be compensated to offset complaints by other tenants. In the much-ridiculed Security tips for North East students/visitors in Delhi pamphlet issued by the Delhi Police in 2005, Northeast migrants were advised to avoid using bamboo shoots and akhuni. If they were to cook it, they should do so 'without creating ruckus in neighbourhood' (DP 2005). Some respondents found this absurd in areas where almost all tenants were Northeasterners, but feel there is little they can do about it.

Far more serious are incidents of harassment and violence by landlords and other tenants. This will be discussed in more detail below but deserves brief mention here. In one case from 2007, another tenant in the building sexually assaulted a young woman from Manipur. When the woman in question reported the issue to the police, the landlord responded by evicting her and all other Northeast tenants in the building (NESCH 2007). In 2008, a house owner assaulted a male from Manipur who just went into the house to inquire about accommodation. When he called the police, they proceeded to beat him further (NESCH 2008a). In December of the same year, two women from Manipur were molested and beaten by their landlord. Police refused to register the case until a local support group followed up (NESCH 2008b). These kind of incidents are numerous and fit into a much larger picture of harassment, violence, and police inaction - all of which has racism at its heart. Landlords have access to Northeastern living spaces in ways that the general public do not. Radicalised perceptions of Northeast women fuel the opportunistic sexual violence in these circumstances. Perceptions of Northeast men legitimise mob violence by landlords, the police, and others. What is important to note is the power landlords have as property-owning citizens with local connections in Delhi when compared to Northeast tenants who are racially vilified and treated as suspect citizens.

Exploitation in the housing market also happens to other migrants new to the city. However, there is the perception among Northeasterners that they experience it at far greater levels and for reasons that are particular to their race. Further, they feel they have limited ways to redress this. If their landlord cheats them they rarely take the issue to the authorities, as they fear being made homeless. However, migrants have found ways to cope. Northeasterners who don't speak Hindi will ask friends who do to deal with landlords. Northeast males will deal with landlords on behalf of female tenants. There is also a growing trend of passing housing onto friends or tribe and clan members when leaving the city. As clusters of Northeast migrants have developed in parts of Delhi, landlords too have seen the value of being known as sympathetic to Northeast lifestyles. In Humayanpur and Munirka, there are scores 
Image 4.1 Northeast Housing. GTB Nagar, Delhi

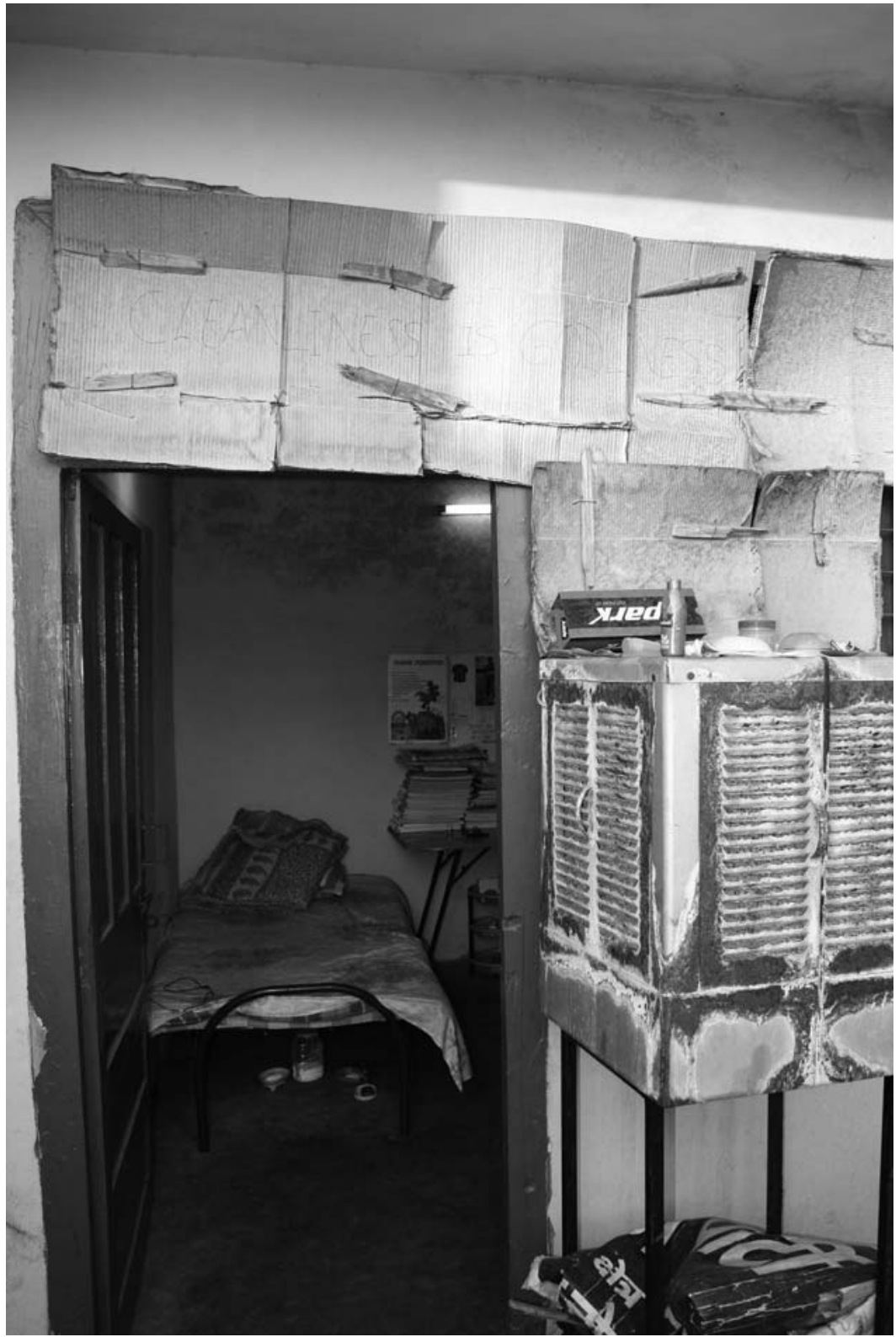


of small real estate agents operating out of small shop-fronts, Internet shops, and grocery stores. Many of them specialise in finding houses for Northeasterners with landlords that tolerate their lifestyles, advertising their services in English throughout neighbourhoods on computer printouts and handwritten signs.

\section{Harassment and violence}

Violence is the most telling manifestation of racism in Delhi and a measure of the place that Northeasterners occupy in the city and in mainstream Indian society. It is imperative not to understate this. Respondents were adamant that the day-to-day violence that characterises their time in Delhi is continually downplayed in the media, by the authorities, and by non-Northeasterners. Delhi has a reputation as a violent city. Murder, rape, mob violence, kidnapping, assault, and sexual harassment incidents are splashed across the print and television media every day. And these are only the incidents that are newsworthy, usually incidents that are particularly bloody or if they happen in an upscale neighbourhood or shopping precinct. One of the difficulties in discussing violence experienced by Northeasterners in Delhi is the counterclaim that Delhi is a violent city and no community is immune. It is important to state that I reject this argument unequivocally. This argument was presented to me a number of times during fieldwork by nonNorteasterners. As one respondent from Nagaland put it, 'they will always go on about Delhi being unsafe. They think it is not different for us. But it is. We are walking targets.' Northeasterners are targeted for violence in ways particular to their race. This applies to sexual violence targeting women, and to more general violence directed at both men and women. It is imperative to recognise that the problem lies not only in the violence itself but also in the way the police treat violent incidents, and the ways in which the discourse around violence blames Northeasterners for inviting violence. While it may be argued that violence by 'a few bad apples' cannot be used to reflect the attitudes of an entire city or indeed a broader social environment of north India, respondents in Delhi and back in Northeast believe violence reflects and even exemplifies their experiences in the Indian heartland. Northeasterners are targeted because of their race, they have virtually no recourse to justice, and they are blamed for the violence they experience. Convincing migrants that this environment is not symptomatic of a broader social attitude is disingenuous.

Harassment and violence are frequently linked. Violence often follows a period of harassment, and those who have experienced violence can be harassed by the perpetrators and their associates to prevent them 
from taking action. Yet they can also be viewed separately - each part of an overarching racial framework of discrimination discussed above. An argument can be made for describing harassment as a form of violence and I am very sympathetic to this view, however externally derived definitions are of limited utility here. Respondents generally distinguished between violence and harassment, the latter of which they viewed as what could best be described as 'everyday encounters' involving verbal taunts and threats, unwelcome advances, provocations, groping in public places, and intimidation. It needs to be noted that in describing these acts as 'everyday' the aim is not to downgrade their seriousness but instead to reflect their frequency and the ways in which respondents have come to accept this kind of harassment as a part of their lives in the city. Respondents considered violence to be assault, rape, groping or molestation in private and/or the workplace and/or university or college, and murder. In effect, violence was the acceleration of harassment beyond what was tolerable.

Macro data on harassment and violence experienced by Northeasterners in Delhi does not exist. Nonetheless, compiling data from a number of sources combined with incidents related by respondents helps to create a coherent picture. The North East Support Centre and Helpline, a church-based NGO in Delhi, records major incidents of harassment and violence against Northeast migrants. Studying their archives from the years following the spike in migration to Delhi shows that incidents have increased in frequency and severity. Though this could be explained by more incidents being reported as awareness of the violence grows, it is also likely that as the population of migrants increases, harassment and violence has also increased. Either way, their archives have gone from listing an incident every few months in 2005 and 2006 to listing almost weekly incidents from 2009 onwards. Newspapers back in the Northeast report incidents experienced by citizens of the state or ethnic group in question as well. For these local news outlets, the stories are popular and affirm the dangers of out-migration to the heartlands. They are also an opportunity to rail against India in editorials. Yet none of this detracts from the severity of violence or the impact it has on migrants in Delhi, on those who have returned home, and on potential migrants. Northeast student unions also report incidents and take action following certain cases. As with newspapers, the cases triggering action have usually been those affecting a member of the ethnic group in question. For example, violence directed at a Kuki student from Manipur will provoke a response by the Kuki Students Organisation in Delhi, but in keeping with the growing sense of panNortheast solidarity, other students unions may also respond and mobilise their members for joint political actions, as was the case in both the incidents I will discuss below. 
Official statistics are not of much use, as Northeast migrants rarely 'show up' in aggregate figures of violence in Delhi. However, data from a few select reports is worth mentioning, though it pertains to violence experienced by women only. The National Family and Health Survey, the primary source of comprehensive data on violence against women in India produced by the Ministry of Health and Family Welfare compiles statistics by state, and their 2009 report shows that Delhi has a lower percentage of violence against women than the national average (I6.5 per cent for Delhi compared with 35.5 per cent nationally) and a lower percentage than all Northeast states. The National Family and Health Survey includes harassment in its definition of violence against women which includes 'emotional violence', 'sexual violence', and 'physical violence’ (MHFW 2009: 494-95), yet violence was defined as 'violence by spouses as well as by other household members' (MHFW 2009: 494). This does not account for what many Northeast women experience in Delhi: harassment and violence perpetrated by people who are not family members occurring outside the home; this partially explains the limits of such data. The National Crime Bureau's 2009 report contains a section tabling 'Incidence and Rate of Crime Committed against Women' by state and territory. Delhi ranks first overall for cities with the most crimes against women (2010: 385-86). These numbers are limited, as they exclude unreported crimes and the high levels of everyday harassment experienced in the city.

Conversations with respondents gave a much more vivid picture of the everyday nature of sexual harassment faced by Northeast migrants. Virtually all respondents had experienced harassment in some form. This included harassment by strangers and by known perpetrators, especially co-workers, bosses, classmates, and neighbours. Female respondents told stories of verbal taunts and threats (often when advances were refused), obscene gestures, unwelcome advances, groping in public places, spying, attempted abduction, and sexual violence. Male respondents experienced verbal taunts and threats, assaults, and police harassment, especially in cases where they attempted to confront perpetrators of harassments and violence.

The following relates a fairly typical everyday example. Sonia, a student from Manipur, related an incident on the bus on the way from the market back to Munirka. She was travelling with four other Northeast women and they had to commute a long way to find affordable food, which they would buy in bulk. Returning on the bus, there was a man watching her and her friends for a long time. He moved closer to the front to get off the bus and in doing so he made to reach for the handle to steady himself and instead groped one of the women and then hopped off the bus. Sonia was infuriated and got down off the bus and confronted the man, telling him he cannot sexually assault women and 
hope to get away with it. The man responded by slapping Sonia in the face. She was so stunned, she did not know how to react. No one on the street responded. The man was wearing a suit and tie, and Sonia is convinced that no one in Delhi would intervene to stop a white-collar male assaulting a Northeast female. She also believes that the man would not slap an Indian woman in public, but striking a Northeast woman was tolerated.

Respondents related scores of other stories of incidents they experienced or witnessed. In addition, there were certain violent incidents that happened to other Northeasterners in Delhi that have become part of migrant folklore. These incidents were raised again and again by different respondents and presented as evidence of racism and discrimination. These include the rape and murder of a Manipuri woman in her rented room in south Delhi in January 2007. This case was also remembered because in the aftermath, blame for the incident was directed at the murdered woman for allegedly inviting the attack. In a case from October 2007, two women from Nagaland were subject to sexual advances by their boss. When the women resisted, they were suspended from work without pay. In January 2008, a gang of more than 20 men attacked and sexually assaulted two sisters from Manipur in the internet café the two sisters ran. In October 2008, a female Naga student was murdered by another student (a non-Northeasterner) when she resisted his sexual advances. In mid-2oro, a Manipur woman was sexually assaulted and beaten by her boss for watching television at work in an empty restaurant.

There are many possible explanations for these particular incidents recurring among respondents. It appears respondents remember incidents that took place while they themselves have been in Delhi. The two murders stand out for their simple tragedy and the blame heaped on the victims. Respondents recalled events where bosses were the perpetrators even when the level of violence was not high, suggesting that such events could happen (and have happened) easily in their own situation. Given the dependence of many Northeasterners on work to stay afloat in Delhi, send money home, and pay for their studies, this seems a pertinent fear. The attack by the gang of men on the Manipuri sisters attempting to run a business reflects a sense of vulnerability that even if Northeasterners manage to set up livelihoods in Delhi, they are still not free from potential violence.

As the bulk of my fieldwork took place in the first months of 20II, there were two incidents that captured the sense of vulnerability and growing anger among Northeast migrants. These incidents were talked about all the time: whether discussions were about race, gender, Delhi, India, work, safety, or housing. The first incident occurred in November 2010. A 30-year-old call centre worker from Mizoram was 
abducted at gunpoint and gang-raped. The perpetrators waited for the woman to be dropped off at her home in a Northeast neighbourhood in the early hours of the morning after working a shift at a call centre, suggesting that she was carefully targeted (Chandra 20I0). The police failed to make any arrests. Six days later, almost 2000 people, the majority mobilised by Northeast student unions and church groups, protested at Jantar Mantar: a well-known protest site in central Delhi. By early December, a number of these groups had secured a meeting with the Chief Minister of Delhi, Sheila Dixit, and they submitted a list of I5 demands to better ensure the safety of Northeast migrants (NESCH 20IO). Arrests slowly followed. Respondents pointed to this as evidence that the police will never take violence against Northeasterners seriously and that it takes the Chief Minister to push them into action.

In the second incident, a brother and sister from Manipur were attacked in their flat in Munirka in April 20II. The incident has been reported with some variation from different sources but essentially an argument broke out between the siblings from Manipur, 'James' and 'Helen' (names changed in the press release and subsequent reporting), and their landlord who lived in the same building (NESCH 2oIId). James and Helen are Hmars from Manipur. The attack happened after the siblings confronted their landlord following continued sexual harassment. The landlord frequently made obscene gestures towards Helen through the window of the flat. On the night of the incident, the siblings discovered that the landlord had installed a camera in their flat and was using it to spy on Helen. When they confronted the landlord, they were savagely beaten. Others joined the beating, including other neighbours. James had severe head injuries and was admitted to the trauma ward of the All India Institute of Medical Sciences hospital. Helen sustained facial injuries. The case of James and Helen evoked fear and anger among other migrants, as it epitomised their vulnerability in Delhi. James and Helen captured the typical 'new' migrant experience: James was working for a multinational phone company and Helen in a restaurant. They were working and supporting themselves. They were not the children of wealthy elites living the Delhi highlife and thus they struck an even deeper chord with migrants from similar backgrounds. They experienced high levels of harassment and when they tried to confront the perpetrators they were turned on quickly and savagely in the flat where they had been living. As one respondent from Nagaland said after the incident, 'you are not safe anywhere here'.

As violence against migrants has become publicised through activism in Delhi and back in the Northeast, the issue has entered the public sphere. Public reactions are instructive of the depths of racism against Northeasterners. In May 2005, following the gang-rape of a I9-year-old woman from Mizoram who was attending Delhi University, the vice- 
principal of the university college she attended issued a press release. The principal insisted that women from the Northeast should wear salwar-kameez; conventional Indian dress consisting of loose trousers (salwar) with a long shirt over the top (kameez) (Arambam 2008). This sentiment fits a common discourse that lays blame with Northeast women for the violence they experience, identifying their dress and their loose lifestyles as 'asking' for harassment and violence (Puri 2006). The Delhi Police have echoed this sentiment. In the aforementioned Security tips for North East students/visitors in Delhi issued by the Delhi Police, Northeast women are advised to act and dress more conservatively. The pamphlet reads: 'Revealing dress to be avoided. Avoid lonely road/bylane when dressed scantily. Dress according to sensitivity of the local populace.' Respondents found this pamphlet and its sentiments amusing but also instructive of the ways they are viewed. Northeast women are held responsible for the sexual harassment they have to endure and the perpetrators are ignored.

At the heart of this discourse of blame is a deeper association between the loose 'exotic' women and their origins in the separatist frontier. In other words, the loose Northeast women deserving of harassment and violence are not separate from the separatist anti-national frontier dweller. This is epitomised in the same press release by the college principal in 2005. The quote was reproduced in the Northeast monthly magazine Eastern Frontier. It reads: 'All the NE (Northeast) girls are sent by the militants of the region in order to seduce the mainland people so they are molested (and) raped. In this way, they are trying to culminate anti-Indian sentiment' (in Arambam 2008). The logic itself is astonishing, but perhaps even more instructive is that this view is not being expressed by a villager from rural Bihar coming to terms with Northeasterners for the first time after migrating to Delhi, but by the principal of a college at one of India's most prestigious universities.

\section{Responding to Racism}

Northeast migrants respond to racism in direct and indirect ways. Violent incidents are taken to the police - though there are clear limits to this as seen above - or to support networks including student organisations and church groups. Putting violent incidents aside, racism is an everyday phenomenon for most respondents consulted in this research. Attention to the ways migrants respond to racism offers insights into the agency of migrants and the conditions in which their agency functions. This matters for two reasons. First, responding to racism helps to affirm tribal and ethnic identities and pan-Northeast solidarity. Second, responding to racism helps to broaden the discourse on Northeast 
migrants beyond victimhood. As attention to the difficulties faced by Northeast migrants in Delhi has grown in the last few years, concern for the 'unfortunate Northeasterner' has begun to grow among concerned civil society organisations, intellectuals, and journalists. While welcomed by some, a number of respondents commented that this perspective frustrated them. Northeasterners pride themselves on surviving the city, discussed further in chapter 6, and some respondents expressed growing unease at their portrayal as victims. Some felt that this evoked the stereotype of the backward frontier dweller, bewildered by the modern city. Responses vary and include standard resistance narratives and also pragmatic responses.

Here I focus on the three main responses that came up in interviews and conversations: tolerance, retaliation, and safety. Note that I am excluding protests following violence, as these are discussed at other points in this chapter and in chapter 6 .

\section{Tolerance}

Tolerating racism is not easy but is necessary for a visible minority in a big city. Many respondents expressed a desire to retaliate to racist comments, taunting, and name-calling but recognise that as a minority this is only going to get them into trouble and threaten their longevity in the city. Adi, a 24-year-old man from Arunachal Pradesh, related a story of walking through the area around G.T.B Nagar Metro station one afternoon with his girlfriend, also from Arunachal Pradesh. They passed a group of men congregating outside a shop. The men started to make kissing noises and one man grabbed his crotch and made sexual overtures towards the woman. Adi told the men in Hindi to be quiet, but they threatened that if he didn't keep quiet he would be beaten up. Adi describes looking up at the shopkeepers, the peddlers in the street, and the other passersby and realising that no one would help him if he got into a fight. They backed away to a cross street and hailed a passing rickshaw. While telling this story, Adi referred to a case from 2008 when a group of students from Arunachal Pradesh were beaten up by a group of shopkeepers in an argument over change. He added, 'I know what can happen. So I have to keep quiet.'

In less threatening situations, many respondents simply ignore remarks and pretend they don't hear them. An interesting contrast can be made here between migrants who have been in Delhi for some years and more recent arrivals. Zana, a male from Nagaland, has been in Delhi for five years. When he hears racist remarks, he simply ignores them. I asked if this bothered him and he replied 'I expect them [Indians] to be racist. It is not worth bothering about them.' Ponali, a student from Arunachal Pradesh, said she used to respond but has 
gradually become immune and cannot be bothered to respond most of the time. In contrast, when visiting two Naga males who had recently arrived in Delhi, they were still somewhat overwhelmed by the continual harassment. As a result, they rarely went outside except to attend class or buy vegetables and food from the local vendors.

Verbal abuse is one thing, but discrimination by landlords and employers is another. In the case of landlords, many respondents simply leave and move in with friends or try to find another place to live. Those who have been in Delhi for longer are much better at negotiating with landlords and will call their bluff when they ask for very high rents and go elsewhere. With more Northeast migrants in Delhi, there are more neighbourhoods to choose from. Landlords and real estate agents are beginning to realise their returns are no longer guaranteed. Similar stories were told of negotiations with employers. Stephen, a 24-year-old Naga in Delhi working in a call centre, said that Northeasterners were in such demand in call centres that if the employers treat them badly they just leave and get a job elsewhere, usually through friends. However, respondents working in other sectors, especially retail, said changing jobs was more difficult.

\section{Retaliation}

In other cases, migrants retaliate. Respondents talked about starting fights, while others told stories of fights they had seen or heard about. These include a number of infamous stories told and retold so many times that the Northeasterners in the story become shorter and skinnier (many hill people are quite short and this is exaggerated in stories of heroism) with each retelling and the Indians that were beaten up bigger and tougher. However, these stories become the stuff of legend. During 20II, there was a story about a student from Arunachal Pradesh who was being hounded by a much larger Indian after a dispute over parking on a university campus. After being pushed to the limits by his tormentor who was kicking his car and calling him names, the Arunachali reportedly snapped and pulled a handgun out of his glove box and chased his tormentor through campus, into a neighbouring housing area, and back to the campus. Whether it was true or not, the story was making the rounds among migrants, and I heard it again and again. I mention it because at each retelling, a discussion about revenge fantasies would usually ensue. The Arunachali had become a hero because he had carried out what so many migrants dream of doing each time they are subject to racism and torment.

Northeast migrants, especially men, are very conscious of how they are perceived in the Indian mainstream as violent people from a violent region, and there does appear to be a self-conscious effort to steer clear 
of actions that may enhance this stereotype. Fights happen in different parts of the city, though they usually happen in or close to Northeast neighbourhoods where migrants have strength in numbers. In September 20II in Safdarjung, an area with a large population of Northeast migrants, though they live in pockets, two Manipuri migrants were attacked with bricks when returning from work one evening. The fight escalated as other Northeasterners joined the Manipuris and other non-Northeasterners joined the initial attackers. When the police came, the two Manipuri youths were arrested, leading to protests from other migrants (E-Pao 20II). Fights also break out between different tribal and ethnic groups from the Northeast in Delhi, usually in relation to incidents back home. This will be discussed further in chapter 6 .

With limited means of retaliation, Northeast migrants use humour to respond to racism. Northeast migrants use humour to laugh at the society that, as far as they are concerned, does not 'get' Northeast life. In saying this, I do not regard this humour as apolitical; it is a product of the politics of race and of state formation in colonial and postcolonial India and the relationships that these engender between peoples of the frontier and heartland. However, humour is more about surviving Delhi than mobilising action against the city's authorities or its inhabitants (see Sorenson 2008). Patu, a male student from Arunachal Pradesh related that he is so tired of people pointing at him and saying 'China' that now when it happens he points back and says 'Pakistan' or 'Bangladesh'. He noted with satisfaction that this usually leads to the person making the initial comment to say something like 'but I am Indian', to which he answers 'so am I'. If they refuse to believe this, he also refuses to believe them. Patu leaves the encounter amused and not angry. Furthermore, he was able to stand his ground and contest being called Chinese by making the other person feel what it is like to be mistaken for another nationality based on appearance.

Stereotypes of the backward frontier dweller are used by migrants to make fun of mainstream ignorance. Lily, a postgraduate student from Nagaland, said that when people ask her what Nagaland is like, she says things such as 'we all live in trees', 'we have tigers in our compound', 'we only eat dog', or 'my uncle collects skulls'. She began doing this when a roommate during her undergraduate days remarked with surprise that Lily had a hairdryer and knew how to use it. Northeasterners are very aware of how they are perceived and are willing to respond by enhancing the stereotype to gain the upper hand. They may choose to drop the ruse later but they may not. Stereotypes are turned back around and used as signifiers of mainstream ignorance. In one case, Lily said that one of her Indian classmates caught on and started to spread the same stories, heightening the ruse. She said this made it even more believable. Again, with few other ways of retaliating, humour 
has become a way to diffuse tensions but also to ridicule. Further still, it breaks down some barriers between communities and opens up friendships.

Northeast migrants also use humour to make fun of Indians and Indian society. It is here that a degree of reverse racism and cultural caricaturing is evident. On Sunday afternoons in Humayanpur, I would join Northeast neighbours after church to cook lunch. We would usually cook Northeast food or Korean food and sit around talking until the evening. Invariably, stories would be told that caricature Indian society. This helps maintain bonds among migrants, as they all feel a strong sense of difference from the Indian mainstream, even among those with lots of Indian friends or those with Indian partners. Indians are caricatured as harsh and cruel towards each other, ignorant of Northeast societies, holders of bizarre beliefs and taboos around caste and religion, and obsessed with talking and arguing about everything. Interestingly, many of these attributes are related to the ways Northeasterners see themselves, e.g. as egalitarian, cosmopolitan, and comfortable with silence. Most friends would admit to knowing Indians that they did not view in this way, but it was important for them to caricature Indians as they felt themselves caricatured. This allows migrants to share a common view of Indians that differentiates them and to share a language that unites them as minorities in the city.

\section{Safety}

Northeast migrants respond to racism, harassment, and violence by creating safe spaces. These spaces are laboriously carved out of enclaves, lal dora areas, and neighbourhoods. This practice of place-making is discussed in detail in chapter 6 but it is worth mentioning briefly here. As Northeast migrants rarely own property or capital in Delhi, they have limited means of controlling the urban environment. One of the ways migrants have countered this is by territorialising neighbourhoods. As a marginal population, territorialisation is seldom overt but instead takes place through everyday practices. In Humayanpur where I lived during fieldwork, Northeasterners staked their claims to the neighbourhood in a number of ways. First, they 'hung out'. They simply occupied neighbourhood space. While not always motivated by an overarching purpose, for instance, many friends spent time in the neighbourhood because their flats were small and crowded or cold in winter and too hot in summer. Northeasterners felt safe in such neighbourhoods and being outside extended the feeling of safety to others, especially new arrivals.

Humayanpur has a small market in a square where a number of narrow alleyways intersect. Around this square are a few eating places, 
vegetable vendors, and internet and phone shops. Northeast migrants hang out in this space, talking, gossiping, eating, and loitering. If I ever wanted to meet new migrants or find people I had already met, I had only to loiter in this square in the evening and I would usually run into someone. Most of the businesses are usually run by non-Northeasterners but recently a number of Northeast businesses have opened - a Mizo butcher, two Northeast eateries, two Tibetan/Bhutanese eateries, a Naga-run grocery store, a Korean DVD shop, and a clothes shop run by Northeasterners who get their stock from the border markets back home. Revisiting Delhi in December 20II, I found that even more of these places had opened up. This was very noticeable in Munirka, which is much bigger than Humayanpur and now hosts a Northeast butcher, several grocery stores, a travel agent, several clothes shops, and three restaurants. It was surreal to be in the centre of a densely populated Delhi neighbourhood and accompany friends to shops where they would speak in Meitei, Naga, and Mizo to shopkeepers and exchange news while they bought different items. Sometimes friends would walk far out of their way to patronise these shops. All of this matters because Northeasterners are physically present in the public spaces of the neighbourhoods. These become safe spaces through the contestation of neighbourhood space (see Kong \& Law 2002). Contestation is not always overt. It does not always involve spectacular displays of agency. It is a far more subtle process. As one respondent from Meghalaya put it, it was like 'a silent takeover.'

Safety also comes from the density of the Northeast population. In Humayanpur and Munirka, the density of the population is extremely high. As lal dora areas, the houses have been built up in a haphazard way to increase property revenue and exploit vague planning laws. As Northeast migrants covet this and other neighbourhoods, landlords and estate agents similarly covet Northeast renters as they know they want to live close together and will pay higher rent to do so. In these neighbourhoods, someone from the Northeast is usually nearby, even late at night, and if not, they are never too far away. Even late at night there are Northeast men and women walking around the streets and alleyways. Respondents say that they would never contemplate doing this in other parts of Delhi, but in these neighbourhoods they feel safe. Considering the reputation Delhi has for crime and the precautions taken by many residents after dark, this is significant. In recent years, however, attacks against Northeast migrants have carefully targeted these neighbourhoods, eroding some of these assurances.

In these neighbourhoods, the lines between public and private are blurred. Flats are small and many are windowless so the space between flats, landings and stairwells, and the streets and alleyways of the neighbourhoods become the sites of conversations, meals, and arguments. 
Migrants move between each other's flats without knocking, and many leave their doors unlocked when they are inside. Northeast residents have begun to use symbols to mark their dwellings. Some affix a small crucifix to the door, others hang a tribal shawl in the window or behind an iron grill, others paste bible verses or magazine pictures of home to their doors and walls. Visible flags are less common lest they inflame parochial fissures.

Success in creating safe spaces is uneven in different Northeast neighbourhoods. Thus while Humayanpur feels safe for residents and visitors, other neighbourhoods like Munirka are considered far more dangerous. Furthermore, as Northeast neighbourhoods have become more distinct, there is the fear that harassment and violence can now be easily targeted. In the aftermath of the gang-rape of the Mizo call centre worker in late 20I0, discussions revealed insecurities around the entry ways to the neighbourhood. Many residents felt that they were safe once inside the neighbourhood, but getting from the main road meant passing through other areas they did not trust.

I wish to make a final point on safe spaces that came up during my fieldwork. Many Northeast migrants come to Delhi from volatile, violent, and unpredictable environments. As mentioned in chapter 2, much of the Northeast is heavily militarised. This affects different parts of the region in differing degrees, yet the existence of exceptional laws such as the AFSPA that allows for arbitrary detention, firing on groups of more than five people, and the search of any premises without a warrant (McDuie-Ra 2009a: 257-8) - combined with inter-ethnic tensions and violence, a proliferation of armed ethno-nationalist and student groups, extortion, smuggling, curfews, and roadblocks - makes for a brutalised frontier culture of violence (McDuie-Ra 20I2a). Delhi is certainly a dangerous city, but in fact for many respondents it was no more dangerous than their hometowns and cities, and for some, especially those from parts of Assam, Manipur, and Nagaland, Delhi seemed much less dangerous than what they were used to. Of course, individual migrants perceive danger and risk in varying ways from one another even if they come from the same district or town. However, there was a very strong sense among many migrants, especially men, that they could handle Delhi and protect others from its dangers because of what they had experienced back home. I will examine this further in the next chapter when discussing masculinity. Interestingly, there was also a sense of shared memory of past danger, even among those who were too young to have lived through periods of violence in their home locations. 


\section{Race in Contemporary India}

What can the experiences of Northeast migrants in Delhi tell us about race in contemporary India? Consideration of racism in India is overshadowed by historical experiences of racism during colonial rule (Bayly 1999), so-called communal frictions - particularly HinduMuslim conflicts (Baber 2004) - and debates around caste and racism (Pinto 200I; Visvanthan 200I). Since gaining independence, and particularly when India played a prominent role in the non-aligned movement and Afro-Asian solidarity, intellectuals and politicians in India publically criticised racism in other parts of the world, particularly South Africa and the United States (Gupta 1978; Logan I985). This enabled racism to be externalised: it was something that happened outside India. As more and more Indians migrated outside India after independence, their experiences of racism completely engulfed the discourse on racism within India. As Zaheer Baber (2010) notes, in India, racism has come to mean something 'white people do to Indians', deflecting attention away from racism towards minorities and foreigners in India. It is important to note that I am in no way suggesting that the experiences of racism encountered by Indians historically or by Indians abroad are not deplorable, nor am I suggesting that they are overstated. I merely wish to argue that the focus on this type of racism obscures the experiences of racism within India. This is a sentiment shared by many Northeast migrants in Delhi and back in the frontier.

The non-resident Indian (NRI) and the person of Indian origin (PIO) are not only vital parts of the Indian economy but also part of Indian national identity, portrayed in films, advertisements, and countless novels. As Mani and Varadarajan argue, the celebration of the NRI/PIO creates an "unbroken link between "Mother India" and her "children abroad" ' (2008: 45). Thus, racism experienced by Indians abroad, especially when involving violence, can be seen as attacks on these 'children abroad'. Interestingly, the experience of racism overseas has also become an important part of the identity narratives of different categories of Indians abroad - from 'pioneering migrants' such as Sikhs in Canada (Basran \& Bolaria 2003) to middle-class and professional migrants in the United States negotiating 'model minority' status (Bhatia 2007) to Indian students living and studying in Australia (Baas 20I0).

The Bradford riots in the United Kingdom in $200 \mathrm{I}$ and violent attacks on Indian students in the United States and Australia, including murders in both locations, have been widely covered in the media in India and abroad. The racist attacks on Indian students received such widespread coverage in print, television, and online outlets that the task of compiling sources from India and Australia is virtually impossible. Cases of racism against Indian celebrities also make big headlines, 
especially the case of the actress Shilpa Shetty on the English reality television programme Celebrity Big Brother and racist slurs directed at Indian cricket players when playing abroad, especially in Australia (Finnis 2007; Mehta et al. 2009; Riggs \& Due 2010). Receiving less coverage but certainly not completely neglected are the abuses experienced by Indian domestic workers and labourers in the Gulf, and violence against Indians in Fiji (Trnka 2008). Racist violence, abuse, and the denial of rights in these locations are very real and indefensible, yet the preoccupation with this kind of racism makes introspection on racism within India very difficult.

Blanket coverage of violence against NRI/PIOs is countered by silence on violence against Northeasterners by Indians. For many respondents, racism by Indians not only marked their experiences of Delhi but also their experiences of military occupation back home. In an incident that would have caused national embarrassment had the speaker not been from a small frontier state, the Chief Minister of Mizoram, Pu Lalthanhawla, stated that he experienced racism in India while speaking at an international forum on water in Singapore. Lalthanhawla was quoted as saying 'I am a victim of racism ... In India, people ask me if I am an Indian. When I go to south [India], people ask me such questions. They ask me if I am from Nepal or elsewhere' (Times of India 26/6/2009).

Northeast migrants are highly critical of the lack of recognition about racism in India. Yet few expressed surprise. What angered many migrants was the hypocrisy. This came out forcefully when discussing the violence against Indian students in Australia. As an Australian, people throughout India would ask me about these incidents. Working in an Australian university also meant I was seen as someone who could make sense of these attacks. My position on the attacks is unambiguous: they are horrific. As for making sense of them, I would often remark that it is likely the attacks were racially motivated (for an excellent discussion of views on the attacks in Australia, see Baas 2009). This would often open up discussions about race and multiculturalism in Australia. Responses from people in the Northeast varied but usually always reflected their own position within India. Responses were often hostile, not towards the perpetrators or the victims but towards the response.

I was discussing the attacks with a group of Naga students in Kohima in the context of blanket media coverage in India. The comments of one of the students struck me and I wrote them down: 'They [the media/government] only care about this because it happened in a foreign country. How many tribal students get beaten up in Delhi every year? How many girls get raped? No matter how loud we shout, they will never hear.' These conversations continued through subsequent 
visits and into fieldwork with Northeast migrants in Delhi. When the issue came up in Delhi, conversations tended to follow a similar pattern. Respondents were also adamant that this was not just about encounters in Delhi. They also equated the experiences of the Indian state and the armed forces in the Northeast as part of the same phenomenon. They would point out the excesses of the armed forces, even citing particular incidents. As Konsam, a respondent from Manipur put it, 'they [the armed forces] shot Chongkham in the street in Imphal and it was in the national newspaper. No one cared. And they want me to be angry about some guy in a foreign place because he was Indian?' He was referring to the murder of Chongkham Sanjit, a 27-year-old male shot dead by the armed forces in the streets of Imphal, the capital of Manipur, in broad daylight in 2009. The shooting and the dumping of the body in the back of a truck was captured by a photographer and appeared in the weekly magazine Tehelka (Rehman 2009).

There was a further theme that came up several times. A number of migrants mentioned that although they face racism and discrimination in India, they deal with it. These comments were not made with relation to the specific attacks but to a more general practice of complaining about ill treatment abroad. As one respondent from Manipur quipped, 'if the TV was interested in listening to us talk about what we face, they would have to have talk shows 24 hours on every channel. But we are not like that.' Here we can see the ways Northeasterners differentiate themselves from the Indian mainstream, indeed from an imagined 'Indian' archetype. The meaning is clear: Northeast migrants put up with racism all the time but mostly in their own country. No one is interested in hearing about it or doing anything about it, so they endure it. This is an important part of the way Northeast migrants see themselves - as survivors of the hostile city. 



\section{Provincial Men, Worldly Women}

Racism gives the Northeasterner's experience of Delhi a commonality that transcends gender. Beyond this commonality, gender differences in the experience of migration are stark. Leaving aside violence and sexual harassment for the moment, there is a strong sense that Northeast women flourish as migrants while men struggle. This divergence affects relations between men and women migrants. In this chapter I explore these relations and argue that migration from the frontier ruptures the sense of masculinity among Northeasterners. Faced with rapid change, Northeast men attempt to enact the gender norms of home. This leads to strain between men and women. As discussed in the previous chapter, Northeast women are subject to stereotypes about their looseness and sexuality. The constancy of these stereotypes in everyday interactions in the streets, in the labour market, and on campuses provokes the desire among Northeast men to protect and police Northeast women in the city.

In contrast to dominant methods of gender analysis on South Asia generally and migration in particular, I have chosen to analyse gender relations through the prism of masculinity (see Chopra 2004). In doing so, I remain faithful to a gendered analysis that considers the experiences of women and men and relations between men and women. However, I argue that it is masculinity that is most ruptured by migration and that this has the greatest impact on gender relations and evolving gendered identities among Northeast migrants. Again, this is not something readily visible in the frontier itself, though the long-term impact on gender relations back home could be profound in the future.

In this chapter, intersectionality is used as a method of inquiry into the ways Northeast masculinity is experienced, expressed, challenged, and altered through migration. Initially, scholars used intersectionality to examine the intersections of race, class, and gender and to generate a feminist praxis to challenge oppressive structures faced by ethnic minority women (Crenshaw I99I). In recent years, the concept has broadened to account for the intersection of 'multiple axes of differentiation' (Brah \& Phoenix 2004: 76), which can create 'hierarchies of differential access to a variety of resources - economic, political and cultural' (Yuval-Davis 2006: I99). In this case, multiple axes include gender, 
race, labour, and migration, all of which exist in mutually constitutive yet dynamic relationships.

Northeast men and women migrate together. This matters because unlike many other groups in South Asia and in other parts of the world, men are not migrating alone to forge a path or follow an established route, leaving women and families behind (Broughton 2008; Datta et al. 2009; Osella \& Osella 2000), nor are women migrating to work in different professions to men, as is the case in other locations (Constable I997; Momsen I999; Parreñas 200I). Thus men experience migration with women from back home, not in isolation from them. They often find work in the same sectors, though there is the feeling among some migrants that it is easier for women to find work than men. Both men and women send remittances home when they can, though for many the costs of living in Delhi and the opportunities to spend make this difficult. Cases of Northeast women working to support male siblings were more common to encounter during fieldwork than the reverse.

\section{Gendered mythmaking}

Women in the Northeast - and tribal women in particular - are perceived to be living under distinct gender relations and are 'better off than women in other parts of India. During fieldwork in Delhi, I attended a conference on the Northeast. At one of the sessions an Indian feminist academic noted that the Northeast has a 'softer patriarchy' than the rest of India. ${ }^{6}$ I have used this term in the following chapter, as it captures the outsider view of gender relations in the frontier. Women in the Northeast are seen as more empowered, engaged in more egalitarian social and legal relations with men, and less constrained by the patriarchal forms of power that dominate the rest of India. These perceptions are propagated by the existence of a comparatively more egalitarian gendered division of labour (Krishna 200I), adherence to Christianity, indigenous faiths and less rigid forms of Hinduism (Bhaumik 2004; Zote 2006; Singh 2004), visible participation in 'male domains' such as sport and business (Mills 2006; Nongbri 2008), and by racial stereotypes about Northeast women being less bound by conservative traditions and more sexually promiscuous (see previous chapter). Beneath these perceptions are strong patriarchal relations, though these are formed through different traditions than those in other parts of India.

6 North East Fest, Habitat Centre, New Delhi 30-3I Jan 20 II. 
Women in the Northeast rank highly in gender indicators, and this helps to enhance the view of a softer patriarchy. For instance, illiteracy for women in India is 58.2 per cent, yet all female illiteracy rates in the Northeast are below this, and in the hill states female literacy rates are among the highest in India (MHFW 2002: 53). In Mizoram, the literacy rate for women aged I5-49 is 94 per cent and is higher than men (MHFW 2009: 35). Women in all Northeast states get married later than women elsewhere in India (MHFW 2002: 57). Indicators for employment for women are also well above the national average in the hill states, though the proportion of these women who are paid cash for their work is lower than the national average in these same states, suggesting much of this work is agricultural labour on family plots (MHFW 2009: 452). The overall proportion of women in paid employment is higher than the rest of India.

In all states in the Northeast except Tripura, the percentage of women participating in household decision-making is far above the national average, and it is almost double the national average in Manipur, Meghalaya, Mizoram, and Nagaland (MHFW 2009: 467). The majority of families in the hill states are nuclear, which is in contrast to other parts of India where joint families are seen as 'fertile ground' for violence against women (VAW), especially dowry-related violence (Panchanadeswaran \& Koverola 2005: 744). Throughout the Northeast, the sex preference ratio is more balanced than the national average - in other words, preference for more male children than female children is lower and preference for more female than male children is higher (MHFW 2002: I22). There is a range of other statistics that could be cited here to make the same point, namely that the overall trend across a range of different indicators demonstrates that women in the Northeast live in a very different gendered context than women in other parts of India. Most importantly, women are highly visible. They move around on their own without male companions, work, run businesses, and congregate in public spaces in large numbers. For casual visitors to the region, this visibility can be disconcerting and is often lauded.

Northeast women are judged in comparison to women elsewhere in India. When the relative perspective of softer patriarchy is removed from consideration, heterogeneous forms of patriarchy are more obvious. Despite the involvement of women in agricultural production, paid employment, and household decision-making, women are still excluded from formal decision-making institutions (Fernandes \& Barbora 2002). In other parts of India, village and district level institutions have one-third of seats reserved for women under the $73^{\text {rd }}$ Amendment to the Indian Constitution. The $73^{\text {rd }}$ amendment has not been extended to Sixth Schedule areas (tribal majority areas) of the Northeast on the grounds that it is against tradition (Krishna 2004: 390; Nongbri 2003: 
2I3-I9). Exclusion extends to state-level 'modern' politics, where the number of women representatives in the Northeast states is the lowest in India. In many parts of the Northeast, patriarchy is growing stronger as societies undergo rapid social and economic change (Fernandes \& Barbora 2002; Nongbri 2008; Zehol ed. I998).

Furthermore, violence against women in the Northeast is widespread, showing little correlation between exemplary gender indicators and lower levels of violence. From the last two National Family Health Surveys by the Indian Ministry of Health and Family Welfare, the following statistics are striking. In the 2002 National Family Health Survey, VAW was not limited to domestic violence only but also to experiences of violence beyond the household. The percentage of women in the Northeast experiencing VAW was above the national average or marginally below. Compared to the national average of 2I.0 per cent, 3I.I per cent of women in Meghalaya experienced VAW - the second highest in all of India (MHFW 2002: 79). High levels were recorded in other states including 26.4 per cent in Arunachal Pradesh, I9.7 per cent in Manipur, 20.I per cent in Mizoram, and I9.0 per cent in Nagaland. What is even more striking is that the survey also recorded the perpetrators of the violence. In Meghalaya, almost nine out of ten women experiencing VAW were the victims of acts committed outside the family. In Mizoram, it was five in ten, and in Arunachal Pradesh and Nagaland, the ratio was four in ten. The ratio was also above the national average in Manipur and Sikkim. This is dramatically different from the rest of India, where husbands perpetrate 89.5 per cent of VAW. This increases to 98 per cent if in-laws and other family members are included (2002: 79).

It is important to note that in the 2009 survey, the definition of violence was expanded to include emotional, sexual, and physical violence, but the focus was on violence by spouses and household members. In this survey, levels of physical violence and correlated physical, sexual, and emotional violence in the Northeast states was lower and much closer to the national average of 37.5 per cent and 39.7 per cent respectively. The difference is spectacular in certain cases. Meghalaya went from having the second highest rates of VAW in India in 2002 to having the second lowest in 2009 (MHFW 2009: 27). The other hills states were also all below the national average (with the exception of Arunachal Pradesh) after being above in 2002 (MHFW 2009: 5I9). This demonstrates that when violence outside the household is not counted, VAW in the frontier is (comparatively) low, and when it is counted, VAW is very high.

Much of this violence outside the home can be accounted for by the high levels of militarisation, lack of legal deterrents, ongoing ethnic conflicts, and targeted violence by security forces and rival militant 
groups. Yet it is also important not to let Northeast men 'off the hook' as it were, and attribute all violence to outsiders. Attitudinal surveys towards VAW in the frontier are instructive of firmly embedded patriarchal notions among Northeasterners, including men and women. The 2009 National Family Health Survey provides details about attitudes of both men and women towards VAW. Men and women were asked whether they agreed with any of the following reasons as justification for a husband beating his wife: 'she goes out without telling him, she neglects the house or children, she argues with him, she refuses to have sexual intercourse with him, she doesn't cook food properly, he suspects she is unfaithful, and she shows disrespect for in-laws' (MHFW 2009: 474). The percentage who agreed with at least one of the reasons is very high in the Northeast, particularly among women and men in Manipur (89.7 per cent of women and 85 per cent of men), Mizoram (83.0 per cent of women and 82.6 per cent of men), and Nagaland (78.9 per cent for women and 7I.2 per cent for men). In all the other hill states, the percentage agreeing with at least one of the justifications for wife beating is well above the national average of 54.4 per cent of women and 51.0 per cent of men (ibid. 479).

Beyond the direct physical and sexual violence experienced in the Northeast, the psychological aspects of violence are an important part of understanding what constitutes the social environment for women in the frontier and how removal from this environment affects behaviour in Delhi. Murder, rape, and torture by the armed forces and by militant groups instill a deep sense of fear and insecurity in everyday life. This shapes the choices women make about their own mobility and those of their family members, and the choices family members impose on women, which has lasting consequences when mobility is necessary for healthcare, employment, livelihoods, education, and to escape abuse. The environment in which women exist in Delhi is very different. As discussed in the previous chapter, Delhi is dangerous and Northeast women are targeted for sexual harassment and sexual violence. Yet the dynamics of mobility and autonomy are very different than back home in the frontier. It is not simply that women can move about more but that their movements are not constantly monitored by family members and by the armed forces or militants. This is an opportunity many Northeast women in Delhi embrace.

Masculinity in the Northeast is not singular, though it is influenced by two dominant social constructions - one historical and the other contemporary. These constructions converge in the contemporary era. First are 'traditional' male roles: hunting, warfare, slaving, land brokering, and dispute resolution. These are especially pronounced in tribal societies. These roles are popularised in the form of a warrior past and reproduced in folklore, museums, tourism, and local histories (Kikon 
2009b; Patil 20II). In addition, the constitutional provisions of the Sixth Schedule have formalised indigenous institutions of governance that normalise the exclusion of women from decision-making bodies on the grounds of tradition, despite the fact that these institutions have taken on many of the roles of the modern state (Barbora 2008; McDuie-Ra 2007; Nongkynrih 2002). Traditional male roles have become institutionalised, normalising men as community decisionmakers and keeping male roles of the past at the forefront of contemporary society.

The second social construction is the existence of contemporary male roles that have evolved through six decades of armed struggle. As discussed in chapter 2, conflicts exist between different ethnic and tribal groups (and the territorial units representing them), between particular ethnic groups and the Indian state, and between communities indigenous to the region and migrants. Men are active in these conflicts, and masculinity is expressed through allegiance to the ethno-nationalist cause and reproductions of a warrior past.

In this environment, men act as protectors of their community from 'outsiders': members of the Indian armed forces and paramilitary, migrants from other parts of India and surrounding countries, and/or members of rival ethnic and tribal groups. This is enacted through involvement in armed violence, involvement in ethno-nationalist politics, vigilante activity (such as intimidating migrant labourers and shopkeepers), enforcing strikes and boycotts, and the moral policing of women from the ethnic or tribal group. Northeast men are warriors and protectors in an ongoing multi-faceted battle for territorial control and community survival.

Men and women exist in an environment dominated by the nationalist-infused masculinity of the occupying military, the ethno-nationalist masculinity of insurgency and the gun culture, and the obligatory masculinity drawn from the performance of 'traditional' roles. Attention to the impacts of violence in the Northeast has focused predominantly on women (Banerjee 20IO; Bora 20IO; McDuie-Ra 20I2a). The impacts on women have been horrific, yet there is far less attention to the ways that militarisation affects men. Young men are racially profiled as insurgents by the military and are the targets of recruitment by insurgents. Movement, employment, education, and social networks are all jeopardised in this environment. Young men who move in groups attract high levels of suspicion and harassment, yet young men who move around on their own are far more vulnerable to harassment. The psychological impact that militarisation has on young men is rarely examined beyond being a catalyst to join militant groups or the armed forces. Attention is mostly given to combatants, with little attention given to the impacts of militarisation on non-combatants, particularly the long-term 
psychological impacts of living in this environment. Rehabilitation of former militants is almost entirely focused on vocational training and cash incentives, with no resources or consideration of psychological support (Farrelly 2009).

Not all men deal with this well. Narcotic use is very high in the Northeast and particularly high in the states close to the border with Burma. As Kermode et al. have shown, introduction to intravenous drug use is often framed as a rite of passage and a proof of their masculinity among young men in the region (2009). As they argue, 'young men engage in drug use in order to fill a social vacuum created by limited opportunities to meaningfully engage in adult roles within the community' (2009: 1085). Females are also drug users and this is linked to sex work and vulnerability to trafficking, though intravenous drug use is not as high (Kermode et al. 2009). Alcohol use and abuse is widespread among men in the Northeast, so much so that three states have a ban on the sale of alcohol (Manipur, Mizoram, and Nagaland). ${ }^{7}$ This perhaps explains in part the high VAW rates discussed above.

\section{Urbane Women, Provincial Men}

Migration removes men from the environment where their masculinity is produced, while women gain a sense of independence away from the constraints of home. Most respondents felt that Northeast women coped better with migration than men. This was true for both female and male respondents. Putting aside harassment and violence for the moment, Northeast women appear to thrive in Delhi. Their labour is desired in the consumer spaces of malls, spas, restaurants, and call centres, giving many of them a degree of financial independence that they don't have at home. This is not to suggest that back home there is a stigma against women's participation in the labour force but rather that the age at which most Northeasterners migrate, combined with the limited employment opportunities back home, mean that many Northeast women undertake paid work for the first time in Delhi.

7 Statistics on alcohol use published in state summaries of the most recent National Family Health Survey (MHFW 2009) show that Northeast states without bans have very high alcohol use and prevalence rates (Arunachal Pradesh has the highest in India among men). Men are at least more than twice as likely to use alcohol and use it more regularly than women. In states with alcohol bans, usage is still high (though the statistics are likely to be underestimated), and far more men drink than women, although Nagaland is the one exception. In Nagaland, the ratio of men to women drinking alcohol is 4:I, while in Manipur it is 23:I and in Mizoram it is 42:I. By comparison, in Meghalaya, which has no ban, it is I2:I. 
Without reliable statistics it is difficult to determine whether women work more than men or whether they get paid more or less than men. However, many respondents felt that it was easier for women to find work, often attributing this to the sexualised roles demanded by the hospitality and retail sectors. Women who are working are able to engage in conspicuous consumption, particularly of fashion and food. Stereotypes about Northeast women being loose and subject to a separate moral order are enhanced by the visibility of Northeast women in restaurants and bars apparently 'living it up', though many are actually working at these places. It is also difficult to determine whether Northeast women go out more than other women in Delhi or whether they simply stand out because of their physical features.

In virtually all towns and cities in the Northeast, restaurants and bars close in the early evening because of curfews, and in rural areas no such establishments exist. In Manipur, Mizoram, and Nagaland, alcohol is banned, though it is available on the black market. Thus for many migrants, Delhi offers opportunities to go out on the town that don't exist back home. It appears these opportunities are more attractive to women than men. Remy, a Naga woman who works as a singer in a hotel, explained that Northeast migrants became used to going out. Most migrants live in small flats without their parents. Unless they are working, they don't have much to do in the evenings. She added that as so many parts of the Northeast shut down after dark, Northeasterners may only get a chance to experience nightlife in Delhi. The last time she went to Nagaland, she became bored quickly. Everything was shut at sundown, the streets were dark and full of soldiers, and there was nowhere to meet friends. As Remy put it, 'I missed the buzz of city life'.

Many Northeast men work, but few like to spend money on going out and most prefer to stay at home and socialise with other friends from home. Respondents gave many reasons for this. First, as discussed in the previous chapter, going out in Delhi is expensive. Even those that can afford it prefer to save the money for when they return home, especially those that plan to get married, or to send the money home as remittances. From time to time, men would comment that women can afford to go out because Indian and foreign men pay for them in the hope of sexual liaisons or starting relationships, whereas if Northeast men want to go out they had to have money to spend. Few took the point much further than this, but it is interesting to see that some of the stereotypes about Northeast women are repeated by Northeast men. Second, Northeast men are hesitant to go out because they felt they would be provoked. Men commented that they were often refused entry into establishments based on their ethnicity and the assumption they will act violently. Respondents also felt that nonNortheasterners deliberately provoked them into fights, while others 
commented they constantly had to intervene when men made unwelcome advances on Northeast women. Third, many respondents found going out boring. They would rather stay in and eat Northeast food and drink cheaper alcohol. They preferred sitting at home, playing guitar, singing, and playing cards. Many Northeast women enjoy this too, though a number of female respondents felt that this soon became boring and was too much like home.

Angela, a woman in her late 20 s from Manipur, was very animated on the topic of Northeast males. We met a number of times during fieldwork, and conversation would invariably drift towards what she saw as the woefulness of Northeast men. During one of our meetings she remarked that she would rather go out - even when she hardly had any money - than spend time sitting around with people from back home. She found that staying in meant watching Northeast men get drunk, talk about politics, and then she would end up cleaning up after them, something she grew up doing at home. She wanted to go out and try new food, meet new people, and be 'seen'.

The lack of interest shown by most Northeast men in doing these things cast them as unromantic, boring, and provincial in contrast to the urbane and worldly tastes of women. Some Northeast men reported changing their behaviour to be more outgoing, while others complained that Northeast women changed after they migrated and wanted to be treated differently than they were back home. For Northeast men, migration means a more self-sufficient life than at home. They have to take care of themselves unless they have a sibling or relative that will take care of them. Many are very adept at this, and their capacity to take care of themselves, work, and sometimes study is a major source of pride. However, some can't help thinking of life at home where things might have been very different. Some men admitted to missing the provision of household labour by mothers, siblings, and relatives. Male respondents often spoken of 'an easier life' back home where they had more time to be involved in politics, or play sports, or socialise, whereas in Delhi they had to cook, clean, and work.

Several male respondents resented Northeast women going out on the town and disapproved of the ways in which Northeast women were represented in the labour market. It is interesting to note that men also work in similar jobs but do not feel that this carries the same problems for them as it does for women, as their employment in these sectors is more limited. To clarify, employment is limited in the sense that some of the more sexualised jobs such as working in spas, nail salons, and fashion boutiques (with the exception of suits), and as models at car shows and other exhibitions are usually closed to Northeast males. They felt that the highly sexualised representation of Northeast women in the retail and services sector perpetuated stereotypes made by the 
Image 5.1 Northeast wait staff. Hauz Khas, Delhi

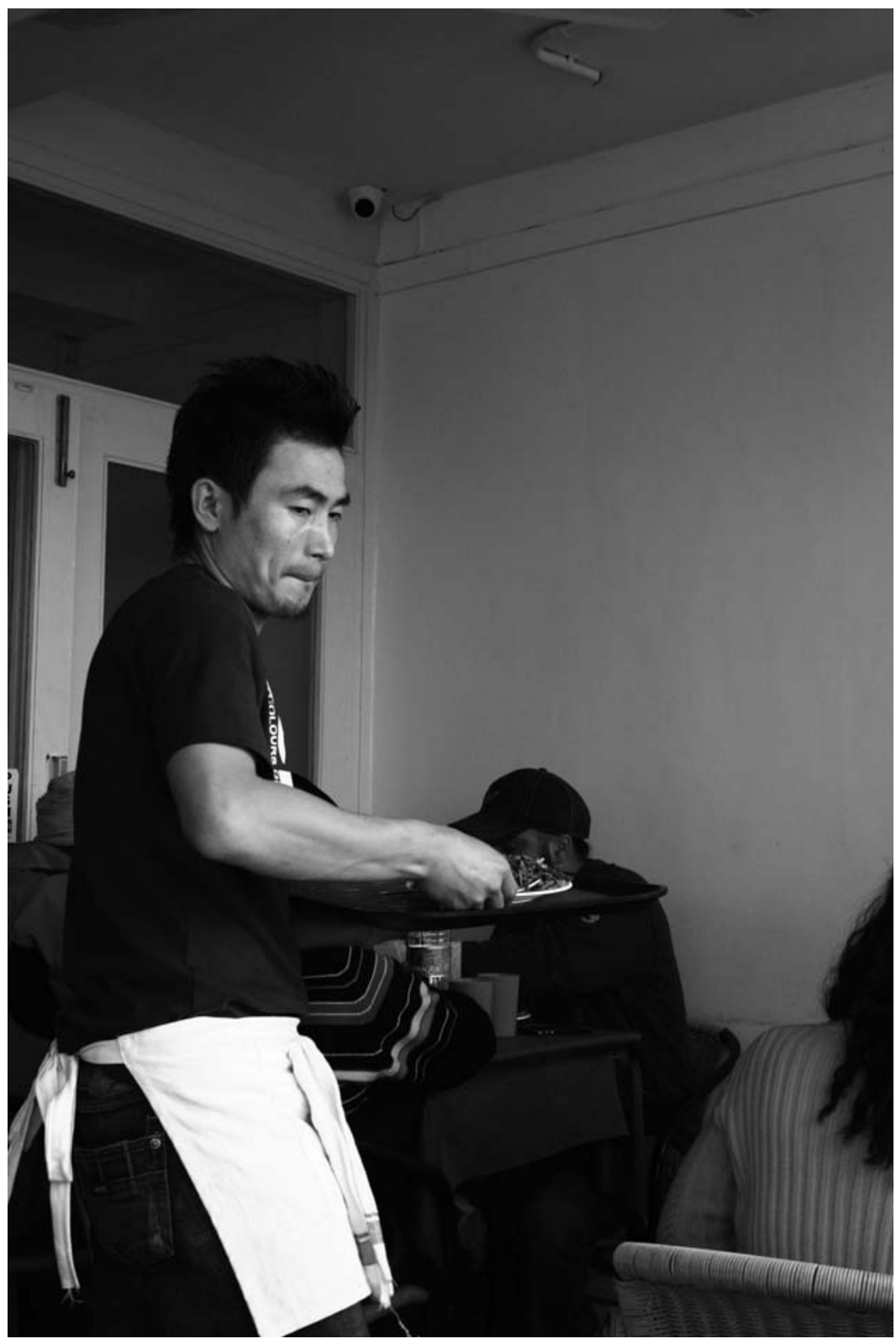


mainstream population about Northeast women's morality. Others felt that it made them targets for sexual harassment and sexual violence. This created a conundrum. The labour market gave women work and a degree of financial independence. Many Northeast men benefit directly from this and few are opposed to it. Yet the way women are exoticised and sexualised in certain jobs perpetuated stereotypes. These stereotypes increased the harassment of Northeast women and encouraged interest from non-Northeast men. Northeast men feel a responsibility to protect women and also feel a diminishing sense of control over Northeast women's sexuality and morality. Work is necessary but the independence it affords and the stereotypes it enhances make many men uncomfortable.

As noted in chapter 2, migration from the Northeast has grown rapidly in the last half decade and the familial configuration of migrants is also changing. The most notable change is siblings migrating to Delhi together. By migrating as siblings, one or more of the family can work while the other studies. This is especially common among middle-income and poorer families who do not have the money to send their children to study or who want to get their children out of the region as quickly as possible. It is common to meet female migrants working to support their siblings. The reverse - Northeast men working to support female siblings - was more unusual. This has a curious effect on gender relations: it has furthered the idea that it is easier for Northeast women to find work than for men. This has meant that many men stop looking. For some men, dependency on female siblings can be very emasculating. This feeling is stronger among men who do not have work but are trying to find it. Some face layers of demoralisation. They are unable to find work at home, they can't find work in Delhi, and they depend upon female siblings to survive. Of course, not all Northeast men are troubled by this, but it puts many into a situation very different from back home. Men depend more on females for survival, and women have begun to resent having to look after their male siblings. Adang, a Naga woman from Manipur, feels that this is becoming so widespread that it will have major consequences for gender relations back home. As she put it, 'why would you want to go home and marry a local man after working in Delhi for years looking after your brothers?'

Academic success highlights further gender differences that are not necessarily radically different from back home but that take on a different character in Delhi. Though there is scant numerical evidence to support it, the perception among Northeast migrants is that men drop out of university and college far more frequently than women. As discussed earlier, there are few barriers to education in the Northeast based on gender, especially in the tribal areas, yet once in Delhi, women seem to thrive in universities and colleges while men seem to struggle. 
Many drop out after taking up work, while others drop out after bad grades. Some fail at university and take up correspondence courses or enrol in degrees from dubious institutions to ward off questions from parents back home. Often parents don't know whether their children are going to classes or not, although some know their children have dropped out. I met students who continued to fail courses but whose parents continued to pay for them to stay in Delhi because they didn't want the shame of their children returning home. Explanations for male dropouts varied from alcoholism, laziness, and immaturity to lack of ambition. There was a strong feeling that many Northeast men in Delhi are simply despondent with depression. It also seems that the very scant class distinctions among Northeast migrants are evident here, if rarely elsewhere. Respondents from more modest backgrounds as well as those who couldn't afford to study or who weren't able to gain admission frequently disparaged those staying afloat with their parents' money.

\section{City Love, Frontier Politics}

These feelings come to a head around sexual relationships between Northeasterners and non-Northeasterners, and specifically between Northeast women and non-Northeast men. By 'non-Northeast' I include Indian men and foreigners, though the former creates far more resentment than the latter, as they are more common and embroiled in the geopolitics of the frontier. There is also a degree of anxiety about relationships between men and women from different tribal and ethnic groups, though this depends on which groups are involved and on other factors, especially religion. Anxiety about intra-Northeast relationships seems more common among relatives back home. For the sake of clarity, in the next section I will refer to non-Northeasterners as 'others' to emphasise the ways such relationships are viewed.

It is difficult to comment on the frequency of relationships between Northeasterners and others with any accuracy. All that can be gauged from the perceptions of respondents is that they are more common between Northeast women and other men, including Indian men and men of other nationalities (especially African migrants). There are relationships between Northeast men and other women, though these are less common. There are also relationships between Northeast men and other men and Northeast women and other women, but these were not discussed at all by respondents.

So why are there more relationships between Northeast women and other men? Respondents gave a number of answers. First, as discussed above, Northeast men are perceived to be boring, unromantic, and 
incompatible with the aspirations and lifestyles of many Northeast women. Second, other men are perceived to target Northeast women owing to the stereotypes that they are more promiscuous and their visibility as exoticised and sexualised subjects. Third, Northeast women have more contact with other men from the types of work they do, the kind of courses they study, and because they go out more often. Most respondents seemed far from convinced when giving these explanations.

Responses to these relationships vary and do include acceptance, though more often than not such relationships lead to tensions. Tensions occur between Northeast men and Northeast women over their behaviour or choice of partner, between Northeast men and other men over interference with 'their' women, and between Northeast women and other women over the alleged 'loose' behaviour of Northeast women.

Among Northeast migrants, women face disapproval from men and indeed some Northeast women for their choice of partner as well as from friends and relatives back home. This was a frequent topic of conversation among respondents in Delhi and back in the frontier. Mothers expressed their anxiety that daughters would marry an Indian in Delhi and never come home, brothers briefed younger sisters on the appropriate relationships they could have in Delhi, student unions warned members leaving for the heartland that they were carriers of unique ethnic identities that outsiders could not appreciate. Northeast women in Delhi had endless stories of interventions from home to disrupt relationships and even to disrupt rumours of relationships. One respondent from Nagaland related a story of her mother travelling for three days to Delhi in an attempt to ambush her and expose her alleged relationship with a non-Naga. No such relationship existed but her mother was convinced and chased one of her daughter's flatmates, a Tibetan male, out into the street before eventually being placated.

Many Northeast men (and some women it must be noted) felt that other men use Northeast women and cannot be serious about the relationship. Several respondents had negative experiences with such relationships, as when it came time to get serious, the men refused to tell their families about their Northeast partners and vice-versa. This affirmed the belief among Northeast men that 'their' women were being duped. Furthermore, Northeast men often found that their own friendships with other men were based on the expectation that they could be introduced to Northeast women. Adi, a student from Arunachal Pradesh, experienced a lot of racism in the streets during his first few months in Delhi. Almost all of his friends were from Arunachal Pradesh and a few other tribals from his neighbourhood. About halfway through his first semester at Delhi University, he was surprised by the 
attention he received from his Indian classmates. As he became more familiar with this group, he accepted their invitation to have tea. He soon learned that they were planning a party and wanted him to introduce them to Northeast women so they could invite them to the party. They also wanted to know if Northeast women were really as promiscuous as they had heard. To Adi, this was evidence that Indian men only see Northeast women sexually. He added, 'imagine if I had asked them to introduce me to their sisters and cousins because I read the Karma Sutra. They would beat me up.'

Respondents also singled out relationships between Northeast women and African men as troubling. African migrants in Delhi are usually always males, though there are some females and entire families, and their worlds interconnect with Northeast migrants in a number of ways. Many have difficulty finding housing due to hardened racist attitudes among landlords, and they end up living in the same areas as Northeasterners and attend the same churches. Initially during fieldwork I thought that relations between Northeast migrants and Africans were impressively convivial. But as time went on and I became more involved in Northeast life, I began to see an intricate micro-politics of race between Northeasterners and Africans, especially between the men. A number of Northeast men felt that African migrants go after Northeast women in order to get access to housing and stay in the country longer. There seems to be little faith in Northeast women seeing through such tactics. The murder of a Kuki woman by her Nigerian boyfriend in May 20II and the attempted rape of a Mizo woman by a group of African males in daylight outside a Delhi shopping mall have added fuel to these perceptions (NESCH 20IIb, 20IIc). Tensions between Northeasterners and Africans were evident in a number of episodes during fieldwork. In one of the Northeast neighbourhoods in south Delhi, an African man was talking to two Northeast women outside a shop. A pair of Northeast men walking just in front of me stopped and accosted the African man, and they started shoving one another. An argument broke out and escalated until the shopkeeper, an Indian, came outside and waved a bamboo stick to disperse the group. In another incident, a church minister from the Northeast remarked to me that he was worried about so many Africans coming to his church. He felt they were only there to meet Northeast women and he was sure they were involved in illegal activities (a common assumption about African migrants in Delhi and other parts of India). Yet he could not turn anyone away from the church.

In extreme cases, Northeast men threaten and intimidate women from their tribe who are in relationships with other men or are suspected to be. Intimidation is also extended to the male in question. These kinds of incidents are common, and during fieldwork there were 
a number of oft-repeated cases doing the rounds. These cases escalated tensions within Northeast migrant communities and neighbourhoods. Respondents related incidents in which different ethnic and tribal student unions based in Delhi became involved and a few cases when ethno-nationalist organisations from back home became involved. In one incident related by a female respondent from Manipur, ethno-nationalist groups from back home learned of two women migrants spending time with Indian males and contacted their families in Manipur, warning them to take action. They threatened to publicise the names and addresses of the two women in Delhi if they did not cease this behaviour. The topic of relationships is popular on Northeast blogs, chat rooms, and discussion boards. In one recent posting concerning a Manipuri (Meitei ethnicity) woman marrying outside the ethnic group, one participant argued that when Manipuri women marry other men, the culture is lost but when Manipuri men marry other women, the culture is preserved. This necessitated the policing of Meitei woman for the good of the Meitei nation, according to the posting (Manipur Talks 20I0). Such views are common among other ethnic and tribal groups as well.

Protecting the tribe or ethnic group from the influx of migrants and the abuses of the armed forces are a central component of masculinity back home. Back home, a particular tribe or ethnic group is usually the majority community in each 'ethnically exclusive homeland', and pressure can be applied to outsiders behaving in ways that offend local sensibilities. Furthermore, pressure can be applied to women behaving in ways deemed inappropriate by conservative social forces. In Delhi, leverage is more limited. As one respondent from Nagaland noted, 'they [women] don't even want our protection'. While the fragility of Northeast masculinity seems pitiable in these encounters, it must be remembered that many Northeast men have grown up witnessing sexual and physical violence directed at members of their community from outsiders and members of rival ethnic groups. Even when not witnessed directly, the stories of these incidents are integral to localised identity politics and activisms back home. Commemoration of these incidents back home ensures that the imperative to protect is strongly woven into masculine identities. Furthermore, as discussed in the previous chapter, violence against Northeast women in Delhi is very real, and the frequency and publicity around major incidents spur the protective behaviour among Northeast men.

In Delhi, Northeast men are confronted with the clash between their desires to protect women from their tribe away from home in a dangerous city and the reality that this protection is often unwanted. In fact, the more they try to protect, the more divisive gender relations become. In response, Northeast males adapt or confront, but more often than not they are confused. A few respondents expressed an urge to marry a 
Northeast woman from back home rather than one that has been living in Delhi. Stephen, the call centre worker from Nagaland, spoke of his desire to marry a Naga woman from his home district, Wokha. He had been involved in two serious relationships since leaving Nagaland both with tribal women - but both had not worked out. Among other things, he put this down to the fact that women from home changed too much in Delhi. He said he needed a 'God-fearing woman' from Nagaland rather than a Naga woman who had been living in Delhi. Again, this was not a universal sentiment but one expressed often enough to indicate a growing feeling that migration was taking Northeast men and women in different directions.

\section{Stuck in Delhi}

Migration leaves Northeastern men 'stuck in Delhi' and far from the action back home. For many migrants, this is a relief. Time in Delhi allows for a modicum of normalcy. There is time to socialise, to work, to consume, and given that most migrants are young, there is time to live free from parental scrutiny. While initially exciting, this lifestyle loses some of its appeal as the years go by. As discussed earlier, the Northeast is a highly politicised environment. Politics, particularly ethno-nationalist politics, are deeply woven into ethnic and tribal identities, and opportunities to participate in politics are everywhere in the region, whether it is through radical students unions, anti-development protests, or cultural preservation associations. Add to this pockets of the region where insurgency and counterinsurgency generate human rights violations, where militants evict members of one community from a particular area followed by counter-evictions, and where illicit cross-border trade pits smuggling gangs against border security forces, and life in Delhi can seem rather dull. As indicated before, this is gendered: Northeast women in Delhi experience new levels of independence by being away from home while Northeast men are cut off from the politics that shape everyday life back in the frontier. An important caveat must be made here. Both men and women participate actively in political life in the frontier, though at the rough end of the political spectrum males tend to dominate. And both Northeast men and women participate in politics in Delhi, particularly protests around violence or demonstrations related to issues back home. Yet only Northeast men mentioned missing political life from back home and feeling guilty for being unable to participate in struggles deemed essential for their region's future survival. Women were pleased to be away from the politics of home; men missed it. This suggests that a little of what it means to be a man is lost through migration. 
Migration has politicised some Northeasterners. A number of respondents mentioned that they were never interested in politics back home but became interested only after migrating to Delhi. For some, this was because their parents tried to protect them from politics as a way of keeping them out of trouble. For others, it was simply because they left home at I7 or I8 and thus could not understand the gravity of what was going on around them until they had space to think about home from a distance and engage in political talk with other migrants.

Others from areas that have been relatively peaceful in their lifetime did not think about the issues that affected other parts of the frontier until they reached Delhi. Northeasterners are drawn together in Delhi by their minority status and their experiences of mainstream society. In this environment, many take an interest in what other communities have lived through. Chen, a student from Arunachal Pradesh, said that it took coming to Delhi to see the 'true colours' of the Indian state. Coming from central Arunachal Pradesh, he experienced a fairly peaceful upbringing and saw only improvements from the increased development assistance by the Indian government. Since coming to Delhi, he has become close friends with migrants from other areas of the frontier as flatmates and classmates. Now he cannot believe the complacency of his friends back home in believing the 'myths of India'.

In Delhi, there are new opportunities to engage in the politics of home. As discussed in the previous section, this adds to the perception (especially among women) that Northeast men are fixated with the politics of home. For men, discussing politics helps to affirm their identity and masculinity, yet it also casts them in a poor light among many women. Northeast women then choose to socialise with others, and this angers and worries Northeast men who feel a duty to protect women in the city.

In contrast, some male respondents expressed caution in sharing political views with other migrants. One afternoon in January 20II, I was playing cards with four Naga male migrants from the neighbourhood in a flat in Humayanpur. The flat had no table so we sat on pillows on the cement floor. When we stood up for a periodic stretch, one member of the group, David, asked me whether I thought an independent Naga state was a good idea. Before I could answer, another member of our group, Tepa, interrupted and scolded David for bringing up politics. Everyone was quiet for a while. I asked if they ever talked about what was happening back home. All four were adamant that they never talked about politics. Even though they were all from Nagaland and all knew each other well since moving to Delhi, they were from different tribes and different towns. They didn't know anything about each other's political views. As the discussion went on, it was clear they were afraid to discuss politics because friendships in Delhi are too valuable. 
They depended on one another to get jobs, to have a place to live, to get through tough times. They had seen the divisiveness of politics back home, and for one member of our group it had major consequences for his family and necessitated his refuge in Delhi. I asked about student organisations and protests held by Northeast groups in Delhi. Tepa was dismissive of most of these protests. He argued that only students have time for this and working migrants can't afford to 'sit in the park' during the day.

Mayan, a postgraduate student from Manipur, said that people are very cautious about expressing their political positions on contentious issues from back home because not all Northeasterners in Delhi are exiles; the sons and daughters of police chiefs live and study alongside the sons and daughters of underground insurgent leaders. Furthermore, ethno-nationalist groups from home as well as state intelligence agents keep tabs on Northeasterners in Delhi. There is a reluctance to speak out too loudly, as one never knows who is listening.

For a number of migrants this triggered strong feelings of guilt. Seeking refuge from militarised environments drives migrants to Delhi, but they leave behind peers and relatives who are able to continue pursuing one cause or another. Feelings of guilt were strong among those who were involved in politics back home but chose to leave while others chose to stay behind. When those who remain are subject to harassment, arrest, and even death, the feelings of guilt intensify. One respondent from the Naga areas of Manipur remarked that he has cousins back home campaigning everyday against the abuses of the armed forces and for more autonomy in hill areas while he was in Delhi working in a call centre. He tried to follow what was going on but communications to his home area were poor. It made him feel useless, but now that he had chosen to leave he couldn't go back until he had made enough money to justify the decision to leave.

Work can make the feeling of futility worse. The kind of work available to Northeast men in Delhi is similar, if more limited, than that available to Northeast women. While this has created opportunities for migrants, it is also seen as lower-status work than what men would like to be doing back home. Unemployment at home is high, but those with work are farming, running businesses, working in the government, or contracting for the government. Working men have status back home. They have connections and contacts. In many cases, working men become 'big shots', a term respondents often used, meaning men who were known throughout their home areas and had power and influence. Working in Delhi is a marked contrast. Work is temporary in the sense that it does not build towards anything. While some respondents have been promoted in call centres and some have achieved meagre promotions in retail to mid-level management, working in Delhi does not 
bring any of the connections like work back home. More open respondents added that work in Delhi does not bring any opportunities to make money by 'playing the system'. This usually meant corruption.

By contrast, most work in Delhi is working for someone else. Yet it was not just working for others that frustrated respondents but also that they worked for Indians. Back home they might work for others but they were usually members of the same ethnic group, at least in the Sixth Schedule areas and the state bureaucracies. Few made a big issue out of this; the point was that they had little invested in work in Delhi and that the kind of work on offer, although decent, was emasculating. As Zana, a respondent from Nagaland, put it, 'here we have become the hospitality caste'. Yet respondents knew that in reality they had few choices. If they could make a living back home, many would not leave in the first place. I do not wish to claim that women are happy working for others and relish their niche in the labour market. While many female respondents aspire to work in the bureaucracy back home and others aspire to run businesses when they return, for many others, especially from non-elite backgrounds, work in Delhi is preferable to work they would be doing back home.

There are others ways aside from politics to demonstrate masculinity in Delhi. Most notable is the acceptance of clan duties among young men. Most tribal societies in the Northeast, and also the Meiteis, maintain clans as a crucial layer of social organisation. Clans serve different functions among different tribes and have evolved considerably over the last century. In a general sense, they are important institutions for local governance in Scheduled Tribe areas, for land distribution and enacting customary land laws, as the basis for civil society organisations, as a basis for church congregations, and as patronage networks in modern party politics. Clan leaders are often included in peace negotiations in conflict areas. Clans also reproduce group identities through the performance of traditional rites and rituals, festivals, and the maintenance of clan lands. Duty to the clan is still common for people in the Northeast as an extension of duty to the family. For most young men, taking on clan duties is an important coming-of-age ritual in most communities.

As most Northeast migrants come to Delhi without their parents and there are few middle-aged and elder migrants in Delhi, clan duties are taken on by men at a younger age than at home. With the increase in migration, Northeasterners are away from home during the years when they would normally be adopting clan duties. Without the opportunity to come of age back home, clan duties are important in the city and clans stand as crucial links to home and networks of support in Delhi. One of the most compelling instances of this during fieldwork followed the death of a member of the Lotha tribe (part of the apex Naga ethnic 
group). The young man in his early 20 s passed away on a Friday night after drinking alcohol and falling asleep. His flatmate then notified other members of the clan, one of whom related the story to me a few days later. A group of five Lothas accompanied the body to have an autopsy at the hospital. They waited for several hours and ensured the body could be stored for another day. Throughout Sunday they asked the Lotha community in Delhi for contributions to send the body home and raise money for the funeral back in Nagaland. Through clan networks, churches, phone calls, and neighbourhood visits, they raised I.5 lakh rupees $(3,400$ USD). The body was flown back to Nagaland on Monday morning. The respondent relating the story said that he didn't even know the deceased but he had to fulfil his clan duty and had spent three full days away from his job at a call centre mobilising clan members. The deceased was alone in Delhi and there were no elders, parents, or siblings to watch out for him; this meant that the clan had to step in. These tragedies enable Northeast males to take on roles of responsibility and enact traditional masculinity in tough times. It also allows masculine norms from home to be reclaimed in the face of ruptures produced by migration.

\section{Fluidity and Adaption}

Challenges to masculinity are paralleled by new ways of expressing masculinity. In making this point I am not suggesting that there is a linear progression between the masculinity of home and 'new' masculinities in Delhi. Rather, Northeast men express their masculinity in new ways that coexist with more conventional expressions. New ways of expressing masculinity don't necessarily replace old ones, but migration to Delhi necessitates the adoption of more fluid ways of being masculine and also makes these expressions more possible and visible than back home. I will focus on two of these: subaltern masculinity and cosmopolitan masculinity.

\section{Subaltern masculinity}

For Northeast men, being a minority community in Delhi can be very emasculating. In practice, it means that Northeast men cannot retaliate in the face of racism and discrimination, whereas at home they can. I do not wish to portray Northeast men as inherently violent, and this is a damaging stereotype against which they must continually battle. Rather, I want to point out the frustration respondents felt at having to put up with discrimination that they wouldn't have put up with at home. Northeast men deal with this frustration by adapting to minority 
status and producing a subaltern masculinity. By this I mean many Northeast men come to relish their role as outsiders - as marginal inhabitants of the city. Northeast men take pride in navigating and surviving the city for themselves and other members of the tribe and clan.

Subaltern masculinity can be seen in a number of actions. The first is navigating the labour market. Despite the demand for Northeast labour, being able to navigate the labour market can be the key to finding decent work. Many Northeast men look down on the work they are doing, as mentioned above, but being in work and being able to get work for others has become an important male role. For Northeast men who have been in Delhi for a while, usually a year or more, helping a new arrival find work by introducing them to a call centre boss, labour agent, or shop manager demonstrates their familiarity with the city and their own survival skills.

The second reflection of subaltern masculinity is negotiating with landlords. As many new arrivals cannot speak Hindi well, migrants who have been in Delhi for a year or more will often negotiate on their behalf. Yet the role of negotiator becomes even more important for Northeast men because they feel they can impose their physical presence on landlords during these negotiations, particularly on behalf of female migrants. This is crucial when there are disputes over rent or complaints by Northeast tenants against their landlords. In this role, Northeast men are able to enact some way of protecting fellow migrants from the city.

The third role allowing Northeast males to demonstrate their masculinity is creating a subaltern knowledge of the city. The Northeast 'map' of Delhi looks very different to most other ways of knowing the city. Knowing where to worship, where to live, where to get food, and where to shop makes Northeast males interlocutors for new arrivals. During fieldwork I accompanied Northeast migrants on missions across the city to find fresh pork, usually bought from south Indians, and fresh beef, usually bought from Muslim butchers. Knowing how much things should cost in Delhi is equally important, especially when it comes to rent (see above) and rickshaw fares. Almost all Northeasterners are dependent on either auto or pedal rickshaws to get around Delhi. Relations with rickshaw drivers are taken as barometers of Northeast migrants' knowledge of Delhi. Recent arrivals spoke of the hassle of negotiating with drivers and the fatigue at being constantly overcharged and having to argue. Those who had been in Delhi for longer, however, used their successful negotiations with auto drivers as evidence that they can handle the city and that they won't be cheated. They also used it as an indicator of improving Hindi language skills, a language they rarely speak elsewhere. Northeastern migrants pride themselves on being able to navigate and negotiate these different worlds within 
Image 5.2 Shopping for Beef. Nizamuddin, Delhi

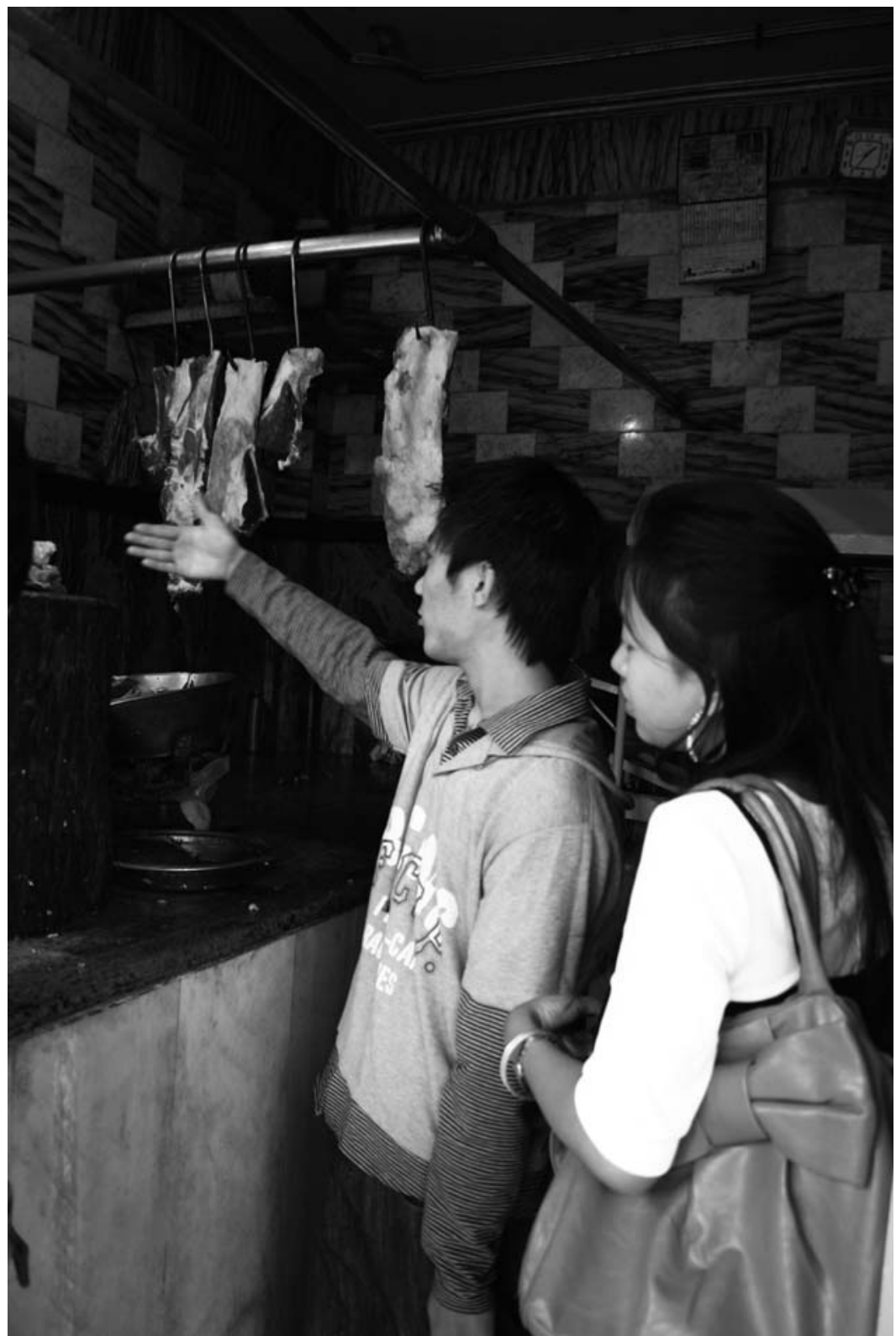


Delhi. For Northeast men, this is particularly important as it gives a sense of purpose and allows them to assume some elements of their role as protectors and enablers.

\section{Cosmopolitan masculinity}

Northeast identity is predicated on differentiation from the Indian mainstream. For Northeast men, migration to Delhi brings them in much closer contact with mainstream Indian society, and many have developed new ways of differentiating their masculinity. They do this by comparing themselves to Indian men and by drawing on cosmopolitan cultural influences. Regarding the former, this involves casting Indian men as treating women poorly and at the same time being excessively mothered. In contrast, Northeast men cast themselves as having more harmonious gender relations - evident in shared households, support networks, and the aforementioned protection of Northeast women. Furthermore, Northeast men view Indian men as predatory in contrast to their supportive clan-based networks. They see themselves as resourceful, independent, and capable compared to Indians in their equivalent class group who they see as dependent on domestic help and privilege.

Northeast men also shape their masculinity through cosmopolitan and decidedly un-Indian cultural influences. Here I am using cosmopolitanism in the manner advocated by Craig Calhoun that accounts for cosmopolitanism 'articulated with locality, community, and tradition' (2003: 875). I will discuss cosmopolitanism further in the following chapters. Northeast men in Delhi cast themselves as worldly cosmopolitans in contrast to their depiction as backward frontier dwellers in mainstream society. Cosmopolitism is demonstrated through knowledge of Western and Asian music, film, and fashion. Particularly notable is replicating Korean pop culture and global hip-hop culture. As will be discussed in the following chapter, Korean pop culture has a huge appeal among Northeast men and women (Kshetrimayum \& Chanu 2008; Akoijam 2010a). As respondents in Delhi and back in the Northeast pointed out, the Korean actors look like them, they are mostly Christian, they are always involved in love stories, and there is no singing and raunchy dancing as in Indian films. Engaging Korean popular culture is a way of resisting Indian cultural domination. In Delhi, Korean hairdressers and simple restaurants (as opposed to more expensive ones aimed at Korean expats) have grown in Northeast-inhabited areas and are often staffed by Northeast migrants. Korean DVD stalls are found in Northeast neighbourhoods. For Northeast men, Korean pop culture creates an odd juxtaposition. The fascination with Korean pop culture brings an androgynous metro sexuality to the warrior 
image. Styled spiky hair, hair dyes, Korean street fashion, and an appreciation for Korean films and food have become important expressions of cosmopolitan masculinity. Regarding hip-hop culture, this is expressed in dress: sneakers, basketball jerseys, baggy skateboarding jeans, and of course, Northeast rappers. Often the two influences are combined and overlap, as they do in other parts of Asia but rarely in India. Rock music is also popular, and the Northeast has a number of rock festivals that have spawned a number of bands; many make their living playing shows in Delhi and other cities. For Northeast men, unIndian cultural influences allow them to be more urbane and less parochial but continue to differentiate them from the Indian mainstream and thus preserve the key element of their identity.

Attention to the gendered impacts of migration reveals the ruptures to Northeast masculinity and the effects this has on gender relations. Migration is having a gendered impact: women thrive while men struggle. Replicating gender roles from home exacerbates tensions, leaving Northeast men to contemplate the clash between their desire to protect women from their tribe and the reality that many women do not want this protection. This begs the question: what impact does migration have on Northeast femininity? Recurring throughout the chapter are details of the ways women handle migration to Delhi. This is not to say they too do not experience rupture and disorientation, but there is also affirmation, particularly of women's independence and economic empowerment, sexuality, and familial responsibility. Women migrants navigate these duelling elements of what it means to be a Northeast woman throughout their time in Delhi, yet they also navigate them back home.

Migration distances men and women from the sites where gender roles are constructed and reproduced. Migrants are in Delhi working and studying, while friends and relatives are being 'real men' back home. Engaging in the politics of home is possible in Delhi, but many Northeast migrants are wary of open political expression. One of the few ways to enact male roles from home is through clan responsibilities, but these opportunities can be few. For Northeast women, being in Delhi gives opportunities to work, consume, and study that friends and relatives back home do not have. Friends and siblings back home are being 'real women' by undertaking household labour, having children, and taking care of family members, and migration frees women from their traditional roles and responsibilities, even if only for a few years. Yet perhaps the different experiences of migration also reflect changing gender norms back home, particularly regarding women's career and lifestyle aspirations. Does this suggest that men are hanging on to an identity firmly rooted in the past and that women are embracing one 
reflective of the future? Perhaps, although the extent to which this applies throughout the frontier needs deeper investigation.

Northeast men do adapt to life in the city and they find new roles as protectors and enablers able to navigate and survive the city. This in turn allows them to compare themselves favourably to the Indian mainstream and their perceptions of Indian masculinity. Far from home, new expressions of masculinity are more visible and also more necessary as a minority community in the city. Northeast men latch on to Western and Asian cultural influences to partially reshape what it means to be a Northeast man. Importantly, such new expressions coexist alongside more conventional expressions of masculinity, showing the fluidity of masculinity even among a group where masculine norms appear rigidly defined. Women also embrace these roles, and the expression of subaltern and cosmopolitan identities redraws lines of commonality and shared experience among male and female migrants discussed in the following chapter.

A final note on gender relations among Northeast migrants needs to be made here. In this chapter I have focused on the divergence among Northeast men and women in Delhi. This was a striking phenomenon of this study, especially considering that ethnic and tribal communities from the frontier are rarely subject to deep intra-community interrogation. They are assumed to experience mainstream Indian similarly rather than divergently. However, it is important to iterate that there was a flipside to this. Racism, violence, harassment, and shared ties (clan, tribal, pan-Northeast) mean that there are significant parts of the migrant experience that are common for Northeast men and woman. Furthermore, experiences of the city can have the effect of bringing men and women closer together. Unity is evident in times of crisis and in times of normalcy. 



\section{Place-making in the City}

For Northeast migrants, life in Delhi can be extremely challenging. Discrimination, harassment, and violence combined with changing gender dynamics and difficult economic circumstances make life in Delhi tough. Nonetheless, Northeastern migrants get on with life in the city in ways that are mostly invisible to other communities. In this chapter I go beyond the notion of Northeast migrants as 'victims of the city' to focus on the ways they exercise agency to navigate, negotiate, and ultimately survive and even thrive in the city. The key question at the heart of this chapter is simple: how do Northeasterners get by in Delhi? I am concerned with the tactics, practices, politics, and objects that are imperative to Northeast life in Delhi. Bringing these together and arranging them into neat themes is difficult. The concept of place-making, drawn from Henri Lefebvre's dialectical approach (I99I) to everyday life and the social production of space provides a loose framework for analysing the ways Northeastern migrants create place from the bottom-up in the context of attempts by governments and agents of capital to colonise space. Theorists of space and place, particularly in human and political geography, usually draw a distinction between the two, wherein space is rootless and shaped by external forces and place is rooted and shaped through human agency to produce and reproduce a social and moral meaning (Agnew 20II: 322). Often the struggle to create place out of space is a counter-hegemonic struggle, a concept particularly apt in the context of the reorganisation of urban space in India in a neoliberal era (Baviskar 2003; Bhan 2009). Yet clearly distinguishing between space and place can be empirically hazardous, and even the most localised place is usually affected by external influences of the space in which it is embedded (Merrifield i993).

Here I adopt John Freidmann's use of place and place-making as an entry point to understanding Northeast life in Delhi. Freidmann defines places as 'small spaces' of a city. Place-making occurs when a material space is inhabited and allows patterns and rhythms of life to develop. Freidmann arrives at seven propositions for understanding place-making in China (2007: I72). Five of these are relevant for Northeast migrants, as the final two apply to communities with longer roots in a place and closer relationships to state authority. First, place-making is a 
social process characterised by contestation. Place is not granted but made through social practices which often invoke competing claims over material space. Once created, places are not fixed but subject to continued contestation. Second, habitation of material space leads to patterns of everyday life centred on places of encounter where rituals of life are performed (such as parks, markets, churches, restaurants, houses). Third, places are impermanent and undergo changes over time. Fourth, the rituals of everyday life offer a sense of security and stability. Fifth, the autonomy of place is illusory and subject to regulation - in the case of Northeasterners, regulation by the property owners from whom they rent, by the city authorities who covert urban space for investment, and by the politically active middle classes who pressure the city authorities to re-classify space in the pursuit of varied agendas (Baviskar 20II).

For Northeast migrants, getting by in Delhi depends on the creation of places and the capacity to express ethnic and tribal identities. The two are linked. The practices that produce places are derived from expressions of identity and the existence of places enables further expressions of identity. In fact, the two help to define one another and vice-versa. However, designating which of the different tactics, practices, politics, and objects fit into place-making and which fit into expressions of identity can be precarious, as most actions and objects fit into both. The problem comes from having to take migrant experiences of Delhi and fitting them into a rigid conceptual framework. The consequences of this is to take an action, such as Nagas practicing dancing in Deer Park, a pastime observed on a number of occasions during fieldwork, and then deliberate over whether this is a place-making practice, an expression of Naga identity, an act of resistance against Indian cultural hegemony, or a reinvention of tradition to circumvent existing power relations. In trying to make a point in the conceptual language of trendy academic thinking, the action in question drifts further away from the empirical context in which it is performed and risks being either reified or given meaning adjacent to its original intention. In other words, it is possible to read too much into some actions, just as it is possible to read too little into others.

Being a Northeast migrant in Delhi involves expressing multi-layered identities - tribal, pan-Northeast, and cosmopolitan. Identity is a ubiquitous concern in Northeast India. Ethnic and tribal identity is the primary way of articulating political positions, accessing development 'goods', maintaining control over land, and achieving political autonomy. As the dominant way of expressing politics, issues that can be articulated through ethnic and tribal identity gain at least some response from the state, insurgents, and civic actors, whereas issues that cannot have difficulty gaining political traction. Given this, expressions 
of ethnic and tribal identity in the Northeast have become narrower in recent years. At worst, this results in inter-tribe and internecine violence, but more common is the hardening of boundaries between different ethnic and tribal groups. Yet in Delhi the shared experience of racism and discrimination on the one hand, and shared cultural and (often) religious beliefs on the other, has fostered pan-Northeast unity. Northeast unity does not always overcome parochial identities and often the two coexist, but it is important to note that in Delhi a kind of Northeast solidarity exists that is ephemeral in the frontier itself. As suggested in the previous chapter, many Northeasterners also see themselves as cosmopolitans, though a cosmopolitanism captured in a dual process of cultural enclosure as well as openness to worldly - and explicitly un-Indian - cultural influences (see Darieva 20II). Cosmopolitanism helps to refute the backward frontier dweller stereotypes and allows for a more common Northeast identity capable of incorporating global influences. Importantly, cosmopolitanism is utilised by Northeast migrants to differentiate themselves from the Indian mainstream and reiterate their separation. Expressing these identities helps to produce place in Delhi. The existence of places, 'small spaces', enable migrants to express their identity/identities. Through these actions, Northeast migrants can get by in Delhi.

\section{The Northeast Map of Delhi}

During a visit to Delhi in December 20II, I attended an academic seminar at a research institute with a friend and fellow academic originally from Manipur. After the seminar we were walking back to the metro discussing the paper and my friend was offering a thorough critique of what was presented. I asked him why he didn't comment in the seminar. His answer is instructive for the content of this chapter. He said that other academics in Delhi only take him seriously if he is commenting about papers on the Northeast. He went on to say that it is fine for Indians to become overnight experts on the Northeast but it is never accepted that a Northeasterner could know about the rest of India and comment on its society in any critical sense. As we walked, he gestured to the streets around him and added, 'I have lived here for ten years and I know Delhi in a completely different way to them. I know the city by foot and by bus. I know the city by places to get meat, alcohol, and meet other Manipuris.' He added that Northeast people have to mix with people from other communities that some people don't even know exist in the city. Despite seeing the city in a radically different way from other people he knew, as a migrant he would never be able to comment on it to people born in the city and be taken seriously. 
Delhi is a city of approximately I5 million people, and Northeast migrants are a tiny portion of this population. Yet because they work in such visible occupations, because of their racial differentiation from the majority of the population, their visibility in public and semi-public urban spaces, their exoticisation in the labour market, and because of the attention they attract, they seem to be far more numerous, especially in south Delhi. Northeasterners have a presence in the city, though their presence is concentrated in certain places. These places are both overt and concealed. Northeasterners occupy a set of disparate places where they live, pray, socialise, celebrate, and establish everyday patterns and rituals. Thinking about these places - these 'small spaces' in the city raises a number of pertinent questions: What are these places? Where are these places? How did they become Northeast places? Or indeed, Meitei places, Mizo places, Naga places? What do Northeasterners do in these places? Will they remain Northeast places? I will address these questions by describing the Northeast map of Delhi; the way of knowing the city alluded to by my friend above. Obviously, there is no single Northeast map of Delhi. However, it is possible to sketch a rough map that most Northeast migrants will recognise even if the locations are imprecise. Northeasterners live, work, and worship in different places in Delhi, but generally the range of different places is not immeasurable.

The Northeast map is a form of urban knowledge. It is a view of Delhi from a small community, though the Northeast view is very different from that of other marginal communities: slum dwellers, rural migrants, pavement dwellers, or informal labourers. As I have discussed throughout the preceding chapters, Northeasterners inhabit a very specific niche in Delhi. They work in certain occupations, live in certain neighbourhoods, eat certain foods that most other communities don't eat, practice minority religions (for the most part), and experience security and safety in certain ways affecting mobility and choice of transportation. Many other people in the city share some of these things, but only Northeasterners navigate through all of them. In other words, you may find a non-Northeasterner working in retail and going to church, but they are unlikely to live in a Northeast neighbourhood and roam the city seeking bamboo shoots or spend their weekends practicing dances for aoleang mon $\mathrm{u}^{8}$. There are a number of catalysts for movement into different places within the city: study and work are obvious and have been dealt with in other chapters. Here I will focus on three further catalysts for movement: neighbourhoods, food, and religion.

8 A Konyak Naga festival. 


\section{Neighbourhoods}

The Northeast map of Delhi links neighbourhoods throughout the city. Arjun Appadurai (1996) conceptualises neighbourhoods as localities that are relational, contextual, and also fragile. He posits that 'neighbourhoods are inherently what they are because they are opposed to something else and derive from other, already produced neighbourhoods' (I996: I83). Thus for Appadurai, neighbourhoods require 'the continuous construction, both practical and discursive, of an ethnoscape (necessarily nonlocal) against which local practices are imagined to take place' (I996: 184). In other words, place-making in neighbourhoods depends upon the construction of both locality in a certain space and the recognition of a nonlocal space outside the locality inhabited by others. For Northeast migrants, this means that creating neighbourhoods depends upon place-making in that particular locality as well as recognising the difference between that locality, other localities, and the city more broadly. Thus to ask a Northeast migrant where they live and why usually elicits a response along the lines of, 'I live in Humayanpur because there are a lot of Northeast people there and it is not like other parts of Delhi.' Being not like other parts of Delhi can mean the neighbourhood is felt to be safer, more familiar, and more friendly, and at the same time less dangerous, less alien, and less hostile/racist.

For Northeast migrants, community is formed within neighbourhoods but also between neighbourhoods in different parts of the city. Networks based on kin, clan, tribe, ethnicity, and friendship mean migrants are constantly moving within the neighbourhoods where they live and to neighbourhoods where other Northeasterners live. Neighbourhoods also contain ancillary places - what Freidmann refers to as 'spaces of encounter', that is public, private, and semi-private places where people come together and 'the daily rituals of life are performed' (2007: 272).

In Northeast neighbourhoods in the lal dora or village areas of Delhi, the streets are narrow and access by car can be very difficult. Residents usually have to walk through the narrow alleyways to a main access road or cut through different pathways to reach the main road. This means there are always people on the move on foot through the neighbourhood and that residents are always stopping to chat with friends in doorways, outside shops, and in the small restaurants.

In Humayanpur, the neighbourhood where I lived during my fieldwork, the market square is a vibrant space of encounter. The space itself is not a square in a planned sense; it is just an empty area. It is enclosed on one side by the back of a school wall. On all other sides there are small shops at the base of apartment buildings. Alleyways lead off the square in different directions. Vendors peddle vegetables from carts 
Image 6.1 Northeast restaurant. Humayanpur, Delhi

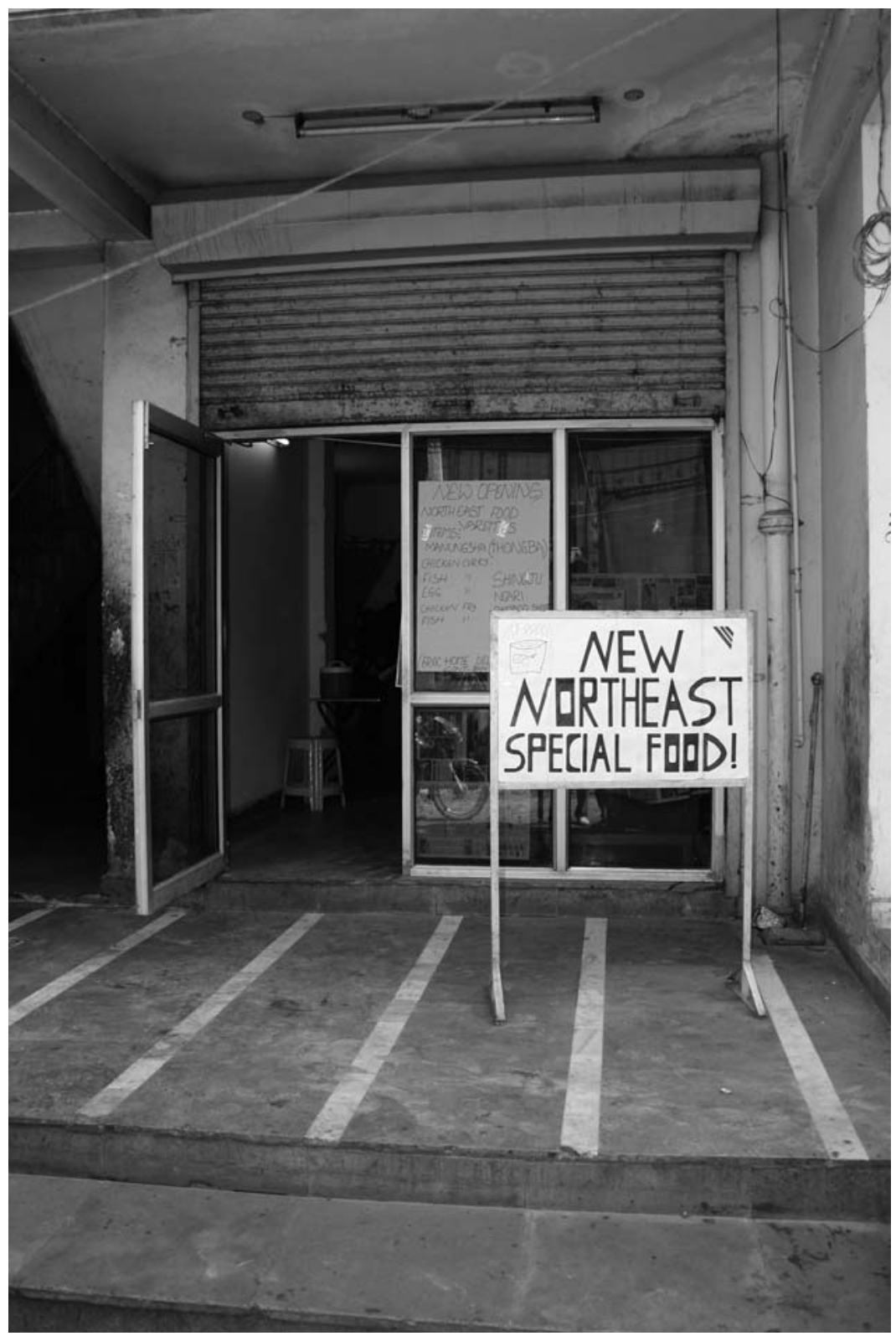


parked along the back of the school wall. Residents sit around the square on low concrete walls of different heights, plastic armchairs, and wooden stools. A few auto rickshaws are parked at the end of the only alleyway leading out to one of the feeder roads.

Northeast migrants spend time hanging out in the market square. It has become a meeting place, a place to stop by on the way home or the way out, a place to gossip, to kill time, to buy provisions, and to meet new arrivals from home. At first glance there is very little to designate this as a distinctly Northeast place. When I was first brought there by a friend from Nagaland and told that it was the hub of Northeast life in the neighbourhood, I was dubious. There were a few Northeasterners buying vegetables, eating at the Bhutia restaurant, and visiting the mobile phone shop, but it was not as I had imagined. However, my first impression had more to do with the time of day and the season.

As I became more used to the rhythms of the neighbourhood I learned the square was busiest at night when migrants had returned from work and were waiting for friends, buying food, or using the Internet cafes. On Sundays the square filled with Northeast migrants socialising after church, men in shirts and jackets and women in dresses and high-heeled shoes. In the early mornings, migrants met in the square chatting with one another while they waited for colleagues to join them before setting off for work at the call centre. Once the group was assembled, they walked to the main road to wait for the bus to collect them to travel to Gurgaon or Noida. A similar scene was repeated for the night shift workers. When the weather got warmer, migrants spent more and more time outside, as flats were poorly ventilated and boiling hot, especially on the upper floors. In the warmer months, men wore shorts and vests out in the square and women wore short pants and skirts. A number of acquaintances in the square said they would think carefully about wearing these kinds of clothes outside the neighbourhood as they would likely be harassed, but in this area they felt comfortable doing so. Even though there were non-Northeasterners around the neighbourhood, there was less chance of being harassed in this neighbourhood.

As mentioned in chapter 3, the lines between public and private are blurred in Northeast neighbourhoods. Flats are small and many are windowless, so the space between flats, landings and stairwells, and the streets and alleyways of the neighbourhoods become the spaces of encounter; especially in the very dense alleyways of Humayanpur and Munirka. In fact, parts of Munirka see so little natural light that a small open space where a number of alleyways intersect has been dubbed 'the airport' by migrants. In Humayanpur, migrants move between each other's flats without knocking and many leave their doors unlocked when they are inside. It is just like home. While it may be argued that 
all neighbourhoods posses these characteristics to some degree, this blurring of space needs to be understood in the context of the enclosure of space in middle and upper class Delhi neighbourhoods where gates, security guards, and cars are reshaping neighbourhoods throughout the city (Waldrop 2004). It is not just Northeasterners resident in these neighbourhoods but friends from other parts of the city that drop by, socialise in the square, and wander between apartments. Though clichéd, the neighbourhoods effectively function as an extension of village and neighbourhood life back home.

For a community racially distinct from the Indian mainstream, a sense of place comes from seeing Northeast people in the neighbourhood. Where Northeast migrants are physically present in the public spaces, the character of these neighbourhoods evolves. Northeast businesses are starting to open in these neighbourhoods: butchers, restaurants, DVD shops, clothes shops, hairdressers. This gives a sense of permanence or at the very least a longer-term view of Northeast migration to the city. Along with this comes a sense of safety. Alongside this sense of safety is a sense of belonging. Importantly, the sense of belonging is not to Delhi itself, but to the localities within Delhi, where a little piece of home is recreated. Home is not recreated through material space - which barely resembles anywhere in the Northeast, even its most dense urban areas - but through the lived experience of Northeast neighbourhoods.

Just outside Humayanpur is Deer Park, a large green space at the centre of the larger area known as Safdarjung. Deer Park is close to three Northeast neighbourhoods and during weekends it is a space of encounter for migrants living in the area and from farther afield. Northeasterners use the park for picnics, courting, meetings (for things like planning festivals and protests), and to practice music, singing, and dancing. Often I would go to the park with neighbours and friends while they rehearsed for cultural events. One afternoon I watched while a group of Nagas practiced a dance they were to perform at an upcoming festival. One member of the group played a tati, a string instrument made from a hollowed gourd. A group of ten men and women practiced their dance steps and a few latecomers joined in as they arrived. A crowd of onlookers visiting the enclosures of deer that give the park its name had gathered to witness what must have seemed a strange spectacle. The dancers were wearing fashionable clothes typical of Northeast youth: sneakers, jeans, t-shirts, and hooded sweatshirts. As the tati played, the men chanted in low rhythmic tone as they danced. Then the women chanted a higher tone on the alternate beat. A few people in the crowd took photos with their mobile phones. The dancers went on unperturbed. From time to time they would fall out of step and start laughing. After a while the tati player took a rest on a park bench. He 
Image 6.2 Naga migrants practicing dance. Deer Park, Delhi

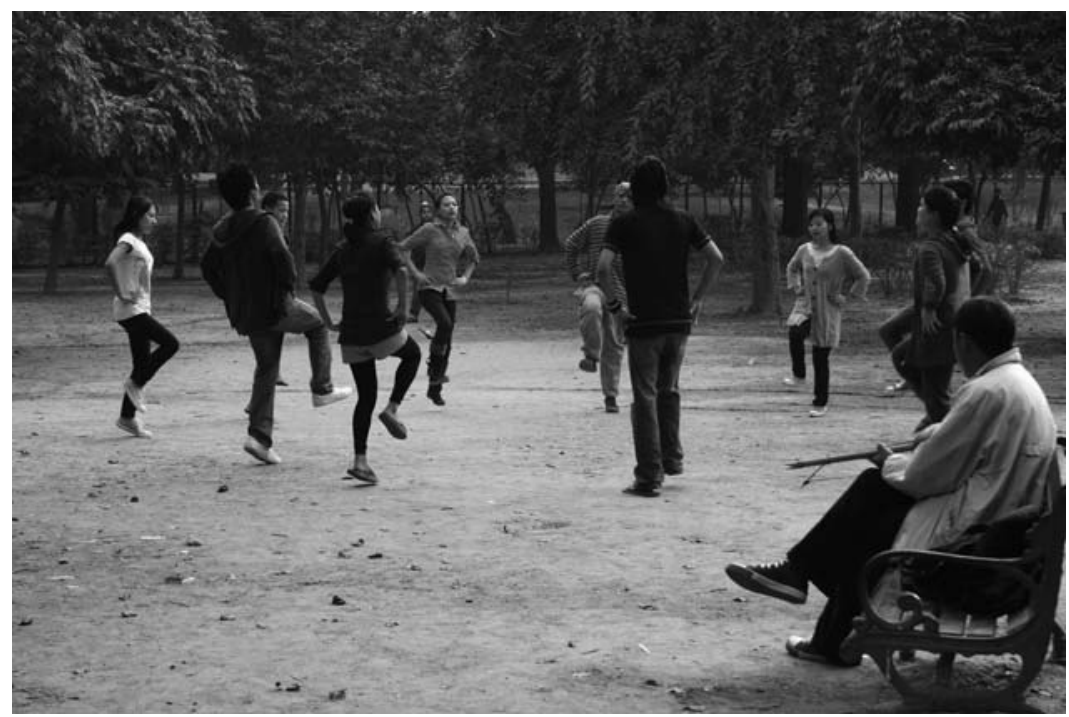

pulled out his mobile phone and started to play a game. Some of the dancers got out a badminton set and started to play. Others sat on the grass and we chatted. After about 15 minutes, more friends arrived and they started up again.

The scene was surreal. Within the same park lie the ruins of the Hauz Khas, a $13^{\text {th }}$ century mosque and madrassa built around a royal water tank. Remnants of Mughal Delhi lay all around. Yet here the area's most recent inhabitants were creating a small space by recreating a festival dance from steep hills over 2,000 kilometres and several ecological zones away, and doing so in the most recent fashions to boot. For the dancers this was their backyard, the nearest green space to where they lived, and part of their map of Delhi. Yet they were using the space in an entirely different way from other urban inhabitants.

\section{Food}

Northeasterners cannot get by in Delhi without access to Northeast food. Again I stress the difference in food from the existing variations within mainstream Indian society. Northeast food, especially from the tribal areas, is most unlike cuisine found to the west of the frontier and far closer to food found to the east, in Burma, and to the north, in China (Yunnan). Respondents would mention the centrality of food time and time again. Food is what respondents missed most about 
home. Being unable to get food is what they hated most about Delhi. Sharing food is central to friendships. Food is embedded in ethnic and tribal identities, and being a Hmar, a Khasi, or a Nishi in Delhi means being able to eat the food of home. Knowing where to locate food is fundamental to Northeast knowledge of Delhi. Veterans of the city build this knowledge over time and pass it on to newcomers. One of the enduring rites of passage for young migrants in the city is learning where they can find pork, beef, and bamboo shoots as well as the language and bargaining skills to locate food. During fieldwork I spent long periods of time accompanying migrants on food locating and buying missions. These missions revealed a great deal about the ways they navigate the city to get by.

Northeast food is varied and I do not wish to portray the food as wholly similar nor do I wish to overlook the core differences, particularly between the cuisine of the valley areas and of the hill areas. However, it is important to iterate that Northeast food is very different to food found in other parts of India - taking into account, of course, the dramatic diversity within India. Vaishnavite Hindu communities in Assam and Manipur observe food taboos according to religious beliefs but food habits are not uniform among these communities. Furthermore, many members of these communities just as readily ignore these taboos, and many respondents from these communities admitted that it was when they moved to Delhi away from their families that they began eating foods considered taboo for the first time.

Tribal communities on the other hand don't have any major food taboos. This does vary among some communities, particularly among stricter adherents of Buddhism and those from mixed families, but for the most part tribals eat everything and this is an important part of their identity. To avoid constant qualifiers in this section, I am going to refer to the general eating habits of migrants living in Delhi. Ahom and Meitei migrants are exceptions to some of these habits, but I encountered so many 'food rebels' breaking taboos when they migrated to Delhi that the general habits hold firm enough.

Migrants eat a lot of meat, including beef and pork. This is important in India, where $80 \%$ of the population is Hindu and do not eat beef and where the next largest group is Muslim (13.5\%) and do not eat pork. Pork is common among all hill communities in the region and among many Ahoms and Meiteis. For communities inhabiting steep topography, pigs are easier to keep than cows, and wild pigs can be hunted in the forests. Alongside pork, an essential part of most cuisine is bamboo shoots (again a product of hill ecology), as well as chilli, fermented fish (known by different names among different communities), yam, garlic, and ginger. Chicken and fish are also popular. In several hill areas, people eat dog, much to the consternation of others in India and farther 
afield. Hunting is an important part of village life, and thus all manner of wild animals are included in the diet from time to time. Snails are also widely eaten.

I will recount a food-finding mission to demonstrate the scope of the Northeast map of Delhi. One weekend, two Naga respondents - Zana and Lily - agreed to take me on a food mission. We had decided that we wanted to cook beef and pork for other friends in the neighbourhood. We first travelled from Humayanpur to the INA market by auto rickshaw and the Delhi Metro. INA is a large market popular with migrants from all kinds of communities. In INA, there is no one calling out 'chinky'. Zana explained that the sellers are used to Northeast customers as well as Chinese, Burmese, Nepalis, and other foreigners including African migrants. The sellers are mostly from other parts of India. A Malayali speaker from Kerala ran the pork shop we visited. The butcher began in English but Zana switched straight to Hindi. He told me this makes the butcher realise that he has been in Delhi a long time and is not going to be cheated easily. Used to Northeast customers, the butcher picked out parts of the pig with thick layers of fat. Zana wanted leaner meat and argued with the butcher until a leaner cut was produced. Zana claimed the lean cut was frozen and argued that this would make the weight too heavy. Given we were buying a large amount, the butcher soon agreed to lower the price. Across the narrow thoroughfare was a vegetable shop popular with Northeasterners and with migrants from East and Southeast Asia. The shop carried turnips, radishes, black sesame seeds and other roots and leaves difficult to find in Delhi. Here my friends greeted a number of other Northeasterners doing their shopping. Lily said, 'We shop here because they are used to us. They have the food we use and they don't try to cheat us because we are the best customers.'

Beef is not sold in INA, so we had to find out where we could get it. There is a shop in Humayanpur run by migrants from Mizoram that sells beef, but not all the time. Zana telephoned a friend from his mobile phone and asked him to go to the 'Mizo shop' (the shop has no sign and is just known as the 'Mizo shop') and have a look at the beef. A few minutes later he got a call back reporting that there was only a small amount of beef and it looked old. There is a butcher in Munirka run by Thangkhul Nagas from Manipur. Zana called a friend in Munirka. We waited for him to go and check. A few minutes later he called back to say the butcher was closed because they were at a wedding. Zana dialled another number and told me, 'This friend always knows where to get good beef.' This particular friend told us to wait for a few minutes. While we waited, he telephoned someone else from Manipur and then telephoned us back with directions to the best beef of the day to be found in the Muslim area of Nizamuddin. We arrived 
by auto rickshaw on the outskirts of a market area. Unlike INA, the market was small, and initially people in the market looked at us with some uncertainty. Zana and Lily did not hesitate. They walked until they found the wooden shop front they were looking for and began selecting cuts of beef from the hanging carcass. The butcher spoke only in Hindi and both buyer and seller were happy with the price, so we went back towards the INA Metro station.

After we got the beef, Zana made sure to report it to his friends by telephone so that anyone else wanting beef that day would know where to find good quality and have a rough idea of the price. Zana was very proud of this haul. He said to me, 'You see, most people don't know you can get all these things in Delhi. But we tribals, we have to know.' As we walked through the subway tunnel I took my turn to carry the plastic bags of meat, one in each hand. Zana commented, 'If a Hindu came, they would smell beef and run away; if a Muslim came, they would smell pork and run away. But if a tribal came, they would be happy to see you.'

As migration has increased, there are several restaurants serving Northeast food in Delhi. None of these would classify as fine dining. Most are a few plastic tables in a small shop. There are a few exceptions - Naga Kitchen in Green Park and a few of the more expensive Himalayan-themed restaurants. Northeast migrants also know where to get Korean, Japanese, and Tibetan food. Many of these places employ Northeast migrants and this helps Northeasterners to locate them in the first instance. As eating out is relatively expensive, cooking is important. In the lal dora enclaves where housing is crowded and the living areas are labyrinthine, neighbours get to know each other quickly and often this begins by sharing food, cooking space, and recipes. Stephen, a Naga, wanted to cook lunch for me one day but he didn't know exactly how to make the dish he wanted to cook. So he disappeared to one of the Internet shops in Humayanpur to look it up. Later he showed me the page where he found the recipe, a Facebook page called 'I Love Naga Food!' which at the time had over I500 members - the majority of whom are migrants in Delhi, Bangalore, and back in the Northeast.

Cooking also matters for identity because many Northeasterners believe that their ability to cook, which is common for both men and women, separates them from Indians, at least Indians of their peer group or equivalent class. Male respondents were quick to point out that Indian men never cooked and didn't know how (itself an illfounded stereotype but one repeated frequently by respondents), and they see them as dependent on their mothers or domestic helpers to do their cooking for them. As one respondent noted as her partner from Manipur cooked dinner late one night, 'One thing you can always count on with Northeast men: they can cook.' 


\section{Religion}

Religion epitomises the interlinked practices of place-making and expressing identity. Discussing religion among Northeast migrants encounters similar problems to discussing food. All major religions are practiced in the Northeast along with indigenous faiths, some of which are practiced in tandem with major religions. In the hills, religion is not necessarily simple, but most communities in the hills have been at least partially converted to Christianity over the last century and a half (Brekke 2006; Downs 2003; Eaton I997; Joshi 2007; Thong 2010). The notable exceptions are Arunachal Pradesh, where different tribal and ethnic communities follow different faiths including indigenous faiths - most notably donyi-polo 9 and Mahayana Buddhism - and Sikkim, where Hinduism, Buddhism, and Christianity coexist and in some cases overlap. In the valleys, all major religions are practiced, though among the Ahoms and Meiteis Vaishnavite Hinduism is more prominent. Christianity is making headway among the Meitei along with a revivalist movement of Sanamahism and the persistence of lai worship. ${ }^{\text {IO }}$

Religion is far from harmonious in the hills. Interdenominational tensions are common, especially in cases where one tribe follows one denomination and another tribe follows another. This can be linked to political parties and the use of state mechanisms as well. Tensions between followers of indigenous faiths and Christian communities are also common. Christian missionaries from the Northeast work among followers of indigenous religions in their own communities and in other communities. For example, Mizo missionaries travel to Arunachal Pradesh to try to convert followers of donyi-polo to Christianity. Similar attempts at conversion are taking place in the Imphal valley in Manipur among the Meitei, often in tandem with foreign missionaries, especially from South Korea. At the same time, revival movements have led to reconversions back to indigenous faiths in places like Meghalaya. Hindu political parties have begun to covert the region and Hindu civil society organisations are active, offering scholarships and bursaries to families in strategic locations.

The Northeast map of Delhi contains places where faith is practiced and spaces of encounter where religion serves social and welfare functions. There are scores of these places around the city. Most prominent against the backdrop of Delhi are churches. During fieldwork I attended

9 Donyi-polo is an indigenous faith practiced among several tribes in Arunachal Pradesh. It revolves around worship of the sun and moon.

Io Sanamahism is the pre-Vaishnavite faith of the Meitei. It has very localised forms but essentially is the worship of Sanamahi, the creator. Lai are different deities that take male and female forms. Often their worship is accommodated within Vaishnavism (see Parratt \& Parrat I997). 
Christian church services with migrants in different neighbourhoods and from different denominations. Churches were easier places for me to attend, given that as a Westerner, many in the congregation assumed that I was a Christian and made little fuss over my attendance. The size and membership of churches varied incredibly. Large churches, in both physical size and size of congregation, functioned in very similar ways to churches back home. The services were fairly conservative, established denominations had their own premises, and services were held in Northeast languages. Those in attendance were dressed very formally, especially on Sundays. The congregations often featured older members of the particular ethnic or tribal community as well; sometimes they were residents but more often they were parents and relatives visiting Delhi. Ministers in these churches were sent from the frontier, and the increase in migration makes Delhi an important extension of home congregations to be supported and watched over.

The large established churches are a contrast to the many small churches operating throughout the Northeast neighbourhoods of Delhi and close to the university campuses. Their services were held in existing churches shared by other communities, in schools, in community halls, and in rented rooms. Many of these small churches represent denominations less established in the Northeast. Some of these churches had very small congregations and started as breakaway churches from larger entities and in some cases from other small entities. In attempts to boost their numbers, some of these new churches held services in English. This gave them a pan-Northeast congregation and also attracted other Christians in Delhi - most notably African migrants, dalits, Nepali Christians, and Christians from Burma (mostly Chin, Kachin, and Karen refugees). The 'new' churches were the antithesis of the established churches and were characterised by casual clothes, younger preachers, live rock music, and lots of social events.

Another phenomenon of note was the launch of new churches for small ethnic and tribal communities in Delhi. During the duration of my fieldwork, the Mara community, a tribal group in Mizoram and across the border in Burma numbering about I००,০০০ people in total, opened the Mara Evangelical Church in west Delhi with a congregation of between 150 and 200 members, including Mara from India and from Burma. For small ethnic and tribal communities, making their own space for worship is an important part of establishing themselves as a distinct group in Delhi. They are also spaces where communities divided by international and internal borders join one another in a new place.

Several respondents pointed out that religion worked differently in Delhi than back home, though they meant different things by this. Vankhuma, a postgraduate student from Mizoram, said that in 
Mizoram the denominations were always competing, but that in Delhi all the denominations came together. Other respondents used the opportunity of being away from parents to switch religions and denominations. Bahrit, a student from Meghalaya, was part of the Khasi Presbyterian Church back home and when he first came to Delhi. He found it very dour and when some Naga friends invited him to their evangelical church he went along and then became very involved. He said that his parents still didn't know and when they come and visit he takes them to the Khasi Presbyterian Church so they don't suspect anything. Other respondents took the opportunity of being away from home to stop going to church. During one conversation with two Naga flatmates, this admission revived an ongoing argument. One of the flatmates was angry with his friend for no longer going to church and said he only used the church when he was in trouble. The reverse is also true. Some respondents started going to church for the first time in Delhi or for the first time since they were small children. Other respondents admitted that they went to church to meet members of the opposite sex. This can have unwanted consequences, however: as one respondent told me, he had changed churches twice to escape from exgirlfriends!

The dominance of Christianity among tribal migrants can marginalise non-Christians to some extent. Hindus and Muslims from the Northeast have places to worship, though those who followed indigenous faiths found Delhi a difficult place to perform religious rituals. Nani, a postgraduate student from Arunachal Pradesh, practices donyipolo and said it was almost impossible to keep this up in Delhi. Migrants from Ziro, her hometown, attempted to get together and perform donyi-polo rituals but it was difficult to make the necessary sacrifices and as a group they lacked correct knowledge of the rituals. She also mentioned that not being a Christian meant she had fewer ways of networking and getting support in Delhi. She feared that many other followers of indigenous religions would end up converting to Christianity in Delhi; a fear common in Arunachal Pradesh itself (Riddi 2009).

Places of worship dot the Delhi landscape with small spaces that are (almost) wholly Northeastern. These small spaces invigorate a sense of belonging and an untethered link to home. Practicing minority religions in Delhi is also a way of refuting north Indian society by creating alternate spaces of engagement among and between Northeast communities. As spaces of encounter, places of worship help to reinforce Northeast identities, as with the Mara church, and fashion new ones, as with the pan-Northeast evangelical churches held in basements in Moti Bagh. 
Alongside spirituality, these places of worship are also spaces for networking and support. The role of religious communities among migrant and diaspora communities is well studied and understood. Religious communities help newcomers find work, housing, and contacts. As most Northeastern migrants come to Delhi without their parents, religious communities provide support for migrants when they are sick, when they have been subject to violence, when they have financial difficulties, and when there are problems back home. Respondents related incidents where churches helped raise money for surgical operations, emergency housing in the case of domestic violence, alcohol rehabilitation, post-traumatic stress counselling, and for funerals back home. As few migrants are members of labour unions and personal insurance is still a new concept in India, religious communities provide a pool of resources, albeit often stretched thin, that enable migrants to endure unexpected events in Delhi and back home. Religious communities provide moral guidance and in many cases moral policing.

\section{Protesting in Delhi: New places, new identities?}

The Northeast map of Delhi reveals the places where migrants have established themselves. In this section I focus on protests by Northeasterners in Delhi. Protests capture the moments when migrants step out of small places and make claims in the less bounded spaces of Delhi's public sphere. Despite the aversion to politics discussed by some respondents in the previous chapter, protests by migrants in Delhi are becoming more common, suggesting a growing level of confidence among migrants in voicing their discontent and advocating for justice. Protests are also expressions of Northeast identity. Through protests, Northeasterners articulate and build shared positions on different issues. However, protests also emulate divisions from home, and at times Delhi becomes a theatre for enacting parochial politics.

In this section I discuss protests by migrants along parochial lines and as a shared Northeast community. Protests and other events are organised through word of mouth, churches, posters, and increasingly through electronic media including Facebook. Divisions between ethnic and tribal groups exist in Delhi, though the edges are much softer than back home. Most communities have their own associations in Delhi. For example, Mizos have the Mizo Student Union Delhi, the Mizo Welfare Association, and the Mizo Christian Fellowship. Some of these associations are branches of larger associations back home. Some migrants are members or associates of larger apex groups, such as the Naga Student Union Delhi, and then of smaller groups around their 
tribal affiliation, such as the Zeliangrong Welfare Association Delhi. These associations carry out important functions, especially welfare provision. They lobby against violent attacks on migrants. They host political leaders from back home when they visit Delhi. They organise festivals and rituals. As mentioned in chapter 3, Northeast migrants are rarely part of labour unions - both because of the dominance of ethnic over class politics back home and the low levels of unionisation in the sectors in which Northeasterners are employed in Delhi. Northeast migrants moreover rarely fall under the remit of NGOs operating in Delhi. Therefore, insurance and welfare functions are the domain of ethnic and tribal associations and religious organisations. These associations underpin the social networks that provide support for migrants when they first arrive in the city and during tough times. However, as alluded to in the previous chapter, they can also play a monitoring and policing role that frustrates some migrants.

These associations are not necessarily propagators of narrow ethnic identities. Many respondents were easily able to coexist within and between different ethnic and tribal associations. However, migrants are not insulated from events that happen back home. Delhi is not a clean slate, so to speak. Movement back and forth and close contact with friends and family back home enabled by communications technology mean that tensions and violence back home can have repercussions among migrants in Delhi. As discussed in the previous chapter, many migrants actively avoid engaging in the politics of home, while others are politicised. However, from time to time issues come along that galvanise migrants into divisive ethnic camps. During fieldwork in late 20IO and early 20II, the most discussed divisions were among migrants from Manipur. Tensions and violence between the hill and valley populations of Manipur and between the different hill communities have escalated in Manipur in recent decades (Arambam 2007; Gailangam 2008; Maring 2007; Oinam 2003). At the same time, state power has become further concentrated in the hands of the Meitei majority (Jilangamba 20I0; Kikon 20I0; Oinam 2008; Samom 2010). Conflicts, high levels of corruption, and the dire state of the local economy ensure that large numbers of people from all ethnic groups in Manipur migrate out of the state. Whole families from Manipur have moved to Delhi. Migrants from Manipur are commonly found working in malls, restaurants, spas, and call centres.

Animosity between the different ethnic groups from Manipur endures in Delhi, and respondents from Manipur mentioned that things have been even worse since the Mao Gate incident in mid-2oro. Mao Gate is the entry point to Manipur on the highway from Nagaland. In May 2ого, Thuingaleng Muivah - the general secretary of the National Socialist Council of Nagaland-Isak-Muivah (NSCN-IM), the leading 
Naga independence organisation - conducted a peace and reconciliation tour of all the Naga districts in Northeast India in preparation for another round of peace talks with the Indian government. Muivah was born in the Ukhrul district, a Naga majority area in Manipur but claimed by the NSCN-IM as part of a united Nagalim (the name given to the Naga territories in India and Burma). His visit to Manipur for the first time in 40 years was deeply symbolic.

The Meitei community and the government of Manipur opposed Muivah's visit, as they see the peace process as a threat to the territorial integrity of Manipur. The peace and reconciliation tour came at a particularly sensitive time in community relations in Manipur. In April 2010, a number of Naga civil society groups led by the All Naga Students Association of Manipur and the umbrella United Naga Council called for a boycott of the council elections in the hill areas to protest the lack of autonomy (Samom 2010: 33). The government of Manipur was undeterred and scheduled the elections for late May. In response, the boycott became a blockade of the two main highways into Manipur, National Highways 39 and 53. This essentially cut Manipur off from the rest of India. The blockade was to last for over two months.

It is in this environment that Muivah attempted to bring the peace and reconciliation tour to northern Manipur. The government of Manipur announced it would bar Muivah from entering. The governments of Manipur, Nagaland, and India held crisis meetings. Meanwhile, Muivah waited on the Nagaland side of the border at Mao Gate while these deliberations took place. A group of Naga civil society organisations sent ultimatums to the government of Manipur to allow Muivah entry. The government of Manipur re-affirmed its ban. At the same time, civil society organisations in the Imphal valley protested against Muivah's visit. Those supporting Muivah attempted to stop security forces from reaching the gate to block his entry. On 6 May, an enormous gathering of Naga women organised by the Naga Mother's Association and Naga Women's Union Manipur staged sit-in protests on both sides of the border. Manipur security forces tried to stop the demonstrators from reaching the border post and fired tear gas and bullets. Two Naga youths, Chacko and Loshou, were killed and over 70 people were injured. Footage of the shootings shows crowds of protestors, mostly women, running to the side of the road to get shelter. The uncertainty that followed meant many protestors who had come to Mao Gate could not return home and as many as 4000 persons were estimated to be displaced in the weeks that followed, trapped by blockades (Kikon 20IO: 4I). Manipur remained cut off from the rest of India until I8 June.

The situation also played itself out in Delhi. Student organisations in Delhi issued statements of support and condemnation depending on whom they were representing. Naga student groups protested on 7 May 
after the shooting took place, with the largest protest taking place at the Jantar Mantar, located on Janpath, one of Delhi's main thoroughfares close to the central Connaught Place. A group also marched to the Manipur Bhawan (Manipur House) and tried to force entry (E-pao 20IOa). They reportedly damaged the building. A much larger protest took place on Io May, this time outside the prime minister's residence. Led by the Naga Student Union Delhi, the protestors held signs criticising the Chief Minister of Manipur, Iboi Singh, condemning the Manipur security forces, and calling for justice. One of the more striking signs was held up by a young Naga woman and read 'We have lost two sons'. Nagalim flags were also featured and roses were laid next to portrait photographs of the two deceased. Scores of protestors were arrested. At the same time, Meitei migrants were angered that the state was being blocked off. The price of fuel and food had skyrocketed and many were concerned about friends and family members back home. Meitei organisations held their own demonstrations calling on Nagas to end the blockade. Neighbours, friends, colleagues, and even flatmates found themselves on opposing sides as the standoff dragged on.

While Delhi is where parochial politics are enacted, it is also a place where they can be tempered. Delhi provides a neutral space where divisions from home can be discussed in a less politically charged environment. Respondents recalled that churches across Delhi led prayers for peace in the weeks following the incident. On 9 May, church leaders and members of different Northeast communities lit candles, recited prayers, and sang hymns at India Gate urging for peace (E-pao 20Iob). Aside from the incredible spectacle of Northeasterners occupying one of Delhi's most famed monuments, this was a rare public articulation of frontier politics in the heart of Delhi. Meitei and Naga associations held meetings with one another to explore ways through the impasse. Associations in Delhi representing communities from other Northeast states also became involved in trying to ease tensions. Several respondents argued that they were protesting the actions of the government of Manipur, the chief minister, and the security forces and not the Meitei community. Indeed, many Meiteis feel the same way about the chief minister and there was a shared sense of anger at Iboi Singh that brought some Meiteis and Nagas together. Members of both communities worked hard to steer conflicts away from reactionary communalism and towards identifying the problems at the core of the issue. When I began fieldwork in December 2010, the incident was still being discussed and came up frequently in conversations with members of both communities, though the worst of the tensions had passed. 


\section{Solidarity}

Parochial identities can take precedence in times of crisis. However, what is far more notable among Northeast migrants is a nascent panNortheast identity emerging from solidarity. Here I will discuss solidarity in relation to two unifying issues: the AFSPA and racism in Delhi. These issues have become 'safe' issues in that they are rarely divisive among migrants, as claims are made on the Indian state and the Delhi authorities. This helps to cultivate a shared identity and shared politics in much the same way that diaspora politics functions for other migrant communities (Hall 2003).

The primary example is protests against the AFSPA in Delhi since the mid-200os. Protests against the AFPSA do take place in the Northeast, though they are isolated and fluctuate depending on the magnitude of the conflict and of the military response in different locations (Bora 20IO; Gaikwad 2009; Deo \& McDuie-Ra 20II). One of the limitations of protests against the AFSPA in the Northeast is that the act itself prohibits the assembly of more than five people. Protests in Delhi are able to be held without the threat of military action and have become more common since 2004. Anti-AFSPA protests are held several times a year, usually following an incident in the Northeast or a political deliberation in Delhi over the act. Irom Sharmila, a peace activist from Manipur who has been on a hunger strike in protest over the AFSPA for over ten years and is kept alive by an intravenous drip, has become a leading symbol in the protests and has helped to galvanise different ethnic and tribal groups to contest the act together. In April 20II, a protest organised by the North East Student Organisation - itself a reflection of Northeast solidarity - featured huge banners of Irom's face and protestors wore black cloths across their faces. The protest included members from across the Northeast community in Delhi including members of tribal groups from Arunachal Pradesh and parts of Meghalaya who have had little direct experience of the act. This is different to protests in the Northeast that are usually contained in one location and feature only members of a particular community. This is reconfigured in Delhi and reveals an emergent pan-Northeast identity. This identity is territorialised in a broader way. For migrants, the AFSPA is a draconian law used against their region, not just their tribe or ethnic group. Individuals will protest against the AFSPA even when it doesn't affect their particular home area or tribe, but because it affects some part of the Northeast.

Another example is unity in the face of racism, discrimination, and violence. Respondents often discussed the ways racism brought them 
together. Chen, a student from Arunachal Pradesh, summed it up nicely by saying, 'Northeast people don't bond so much. But if you get a Nishi $^{\text {II }}$, a Khasi, and a Mizo in a room, all you have to do is talk about racism. We all experience it every day. It will get us together.' Nani, also from Arunachal Pradesh, made a similar point. She said few things bring Northeast migrants together, 'but if there is violence, especially rapes, then we will all come and protest. Our student unions usually organise it. They link with each other.' Unlike protests around the AFSPA which are about what happens back home, protests around violence are in response to their experiences of the city. One recent protest came following the gang rape of the Mizo woman at gunpoint in November 20Io discussed in chapter 4 . Up to 2,000 people are reported to have marched, led by members of Mizo associations and church groups but supported by the Northeast community in Delhi. The woman was attacked after being dropped off in a Northeast neighbourhood by the service vehicle from her workplace, suggesting that the culprits were monitoring Northeast localities looking for women returning home late at night. The police handling of the incident and the failure of the call centre to take responsibility for ensuring the safety of workers increased anger among migrants in Delhi.

Other attacks have yielded protests, yet many respondents felt that the momentum from these protests quickly dies until there is another incident, suggesting that sustained political pressure is difficult for an exceptional community with no formal political representation in the city. What is interesting to note here is that the targets of these claims are the local authorities in Delhi, especially the police and the National Capital Territory Government. This is in contrast to the protests against the AFSPA that target events back home, suggesting a shift in the territorial perception of citizenship. Northeast migrants make claims related to home where they 'belong', but they have increasingly begun to make claims related to their lives in Delhi where they live but where they are marginalised and their citizenship is constantly doubted. Importantly, Northeast migrants are not seeking inclusion in the city; instead they are seeking justice during their stay in the city. This enhances their sense of place and belonging by publically demonstrating discontent and calling on authorities to take action. The message being sent is that they are not going anywhere, and the city needs to get used to it.

II One of the tribal groups of Arunachal Pradesh. 


\section{Cosmopolitanism}

At home in the Northeast, identity is predicated on being un-Indian and adhering to the practices and politics of clan and tribe. However, shifting and multiple identities are rarely given consideration and the communities of the Northeast are viewed in much the same ways as they were at the time of Indian Independence in 1947. Discussing identity with Northeast migrants in Delhi renders shifting identities more visible. I hesitate to infer that migration itself is wholly responsible for shifts in identity, as many of these aspects are also visible in the Northeast. However, in Delhi they are articulated more forcefully and more instrumentally.

It is not just expressing ethnic or tribal identity, or even nascent Northeast identity, that matters in Delhi but challenging what being it means to be a Bhutia, a Naga, or a Mizo, in contemporary India. Public representations of peoples from the Northeast continue to be mired in colonial anthropological modes. The stereotype of the exotic frontier dweller from the pure and unspoiled remote hill country is persistent. Government policy and planning continues to represent frontier peoples as backward prisoners of facile ethnic politics and in need of state guidance. Yet Northeast migrants show the ways that external global cultural elements have become an important part of articulating who they are and who they are not. Cosmopolitan elements affirm a common Northeast identity and challenge dominant stereotypes.

Ethnographic accounts of cosmopolitanism focus less on pretentions to a universal humanism that is the antithesis of more narrowly conceived national and ethnic identities, and instead pay attention to a more complex interplay between ethnic, national, and worldly components in grounded social contexts (Calhoun 2003; Darieva 20II; Pollock et al. 2000; Robbins 1998). As Schiller et al. argue, rootedness and openness to external influences need not be seen as oppositional. They contend that 'a cosmopolitan dimension and the maintenance of ethnic/national ties or religious commitment and identities can occur simultaneously in the daily activities and outlook of some mobile people' (20II: 400). Mica Nava's study of popular cosmopolitan expressions in England in the early $20^{\text {th }}$ century draws attention to vernacular expressions of cosmopolitanism in everyday life. Nava shows that for English women of a certain background, cosmopolitanism 'was not about the erosion or disavowal of difference ... (but) a counterpoint to the perceived conservatism of the dominant culture' (2002: 94). Migration is an important part of understanding grounded cosmopolitanisms, and Pnina Werbner's study of working-class cosmopolitanism among transnational Pakistanis (I999) shows the multidirectional nature of cultural exchange among those crossing borders. And in Gordon Mathew's rich 
ethnography of Hong Kong's Chungking Mansions, Africans and South Asians experience cosmopolitanism through 'low-end' globalisation, a cosmopolitanism that is 'beyond the imaginations of much of the Hong Kong world that surrounds it' (2OII: 2I4). These approaches to grounded cosmopolitanisms that do not necessarily erase or discourage ethnic and national identities but enable a certain group to create place in distinctive ways, often in contrast to the larger space around them, are illustrative of the Northeast migrant experience.

Although viewed as marginal and 'backward' in mainstream India, Northeasterners are linked to global networks in ways that bypass the rest of India. Here I am not just referring to cross-border networks between communities in the Northeast and their kin across international borders but to connections beyond the frontier to global subcultures. Cosmopolitanism is an important part of Northeast identity in the frontier, especially in urban areas. Yet in Delhi, away from the frontier, cosmopolitanism takes on added significance as a way of differentiating oneself from the Indian mainstream and contesting archaic stereotypes. Furthermore, being away from the insularity of home can allow for more vibrant expressions of cosmopolitanism among some migrants. Respondents demonstrated a number of cosmopolitan influences in what they consume, what they reproduce, and what they relate to. I will focus on three: fashion and music, the Korean Wave, and global Christian culture.

\section{Fashion and music}

'If you are trying to spot the next hot trend, head to the Northeast. Forget the metros, street fashion is born in Shillong, Kohima, and Imphal' (Banan 20I0). The statement above opens a feature story on Northeast fashion in the weekly news magazine Tehelka. Later the author adds that fashion trends 'hit Gangtok, Shillong, Imphal, and Kohima before they hit mainland India.' In a feature on Northeast fashions in Motherland magazine, a Delhi-based subculture journal, a young Naga fashion blogger notes that Nagas are adopting fashions way ahead of other parts of India. The article notes: 'In Delhi, adopted trends are late to catch on and stay long after their expiry date; nothing like that happens in Nagaland' (Merelli 20II: 23). Fashion blogs abound as do fashion magazines published in various Northeast languages, such as Lunglen, a Mizo fashion monthly. The fashion show (complete with runways), endless beauty contests, and local versions of American Idol (Manipur Idol, Mizo Idol, and Naga Idol being the best established) have become staples of life in the frontier. Even local agricultural fairs in rural and semi-rural areas will have a fashion show and beauty contest. Northeastern performers have also fared successfully in national music 
competitions, including Indian Idol (Prashant Tamang from Darjeeling won in 2007, Sourabhee Debbarma from Tripura won in 2009, and Amit Paul from Meghalaya was a runner up in 2007) and the Naga band Divine Intervention won MTV India's Rock On 2010 competition notably singing in Hindi, inviting a mix of consternation and fascination back in the frontier. These successes are drawn from a rich culture of rock, rap, and punk music in the Northeast, developed through decades of rejecting Indian popular music and Bollywood. Add this to the presence of Northeast men and women in fashion boutiques, spas, and restaurants in cities throughout India and it is evident that there is a transformation of the subjectivity of ethnic and tribal communities underway. This subjectivity may take different directions. In one direction lies the potential to enhance the sexualised stereotypes, especially for Northeast women. In the other direction lies the potential to challenge the stereotypes, particularly related to backwardness and isolation.

The images of fashionistas and rock stars jar with the half-naked tribesman floating down the river on a bamboo raft from the Incredible India commercials. The people in the 'remote' and 'isolated' frontier are not seen as guardians of primitive near-naked pasts but innovators of contemporary style. Fashion fits the cosmopolitan identity while simultaneously contesting the stereotypes of the backward frontier dweller. For Northeast migrants in Delhi, dress matters. Many of the looks are styled on East Asian fashion, including Korea, and some Western subcultures. As a Mizo professional quoted in the Tehelka article states, 'We resemble people from Korea and China. It's better to dress like them than to dress like Bollywood stars' (Banan 20I0). There is a history to contemporary Northeast dress, a history entangled in the clothes worn by missionaries, the kinds of clothes crossing the borders from China and Burma, and edicts by insurgent groups threatening violence against those wearing Indian clothing (Akoijam 20Iob).

Northeast migrants are scrutinised for the ways they dress. Their style is coveted, commodified, and also used against them. Being considered stylish gets Northeast people jobs, but it also constructs a separate moral order; because of the way they dress, Northeast people are subject to stereotypes about their lifestyles, sexuality, and decency. This has further ramifications when harassment and violence are enacted based on the notion that Northeast migrants - and women in particular - deserve it because of how they are dressed. Yet it also leads to mimicry. Monpa, a postgraduate student from Arunachal Pradesh who had been living in Delhi for seven years, said when she first came to Delhi she never dressed like a north Indian and classmates at the university would comment on her dress all the time and make derogatory remarks. Now she said, 'they all try to dress like us.' Respondents made the point that if they have spare income, they will spend it on clothes. It 
has become an important part of Northeast identity to dress well and with a sense of style different from other people in Delhi.

In Delhi, Northeast migrants shop at Sarojini Nagar market, an enormous market in south Delhi popular for its rejects from the global garment industry. Northeast migrants have a reputation for being able to create unique outfits from clothes that others pass over. A number of boutiques run by Northeast migrants have opened in trendy shopping areas, such as Khan Market, and in areas with large Northeast populations in Delhi. These shops trade on the reputation of Northeasterners for their fashion sense and connections to trends that bypass Indian mainstream fashion, and the fashions of the global chain stores in the malls. This is one of the few forms of distinctly Northeast capital found in Delhi, but one that appears to be growing.

Dressing in Western and Asian fashion is a statement. Respondents were very unapologetic about how they dressed. If the rest of Indian society didn't like it, Northeast migrants didn't care. In the public discourse on violence against Northeasterners in Delhi, migrants themselves are blamed for inviting attacks because of their dress. Some respondents mentioned that when they arrived in Delhi, they did try to wear 'Indian clothes'. But this did little to change the way they were treated in public, so they gave up and chose to dress like they would back home. If this leads to negative stereotypes about their character, then that is not their problem: they face stereotypes regardless.

The key to fashion is that Northeasterners are connected to worlds beyond India. They do not need to emulate mainstream Indian society. In fact, global connections enable Northeasterners to reject most elements of mainstream Indian society - a society they feel at worst rejects them and at best just doesn't understand them. In many ways, fashion, as with other cosmopolitan elements, is a contemporary manifestation of the sense of difference and separateness underpinning Northeast identity from the colonial era through to the insurgency-marred decades after Indian Independence. Rejection is just expressed in different ways by the present generation. Rejection makes migration to Delhi even more intriguing. Migration from the frontier to the heart of the society that Northeasterners reject is seemingly contradictory. Indeed, migration from a frontier where the very legitimacy of the Indian state is questioned to the seat of power of the same state seems paradoxical; yet more Northeasterners than ever before are migrating. Evidently, physically being in Delhi no longer involves a compromise of what it means to be a Karbi, a Meitei, or a Naga.

At the same time, connectivity between Northeasterners and certain realms of mainstream India is thickening. Work is an obvious connection, involving the exercise of citizenship to legally work and live in Delhi. Yet it is also through popular culture that Northeasterners are 
connecting to the rest of India. This will be discussed further in the following chapter.

\section{The Korean Wave}

Korean popular culture is phenomenally popular in the Northeast and among Northeast migrants. The so-called 'Korean Wave' refers to the production and export of Korean culture - mostly film, television, and pop music - and its phenomenal reception in other parts of Asia (Dator 2004; Lin \& Tong 2008). The Korean Wave is a crucial element of the cosmopolitan identity of Northeasterners. It is the preferred cultural reference point for Northeasterners and it orients social life, aspirations, and desires away from India to East Asia. In the early 2000s, it was still uncommon to see Korean films for sale in the markets of the Northeast. In the second half of the 2000s, Korean popular culture had taken such a hold in the Northeast that fan clubs were established in Kohima and Imphal, posters and other paraphernalia adorned the walls of houses in towns and villages, and Korean language courses were being taught in schools and privately. Young people throughout the region started sporting Korean hairstyles, makeup, and fashion. Korean films and serials, usually always referred to as 'Korean movies', were indispensible to both the young and the old.

At the Hornbill Festival, the flagship festival in Nagaland that attracts tourists from all over the world, there is a Korean Pavilion where Korean bands perform and where other exhibitions of Korean culture take place, including a Korea-Naga wrestling match in 20I0. One of the more ironic scenes of the Hornbill festival in recent years is the contrast between the highly orchestrated 'traditional' Naga dancing popular with foreign and Indian tourists, and the Korean pop concert and Naga Idol contest crowded with Naga and other communities from the Northeast.

Korean films and serials are aired on the satellite channel Arirang. Korean DVDs and VCDs are widely sold throughout the markets of Aizawl, Imphal, Shillong, Dimapur, and Kohima. During visits to these towns in recent years, I have followed friends around while they hunt down the latest releases. We rarely have to go far. Most films come through the border with Burma at Moreh, and thus Aizawl, Kohima, and Imphal are said to receive the latest films first. In Imphal, I was given a long spiel by a 'Korean movie' vendor who knew all the plots and cast members. When I asked him to recommend some Meitei films from an adjacent stack, he refused, telling me they were not good quality like Korean movies. In Aizawl, Korean films are sold on tables throughout the town. They are sold as either 'original version', Korean with English subtitles or 'Mizo Version' with either Mizo subtitles or in 
some cases Mizo dubbing. The fact that a group of individuals are significantly competent to translate and dub Korean films into Northeast languages onto movies that sell for very cheap prices is an indication of the extent of the phenomenon. The discs are inexpensive and range from between 50-I00 rupees (USD I-2) for a pirated disc and I00-300 rupees (USD 2-6) for a series in proper packaging.

Knowledge and consumption of Korean popular culture is part of being a Northeast youth. The rejection of mainstream film and television is not just aesthetic but bound up in questions of identity. In Delhi, recreating small pieces of home involves shared consumption of Korean movies. In a lot of the flats, Northeast migrants did not have televisions and instead watched DVDs on their computers. There are Korean movie vendors in Northeast neighbourhoods, and migrants also download movies through their computers and trade them with one another. Friends and respondents had a folkloric respect for those who watch an entire Korean drama series in one sitting or over a weekend, and word of such heroism travelled fast.

Consumption of Korean culture does not stop with movies. Style is crucial. In Delhi, Northeast migrants have started Korean-themed hair salons. In Green Park, an area of south Delhi close to a number of Northeast neighbourhoods, there is a hair salon with Korean writing on the shopfront that is staffed by women from Nagaland and Manipur. Korean restaurants are spreading in north and south Delhi. These restaurants are of two types. The first are those aimed at being 'authentically' Korean and catering to Korean tour groups and expatriates. The second are cheaper student-oriented restaurants close to the Northeast neighbourhoods. I ate with friends in Korean restaurants in all price ranges during fieldwork. My dining companions knew all the different types of food, knew what would combine well, and would attempt to use chopsticks where they could (chopsticks are not common in most of the Northeast but are more common in the Himalayan areas). Northeast migrants worked as wait staff in these restaurants, usually for Korean owners, and some of the more senior Northeast staff could be heard conversing with owners in Korean. One of the well-established Korean restaurants had posted an advertisement on electricity poles in tribal neighbourhoods in December 20II. The restaurant was looking for new staff 'with knowledge of Korean culture'. The advertisement was in English and posted outside Northeast shops and clearly targeted at Northeast migrants. Northeasterners emphasise the similarity between Korean food and their own cuisines - fermented vegetables, lots of pork and beef, rice, and chilli. For many, this deepens their connection to Korean culture.

What explains the popularity of Korean popular culture among Northeasterners? There are a number of possible answers to this. The 
first is simply that Korean popular culture is well-received in other parts of East and Southeast Asia and its extension to the Northeast is a reflection of a regional phenomenon. An explanation given in the media is that after insurgent groups banned Hindi films and satellite television channels in Manipur in 2000 , Korean culture has filled the vacuum (Akoijam 20I0a). While compelling, this overlooks the fact that Korean culture is as popular in neighbouring states like Meghalaya, Mizoram, and Nagaland where Hindi films are not banned.

Respondents in Delhi gave varied answers for why they liked Korean popular culture. First, Koreans look like Northeasterners. They are, broadly speaking, racially similar. This answer was almost universal among respondents when the subject came up - simply: 'they look like us'. With the very recent exception of some music programmes, Northeast and people with their features never appear in Indian entertainment programmes or films. Northeasterners may appear on the news running from crossfire or protesting the atrocities of the armed forces, but that is the only time they are represented. Korean movies show people who look like Northeasterners living lives to which they can aspire.

Second, Northeasterners feel that Koreans have a similar sense of morality and values. The plots in Korean movies revolve around love stories, which appealed to Northeast men and women. Characters were always taking care of their families and respecting their parents. Devious characters always end up getting what they deserve. Though seemingly universal themes, respondents related these closely to their own worldview. The moral certainty of Korean movies was compared to the 'immorality' of Bollywood films. Some respondents mentioned that as Koreans are Christians, they felt a bond with the characters and the problems they face in life.

Thirdly, Korean movies are about ordinary people and ordinary things. Korean movies feature people from villages moving to cities and the villagers are not mocked, rather it is the haughty city folk that are portrayed negatively and have to change their ways. Working class characters are also featured and are often rewarded for their humility. Materialistic characters usually learn to be better people and stop chasing superficial happiness. Things don't always end happily in Korean movies, but this reflects life. Again, comparisons were made to Bollywood where spectacle, improbability, and extravagant singing and dancing sequences are deemed to be too unrealistic. Korean movies on the other hand relied on few stunts, few explosions, few acrobatics - instead, they told 'real life' stories.

Recently there has been a small backlash against the popularity of Korean culture among Northeasterners. Several older migrants mentioned that they feared that ethnic and tribal traditions might be 
supplanted by Korean styles and habits. There was also a sense that the lifestyles portrayed in Korean movies were creating aspirations and consumer desires that many poor and lower-income families could not accommodate. Some young Northeasterners raised similar concerns, though overall this was rare. As respondents pointed out, the idea that Korean culture will endanger ethnic and tribal traditions is based on a very outdated notion of fragile cultures and ignores the ways these cultures have persevered through British and Indian domination and the impacts of Christian conversion.

\section{Global Christian Culture}

There is little contention that Christianity is an important component of Northeast society and identity, even for individuals who do not practice the Christian faith. Christianity has connected many Northeasterners to a global culture that does have other nodes in India but is largely globally orientated. Global Christian networks bring visitors to the Northeast from other parts of the world. They come for mission work, to speak at churches, to lecture at theological colleges, and groups of students come for study tours and stay in villages and homes. Some of these visitors combine their visits with tourism. During the very strict entry regime in states like Manipur, Mizoram, and Nagaland that existed until very recently, the only visitors able to get permits for long visits were those connected to churches or religious organisations. During my visit to Mizoram in early 20II, I was able to view the registry of visitors for the last ten years at the foreigner's registration office. The data was free to view in a table posted on the office wall. Of the 4,094 total foreign visitors to the state, the largest number by a long way were from Australia, the United Kingdom, and the United States. These numbers remained consistent over the ten-year period. In the years from 2005 to 2010 , there was a spike in the number of Korean visitors. I asked why there were so many visitors from these countries in particular and was told that they came for missionary work. There were even several foreign missionaries in residence in Aizawl, something very difficult for other Indian nationals to achieve in Mizoram unless posted by the central government or the armed forces, or if they were married to a Mizo. Indeed, encountering foreign missionaries and Christian aid workers is quite common in the Northeast, as there are few other foreigners in many of the hill areas, especially those with no inherent tourist attractions.

There are also major public events held in the hill areas of the Northeast by visiting theologians, preachers, and Christian musicians. Northeasterners travel from rural areas for these events. The growth in the local music scene in the Northeast has spawned a number of 
Christian Rock bands (and many non-Christian rock bands too), and it is common to have concerts combined with Christian events. Choirs are also popular, and the Shillong Chamber Choir is highly regarded in the Northeast and around the world. The biggest visit of all was Pope John Paul II's visit to Shillong in I986. This visit is extremely important to Christians in the Northeast, including non-Catholics, because it signifies global recognition of the region and its people by a major international figure - recognition and legitimacy rarely conferred by the Indian state, especially at that time. Photographs of the day are regularly found in houses across the hill areas and in books and pamphlets commemorating the day. Many attendees wore traditional dress for the event, and most published photographs depict the traditionally dressed tribals performing for the Pope, who was dressed in papal regalia (George I990). Celebrations to mark the 25th anniversary of the visit were planned throughout the region for $201 \mathrm{I}$.

The inflow of people, media, and organisations into the frontier is matched by an outflow of people from the frontier to other parts of India and the world to work and study as part of these networks. Northeasterners pursuing careers in the church often spend periods training in ministries in the West. Here they meet people from other parts of Asia and Africa undertaking training. Others remain and work in ministries overseas for a number of years before returning to the Northeast. Northeast students receive scholarships to theological colleges and universities all over the world. Students and teachers from theological colleges in the Northeast travel to conferences and workshops abroad and share their ideas and experiences back home. Teachers in theological colleges also spend a sabbatical leave abroad. There are a growing number of pilgrimage tourists from the Northeast, and in middle-class and upper-class homes throughout the frontier it is becoming common to see photographs of relatives in Bethlehem or the Vatican alongside photos of weddings, ancestral houses, relatives standing in front of cars, and holidays to Bangkok.

Northeasterners travel as missionaries to other parts of Asia and within India. Even more common is missionary work among members of one's own ethnic or tribal community or other communities in the Northeast. Mission work is also a way for young people to get out of the region for a few months or a few years. This is important when they originate from areas of heightened conflict or limited economic opportunities. In larger families where there is not enough money to send all of the children to study outside the Northeast, mission work gives other siblings an opportunity to migrate. With a well-educated and literate population and English as the common lingua franca, it becomes easy for Christian visitors to preach, teach, and perform in the Northeast. Similarly, it is relatively easy for Northeasterners to be supported 
financially and bureaucratically to go abroad and study, teach, and preach in other countries.

Why does all of this matter for the study of Northeast migrants in Delhi? Simply put, global Christian networks outwardly orient the worldviews of ethnic and tribal communities. They may be citizens of India, but the dominant faith directs their identity outward, especially during periods of overt expressions of Hindu nationalism in mainstream India society. While there are strong connections with other Christian communities in India, especially south India, Northeasterners are not perched on the far eastern frontier of India gazing inward towards a spiritual heartland. They gaze outward towards a global religious community. Obviously this is more limited for non-Christian communities. However, transnational connections among Sikkimese Buddhists and Muslims from Assam and Manipur can function in similar ways. When they migrate to Delhi, this outward orientation affirms the cosmopolitan elements of their identity. A Mizo walking in Shanti Niketan in south Delhi may get called 'chinky' in the morning when walking to the local fruit vendor, may get asked if she lives among tigers when meeting a new classmate on campus at lunchtime, but in the afternoon she is headed to the airport to meet a theologian from Melbourne whom she met through a cousin who attended bible college in Australia. In Delhi, this gives Northeast migrants a cosmopolitan identity and one that compares favourably with the international aspirations of the Indian middle classes. As study and migration abroad are integral parts of the aspirations of the middle and upper classes in India, Northeast migrants in Delhi revealed that they enjoyed being able to mention their own travels and their links with people in other countries, often perplexing their classmates who could not figure how these 'chinkies' from the frontier were able to travel abroad when they were still trying to accomplish this for the first time.

As cosmopolitans, Northeasterners act in ways that are unexpected neither the backward stereotypes nor the sympathetic construction of the Northeast victim are able to account for what it means to be a Northeasterner in contemporary India. As I have argued above, this is not strictly an urban phenomenon. Cosmopolitan identities are exercised back home in the frontier too, in both towns and villages. Yet it is in the heartlands that cosmopolitanism takes on new meaning as a way to draw upon external influences to emphasise their difference from the Indian mainstream while at the same time enforcing ethnic, tribal, and pan-Northeast elements of identity. For an older generation of Northeasterners, their difference was emphasised by drawing on traditions from agrarian practices and communities, rebellion against state control, and folklore. For younger generations, their difference is emphasised through an even more complex milieu of global influences, 
resilient and reconstructed elements of traditions, separatist identities from growing up in an era of conflict, and a much deeper awareness of India than their parents and grandparents. Awareness of India does not necessarily lead to acceptance but to more frequent encounters between frontier dwellers and the heartlands and more adept negotiation and navigation of these encounters. 


\section{Conclusion}

As I was winding up fieldwork for this book, I met a friend from Nagaland studying for her PhD in Delhi. Julee and I sat on a wonky table in a university cafeteria while she quizzed me about this research. I laid out the story I wanted to tell piece by piece. I sketched the trajectory on the table by moving spilled grains of sugar to show the different parts of the story - a small pile here for what was happening in the Northeast, a small pile there for what was happening in Delhi. Our tea overflowed while the table wobbled and my entire structure slowly trickled into a milky sugary mess. Julee asked, 'Is this mess the Northeast or Delhi?' I mumbled some non-committal answer and she said, 'Make sure it is Delhi: I am tired of people talking about the mess in the Northeast.'

I began this book by suggesting that stories of Northeast migrants enable us to escape some recurring themes in research on the Northeast. It allows us to concentrate on things other than the 'mess', so to speak. Yet the mess can't be completely brushed aside. It is essential to understanding why people leave the frontier and to understanding experiences of separatism, territoriality, militarisation, federal statehood, and bureaucratic dysfunction - experiences that shape their attitude to the Indian heartland. However, in telling the story of Northeast migrants I have attempted to highlight elements of what it means to be an ethnic minority from the far eastern frontier in $2 \mathrm{I}^{\text {st }}$ century India. This has also been a story about Delhi and the intricacies of emerging spaces of neoliberal capital in the 'global city'. New labour markets are linking Delhi to the frontier in ways never before seen. This has also been a story of Northeasterners themselves - why they leave, why they choose Delhi, what they do when they are there, what is done to them while they are there, and how they contend with these challenges. Before concluding, I will provide some thoughts on further research in this and other contexts. 


\section{Further Research}

What does the story of Northeast migrants tell us about other places? Here I focus on three themes raised by this book that invite further research from scholars of Asian Studies.

\section{Borderlands and citizenship}

Research into borderlands has grown substantially in the last decade and a half. The pioneering work of Willem van Schendel (2002a; 2005) is paramount in the Asian context. His provocative challenge to locate borders in the centre of our analysis and rethink space beyond the nation-state has resonated with scholars in history, politics, and anthropology. Especially compelling is his concept of Zomia, his name for the upland massif stretching throughout mainland Southeast Asia to the Yunnan province in China, the hill areas of Northeast India, the Chittagong Hill Tracts in Bangladesh, and the Himalaya (2002a: 653). For Van Schendel, a focus on Zomia unsettles academic study partitioned into regional specialisations and area studies excluding vast areas of Zomia and/or analysing them as peripheries of existing nation-states. This has major implications for the Northeast frontier. Through a borderlands lens, the Northeast is no longer India's periphery but a space that is part of a shared cultural zone extending east, north, and south across relatively recent international boundaries.

James Scott (2009) has historicised Zomia in his seminal work, The Art of Not Being Governed. Scott concentrates on what he terms the 'greatest social cleavage' in Southeast Asian history: the hill-valley divide (2009: 2). As valley 'civilizations' spread through the expansion of wetrice cultivation and 'enclosed' non-state space, various peoples wishing to escape taxes, conscription, warfare, slavery, forced labour, and disease headed for the hills. These 'shatter zones' (2009: 24), out of range of state authority, were characterised by linguistic and cultural diversity and by relative geographic inaccessibility. Hill peoples inhabiting the peripheries of state space have been much maligned by histories that privilege 'civilizations'. In these histories, hill peoples are seen as barbaric, primitive, and threatening. Scott contests this view by arguing that the attributes labelled barbaric are not signs of pre-civilisational peoples but adaptations to life in shatter zones and the continuing desire of hill peoples to evade assimilation and incorporation into the state. Rather than viewing hill peoples as being outside history, Scott instead gives them an anarchist history. Scott sees Zomia as the key to understanding the dialectal and symbiotic relationship between hills and valleys, emphasising their connection and their mutual antagonism. 
Interest in Asian borderlands has proliferated in the wake of these influential studies. Research networks, conferences, and scores of publications draw attention to borderlands from multiple academic disciplines. The upsurge in borderland studies has given new life to studies of the Northeast frontier. The effect has been nothing short of emancipatory. Conceptualising the region as a borderland renders alternative economies, geographies, histories, identities, nationalisms, and transnational relationships visible. In effect, the Northeast can be analysed both within and outside India. The region is no longer simply viewed as India's periphery but a region where communities are connected across international boundaries. While state-making has ruptured these connections, communities have found new ways to circumvent borders and challenge attempts by different sovereign governments to enclose territory.

The borderlands paradigm demonstrates the ways communities in frontiers look 'outwards' across borders, thereby challenging statist notions of citizenship and belonging. In many ways, this suggests a 'natural' outward orientation by communities whose lives are intimately linked across borders. Borderlands studies have enabled this outward orientation to take centre stage in studies of the Northeast. However, enthusiasm for analysing outward orientation has made inwards orientation by frontier dwellers less apparent and the study of inward orientation potentially less inventive.

Migration to Delhi reveals the inwards pull of the heartland. As India's economy grows and as cities are transformed through globalisation opening new labour markets, looking inwards from the frontier has a new dimension. Economic changes create opportunities for frontier dwellers, and citizenship makes migration possible. Frontier dwellers have multiple identities and allegiances that transcend state-created boundaries. These identities are certainly fluid, as recent decades of political disorder in the frontier have shown. Yet often overlooked within the analysis of identities among Northeast frontier dwellers is citizenship.

Citizenship figures in the multiple and complex identities of Northeast people, though rarely in a straightforward fashion. On the one hand, identity is predicated in part on rejecting India, demonstrated through ethno-nationalism, insurgency, and extreme notions of territoriality. On the other hand, Indian citizenship provides material benefits that related ethnic groups in neighbouring countries do not share (see Bal 2007). The Sixth Schedule receives most attention in this regard, but citizenship also gives different Northeast communities legal access to the burgeoning cities of the heartland to live, work, and/or study.

The inwards pull of citizenship is intensifying for frontier dwellers, though clearly Indian citizenship does not entail wanton allegiance to 
the Indian tricolour. Northeast migration shows the different ways in which citizenship is understood by frontier dwellers in ways not always visible in the frontier itself. For many Northeasterners, citizenship is instrumental. It is something that they hold and therefore it might as well be utilised. Given the push factors behind migration from the region, individuals seeking to migrate have a limited set of choices about where they can go to find work. As citizens, they can go to the heartland cities of India and live and work legally. As citizens, there are also places in universities and colleges and jobs in the public sector. Therefore, while Northeasterners do look outwards across international borders to kin, to co-ethnics, to former territories, the pull of citizenship means Northeasterners are also looking inwards and utilising their citizenship status to meet livelihood needs, changing aspirations, and find safety.

The possibility of Northeasterners feeling something beyond instrumental citizenship also needs to be considered. The place-making practices are in some ways a performance of a type of citizenship. Northeasterners have a right to the city conferred by their citizenship, though there are boundaries to what this notion of rights entails. Northeast migrants are not interested in formal political representation in Delhi nor are they interested in shaping the ways Delhi is developed and governed. But they do contest the instances where their rights as citizens are violated. Some Northeast migrants also take the opportunity of being in Delhi to protest violations of rights back home. Citizenship enables adversarial politics utilised by Northeast migrants to make rights claims on the national and city governments, the police, and in some cases other citizens.

It is also important to recognise that some Northeasterners engage in active citizenship. This is true in the Northeast itself, where pride in Indian citizenship is evident in celebrations of Indian nationalism, support for national political parties (as opposed to regional parties), gratitude for protection from 'hostile' neighbours (far more evident in Arunachal Pradesh and Sikkim, where the 'China threat' is played out incessantly in public discourse), and in members of ethnic minority and tribal communities enlisting for the armed forces and paramilitary. In Delhi, there are Northeasterners who engage in active citizenship, though there is a sense that migration to the heartland erodes feelings of national belonging. Migrants who waved flags on Indian national holidays, learned the geography of every Indian state, and supported Indian sporting teams find that in the heartlands, people think they are foreigners, no one knows where their states are, and they are targeted for harassment and violence. Suspicion of the mainstream population is widespread among Northeast migrants from areas with enduring experiences of state violence. Yet for migrants from other areas of the 
frontier, migration can be a confronting experience that destabilises their conceptions of citizenship and national belonging.

Northeast migration is a compelling example of the inward pull of citizenship. This raises the following question: does Northeast migration suggest that Northeasterners are effectively surrendering to an inexorable national homogenisation of identity? Or to put it another way, does Northeast migration suggest Northeasterners are becoming willing Indian subjects? That the struggles for independence and autonomy are a thing of the past? This research suggests that Northeast migration is far from an expression of surrender to the power of the Indian economy and nation-state. Migration does not threaten ethnic or tribal identity. In contrast, migration affirms difference. Difference is expressed through parochial, pan-Northeast, and cosmopolitan identities - all of which affirm differentiation from the Indian mainstream.

One element of identity that is shifting through migration is the sense of pan-Northeast solidarity. In some ways, this is a retrograde identity that was popular in the decades leading up to and immediately following Indian Independence, especially among elites, but one that has capitulated to narrower ethno-nationalist tendencies since the early I980s. Away from the frontier, narrow identities are less viable in the face of shared experiences of the heartland. Race singles out Northeast migrants but also provides common ground, and migrants depend on one another to contest the experiences of the heartland. While panNortheast solidarity does not hold absolutely, as was the case following the Mao Gate incident in 20I0, for the most part solidarity cuts across ethnic, religious, and territorial rivalries that have been so destructive back home.

Importantly, it is not just citizenship itself that drives the inward pull from the frontier to the heartland cities. Citizenship makes movement possible, but it is the cities themselves that pull migrants. Research into the impacts of globalisation on borderlands stresses the changes brought through greater connectivity between nation-states that pass through frontiers. In the case of the Northeast, increased investment, resources extraction, and infrastructure links to neighbouring countries detailed in the Indian government's North East Vision 2020 agenda will significantly alter life in the region (McDuie-Ra 2009b). This study has shown that this is only half the story. Frontiers are also profoundly affected by changes taking place elsewhere - in this case, the transformation of heartland cities like Delhi. The transformation of the Indian economy through globalisation is fuelling demand for frontier labour in Indian cities. These changes do not alter the physical landscape of the frontier in the same ways that gas pipelines, hydropower dams, and border trading posts do, but the impact on the social landscape is substantial. 
This has important implications for other contexts. In borderlands throughout Asia and other parts of the world, the outwards orientation of borderlanders across frontiers is met by the inwards pull of work, education, and safety. Borderlands in Asia are undergoing intense transformations, as regional integration hastens the development of connections over land between neighbouring countries. These connections pass through borderlands. Once dead-ends and buffer zones, frontiers are becoming corridors for goods, people, resources, and capital. For Asian borderlands in proximity to the rapidly rising economies of China, India, and Russia, these changes are taking place with even greater intensity. However, the creation of corridors is countered by increased state control in borderlands. 'Opening' the frontiers means an increased military presence, and in the case of India this is coupled by measures to fence its international borders and channel movement through specific borders posts where movement can be monitored, controlled, and taxed (McDuie-Ra 20I2b). Connectivity also allows for renewed assaults on insurgent and separatist groups, though in some locations, connectivity follows peace accords.

The changes to borderlands are unsettling for communities living in these areas. The patterns of movement that borderland communities have always undertaken are becoming easier, but they are also becoming easier for others from outside the frontier, increasing access to natural resources, border markets, and trade routes. Bigger players seize the opportunities of connectivity as much as local communities. As these changes take hold in different borderlands, attention needs to be paid to how communities respond.

Further research into the inwards pull of citizenship in other borderlands will enable substantive comparisons to be made. A key task is identifying the conditions under which frontier dwellers look towards heartlands. Furthermore, a sense of which groups and individuals continue to look outwards across borders, which look inwards to heartlands, and which look both ways will deepen our understanding of the relationships between frontiers and heartlands in a globalising era.

\section{Ethnic Minorities and Asian Cities}

As frontier dwellers move inward to distant and often alien cities but where their citizenship is recognised, new patterns of ethnic minority migration within nation-states are visible. Whether it is Kachin migrants in Yangon, Uyghurs in Beijing, or Yawi Muslims in Bangkok, engagement between frontiers and heartlands reveal complex dynamics, especially for ethnic minority communities who view national citizenship with ambivalence and sometimes hostility. What is it that alters their perceptions enough to migrate to the heartlands? Is it simply 
necessity? It is changing perceptions of risk? Of trust? How do ethnic minorities experience the heartland? How do they negotiate with its inhabitants? Do they hide or affirm their minority identities? What happens when they return home?

This opens up inquiry into ethnic minorities in Asian cities. Studies of ethnic minorities, especially tribal or indigenous minorities, tend to be rooted in homelands - perhaps a legacy of the domination of anthropologists in producing knowledge about such communities. Yet as the inwards pull of citizenship brings ethnic minority peoples from further and further away to rapidly transforming cities, new waves of internal migrants are altering urban landscapes. Such research is different from studying transnational migrants who become ethnic minorities when they migrate to cities in other countries, regardless of whether they were minorities back home. While ethnic minorities have migrated to Asian cities for centuries, as new areas come under different degrees of state control, these migrations shift in intensity. These migrations are dynamic. The case of Northeast migrants shows the ways in which dramatic new patterns of ethnic minority migration have emerged in the last decade. In other cases, the dynamic could just as easily be reversed, with ethnic minority migration decreasing from frontiers as local economies grow or as opportunities in heartlands dry up.

Ethnic minority migrants are different from other urban migrants because of their minority status. In an era of scholarship consumed by transnational migration and diaspora studies, internal migration by minorities, especially from frontiers, receives far less attention. For ethnic minorities who look different, speak a different language, practice a different religion to the dominant community and in many cases to other ethnic minority communities, internal migration can be just as disorienting, jarring, and rupturing as international migration, despite their citizenship status. For these migrants, internal migration is akin to being foreign. Internal migration has few of the overt dislocations prevalent in international migration, especially South-North migration, but that makes study of this phenomenon more intricate, multifarious, and rewarding.

The ways ethnic minorities navigate, negotiate, and survive in Asian cities uncovers social, political, and economic practices of place-making and identity articulation and re-articulation. These practices occur in varied contexts where state approaches and policies towards minorities meet social perceptions of different ethnic groups by the mainstream society and indeed other minority communities (see Yeh 2009). A comparative approach to the practices ethnic minorities adopt as internal migrants will offer insights into place-making and identity in ways often missed by studies that focus on transnational migration or orthodox rural-urban migration. Furthermore, ethnic minority migrants go home. 
Tracing the return of migrants and the ways their return affects the local context should show variation between communities where migration is long established and communities where it is relatively new or where migration is now taking place to more distant places.

Ethnic minority migration to Asian cities provokes further inquiry into how these cities are changing. If, as many scholars argue, Asian cities are being transformed by neoliberalism, research into how neoliberalism affects ethnic minorities will provide significant insights into pull factors for migration and the experience of neoliberal urban space. Neoliberalism is usually assumed to be detrimental to ethnic minorities, especially those considered indigenous or culturally vulnerable. Yet as this research shows, the neoliberal transformation of Delhi is creating spaces of engagement between ethnic minorities and the Indian mainstream. The desire for Northeast labour in the denationalised and de-Indianised spaces of the global city is fuelling a rapid increase in migration from the Northeast frontier, the very limit of India's geographic and territorial imaginary. It is precisely because these spaces are cast as 'global' that they are open to peoples outside the boundaries of the nation. Economic inclusion is possible in spaces that are stripped of overt Indian-ness: shopping malls, spas, restaurants, and call centres. More Northeasterners than ever before are engaging with mainstream India through the transforming city. This suggests that for certain ethnic minorities, the denationalised spaces of neoliberal capital offer inclusion- denied in other parts of the city and perhaps the nation-state.

The transferability of this phenomenon to other contexts warrants more scholarly attention. As cities throughout the world transform and the middle and upper classes seek de-nationalised space to pursue consumer desires, to exhibit status, and to participate in being global, ethnic minorities (whether citizens or non-citizens) otherwise marginalised in nationalised space may find new opportunities for inclusion. However, it is possible to take this too far. Outside these spaces of economic inclusion, Northeasterners continue to live as exceptional citizens - even suspect citizens. Engagement between Northeasterners and the Indian mainstream is performed through a set of relations around upper and middle class consumerism and the growth of the services sector wherein Northeast labour is valued for its aesthetics and productivity. Engagement is limited to an adjacent space partitioned from the possibilities of social change.

Importantly, this case is not an endorsement of neoliberalism. Rather, this case reflects the need for an ongoing critical engagement with neoliberalism and ethnic minorities. As Aihwa Ong argues, the challenge for scholars is 'to identify an analytical angle that allows us to examine the shifting lines of mutation that the neoliberal exception generates' (2006: I2). It also shows the ways in which critical analysis of 
neoliberalism directs attention to the ways in which the city and the periphery are connected and the limits of this connectivity.

\section{Cosmopolitanism}

As this study has shown, cosmopolitan is not necessarily an abstract Eurocentric privilege but a lived experience of everyday life in the frontier and in Delhi - what Robbins refers to as 'actually existing cosmopolitanism', situated in time and space (I998: 2). The case of Northeast migrants responds to calls to 'redraw the map' of cosmopolitanism by focusing on its various manifestations in non-European settings (Pollock et al. 2000: 585-86). For Northeast migrants, cosmopolitanism is not a worldview that promotes a universal humanism. Rather, it is a way of reshaping ethnic, tribal, and pan-regional identity, challenging mainstream stereotypes, and enabling Northeasterners to endure Delhi. It also affirms differentiation from the Indian mainstream. To put it plainly, for Northeasterners, their perspective is closer to one of 'we are cosmopolitan, you are not, and that is why we are different' than to any pretentions of a universal human identity that is antithetical to ethnic and national identities.

This kind of cosmopolitanism does not exclude or even fragment ethno-nationalism. For Northeast migrants, as with many other ethnic minorities in Asia and other parts of the world, ethno-nationalism is a vital counter to hegemonic nationalism. It is crucial in protecting identity and homelands and in advocating for autonomy, rights, and recognition. Cosmopolitanism does not threaten or replace ethno-nationalism for Northeasterners. In fact, it helps affirm ethnic identity, though it could be argued that cosmopolitanism enables a pan-Northeast identity that the more exclusionary forms of ethno-nationalism back in the Northeast preclude. In this sense, cosmopolitanism does cross boundaries between peoples, just on a far more localised scale, what Calhoun refers to as 'local and particularistic border crossings and pluralisms' (2003: 875). In Delhi, cosmopolitanism signifies otherness, non-Indianness, and a shared sense of what it means to be a Northeasterner in the ${ }_{2 \mathrm{I}}{ }^{\text {st }}$ century. As such, it draws together communities from different parts of the frontier, from different ethnic groups, and from different political camps. This is no mean feat, as anyone privy to the current state of politics in the Northeast would appreciate.

This is a very different cosmopolitanism from the version advertised on the Delhi streets in the Delhi meri jaan campaign discussed in chapter 3. The vision of cosmopolitanism conjured by the government and the marketing professionals responsible for the slogan is one clearly within the boundaries of the Indian national imaginary. Northeasterners shun these prescriptions and reproduce their own 
cosmopolitanism from diverse global influences and resilient ethnic and tribal identities.

It is crucial to note that Northeasterners do not become cosmopolitans by migrating, and as such, cosmopolitanism is not reserved for those with mobility. Indeed, as many respondents in this study stressed, they had better access to global influences back home where proximity to East and Southeast Asia ensured a steady flow of goods, people, and cultural exchange used to further a sense of identity beyond the local. Though they don't become cosmopolitans by migrating, it is as migrants that Northeasterners emphasise their cosmopolitan predilections through their encounters with the Indian mainstream. Migration subjects Northeasterners to racism, stereotypes, and discrimination on a scale and intensity not felt at home. In response, Northeasterners draw upon their sense of cosmopolitanism to get by in the city and to challenge the ways they are cast by the mainstream. Therefore migration does not make Northeasterners cosmopolitan but it locates them in an environment where flaunting their cosmopolitan identities has become essential to negotiating, navigating, and surviving the city. Yet it is also true that they bring back bits of the heartland to home - knowledge of the heartland and its people, knowledge of other migrants in Delhi (Afghanis, Africans, Iranians), languages, food, friends, and even lovers and spouses.

Similar and divergent cosmopolitanisms no doubt exist throughout Asia, especially among peoples cast as backward by majority communities and cast as culturally and socially vulnerable by their supporters. Uncovering the dimensions of these lived cosmopolitanisms among ethnic minorities challenges conventional understandings of minority peoples, especially frontier dwellers, and opens up the possibility for multiple identities beyond, but not excluding, nationalism and ethnonationalism. 


\section{Short Biographical Note on the Author}

Dr Duncan McDuie-Ra is a senior lecturer in development studies at the School of Social Sciences and International Studies of the University of New South Wales in Sydney, Australia. His research focuses on development and change in Northeast India and other border areas of Asia and the Pacific. His most recent book is The Politics of Collective Advocacy in India: Tools and Traps (Kumarian, 20II), co-authored with Nandini Deo. 



\section{Bibliography}

ACHR Asian Centre for Human Rights (2008a), Torture in India 2008: A State of Denial, New Delhi: Asian Centre for Human Rights.

- (2008b), India Human Rights Report 2008, New Delhi: Asian Centre for Human Rights.

Agamben, G. (2005), State of Exception. Chicago: The University of Chicago Press.

Agnew, J.A. (20II), 'Space and place', in J.A. Agnew and D.A. Livingstone (eds.), The Sage Handbook of Geographical Knowledge, 316-330. London/Thousand Oaks/New Delhi/Singapore: Sage.

Akoijam, S. (20I0a), 'Korea Comes to Manipur', Caravan, I October 20II. < http://www.caravanmagazine.in/Story/522/Korea-Comes-to-Manipur.html>

- (2010b), 'Home Before Dark', Himal Southasian, 23 (7): 56-57.

- (20II), 'Feeling Nepali: A Manipuri in Kathmandu', Himal Southasian, 24 (8): 56-7.

Appadurai, A. (I996), Modernity at Large: the cultural dimensions of globalization. Minneapolis: University of Minnesota Press.

Arambam, L. (2007), 'Politics of Ethnicity and Armed Violence in Manipur', Eastern Quarterly, 4 (2) < http://manipurresearchforum.org/polethnicityarmed_vio- lencmanipur. htm >

- (2008), Prejudice, Ignorance, Intolerance. Eastern Frontier, March < http://kapilarambam. blogspot.com/2008_02_oI_archive.html>

Baas, M. (2009), 'Curry Bashing: Racism, violence and alien space invaders', Economic and Political Weekly, 44 (34): 37-42.

- (2010), Imagined Mobility: Migration and transnationalism among Indian students in Australia. London: Anthem Press.

Baber, Z. (2004), ' "Race”, Religion and Riots: The "Racialization” of communal identity and conflict in India', Sociology, 38 (4): 70I-7I8.

- (20I0), 'Racism without Races: Reflections on racialization and racial projects', Sociology Compass, 4 (4): 24I-248.

Bahadur, T.K. (2009), Urbanization in North-East India. Delhi: Mittal Publications.

Bal, E. (2007), They Ask If We Eat Frogs: Garo ethnicity in Bangladesh. Singapore: ISEAS Publishing.

Banan, A.A. (20I0), 'The Only Fashionistas', Tehelka Magazine, 7 (4I). < http://www.tehelka. com/story_main47.asp?filename=hubı6ıогоThe_only_Fashionistas.asp $>$

Bandyopadhyay, S. and Chakraborty, D. (I999), 'Migration in the north-eastern region of India during I90I-I99I: Size, trend, reasons and impact', Demography India, 28 (I): 75-97.

Banerjee, P. (2010), Borders, histories, existences: Gender and beyond. New Delhi: Sage Publications.

Banton, M. (forthcoming), 'The Colour Line and the Colour Scale in the Twentieth Century', Ethnic and Racial Studies.

Barbora, S. (2002), 'Ethnic Politics and Land Use: Genesis of Conflicts in India's NorthEast', Economic and Political Weekly, 37 (13): 1285-1292. 
- (2008), 'Autonomous Districts and/or Ethnic Homelands: An Ethnographic Account of the Genesis of Political Violence in Assam (North-East India) Against the Normative Frame of the Indian Constitution', International Journal on Minority and Group Rights, I5 (2/3): 313-334.

Baruah, S. (1999), India against itself: Assam and the politics of nationality. Delhi: Oxford University Press.

- (200I), 'Clash of Resource Use Regimes in Colonial Assam: A nineteenth century puzzle revisited', The Journal of Peasant Studies, 28 (3): 109-24.

- (2002), 'Gulliver's Troubles: State and Militants in North-East India', Economic and Political Weekly, 37 (4I): 4I78-4I82.

- (2003a), 'Citizens and Denizens: Ethnicity, homelands, and the crisis of displacement in Northeast India', Journal of Refugee Studies, I6 (I): 44-66.

- (2003b), 'Nationalizing Space: Cosmetic federalism and the politics of development in northeast India', Development and Change, 34 (5): 915-39.

- (2003c), 'Confronting Constructionism: Ending India's Naga war', Journal of Peace Research, 40 (3): 32I-38.

- (2005), Durable Disorder: Understanding the politics of northeast India. New Delhi: Oxford University Press.

- (20I0), 'Indigenes and Interlopers', Himal SouthAsian, 23 (7): 26-3I.

Basran, G.S., and Bolaria, B.S. (2003), The Sikhs in Canada: Migration, race, class, and gender. New York: Oxford University Press.

Bates, C.N. (1985), 'Regional Dependence and Rural Development in Central India: The pivotal role of migrant labour', Modern Asian Studies, I9 (03): 573-92.

Baviskar, A. (2003), 'Between Violence and Desire: Space, power, and identity in the making of metropolitan Delhi', International Social Science Journal, 55 (I75): 89-98.

- (20II), 'What the Eye Does Not See: The Yamuna in the imagination of Delhi', Economic Q Political Weekly, 46 (50): 45-53.

- and Ray, R. (20II), 'Introduction', in A. Baviskar and R. Ray (eds.), Elite and everyman: The cultural politics of the Indian middle classes, I-23. New Delhi: Routledge.

Bayly, S. (1999), Caste, Society and Politics in India from the Eighteenth Century to the Modern Age. Cambridge: Cambridge University Press.

Béteille, A. (199I), Society and Politics in India: Essays in a Comparative Perspective. New Delhi: Oxford University Press.

Bhan, G. (2009), ' "This is no longer the city I once knew". Evictions, the urban poor and the right to the city in millennial Delhi', Environment and Urbanization, 2I (I): I27-I42.

Bhatia, S. (2007), American Karma: Race, culture, and identity in the Indian diaspora. New York: New York University Press.

Bhaumik, S. (2009), Troubled Periphery: A crisis of India's North East. New Delhi: Sage Publications.

Black, D. and Van Der Westhuizen, J. (2004), 'The Allure of Global Games for "Semi-peripheral" Polities and Spaces: A research agenda', Third World Quarterly, 25 (7): II95-I2I4.

Bora, P. (2010), 'Between the Human, the Citizen and the Tribal', International Feminist Journal of Politics, 3 (4): 34I-360.

Brah, A. and Phoenix, A. (2004), 'Ain't I a woman? Revisiting intersectionality', Journal of International Women's Studies, 5 (3): 75-86.

Brekke, T. (2006), 'Baptism and the Bible in Bengal', History of Religions, 45 (3): 213-233.

Brosius, C. (2010), India's Middle Class: New forms of urban leisure, consumption and prosperity. Delhi: Routledge.

Broughton, C. (2008), 'Migration as Engendered Practice: Mexican men, masculinity, and northward migration', Gender and Society, 22 (5): 568-589.

Brown, J.M. (2006), Global South Asians: Introducing the modern diaspora, vol. I. Cambridge: Cambridge University Press. 
Calhoun, C.J. (2003), 'The Class-consciousness of Frequent Travelers: Toward a critique of actually existing cosmopolitanism', The South Atlantic Quarterly, IOI (4): 869-97.

Census of India (20II), Provisional Population Totals Paper 2. Delhi: Office of the Registrar General and Census Commissioner <http://censusindia.gov.in/20II-prov-results/paper2/ census2oII_paper2.html>

Chakrabarti, P. (2008), 'Inclusion or Exclusion? Emerging effects of middle-class citizen participation on Delhi's urban poor', IDS Bulletin, 38 (6): 96-I04.

Chandra, M. (2010), 'Moti Bagh Gangrape: what went wrong?', Mizoram Express, I2 January.

Chaplin, S.E. (20II), 'Indian Cities, Sanitation and the State: The politics of the failure to provide', Environment and Urbanization, 23 (I): 57-70.

Chatterjee, P. (200I), A Time for Tea: Women, labour, and post-colonial politics on an Indian plantation. New Jersey: Duke University Press

Cheah, P. (2006), 'Cosmopolitanism', Theory, Culture \& Society, 23 (2-3): 486-96.

Chenoy, A.M. (2002), Militarism and Women in South Asia. Delhi: Kali For Women.

Cho, S.K. (I997), 'Converging Stereotypes in Racialized Sexual Harassment: Where the model minority meets Suzie Wong', Journal of Gender Race and Justice, I: I77-2II.

Chopra, R. (2004), 'Encountering Masculinity: An ethnographer's dilemma', in C. Osella, F. Osella and R. Chopra (eds.), South Asian masculinities: Context of change, sites of continuity, 36-59. New Delhi: Women Unlimited.

Clarke, C., Peach, C. and Vertovec, S. (2010), South Asians Overseas: Migration and ethnicity. Cambridge: Cambridge University Press.

Cline, L.E. (2006), 'The Insurgency Environment in North East India', Small Wars and Insurgencies, I7 (2): I26-I47.

Collier, P. and Hoeffler, A. (2004), 'Greed and Grievance in Civil War', Oxford Economic Papers, 56 (4): 563-595.

Constable, N. (1997), Maid to Order in Hong Kong: Stories of Filipina workers. New York: Cornell University Press.

Crenshaw, K. (I99I), 'Mapping the Margins: Intersectionality, identity politics, and violence against women of color', Stanford Law Review, 43 (6): I24I-I299.

Dai, M. (2007), 'Living the Untold Myth: Politics of conflict in Arunachal Pradesh', in J. Saikia (ed.), Frontier in Flames: North East India in turmoil, 50-64. Delhi: Penguin/Viking.

Darieva, T. (20II), 'Rethinking homecoming: Diasporic cosmopolitanism in post-soviet Armenia', Ethnic and Racial Studies, 34 (3): 490-508.

Das, N.K. (I989), Ethnic Identity Ethnicity And Social Stratification in North-East India. New Delhi: Inter-India.

Das, S.K. (ed.) (2008), Blisters on their feet: Tales of internally displaced persons in India's NorthEast. Delhi: Sage Publications.

Dasgupta, J. (1997), 'Community, Authenticity, and Autonomy: Insurgence and institutional development in India's Northeast', Journal of Asian Studies, 56 (2): 345-70.

Dator, J. and Seo, Y. (2004), 'Korea as the Wave of a Future', Journal of Futures Studies, 9 (I): 3I-44.

Datta, K., McIlwaine, C., Herbert, J., Evans, Y., May, J., and Wills, J. (2009), 'Men on the move: Narratives of migration and work among low-paid migrant men in London', Social and Cultural Geography, io (8): 853-873.

De Haan, A. and Rogaly, B. (I994), 'Eastward Ho! Leapfrogging and seasonal migration in eastern India', South Asia Research, I4 (I): 36-6I.

De Maaker, E. (2007), 'From the Songsarek Faith to Christianity: Conversion, religious identity and ritual efficacy', South Asia: Journal of South Asian Studies, 30 (3): 517-30. 
Deka, P. (I986), 'Political Factors and Urbanization in North-East India, I96I-I98I' in C.S. Yadav (ed.), Comparative Urbanization: City growth and change, 357-376. Delhi: Concept Publishing Company.

Delhi Development Authority (2007), Master Plan for Delhi 2021. Delhi: Delhi Development Authority.

Delhi Police (2005), Security Tips for North East Students/Visitors in Delhi. Delhi: Delhi Police West District.

Deo, N. and McDuie-Ra, D. (20II), The Politics of Collective Advocacy in India: Tools and Traps. Sterling, VA: Kumarian Press.

Downs, F. (2003), 'Christian Conversion Movements in North East India', in R. Robinson and S. Clarke (eds.), Religious Conversions in India: Modes, Motivations and Meanings. 38I400. New Delhi: Oxford University Press.

Dubey, A. and Pala, V. (2003), 'Role of Christianity in Fostering Education in Northeastern Region: Statistical evidence', in T.B. Subba, J. Puthenpurakal and S.K. Puykunnel (eds.), Christianity and change in northeast India, 63-92. Delhi: Concept Publishing.

Dupont, V.D.N. (20II), 'The Dream of Delhi as a Global City', International Journal of Urban and Regional Research, 35 (3): 533-554.

Dutt, S. (I98I), 'Migration and Development: The Nepalese in northeast', Economic and Political Weekly, i6 (24): I053-5.

Eaton, R.M. (I997), 'Comparative History as World History: Religious conversion in modern India', Journal of World History, 8 (2): 243-27I.

Echtner, C.M. and Prasad, P. (2003), 'The context of third world tourism marketing', Annals of Tourism Research, 30 (3): 660-682.

Ekin, A. (20II), 'Northeastern Promises', Motherland, 02 (04): 49-53.

Elwin, V. (1959), India's North-East frontier in the nineteenth century. London: Oxford University Press.

E-Pao (20I0a), 'Students storm Manipur Bhawan', 7 May <http://e-pao.net/GP.asp? src=I7..080510.mayio>

- (2010b), 'Nagas light candles for peace in Delhi', 9 May <http://www.e-pao.net/ epRelatedNews.asp?heading $=\mathrm{I} 5 \& \mathrm{src}=\mathrm{I00} 5 \mathrm{IO}>$

- (20II), 'NE Boys at Receiving End in Delhi', I4 September < http://www.e-pao.net/GP. asp? src $=8 .$. I509II.sepII>

Eriksen, T.H. (2002), Ethnicity and Nationalism. London: Pluto Press.

Favero, P. (2005), India dreams: cultural identity among young middle class men in New Delhi. Stockholm: University of Stockholm.

Farrelly, N. (2009), " "AK47/MI6 Rifle-Rs. I5,000 each": What price peace on the IndoBurmese frontier?', Contemporary South Asia, I7 (3): $283-297$.

Fernandes, L. (2004), 'The Politics of Forgetting: Class politics, state power and the restructuring of urban space in India', Urban Studies, 4I (I2): 24I5-2430.

- (2006), India's New Middle Class: Democratic politics in an era of economic reform. Minneapolis: University Of Minnesota Press.

— and Heller, P. (2006), 'Hegemonic Aspirations', Critical Asian Studies, 38 (4): 495-522.

Fernandes, W. and Barbora, S. (2002), Changing Women's Status in India: Focus on the Northeast. Guwahati: North Eastern Social Research Centre.

Finnis, E. (2007), 'Celebrity Big Brother, Inequality and Hindu nationalism in India: Opportunity for critique of internal inequalities minimized in debates about international racism', Anthropology News, 48 (6): 30-3I.

Friedmann, J. (2007), 'Reflections on Place and Place-making in the Cities of China', International Journal of Urban and Regional Research, 3I (2): 257-279. 
Gaikwad, N. (2009), 'Revolting Bodies, Hysterical State: Women protesting the Armed Forces Special Powers Act (I958)', Contemporary South Asia, I7 (3): 299-3II.

Gailangam, K. (2008), 'Kuki-Naga Conflict and its Impact on the Zeliangrong People', in S. K. Das (ed.), Blisters on their feet: Tales of internally displaced persons in India's North East, 20I-203. New Delhi: Sage.

Ganguly, J.B. (ed.) (I995), Urbanization and Development in North-East India: Trends and policy implications. Delhi: Deep and Deep.

George, M.C. (I990), Centenary of the Catholic Church in North-East India 1890-1990. Shillong: Archbishop's House.

Ghertner, D.A. (20II), 'Gentrifying the State, Gentrifying Participation: Elite governance programs in Delhi', International Journal of Urban and Regional Research, 35 (3): 504-532.

Giersch, P. (200I), " "A Motley Throng”: Social change on Southwest China's early modern frontier, I700-I800', The Journal of Asian Studies, 60 (I): 67-94.

Gogoi, N.K. (2006), Continuity and Change Among the Ahom. New Delhi: Concept Publishing.

Gooptu, N. (20II), 'Economic Liberalization, Urban Politics, and the Poor', in S. Ruparelia, S. Reddy, J. Harriss and S. Corbridge (eds.), Understanding India's New Political Economy: A great transformation?, 35-48. Abingdon/New York: Routledge.

Goswami, U. (2006), 'Enabling IDP livelihoods in western Assam: Nobody's responsibility', Refugee Survey Quarterly, 25 (2): 60-68.

Government of India (2002), National Human Development Report 2001. New Delhi: Planning Commission.

Government of Meghalaya (2010), IT Vision 2020. Shillong: Government of Meghalaya.

Grossman, H.I. (I99I), 'A General Equilibrium Model of Insurrections', American Economic Review, 8I (4): 9I2-92I.

Guha, R. (I999), Savaging the Civilized: Verrier Elwin, his tribals and India. New Delhi: Oxford University Press.

Guo, X. (2009), State and Ethnicity in China's Southwest. Leiden/Boston: Brill.

Gupta, A. (1978), 'India and Africa South of the Sahara', International Studies, I7 (3-4): 639653.

Gupta, A. and Sivaramakrishnan, K. (20II), 'Introduction', in A. Gupta, K. Sivaramakrishnan (eds.), The state in India after liberalization: Interdisciplinary perspectives, I-27. Abingdon/ New York: Routledge.

Gupta, N. (I98I), Delhi between Two Empires, 1803-1931: Society, government and urban growth. New Delhi: Oxford University Press.

Gurdon, P.R.T. (I907/I9I7), The Khasis, New Delhi: Kosmo Publishers.

Hall, S. (2003), 'Cultural Identity and Diaspora' in J.E. Braziel, and A. Mannur (eds.), Theorizing diaspora: A reader, 233-246. Malden, MA: Blackwell.

Harriss, J. (2005), 'Political Participation, Representation and the Urban Poor: Findings from research in Delhi', Economic and Political Weekly, 40 (II): IO4I-IO54.

Harvey, D. (2003), 'The Right to the City', International Journal of Urban and Regional Research, 27 (4): 939-94I.

- (2005), A Short History of Neoliberalism. Oxford: Oxford University Press

Hasan, D. (2004), 'Out of the Box: Televisual representations of North-East India', Sarai Reader 2004: Crisis/Media, I26-I29.

- (2009), 'Guns and Guys in the Jungle; news and terrorism in North-East India', Studies in South Asian Film and Media, I (2): 265-283.

- (20I0), 'Talking Back to "Bollywood": Hindi commercial cinema in North-East India', in S. Banaji (ed.), South Asian media cultures: Audiences, representations, contexts, 29-50. London: Anthem Press.

Hazarika, S. (I995), Strangers of the Mist. New Delhi: Penguin Books. 
- (2000), Rites of Passage: Border crossings, imagined homelands, India's East and Bangladesh. Delhi: Penguin Books.

- (2004), 'Land, Conflict, Identity in India's North-East: Negotiating the future', Futures, 36: 77I-780.

Human Rights Watch (2008), Getting Away with Murder: 50 Years of the Armed Forces Special Powers Act. New York: Human Rights Watch.

Humphreys, S. (2006), 'Legalizing Lawlessness: On Giorgio Agamben's State of Exception', European Journal of International Law, I7 (3): 677-687.

Hussain, M. (2008), Interrogating Development: State, displacement and popular resistance in North East India, New Delhi: Sage Publications.

Huysmans, J. (2008), 'The Jargon of Exception: On Schmitt, Agamben and the absence of political society', International Political Sociology, 2 (2): 165-183.

Indian Express (2008), 'Naga Girl Alleges Region Bias at GK lounge bar', 24 June.

Jahoda, G. (1999), Images of Savages: Ancient roots of modern prejudice in western culture. London: Routledge.

Jeffrey, C. (20I0), Timepass: Youth, class, and the politics of waiting in India. Stanford: Stanford University Press.

Jilangamba, Y. (2010), 'Ethnicity and Territoriality', Himal SouthAsian, 23 (7): 38-40.

Jones, S. (1978), 'Tribal Underdevelopment in India', Development and Change, 9 (I): 4I-70.

Joshi, V. (2007), 'The Birth of Christian Enthusiasm among the Angami of Nagaland', South Asia: Journal of South Asian Studies, 30 (3): 541-557.

Kapur, D. (2010), Diaspora, Development, and Democracy: The domestic impact of international migration from India. Princeton: Princeton University Press.

Kar, B. (2009), 'When was the Postcolonial?: A history of policing impossible lines', in S. Baruah (ed.), Beyond Counter-Insurgency: Breaking the impasses in Northeast India, 49-77. New Delhi: Oxford University Press.

Karlsson, B.G. (20II), Unruly Hills: A political ecology of India's Northeast. New Delhi: Social Science Press.

Kermode, M., Longleng, V., Singh, B.C, Bowen, K. and Rintoul, A. (2009), 'Killing Time with Enjoyment: A qualitative study of initiation into injecting drug use in North-East India', Substance Use and Misuse, 44 (8): 1070-1089.

Khetrimayum, O. and Chanu, N.V. (2008) 'Mapping Cultural Diffusion: The Case of "Korean Wave" in North East India', in S. Narsimhan and T.-Y. Kim (eds.), India and Korea: Bridging the Gaps, I8I-I95. Delhi: Manak.

Kikon, D. (2009a), 'The Predicament of Justice: Fifty years of Armed Forces Special Powers Act in India', Contemporary South Asia, I7 (3): 27I-28.

- (2009b), 'From Loincloth, Suits, to Battle Greens: Politics of Clothing the 'Naked' Nagas', in S. Baruah (ed.), Beyond Counter-Insurgency: Breaking the Impasse in Northeast India, 8IIo०. Delhi: Oxford University Press.

- (20I0), 'Valley Versus Hill', Himal SouthAsian, 23 (7): 4I-44.

Kong, L. and Law, L. (2002), 'Introduction: Contested landscapes, Asian cities', Urban Studies, 39 (9): 1503-12.

Krishna, S. (200I), 'Gender, Tribe and Community Control of Natural Resources in NorthEast India', Indian Journal of Gender Studies, 8 (2): 307-32I.

- (2004), 'Gender, Tribe and Political Participation: Control of natural resources in NorthEastern India', in S. Krishna (ed.), Livelihood and gender: Equity in community resource management, 375-394. New Delhi: Sage Publications.

Kudva, N. (2009), 'The Everyday and the Episodic: The spatial and political impacts of urban informality', Environment and Planning A, 4I (7): $16 \mathrm{I}_{4}-\mathrm{I} 628$. 
Kumar, S. (2005), 'State "Simplification": Garo Protest in Late I9th and Early 20th Century Assam', Economic and Political Weekly, 40 (27): 294I-2947.

Kundu, A. (2004), 'Provision of Tenurial Security for the Urban Poor in Delhi: Recent trends and future perspectives', Habitat International, 28 (2): 259-74.

Kundu, D. (20II), 'Elite Capture in Participatory Urban Governance', Economic and Political Weekly, 46 (IO): 23-25.

Lacina, B. (2007), 'Does Counterinsurgency Theory Apply in Northeast India?', India Review, $6(3): 165-83$.

Lama, M.P. (2000), 'Internal Displacement in India: causes, protection and dilemmas', Forced Migration Review, 8: 24-26.

Lasetso, R. and Hümtsoe, E. (eds.) (2009), Doing Tribal Christian Theology with Tribal Resources: Cultural resources from northeast India. Jorhat: Eastern Theological College.

Lefebvre, H. (I99I), The Production of Space. Oxford: Blackwell.

Legg, S. (2007), Spaces of Colonialism: Delhi's urban governmentalities. Malden, MA: Blackwell.

Li, T. (2007), The Will to Improve: Governmentality, development, and the practice of politics. Durham: Duke University Press.

Lin, A. and Tong, A. (2008), 'Re-imagining a cosmopolitan "Asian us": Korean media flows and imaginaries of Asian modern femininities', in C.B. Huat, and K. Iwabuchi (eds.), East Asian popular culture: Analysing the Korean wave, 9I-I26. Hong Kong: Hong Kong University Press.

Logan, F.A. (I985), 'Racism and Indian-US relations, I947-I953: Views in the Indian press', Pacific Historical Review, 54 (I): 7I-79.

Luthra, P.N. (I97I), 'North-east Frontier Agency Tribes: Impact of Ahom and British policy', Economic and Political Weekly, 6 (23): II43-49.

MacGregor, W. (I887), 'Journey of the Expedition under Colonel Woodthorpe, R.E., from Upper Assam to the Irawadi, and Return over the Patkoi Range', Proceedings of the Royal Geographical Society and Monthly Record of Geography, 9 (I): I9-42.

Mackenzie, A. (I884/2007), The Northeast-East Frontier of India. Delhi: Mittal.

Madhab, J. (I999), 'North-East: Crisis of identity, security and underdevelopment', Economic and Political Weekly, 34 (6): 320-22.

Malngiang, P. (2002), 'Student and Youth Organisations in Meghalaya', in A.K. Baruah (ed.), Student Power in North East India, I73-I96. New Delhi: Regency Publications.

Mani, B. and Varadarajan, L. (2008), “ "The Largest Gathering of the Global Indian Family”: Neoliberalism, nationalism, and diaspora at Pravasi Bharatiya Divas', Diaspora: A Journal of Transnational Studies, I4 (I): 45-74.

Manipur Talks (20I0), 'Your views in Manipuri girls marrying non-Manipuris' < http://www. manipurtalks.com/index.php?threads/your-views-in-manipuri-girls-marrying-non-manipuris.33/>

Maring, M.D. (2007), 'Meitei-Naga Conflict with Special Reference to the Territorial Issue in Manipur', in L. Jeyaseelan (ed.), Conflict mapping and peace processes in North East India, I33-I44. Guwahati: North Eastern Social Research Centre.

Mathews, G. (20II), Ghetto at the Center of the World: Chungking mansions, Hong Kong. Chicago: University Of Chicago Press.

Mathur, N. (20I0), 'Shopping Malls, Credit Cards and Global Brands', South Asia Research, 30 (3): 2II-23I.

Mawdsley, E. (2009), “ “Environmentality” in the Neoliberal City: Attitudes, governance and social justice', in L. Meier and H. Lange (eds.), The New Middle Classes: Globalizing Lifestyles, Consumerism and Environmental Concern, 237-25I. New York: Springer.

McDuie-Ra, D. (2007), 'Anti-development or Identity crisis? Misreading civil society in Meghalaya, India', Asian Ethnicity, 8 (I): 43-59. 
- (2008), 'Between National Security and Ethno-nationalism: The regional politics of development in Northeast India', Journal of South Asian Development, 3 (2): 185-210.

- (2009a), '50-year Disturbance: the Armed Forces Special Powers Act and exceptionalism in a South Asian periphery', Contemporary South Asia, I7 (3): 255-270.

- (2009b), 'Vision 2020 or Re-vision 1958: The contradictory politics of counter-insurgency in India's regional engagement', Contemporary South Asia, I7 (3): 313-330.

- (2009c), Civil society, Democratization and the Search for Human Security: The politics of the environment, gender, and identity in Northeast India. New York: Nova Publishers.

- (20II), 'The Dilemmas of Pro-development Actors: Viewing state-ethnic minority relations and intra-ethnic dynamics through contentious development projects', Asian Ethnicity, I2 (I): 77-100.

- (20I2a), 'Violence Against Women in the Militarized Indian Frontier: Beyond "Indian culture" in the experiences of ethnic minority women', Violence Against Women, I8 (3).

- (20I2b), 'Tribals, Migrants and Insurgents: Security and insecurity along the IndiaBangladesh border', Global Change, Peace and Security, 24 (I): 165-182.

Mehta, N., Gemmell, J. and Malcolm, D. (2009), ' "Bombay Sport Exchange”: Cricket, globalization and the future', Sport in Society, I2 (4): 694-707.

Menon-Sen, K. (2010), 'Delhi and CWG20I0: The games behind the games', The Journal of Asian Studies, 69 (03): 677-68I.

Merelli, A. (20II), 'Paris, Milan, Dimapur', Motherland, 02 (04): 14-23.

Merrifield, A. (1993), 'Place and Space: A Lefebvrian reconciliation', Transactions of the Institute of British Geographers: 516-31.

Mills, J. (2006), "Manipur Rules Here" Gender, Politics, and Sport in an Asian Border Zone', Journal of Sport and Social Issues, 30 (I): 62-78.

Ministry of Health and Family Welfare (2002), National Family Health Survey 2. Mumbai/ New Delhi: International Institute for Population Sciences/Ministry of Health and Family Welfare, Government of India.

- (2009), National Family Health Survey 3 - National Report. Mumbai/New Delhi: Ministry of Health and Family Welfare, Government of India.

Ministry of Home Affairs (1958/1998), The Armed Forces (Special Powers) Act 1958. Delhi: Ministry of Home Affairs.

Mirchandani, K. (2004), 'Practices of Global Capital: Gaps, cracks and ironies in transnational call centres in India', Global Networks, 4 (4): 355-373.

MoDONER (2008a), North Eastern Region Vision 2020, volume 1. New Delhi: Ministry of Development of North Eastern Region.

- (2008b), North Eastern Region Vision 2020, volume 2. New Delhi: Ministry of Development of North Eastern Region.

- (2008c), North Eastern Region Vision 2020, volume 3. New Delhi: Ministry of Development of North Eastern Region.

Momsen, J. (1999) (ed.), Gender, Migration, and Domestic Service. London: Routledge.

Nag, S. (2002), India and Northeast India: Mind, politics and process of integration (1946-1950). Delhi: Regency Publications.

Nath, L. (2006a), 'Migration, Insecurity and Identity: The Nepali dairymen in India's Northeast', Asian Ethnicity, 7 (2): 129-48.

- (2006b), 'The Nepalis in Assam', in B.J. Deb (ed.), Ethnic issues, secularism, and conflict resolution in North East Asia, I26-133. Delhi: Concept Publishing Company.

National Crime Bureau (2010), Crime in India 2009. New Delhi: National Crime Bureau.

Nava, M. (2002), 'Cosmopolitan Modernity', Theory, Culture \& Society, I9 (I-2): 8I-99.

NESCH (2007), 'A North East Girl Sexually Assaulted and Beaten by Man' < http://nehelpline.net/?p=I4> 
— (2008a), 'A North East Boy Beaten Mercilessly by a House Owner' <http://nehelpline. net/?p=47>

- (2008b), 'Memorandum to National Commission for Scheduled Tribes' < http://nehelpline.net $/ ? \mathrm{p}=405>$

- (20I0), 'A Civil Society Delegation Met Delhi CM, Delhi Police, Child and Women Welfare Ministry and State Women Commission' <http://nehelpline.net/? $=483>$

- (20I1a), North East Migration and Challenges in National Capital Cities. Delhi: NESCH.

- (20IIb), 'Delhi is once again shock with the brutal murder of a tribal woman'. <http://nehelpline.net/?p=538>

- (20IIC), 'Call centre employee molested, beaten up' <http://nehelpline.net/?p=486>

- (20IId), 'Landlord Attacked a North East Brother and Sister in Delhi' < http://nehelpline. net $/$ p $=5$ I2 $>$

Nongbri, T. (2003), Development, ethnicity and gender: select essays on tribes in India. Jaipur: Rawat.

Nongbri, T. (2008), Gender, Matriliny, and Entrepreneurship: The Khasis of North-East India. Delhi: Zubaan.

Nongkynrih, A.K. (2002), The Khasi Society of Meghalaya: A sociological understanding. Delhi: Indus.

Norohna, E. and D'Cruz, P. (2006), 'Organising Call Centre Agents: Emerging issues', Economic and Political Weekly, 4I (2I): 2II5-2I2I.

Nunthara, C. (198I), 'Grouping of Villages in Mizoram: Its social and economic impact', Economic and Political Weekly, I6 (30): I237-I240.

Oinam, B. (2003), 'Patterns of Ethnic Conflict in the North-East: A study on Manipur', Economic and Political Weekly, 38 (21): 203I-2037.

- (2008), State of the States: Mapping India's Northeast. Washington: East West Center.

Ong, A. (2006), Neoliberalism as Exception. Durham: Duke University Press.

Osella, F. and Osella, C. (2000), 'Migration, Money, and Masculinity in Kerala', The Journal of the Royal Anthropological Institute, 6 (I): II5-I3I.

Pachuau, L. (2003), 'Church-Mission Dynamics in Northeast India', International Bulletin of Missionary Research, 27 (4): 154-6I.

Panchanadeswaran, S., \& Koverola, C. (2005), 'The Voices of Battered Women in India', Violence Against Women, II (6), 736-758.

Pandey, G. (200I), Remembering Partition: Violence, nationalism, and history in India. Cambridge: Cambridge University Press.

- (2006), Routine Violence: Nations, Fragments, Histories. Stanford: Stanford University Press.

Parratt, S.N.A. (1980), The Religion of Manipur. Calcutta: Firm KLM.

— and Parratt, J. (1997), The Pleasing of the Gods: Meitei lai haraoba. New Delhi: Vikas Publishing.

Parreñas, R.S. (200I), Servants of Globalization: Women, migration and domestic work. Stanford: Stanford University Press.

Patil, V. (20II), 'Narrating Political History about Contested Space: Tourism websites of India's Northeast', Annals of Tourism Research, 38 (3): 989-1008.

Pels, P.J. (1999), 'The Rise and Fall of the Indian Aborigines: Orientalism, Anglicism, and the emergence of ethnology in India, I833-1869', in P. Pels and O. Salemik (eds.), Colonial Subjects: Essays on the Practical History of Anthropology, 82-II6. Ann Arbor: University of Michigan Press.

Pinto, A. (200I), 'UN Conference Against Racism: Is caste race?', Economic and Political Weekly, 36 (30): $2817-2820$. 
Pollock, S., Bhabha, H.K., Breckenridge, C.A. and Chakrabarty, D. (2000), 'Cosmopolitanisms', Public Culture, I2 (3): 577-589.

Prasad, A. (2003) Against Ecological Romanticism: Verrier Elwin and the making of anti- modern tribal identity. New Delhi: Three Essays Collective: II8.

Puri, J. (2006), 'Stakes and States: Sexual discourses from New Delhi', Feminist Review, (83): I39-I48.

Rajagoplan, S. (2008), Peace Accords in Northeast India: Journey over milestones. Washington: East-West Center.

Rampal, K. (200I), 'Impact of Satellite television on Urban Youth in India', in Y. Kamalipur and K. Rampal (eds.), Media, Sex, Violence, and Drugs in the global village, II5-I30. Lanham MD: Rowman and Littlefield.

Rangasami, A. (I978), 'Mizoram: Tragedy of our own making', Economic and Political Weekly, I3 (I5): 653-62.

Rehman, T. (2009) Murder in Plain Sight. Tehelka 6 (3I) <http://www.tehelka.com/story_main42.asp?filename=Neo80809murder_in.asp $>$

Riddi, A. (2009), 'Emergence of Christianity as New Religious Identity and its Impact on Tradition and Culture Among the Tagins of Arunachal Pradesh', in T.B. Subba, J. Puthenpurakal and S.K. Puykunnel (eds.), Christianity and change in North East India, 232243. Delhi: Concept Publishing Company.

Riggs, D.W. and Due, C. (2010), 'The Management of Accusations of Racism in Celebrity Big Brother', Discourse and Society, 2I (3): 257-27I.

Robb, P. (I997), 'The Colonial State and Constructions of Indian Identity: An Example on the Northeast Frontier in the I88os', Modern Asian Studies, 3r: 245-283.

Robbins, B. (I998), 'Introduction Part I: Actually existing cosmopolitanism', in P. Cheah, and B. Robbins (eds.), Cosmopolitics: Thinking and feeling beyond the nation, I-I9. Minnesota: The University of Minnesota Press.

Robinson, J. (2002), 'Global and World Cities: A view from off the map', International Journal of Urban and Regional Research, 26 (3): 531-554.

Rosencranz, A. and Jackson, M. (2003), 'The Delhi Pollution Case: The Supreme Court of India and the limits of judicial power', Columbia Journal of Environmental Law, 28 (2): 223323.

Saikia, A. (2005), Jungles, Reserves, Wildlife: A history of forests in Assam. Guwahati: Wildlife Areas Development and Welfare Trust.

Saikia, Y. (2004) Fragmented Memories: Struggling to be Tai-Ahom in India. Durham: Duke University Press.

Sakhong, L.H. (2003), In Search of Chin Identity: A study in religion, politics and ethnic identity in Burma. Copenhagen: NIAS Press.

Samom, T.A. (2010), 'Timeline of a Shutdown', Himal Southasian, 23 (7): 32-33.

Sanford, V. (2006), 'Introduction', in V. Sanford and A. Angel-Ajani (eds.), Engaged Observer: Anthropology, advocacy and activism, I-I7. New Jersey: Rutgers University Press.

Schiller, N.G., T. Darieva, and S. Gruner-Domic (20II), 'Defining Cosmopolitan Sociability in a Transnational Age: An introduction', Ethnic and Racial Studies, 34 (3): 399-418.

Scott, J.C. (2009), The Art of Not Being Governed: An anarchist history of upland Southeast Asia. New Haven: Yale University Press.

Shah, A. (2010), In the Shadows of the State: Indigenous politics, environmentalism, and insurgency in Jharkhand, India. Durham: Duke University Press.

Shakespear, L.W. (I9I4), History of upper-Assam, upper-Burmah, and the Northeast Frontier. London: Macmillan.

Shimizu, C.P. (2007), The Hypersexuality of Race: Performing Asian/American women on screen and scene. Durham: Duke University Press. 
Shneiderman, S. and Turin, M. (2006), 'Seeking the Tribe: Ethnopolitics in Darjeeling and Sikkim', Himal Southasian, I8 (5): 54-58.

Siemiatycki, M. (2006), 'Message in a Metro: Building urban rail infrastructure and image in Delhi, India', International Journal of Urban and Regional Research, 30 (2): 277-292.

Singh, C. (2004), North-east India: Politics and insurgency. New Delhi: Manas.

Singh, K.S. (1972), Tribal Situation in India: Proceedings of a seminar. Simla: Indian Institute of Advanced Study.

- (I982a), Economies of the Tribes and their Transformation. Delhi: Concept Publishers.

- (I982b), Tribal Movements in India, vol 1. New Delhi: Manohar.

- (I983), Tribal Movements in India, vol 2. New Delhi: Manohar.

- (1992), People of India: An introduction. Delhi: Anthropological Survey of India.

Singh, M.A. (2009), A Study on Illegal Immigration into North-East India: The case of Nagaland. Delhi: Institute for Defence Studies and Analyses, New Delhi.

Sorensen, M.J. (2008), 'Humor as a Serious Strategy of Nonviolent Resistance to Oppression', Peace and Change, 33 (2): 167-190.

Srivastava, S. (2009), 'Urban Spaces, Disney-divinity and Moral Middle Classes in Delhi', Economic and Political Weekly, 44 (26 \& 27): 338-345.

Subba, T.B. (2003), 'The Nepalis in North-East India: Political aspirations and ethnicity', in A.C. Sinha and T.B. Subba (eds.) The Nepalis in North-East India: A community in search of Indian identity, 54-66. New Delhi: Indus.

Sundar, N. (20II), 'Interning Insurgent Populations: The buried histories of Indian democracy', Economic and Political Weekly, 46 (6): 47-57.

Syiemlieh, D.R. (2005), 'Christian Missions and Tribes in the Hills of North-east India', in T. B. Subba, S. Som (eds.), Between ethnography and fiction: Verrier Elwin and the tribal question in India, I47-I56. New Delhi: Orient Blackswan.

Tarlo, E. (2003), Unsettling Memories: Narratives of The Emergency in Delhi. London: C. Hurst and Co. Publishers.

Taylor, P. and Bain, P. (2005), 'India Calling to the Far Away Towns: The call centre labour process and globalization', Work, Employment, and Society, I9 (2): $26 \mathrm{I}-282$.

Thong, T. (2010), ' "Thy Kingdom Come": The impact of colonization and proselytization on religion among the Nagas', Journal of Asian and African Studies, 45 (6): 595-609.

Times of India (2009), 'I am a Victim of Racism in India: Mizoram CM', 26 September.

- (20I0), 'Mizos Thrilled as Bamboo Dance Costume Stands Out', 6 October.

Trnka, S. (2008), State of Suffering: Political violence and community survival in Fiji. New York: Cornell University Press.

Upadhya, C. (20II), 'Software and the "New" Middle Class in the "New India" ', in A. Baviskar and R. Ray (eds.), Elite and Everyman: The cultural politics of the Indian middle classes, I67-192. New Delhi: Routledge.

Vadlamannati, K.C. (20II), 'Why Indian Men Rebel? Explaining armed rebellion in the Northeastern states of India, I970-2007', Journal of Peace Research, 48 (5): 605-6rg.

Van Schendel, W. (1992), "The Invention of the "Jummas": State formation and ethnicity in Southeastern Bangladesh', Modern Asian Studies, 26 (ог): 95-I28.

- (2002a), 'Geographies of Knowing, Geographies of Ignorance: Jumping scale in southeast Asia', Environment and Planning D, 20 (6): 647-668.

- (2002b), 'A Politics of Nudity: Photographs of the "Naked Mru” of Bangladesh', Modern Asian Studies, 36 (2): 34I-374.

- (2005), The Bengal borderland: Beyond state and nation in South Asia. London: Anthem Press. 
- (2006), 'Stretching Labour Historiography: Pointers from South Asia', International Review of Social History, 5I (I4): 229-26I.

- (20II), 'The Dangers of Belonging', in D. Rycroft, and S. Dasgupta (eds.), The politics of belonging in India: Becoming adivasi, 19-43. London: Routledge.

Vanglaini Daily (20II) 'Two Naga spa recruiters detained by Mizoram Police in Aizawl', 7 October.

Visvanathan, S. (200I), 'The Race for Caste: Prolegomena to the Durban conference', Economic and Political Weekly, 36 (27): 2512-16.

Von Furer-Haimendorf, C. (1939), The Naked Nagas: Head-hunters of Assam in peace and war. London: Methuen and Co., Ltd.

Waldrop, A. (2004), 'Gating and Class Relations: The case of a New Delhi "colony" ', City and Society, I6 (2): 93-II6.

Ward, F.K. (I930), 'The Seinghku and Delei valleys, north-east frontier of India', The Geographical Journal, 75 (5): 412-32.

Watt, G. (1887) 'The Aboriginal Tribes of Manipur', The Journal of the Anthropological Institute of Great Britain and Ireland, I6: 346-370.

Weiner, M. (1978), Sons of the Soil: Migration and ethnic conflict in India. Princeton: Princeton University Press.

Werbner, P. (I999), 'Global Pathways: Working class cosmopolitans and the creation of transnational ethnic worlds', Social Anthropology, 7 (I): I7-35.

Wimmer, A. (2008), 'The Making and Unmaking of Ethnic Boundaries: A multilevel process theory', American Journal of Sociology, II3 (4): 970-1022.

Xaxa, V. (1999), 'Tribes as Indigenous People of India', Economic and Political Weekly, 34 (51): $3589-95$.

Yang, A.A. (1979), 'Peasants on the Move: A study of internal migration in India', Journal of Interdisciplinary History, Iо (I): 37-58.

Yeh, E. (2009), 'Living Together in Lhasa: Ethnic relations, coercive amity, and subaltern cosmopolitanism', in S. Mayaram (ed.), The Other Global City, 54-85. New York/London: Routledge.

Yeoh, B.S.A. and Chang, T.C. (200I), 'Globalising Singapore: Debating transnational flows in the city', Urban Studies, 38 (7): 1025-44.

Yuval-Davis, N. (2006), 'Intersectionality and Feminist Politics', European Journal of Women's Studies, I3 (3): 193-209.

Zehol, L. (1998), Women in Naga society. New Delhi: Regency Publications.

Zote, M. (2006), 'Heaven in Hell: A paradox', in G. Sen (ed.), Where the sun rises when shadows fall: The north east, 203-212. Delhi: Oxford University Press.

Zou, D.V. (2009), 'The Pasts of a Fringe Community: Ethno-history and fluid identity of the Zou in Manipur', Indian Historical Review, 36 (2): 209-35. 


\section{Index}

AFSPA 42-43, II4, I64-I65

Agamben, Giorgio $4 \mathrm{I}$

Ahom, Tai-Ahom I6, 27, 38, I54, I95, I98

Akoijam, Sunita 89

Appadurai, Arjun 149

Armed Forces Special Powers Act

(AFPSA) 42, I64

Arunachal Pradesh 15, 27, 30, 56, 59, 76, 78-79, 85, 90-91, 93, 109, III, I22, I25, I3I, I35, I57, I59, I64I65, I68, I80

Assam I5, I9-20, 27-28, 37-38, 4I,

54, 59, 74, 76, 8I, 83, 86, II4, I54

Australia 96, II5-II6, I73, I75

Baber, Zaheer II5

Bangaldesh 27

Bangalore I3, I8-I9, 2I, 45, 47, 6263, 7I, 156

Bangladesh I5, 37, 40, 48, 70, III, I78

Bangladesh Liberation War I6

Banton, Michael 88

Baruah, Sanjib 48

Baviskar, Amita 53, 68, 75, I45-I46

Bengal 38, 40, 59, 62

Bhan, Gautam 68

Bhutan I5

Bhutia I6, 28, 73, I5I

Borderlands 33, I78-I79, I8I-I82

Bradford Riots II5

Brosius, Christiane 7I

Burma I5-16, 27-28, 30, 38, 40, 48, 59, I25, I58, I62, I68, I70
Burmese I5, 89, I55

Calhoun, Craig I4I, I85

Call Centres I8, 45, 53, 58-59, 63, 76-78, 84-85, I06-IO7, IIO, II4, I34, I36, I38-I39, I5I, I65

Chenoy, Anuradha 43

China I3, I5, 30, 32, 37, 53-54, 73, 87-88, 90-9I, 94, III, I45, I68, I78, I80, I82

Cho, Sumi 96

Christianity/Christian I6, 26, 39, 69, 7I, 8I, I20, I4I, I57-I60, I67, I72-I75

Citizenship 2I, 33, 42, 55, 94-95, I65, I69, I78-183

Colonialism I6, 30, 33, 36-40, 44, $46,59,96$, III, II5, I66, I69

corruption 80-8I, 98, I37, I6I cosmopolitanism I5, 33-34, 69, II2, I38, I4I-I43, I46-I47, I66-I70, I75, I8I, I85-I86

Delhi Development Authority 67

Delhi Metro $6_{5}$

Dhaula Kuan 65

Dibrugarh 47

Dimapur 48, 59, I70

displacement 49, 54

donyi-polo I57, I59

Duala Kuan 64

Dupont, Véronique 67, 75

Eriksen, Thomas Hylland 88

Exceptionalism 4I, 44 


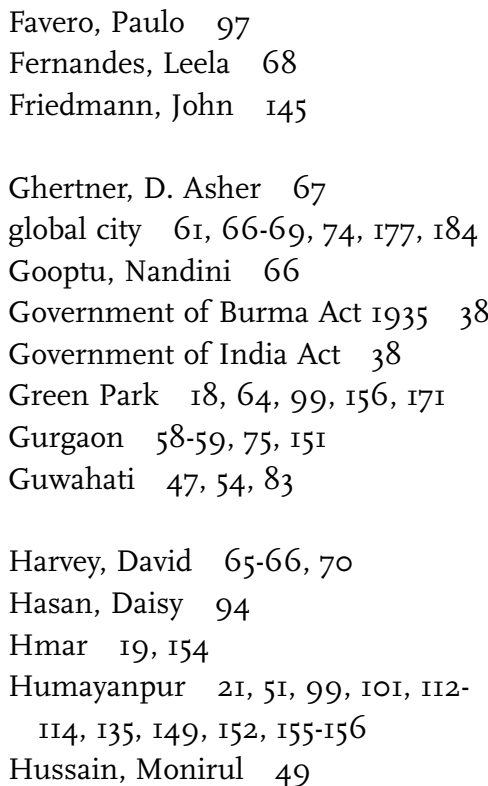

Identity I4, I9, 2I, 28-30, 33, 35, 42, 44, 47, 55, 64-66, 89, 94, I08, II5, I33, I35, I4I-I42, I46-I47, I54, I56I57, I60, I64, I66-I7I, I73, I75, I79, I8I, I83, I85-I86

Imphal 27, 45, 48, 8I, II7, I62, I67, I70

Indian Administrative Services (IAS) 32, 6I, 78-80

Indian Constitution $27,37,54,79$ Indian Government 40, 42, 5I, 8I, I35, I62, I8I

Indian Institute of Technology 64 Irom Sharmila $\mathrm{I}_{4}$

Jawaharlal Nehru University 64, 99 Jeffrey, Craig 46, 54

Kar, Bodhisattva 36

Kashmir 53, 63

Kerala 155

Khasi I8, 29, 78, I54, I59, I65

Khasi Hills 18

Kikon, Dolly 92
Kohima II6, I67, I70

Kolkata I8-I9, 2I, 47-48, 62, 92

Korea I57, I68, I70

Korean 20, 39, 73, II2-II3, I4II42, I56, I67, I70-I73

Kotla 64-65

Kumar Suresh Singh 39

Ladakh, Ladhakis I5

lai, Meitei dieties $\quad$ I57

lal dora 5I, 99, II2-II3, I49, I56

Lefebvre, Henri $\quad$ I45

Lepcha I9, 28

Manipur I3, I5-16, I8-I9, 25, 27-28, 3I, 37, 40, 43, 45, 47, 50-51, 56-57, 63-64, 73-76, 78-80, 82, 86, 9०, IOO-IOI, IO4-IO7, II4, II7, I2I-I23, I25-I27, I29, I33, I36, I47, I54-I57, I6I-I64, I67, I7I-I73, I75

Government of 8I, $\mathrm{I} 62$

Manipuri Io6, III, I33

Mao Gate Incident I6I

Mara I58-I59

Marxism 48

Mathur, Nita 7I

Meghalaya I5, I8, 27, 45, 48, 54, 62, 78-79, 8I, 84, 86, II3, I2I-I22, I25, I57, I59, I64, I68, I72

Meiteis 28, 36, I37, I54 Meitei I6, 27-29, 64, I57, I63

Militarisation 2I, 35, 40-43, 48, 64, II7, I23-I24, I33, I36, I72-I73, I77, I80

Mizo I7, I9, 29, 56, 64, 80, 93, II3II4, I32, I48, I55, I57, I60, I65-I68, I7O, I75

Mizoram I5, 27, 40, 42-43, 55, 59, 63, 79, 85-86, 92, 106-107, II6, I2I-I23, I25-I2 6, I55, I58, I72-I73

Moti Bagh 64, I59

Mumbai I3, I9, 3I, 45, 57, 62-63, 7I, 84 
Munirka 30, 44, 64-65, 99, IоI, IO5, IO7, II3-II4, I5I, I55

Naga I8, 40, 50-5I, 53, 57, 64, 74-75, 8о, 84-85, Іоо, Іо6, ІІо, ІІ3, II6, I26, I29, I34-I37, I46, I52, I55-I56, I59-I60, I62-I63, I67-I68, I70 Lotha tribe I37-I 38

Naga Mother's Association $\mathrm{I}_{2}$

Naga Women's Union Manipur $\mathrm{I}_{2}$ Nagaland I5, I9, 27, 40, 43, 48, 5I, $53,56,59,63-64,74,76,79-80$, 84-86, 92, IO6-IO7, IO9, III, II4, I2I-I23, I25-I2 6, I3I, I33-I35, I37I38, I5I, I6I-I62, I67, I70-I73, I77

National Socialist Council of Nagaland (Isak-Muivah) (NSCNIM) $\quad$ I62

Nava, Mica I66

Nepal I5-I6, 28, 70, II6 Nepalis I5, 28, 48, 89, I55

Nishi I54, I65

Noida 58, 75, I5I

North East Vision 2020 I8I

Ong, Aihwa I84

Pan-Tribalism I04, I47, I59

Pandey, Gyan 20, 49

Partition I6, 40

Safdarjung 64, 99, III, I52

Sanamahism, Sanamahi 157

Scott, James I78

Shanti Niketan 64, 99, I75

Shillong 48, 54, 62, 8I-82, 84, I67, I70, I74

Shilpa Shetty II6

Shimizu, Celine 96
Sikkim I5-I6, I9, 28, 37, 42-43, 54, $58-59,73,79,84,90$, I22, I57, I80

Silchar 47

Siliguri 59

Singapore 59, II6

Sixth Schedule Tribes 37, 54, 79, 95, I2I, I24, I37, I79

Social Movements and Student Organisations IO4, I07, I34, I60, I62-163

and the Church $132,138,146,158$ $\mathrm{I} 60, \mathrm{I} 63, \mathrm{I73}$

and Womens Associations $\mathrm{I}_{62}$

South Extension 64, 99

Stereotypes 32-33, 88, 91, 94, 96, IO०, I09, III, II9-I20, I26-I27, I3I, I38, I47, I56, I66-I69, I75, I85-I86

Tambiah, Stanley 38

Thuingaleng Muivah I6I

Tibet

Tibetan 28

Tibetans I5, 89

Tripura I5, 27, I2I, I68

van Schendel, Willem 40, I78

Vasant Kunj I3, 22, 7I

Verrier Elwin 39

Ward, F. Kingdon 36

Werbner, Pnina I66

Wokha 53, I34

Xiaolin Guo 20

Zomia $\quad$ I78

Zou, David 38 



\section{IIAS Publications Series}

International Institute

for Asian Studies

Josine Stremmelaar and Paul van der Velde (eds.)

What about Asia? Revisiting Asian Studies

2006 (ISBN 978905356959 7)

\section{Monographs}

Alex McKay

Their Footprints Remain. Biomedical Beginnings Across the Indo-Tibetan

Frontier

Monographs I

2007 (ISBN 9789053565186 )

Masae Kato

Women's Rights? The Politics of Eugenic Abortion in Modern Japan Monographs 2

2009 (ISBN 978905356793 7)

Jeroen de Kloet

China with a Cut. Globalisation, Urban Youth and Popular Music

Monographs 3

2010 (ISBN 978908964 I62 5)

Rituparna Roy

South Asian Partition Fiction in English. From Khushwant Singh to Amitav Ghosh

Monographs 4

20I0 (ISBN 978908964245 5)

Chaiyakorn Kiatpongsan

The EU-Thailand Relations. Tracing the Patterns of New Bilateralism Monographs 5

2OII (ISBN 978908964 I64 9) 
Olena Mykal

The EU-Japan Security Dialogue. Invisible but Comprehensive Monographs 6 2OII (ISBN 978908964 I63 2)

Kah Seng Loh, Edgar Liao, Cheng Tju Lim and Guo-Quan Seng The University Socialist Club and the Contest for Malaya. Tangled Strands of Modernity

Monographs 7

2012 (ISBN 978908964409 I)

Eka Srimulyani

Women from Traditional Islamic Educational Institutions in Indonesia.

Negotiating Public Spaces

Monographs 8

2012 (ISBN 978908964421 3)

\section{Edited Volumes}

Gijsbert Oonk (ed.)

Global Indian Diasporas. Exploring Trajectories of Migration and Theory

Edited Volumes I

2007 (ISBN 978905356035 8)

Wen-Shan Yang and Melody Chia-Wen Lu (eds.)

Asian Cross-border Marriage Migration. Demographic Patterns and Social Issues

Edited Volumes 2

20I0 (ISBN 978908964054 3)

Margaret Sleeboom-Faulkner (ed.)

Frameworks of Choice. Predictive and Genetic Testing in Asia

Edited Volumes 3

20I0 (ISBN 978908964 I65 6)

Birgit Abels (ed.)

Austronesian Soundscapes. Performing Arts in Oceania and Southeast Asia Edited Volumes 4

2OII (ISBN 9789089640857 ) 
Dipika Mukherjee and Maya Khemlani David (eds.)

National Language Planning and Language Shifts in Malaysian Minority Communities

Edited Volumes 5

2OII (ISBN 978908964 27I 4)

Gregory Bracken (ed.)

Aspects of Urbanization in China. Shanghai, Hong Kong, Guangzhou Edited Volumes 6

2012 (ISBN 9789089643988 )

Barak Kalir and Malini Sur (eds.)

Transnational Flows and Permissive Polities. Ethnographies of Human

Mobilities in Asia

Edited Volumes 7

2012 (ISBN 9789089644084 ) 


\section{IIAS}

International Institute

for Asian Studies

\section{PUBLICATIONS SERIES}

\author{
Monographs 9
}

Northeast Migrants in Delhi: Race, Refuge and Retail is an ethnographic study of migrants from India's north-east border region living and working in Delhi, the nation's capital. Northeast India borders China, the Himalayas, and Southeast Asia. Despite burgeoning interest in the region, little attention is given to the thousands of migrants leaving the region for Indian cities for refuge, work, and study. The stories of Northeast migrants reveal an everyday Northeast India rarely captured elsewhere and offer an alternative view of contemporary India. Northeast migrants covet the employment opportunities created by India's embrace of globalization; shopping malls, restaurants, and call centres. Yet Northeast migrants also experience high levels of racism, harassment, and violence. Far from simply victims of the city, Northeast migrants have created their own 'map' of Delhi, enabling a sense of belonging, albeit an uneasy one. Interdisciplinary in nature, this book will appeal to scholars of anthropology, urban studies, geography, migration, and Asian Studies.

Dr Duncan McDuie-Ra, PhD is Senior Lecturer in Development Studies, School of Social Sciences, University of New South Wales, Sydney, Australia.

"McDuie-Ra's illuminating account of the unexpected lives of northeast migrants in a metropolis compels us to rethink conventional ways of thinking about India's changing frontier lands and peoples. This rigorously researched and superbly written book is anthropology at its best."

- Amita Baviskar, Associate Professor at the Institute of Economic Growth, Delhi University

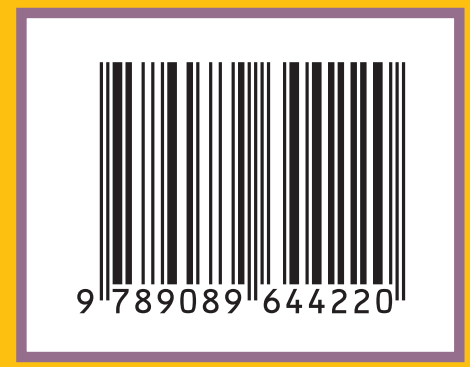

ISBN 9789089644220

AMSTERDAM UNIVERSITY PRESS

www.aup.nl 